\title{
HIGH PERFORMANCE ENVELOPE DESIGN FOR THE MODULAR BUILDING SYSTEM
}

\author{
By \\ David Hawkins \\ Bachelor of International Business, Carleton University, 2009
}

\author{
A thesis \\ Presented to Ryerson University \\ In partial fulfillment of the \\ Requirements for the degree of \\ Master of Applied Science \\ In the Program of \\ Building Sciences
}

Toronto, Ontario, Canada, 2014

(C) David Hawkins 2014 


\section{Author's Declaration for Electronic Submission of A Thesis}

I hereby declare that I am the sole author of this thesis. This is a true copy of the thesis, including any required final revisions, as accepted by my examiners.

I authorize Ryerson University to lend this thesis to other institutions or individuals for the purpose of scholarly research.

I further authorize Ryerson University to reproduce this thesis by photocopying or by other means, in total or in part, at the request of other institutions or individuals for the purpose of scholarly research.

I understand that my thesis may be made electronically available to the public. 


\title{
HIGH PERFORMANCE ENVELOPE DESIGN FOR THE MODULAR BUILDING SYSTEM
}

Master of Applied Science In the Program of Building Sciences, 2014

David Hawkins, Ryerson University

\begin{abstract}
The best way to reduce energy consumption in homes is to reduce air infiltration and increase thermal resistance of the building envelope. This research aimed to develop four envelope systems for the modular building system that are super insulated and designed for maximum air tightness.
\end{abstract}

Rigid sheathing with taped seams is a superior air sealing strategy compared to existing air barrier systems used in the modular building industry. Connection details were developed for vulnerable connection locations using long lasting air sealing methodologies.

Connection interfaces were modeled with THERM software and two connections had bridging more than $\Psi 0.01[\mathrm{~W} / \mathrm{m} \cdot \mathrm{k}]$. Hygrothermal analysis revealed that the moisture content of the structural sheathing layer of the assemblies maintained at safe levels. Annual heating demand reduction of $64-69 \%$ was simulated using the proposed four assemblies compared to an OBC 2012 building code baseline envelope assembly. 


\section{Acknowledgements}

First, I would like to extend my sincere gratitude to my supervisor Dr. Russell Richman, Dr. Miljana Horvat, and everyone within the building science faculty at Ryerson University, for their guidance, support and wisdom throughout the program.

Next, I would also like to thank the entire Passive House community in North America for educating and promoting what it truly means to design and construct efficient buildings. We will continue to march forward, reducing energy consumption, increasing interior comfort and ensuring that buildings will last for centuries to come.

Finally, I would like to thank all of my friends and family who supported me during this thesis. It was a long road, and I could not have done it without you guys - I Love you. 


\section{Table of Contents}

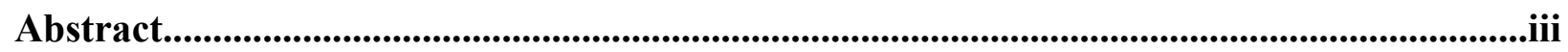

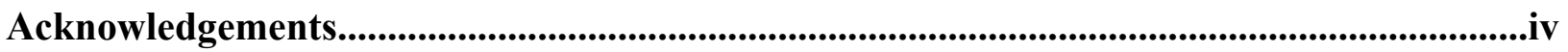

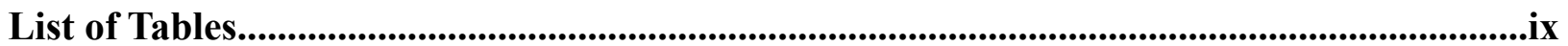

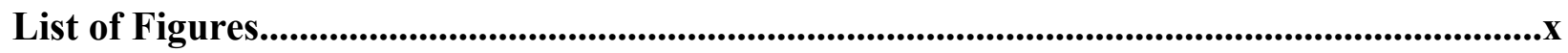

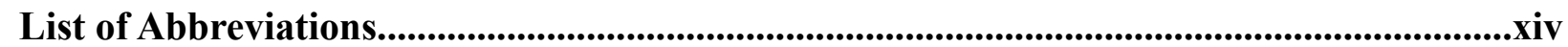

Chapter 1 - Introduction

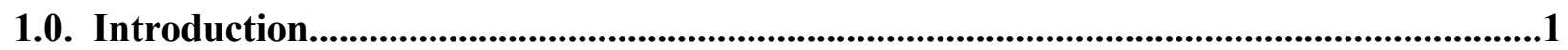

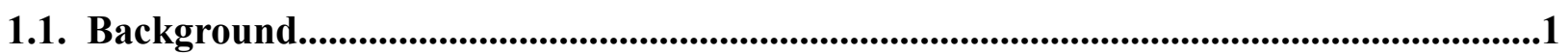

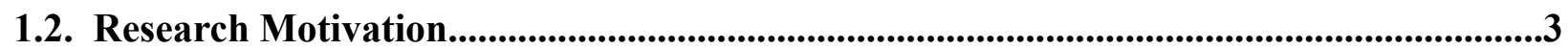

1.3. Objective \& Research Questions.............................................................................................3

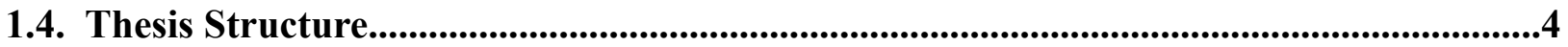

Chapter 2 - Literature Review

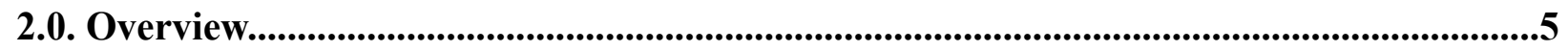

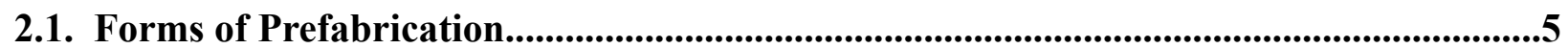

2.1.1. Open Panelized Systems..................................................................... 6

2.1.2. Closed Panelized Systems..................................................................... 7

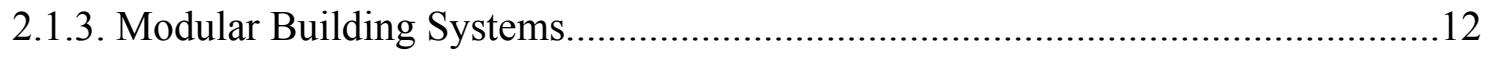

2.2. Modular Building System Examples.......................................................................................27

2.2.1. Modular Example \#1 ............................................................................................................22

2.2.2. Modular Example \#2 .................................................................................................332

2.2.3. Modular Example \#3......................................................................................................36

2.3. High Performance Envelopes..................................................................................................44

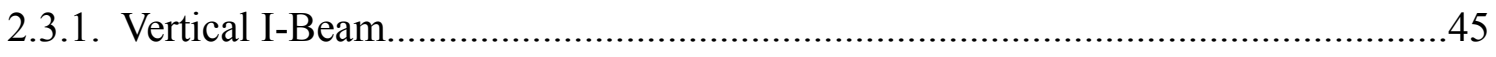


2.3.2. Exterior Rigid Foam.........................................................................................4

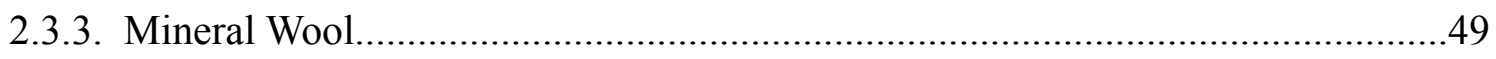

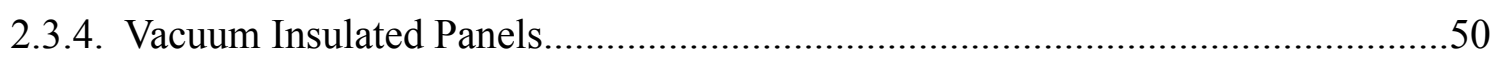

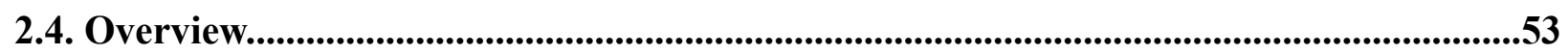

Chapter 3 - Methodology

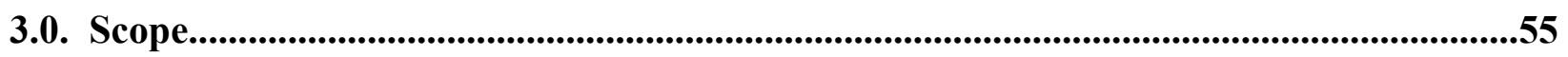

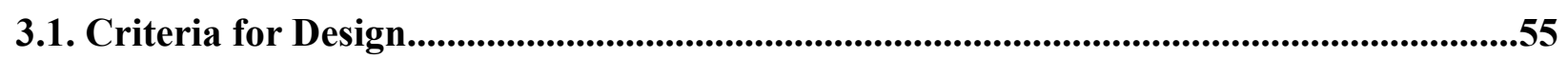

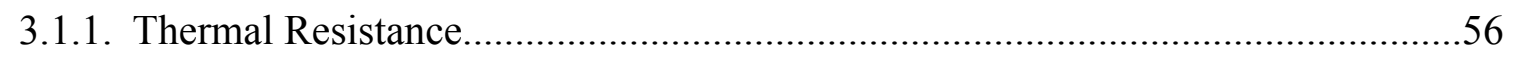

3.1.2. Vapour Control Layer....................................................................................5

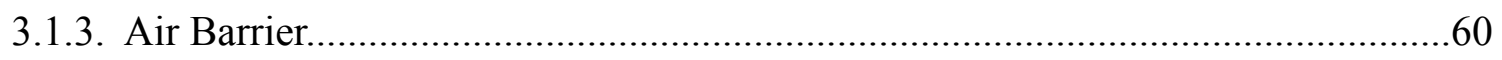

3.2. Thermal, Hygrothermal \& Energy Modeling Analysis............................................................62

Chapter 4 - Connection Details \& Construction Process

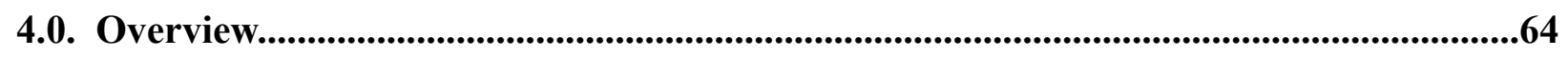

4.1. Proposed Envelope Assemblies........................................................................................................64

4.2. Full Section........................................................................................................................................69

4.3. Wall to Roof Connection....................................................................................................70

4.4. Rim Joist Connection......................................................................................................................74

4.5. Wall to Foundation Connection........................................................................................................75

4.6. Window Header, Sill \& Jamb...........................................................................................................77

4.7. Hinged Roof Truss.......................................................................................................................................81

4.8. Foundation...........................................................................................................................................82

4.9. Construction Process for the Envelope Systems........................................................................84

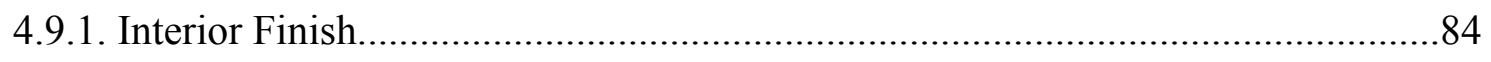

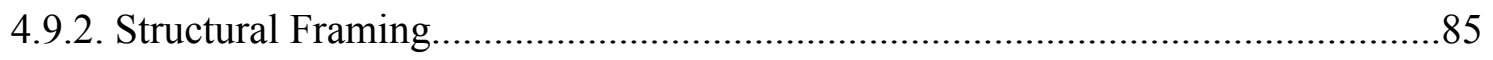




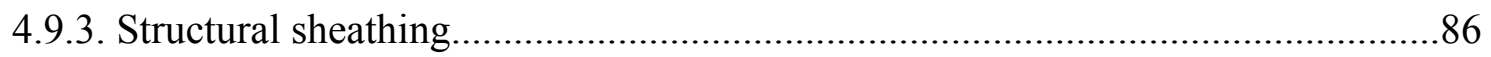

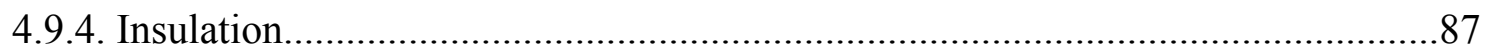

4.9.5. Exterior cladding, furring strips and WRB.....................................................90

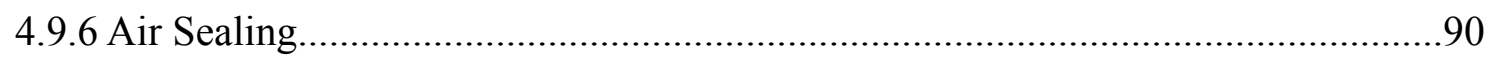

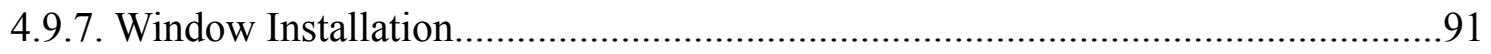

4.9.8. Primary Advantages Gained with Modular...........................................................92

\section{Chapter 5 - Thermal Performance Analysis}

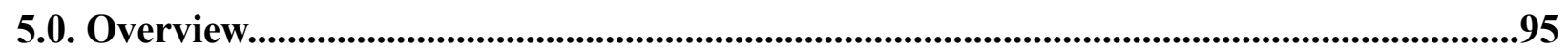

5.1. Effective Thermal Resistance.......................................................................................96

5.2. Linear Thermal Bridges.......................................................................................................102

Chapter 6 - Hygrothermal Performance Analysis

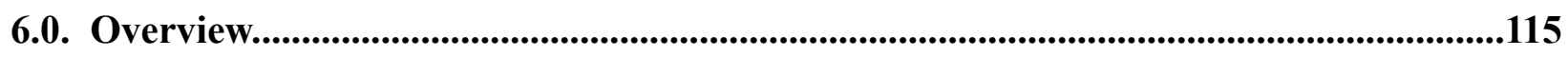

6.1. WUFI ${ }^{\circledR}$ Model Inputs........................................................................................................117

6.2. Results from WUFI ${ }^{\circledR}$ Models........................................................................................................119

6.4. WUFI ${ }^{\circledR}$ Conclusions................................................................................................135

Chapter 7 - Energy Consumption Model

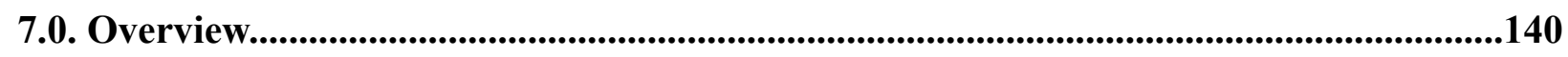

7.1. Assumptions \& Limitations.....................................................................................140

7.2. Model Variations of Inputs...............................................................................................................141

7.3. Results of the PHPP Energy Models............................................................................................142 
Chapter 8 - Conclusions

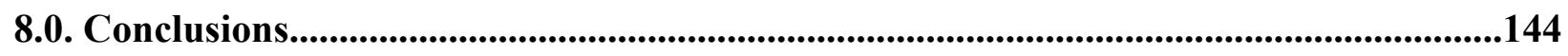

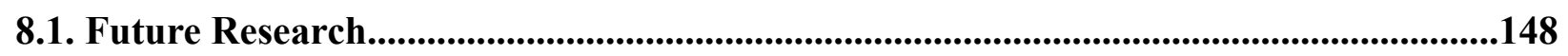

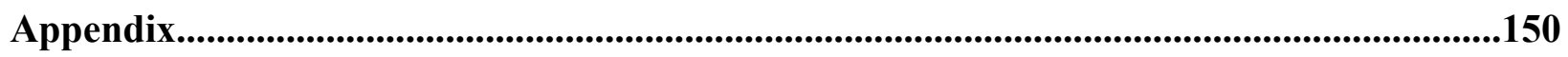

Appendix A - Connection details: Polyisocyanurate Assembly...............................................150

Appendix B - Connection details: Mineral Wool Assembly.....................................................156

Appendix C - Connection details: Vertical I-beam Assembly..........................................162

Appendix D - Connection details: Vacuum Insulated Panel Assembly..............................168

Appendix E - Marriage Connection Details....................................................................................174

Appendix F - Polyisocyanurate WUFI ${ }^{\circledR}$ graphs..........................................................................177

Appendix G - Mineral Wool WUFI ${ }^{\circledR}$ graphs....................................................................181

Appendix H - Vertical I-beam WUFI ${ }^{\circledR}$ graphs............................................................................185

Appendix I - Vacuum Insulated Panel WUFI ${ }^{\circledR}$ graphs.............................................................189

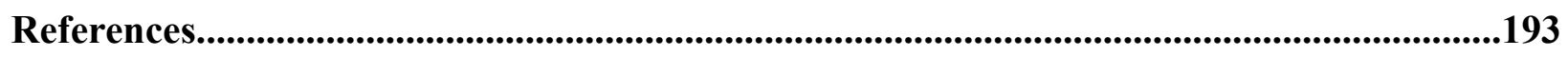




\section{List of Tables}

Table 3-1 Conductivity values of foam [Conductivity values: ASHRAE, 2009b].................57

Table 3-2 Embodied energy of insulation materials [Harvey, 2007].....................................58

Table 4-1 Clear wall RSI value for polyisocyanurate assembly [ASHRAE, 2009b].............65

Table 4-2 Clear wall RSI value for mineral wool assembly [ASHRAE, 2009 b]...................66

Table 4-3 Clear wall RSI value for vertical I-beam assembly [ASHRAE, 2009 ${ }^{\mathrm{b}}$ ]................67

Table 4-4 Clear wall RSI value for VIP assembly [ASHRAE, 2009 , Mukhopadhyaya et al.,

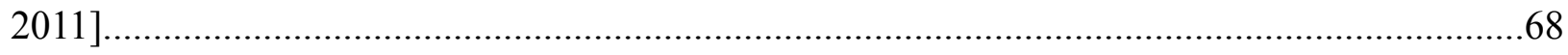

Table 5-1 Conductivity values of material inputs for THERM models..................................96

Table 5-2 Summary of the clear wall and effective RSI values..........................................101

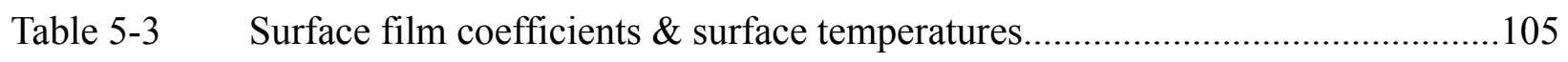

Table 5-4 Summarized table of the linear thermal bridge....................................................114

Table 6-1 WUFI simulation matrix..........................................................................116

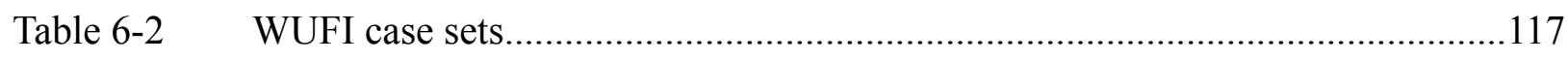

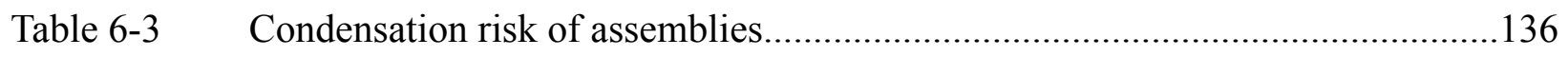

Table 7-1 Envelope areas entered into the PHPP model................................................140

Table 7-2 Envelope RSI values \& ACH values assigned in PHPP model...........................142

Table 7-3 Window performance specifications for PHPP inputs.....................................142

Table 7-4 Summarized results from PHPP models.......................................................142 


\section{List of Figures}

Figure 2-1 Example of open panelized envelope system [Barden Homes, 2013].....................7

Figure 2-2 Closed panelized system [BC Passive House, 2012] ...........................................10

Figure 2-3 Example of closed panelized envelope components [Brute Force, 2013].............10

Figure 2-4 Closed panelized system [Brute Force, 2013] .....................................................11

Figure 2-5 Time table of modular building system [MBI, 2012]...........................................

Figure 2-6 Gantry moving a framed wall........................................................................

Figure 2-7 View of spray glue of gypsum board to roof truss [Eco Classic Homes, 2013]....19

Figure 2-8 View of spray glue of gypsum board to roof truss [Eco Classic Homes, 2013]....20

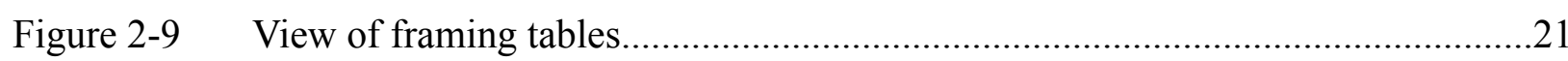

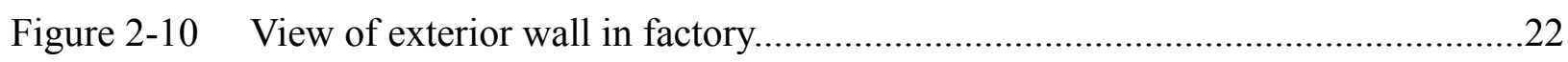

Figure 2-11 Schematic layout of a typical modular production line [Sloditskie, 2013]............26

Figure 2-12 Full section of modular envelope example \#1 [Sloditskie, 2013].........................29

Figure 2-13 Wall to foundation connection from modular example \#1 [Sloditskie, 2013]........30

Figure 2-14 Upper \& lower module connection for modular example \#1 [Sloditskie, 2013]...30

Figure 2-15 Module with WRB left open [NAHB, 2013].......................................................

Figure 2-16 Wall to ceiling detail for modular example \#1 [Sloditskie, 2013]..........................31

Figure 2-17 Modular installed onsite for modular example \#2 [Biebel, 2011]..........................32

Figure 2-18 Full section detail of modular example \#2 [Biebel, 2011].....................................34

Figure 2-19 View of gasket seal for modular example \#2 [Biebel, 2011].................................35

Figure 2-20 View of rim joist at foundation for modular example \#2 [Biebel, 2011]................35

Figure 2-21 EcoTerra house - modular example \#3 [Canadian Mortgage \& Housing

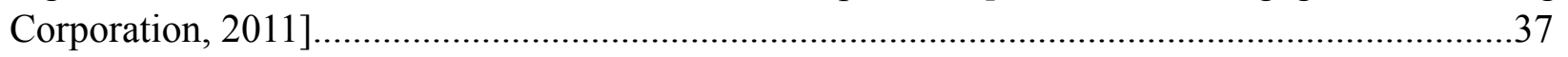

Figure 2-22 Full section detail for modular example \#3 [Chen et al., 2011].............................38

Figure 2-23 Modular being installed for EcoTerra house [Canadian Mortgage \& Housing

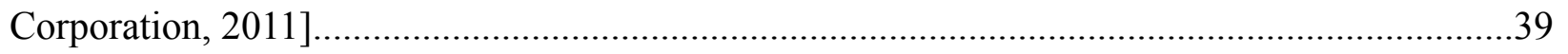


Figure 2-24 Modular being installed for EcoTerra house [Canadian Mortgage \& Housing

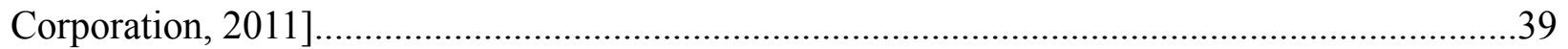

Figure 2-25 Wall to foundation connection for modular example \#3 [Doiron, 2011]................40

Figure 2-26 Rim joist connection in modular example \#3 [Doiron, 2011].................................41

Figure 2-27 Plan view of module connection for modular example \#3 [Doiron, 2011]...........41

Figure 2-28 Wall to ceiling connection for modular example \#3 [Doiron, 2011].....................42

Figure 2-29 View of spray foam insulation in modular example \#3 [Canadian Mortgage \& Housing Corporation, 2011] ............................................................................................4

Figure 2-30 Example of vertical I-beam assembly [Klingenberg, 2012] ..................................45

Figure 2-31 View from the top of a larson truss assembly [Clupp, 2012]................................46

Figure 2-32 View of exterior applied polyisocyanurate assembly [McDonald, 2012].............47

Figure 2-33 View of the exposed modular seams[McDonald, 2012].......................................47

Figure 2-34 View of the seams sealed between between the modules [McDonald, 2012].......48

Figure 2-35 View of the VIPs on the interior side of studs [Parekh \& Mattock, 2012]............50

Figure 2-36 View of the spray foam over top of the VIPs [Parekh \& Mattock, 2012] ..............51

Figure 2-37 View of exterior applied VIP system [Parekh \& Mattock, 2012] ..........................52

Figure 2-38 View of VIP located within the framed cavity [Parekh \& Mattock, 2012]............53

Figure 3-1 Common air leakage pathways [Conservation Technology, 2008]........................61

Figure 4-1 Full section detail of modular building.............................................................69

Figure 4-2 Wall to roof connection for vertical I-Beam assembly..........................................71

Figure 4-3 Rim joist connection for the vertical I-beam assembly.........................................73

Figure 4-4 Wall to foundation connection for polyisocyanurate assembly..............................75

Figure 4-5 Wall to foundation connection for mineral wool assembly....................................76

Figure 4-6 Liquid applied flashing around window buck [Prosoco, 2013]..............................78

Figure 4-7 Window jamb detail of the vertical I-beam assembly............................................79

Figure 4-8 Window header and sill detail of the vertical I-beam assembly...............................80

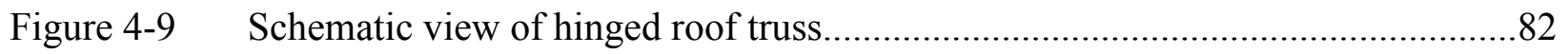


Figure 4-10 Schematic section view of footing with EPS foam..........................................83

Figure 5-1 THERM screen shot of the polyisocyanurate assembly....................................97

Figure 5-2 THERM screen shot of the mineral wool assembly...........................................98

Figure 5-3 THERM screen shot of the vertical I-beam assembly.......................................99

Figure 5-4 THERM screen shot of the VIP assembly....................................................... 100

Figure 5-5 Linear thermal bridge $\Psi$ calculation methodology..........................................103

Figure 5-6 Screen shot from THERM model............................................................. 104

Figure 5-7 Surface temperatures for THERM models.................................................... 106

Figure 5-8 Vacuum insulated panel rim joist..............................................................112

Figure 5-9 Mineral wool assembly rim joist detail..................................................... 113

Figure 6-1 Interior relative humidity testing values..................................................119

Figure 6-2 WUFI ${ }^{\circledR}$ material layers for polyisocyanurate assembly................................119

Figure 6-3 MC of middle of OSB layer for polyisocyanurate assembly - Standard Case.....120

Figure 6-4 MC of middle of OSB layer for polyisocyanurate assembly - Standard Case.....121

Figure 6-5 MC of middle of OSB layer for polyisocyanurate assembly - Intensified Case..121

Figure 6-6 MC of middle of OSB layer for polyisocyanurate assembly - Intensified Case.. 122

Figure 6-7 RH of interior OSB edge of polyisocyanurate assembly - Standard Case...........123

Figure 6-8 RH of interior OSB edge of polyisocyanurate assembly - Intensified Case........123

Figure 6-9 WUFI ${ }^{\circledR}$ material layers for mineral wool assembly....................................124

Figure 6-10 $\mathrm{MC}$ of middle of OSB layer for mineral wool assembly - Standard Case...........125

Figure 6-11 MC of middle of OSB layer for mineral wool assembly - Standard Case...........125

Figure 6-12 MC of middle of OSB layer for mineral wool assembly - Intensified Case........126

Figure 6-13 MC of middle of OSB layer for mineral wool assembly - Intensified Case........126

Figure 6-14 RH of interior OSB edge of mineral wool assembly - Intensified Case.............127

Figure 6-15 WUFI ${ }^{\circledR}$ material layers for vertical I-beam assembly.................................128

Figure 6-16 MC of middle of OSB layer for vertical I-beam assembly - Standard Case........128 
Figure 6-17 MC of middle of OSB layer for vertical I-beam assembly - Standard Case........129

Figure 6-18 MC of middle of OSB layer for vertical I-beam assembly - Intensified Case.....129

Figure 6-19 MC of middle of OSB layer for vertical I-beam assembly - Intensified Case.....130

Figure 6-20 RH of exterior OSB edge of vertical I-beam assembly - Intensified Case..........131

Figure 6-21 RH of interior OSB edge of vertical I-beam assembly - Intensified Case...........131

Figure 6-22 WUFI ${ }^{\circledR}$ material layers for VIP assembly...................................................132

Figure 6-23 MC of middle of OSB layer for VIP assembly - Standard Case........................133

Figure 6-24 MC of middle of OSB layer for VIP assembly - Standard Case........................133

Figure 6-25 MC of middle of OSB layer for VIP assembly - Intensified Case......................134

Figure 6-26 MC of middle of OSB layer for VIP assembly - Intensified Case.....................134

Figure 6-27 Condensation risk hours with extreme RH levels...........................................138

Figure 6-28 Condensation risk hours with high RH levels............................................138

Figure 6-29 Condensation risk hours for vertical I-beam with medium and high RH levels..138 


\section{List of Abbreviations}

BSC Building Science Corporation

COG Center of glass

CPM Critical path method

ERV Energy recovery ventilator

HRV Heat recovery ventilator

ISO International Organization of Standardization

MBI Modular Building Institute

MC Moisture content

NAHB National Association of Home Builders

NRC National Research Council

OBC Ontario Building Code

OSB Oriented strand board

PH Passive house

PHPP Passive House Planning Package

PHIUS Passive House Institute of the United States

RH Relative humidity

SIP Structural insulated panel

TPS Toyota production system

VR Vapour retarder

US EPA United States Environmental Protection Agency 


\section{Chapter 1 - Introduction}

\subsection{Introduction}

Heating is the largest energy consumer in residential buildings in North America [Harvey, 2009]. This means that the most effective way to reduce the total energy usage in homes is to reduce the annual heating demand. There are many strategies to reduce heating demands in homes. Shading, building shape and orientation, exterior cladding material and percentage of glazing can all potentially have a significant impact on the heating load of a house. However, previous research has shown that the most effective way to reduce heat loss is to design a building envelope with thick amounts of insulation and an airtight exterior shell [Shurcliff 1985, Feist 2007]. It has also been shown that these high performance envelopes have their biggest impact on reducing heat loss in a cold climate [Woods, 2001].

The cost and complexity of constructing high performance envelopes is often cited as a barrier to their widespread use [Boqvist, 2010]. These costs can be reduced and construction processes made simpler by using a modular building system compared to the onsite stick build construction methods commonly used [Yu, 2010]. It has also been noted that many elements of waste within the construction process can be reduced or eliminated by moving the construction processes into a controlled interior environment [Ballard, 2000].

This thesis examines the design of high performance building envelopes that can be used in modular building systems for home construction in a southern Ontario climate.

\subsection{Background}

Many benefits can be gained when the construction process is moved into a factory compared to onsite construction [Koskela 2000, Fazio 2000a, Fazio 2000 , Yu 2010]. These include: increased quality control, decreased waste, concurrent processes, reduced costs and increased productivity. Despite these benefits the use of modular building systems represents only 1-2\% of all new buildings constructed in North America [MBI, 2012]. However, in Northern European countries with similar climates to Canada, over $80 \%$ of building envelopes 
for homes are prefabricated in a workshop or factory [Fazio et al., 2000]. Therefore, there would seem to be an opportunity to expand the use of modular techniques in North America especially in the construction of energy efficient buildings.

There are several options for the prefabrication of building envelopes and each has its strengths and weaknesses. The three main forms of prefabrication of envelope systems are: closed panelized, open panelized and permanent modular [Fazio et al., 2000]. The literature identified the advantages of the permanent modular approach to be the most attractive because all of the construction processes benefit from the factory working conditions, not just the envelope. Therefore, because of these advantages, this thesis focuses on the use of high performance envelopes in permanent modular building systems.

The vast majority of the wall systems used in the construction of North American homes are based on $139 \mathrm{~mm}$ stud framing with batt insulation. The air barrier in these wall systems is usually either a polyethylene vapour barrier behind the gypsum board or a weather resistance

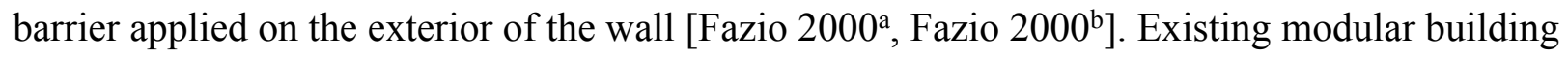
envelope systems used in Southern Ontario are similar in design. The air barriers in these systems are typically either polyethylene sheeting behind gypsum, a weather resistance membrane on the exterior, or spray foam within the framing structure [Fazio 2000, Fazio 2000, Doiron 2011, Biebel 2012]. All of these air-sealing approaches have at least one of the following problems - difficulties in making it continuous across all envelope interfaces [Klingenberg, 2012], long-term durability [Knight et al., 2002] or high-embodied energy within the material [Harvey, 2007]. Therefore, while there are benefits to using prefabricated wall systems, the type of envelopes used in current modular systems cannot achieve the level of efficiency found in modern high performance wall systems. 


\subsection{Research Motivation}

Significant improvements can be made in the typical North American design of the thermal and air barrier layers of modular building envelopes. These improvements can have a number of social and economic benefits.

Developing a low cost, high performance modular building envelope with a variety of insulation options and with durable long lasting air barrier systems can dramatically reduce energy consumption and carbon dioxide emissions in the world [Shurcliff 1985, Harvey 2007]. High performance envelopes can also lower costs of ownership for homeowners and improve home comfort levels [Feist, 2007].

Modular factory methods can increase construction quality [Yu, 2010], help builders deal with a future shortage of skilled workers in Canada [Lefebvre et al., 2012], and allow envelopes to be built in extreme northern climates where temperatures and daylight limit a building season.

Achieving these benefits is the primary motivation for the research in this thesis.

\subsection{Objective \& Research Questions}

The objective of research is to develop options for high performance envelope systems that can be produced by modular manufacturing methods and used to reduce residential heating demand in cold climate.

From the primary research objective, the following specific research questions were derived:

1) What options can be developed for a modular manufacturer to produce a super insulated, airtight building envelope system for a wood framed modular building system in a cold climate context?

2) How do the proposed envelope systems perform in terms of thermal resistance, hygrothermal and overall total energy consumption? 


\subsection{Thesis Structure}

Chapter two explores the literature about the various forms of prefabrication of building envelopes and the current design of prefabricated envelope systems and provides examples of high performance envelope systems built on site. Benefits and drawbacks of the various options were investigated to select the designs, materials and construction methods to be investigated in greater detail in subsequent chapters.

Chapter three outlines the design criteria and potential materials to be used in the development of high performance wall assemblies. The four assemblies that will be analyzed in this research are described here as are the types of analyses that will be done on the assemblies.

Chapter four describes the various connection details of the proposed wall assemblies. It also discusses the benefits of building these assemblies using modular techniques as opposed to onsite methods.

Chapter five analyzes the thermal performance of the wall assemblies and examines their effective thermal resistance (RSI value) and the thermal bridging characteritics of their various connections and interface transitions.

Chapter six covers the hygrothermal analysis of the four assemblies with a primary focus on the moisture content of the structural sheathing and relative humidity levels of the surfaces of the sheathing layer.

Chapter seven displays the results of the energy model comparison of the high performance building envelope systems and how they compare to a standard building-code compliant envelope.

Chapter eight concludes with summary of the results and makes recommendations for future research. 


\section{Chapter 2 - Literature Review}

\subsection{Overview}

The following literature review covers previous research into the forms of prefabricated building envelope systems: the open and closed panelized envelope systems, structurally insulated panels [SIPs] and the modular building system. The differences between the systems were investigated, along with their benefits and drawbacks. Next, several existing modular envelope designs are reviewed. Their various flaws and lack of high performance characteristics are outlined. This provides the current state of modular construction. The final portion of the literature review outlines previous Passive House envelope designs through the delivery of a case study approach. This provides background information to how the proposed envelope designs were developed and gives context to how a high performance envelope should be designed.

\subsection{Forms of Envelope Prefabrication}

Prefabrication of building envelopes can take three main forms of delivery. Open panelized systems, closed panelized systems and complete modular building boxes [Fazio et al., 2000]. Open panels are wood framed walls with sheathing attached. Closed panels have additional components such as insulation, windows, siding, doors and interior finishes. Modular is a complete structure with interiors. All three of these systems were investigated and presented in the following. Although the panelized systems were not the focus for this research, it was deemed important to show other examples of prefabricated envelope systems and how they differ from the modular building system. This provides the reasoning to why the modular building system was selected as the form of prefabrication to delivery the developed envelope systems. 


\subsubsection{Open panelized systems}

Open panelized systems are the most basic form of prefabricated envelope systems possible. It is essentially a wood framed wall with exterior structural sheathing, and a weather membrane is applied in the controlled interior environment during the manufacturing process [Horvat et al., 2001]. Open panelized building systems are the most common form of prefabricated envelope systems used in North America and offer several benefits over onsite envelope construction methods [Fazio, 2000'].

\section{Benefits}

Out of the three types of envelope prefabrication described in this research, the open panel system is the simplest form. This is the primary benefit of the open panelized system compared to the other forms of envelope prefabrication. It requires the least amount of capital investment compared to the other two forms of envelope prefabrication for a carpenter to transfer from onsite construction methods to prefabrication within a workshop [Fazio et al., 2000]. It is potentially a good place for an existing framing subcontractor to begin the transition into prefabrication as it is possible for even small framing crews to start up such an operation. This form of prefabrication is also more adaptable compared to the closed and modular systems. Closed panels have more work completed in the factory and require more design work up front to ensure accuracy. Modular building systems need designs specific for modular. Architects do not need to create specific building designs for the use of open panelized systems and this system can be used with any wood framed structure. Additional benefits associated with open panelized systems are described with greater detail in Section 2.1.3. due to overlapping benefits across all three forms of prefabrication. 


\section{Drawbacks}

Unfortunately, the primary benefit of open panel envelope construction systems is also the primary drawback. Only the wood framing and sheathing is fabricated in the workshop, leaving many processes to be completed in the field. In the high performance envelope context, this mitigates one of the primary benefits of using prefabrication, installing the critical air barrier and thermal resistance layers in a controlled setting. Overall, open panel systems are a good way for a framing subcontractor to make the transition from onsite production to prefabrication, but production of a closed panelized or modular system should be the long-term goal.

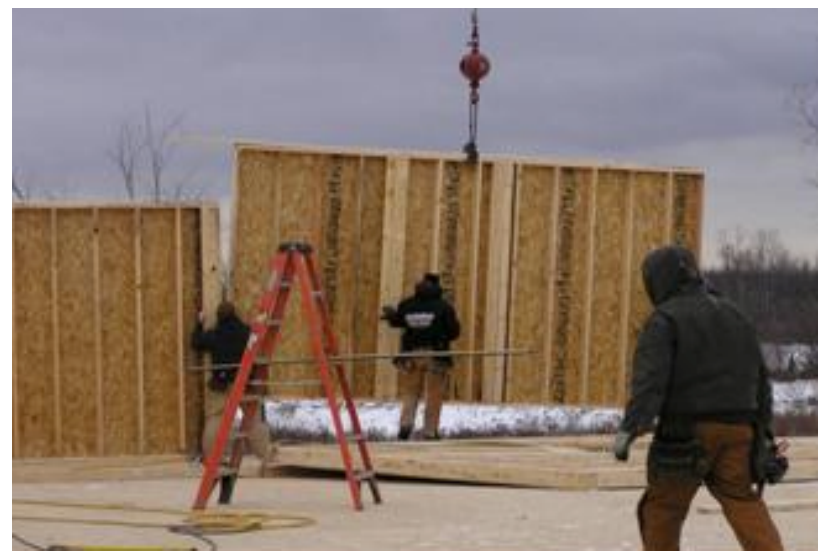

Figure 2-1 - Example of open panelized envelope system [Barden Homes, 2013]

\subsubsection{Closed panelized systems}

The closed panelized system is a more complete envelope when it ships from the manufacturing facility compared to the open panelized systems. In addition to the wood framing and sheathing layer being installed in the factory, the insulation, windows, doors and interior finishes are also applied in the factory before being shipped to site [Fazio et al., 2000]. In some cases, even electrical, plumbing and mechanical equipment can be installed within the panels. The exterior cladding in some cases is installed in the factory, in others it is applied on site during the site installation process. The seams of the panels are connected on site with 
mechanical fasteners and seals are made with tapes and gaskets. Every manufacturer has their own system of attaching the panels on site, and the panel's dimensions vary with each project site's accessibility. Commonly the panels are an entire length of a wall and a crane is used to move it from the truck to its final resting location.

\section{Benefits}

Compared to the open panel, the closed panel building envelope system is a more complete building envelope leaving the manufacturing facility. This allows for greater control of the installation processes for the air barrier and thermal resistance layers. Windows and doors are also installed in the factory. This offers a tremendous advantage compared to the open panel and onsite construction, especially for high performance buildings. High quality windows are heavy, and even medium sized windows require several people to move them around on site. In a factory, this can be performed with greater ease by using gantries and pulley systems, allowing one person to handle a heavy window.

Compared to the modular building system, the closed panelized system has several advantages. First, a smaller capital investment is needed to start a manufacturing process of closed panels compared to modules. This allows the transition from onsite construction to prefabrication with less financial risk. Next, the manufacturing process of panelized systems requires fewer people, less equipment and a smaller facility. Full modules take up a lot of space within a factory compared to closed envelope panels. Finally, closed panels allow for easier transportation to the construction site. In the transportation of the modules, there is a lot of empty air shipped and there are limits on the transportation routes available. This is the primary reason why panelized systems are preferred over full modules in Europe -they are much easier to transport, export and maneuver [Fazio et al., 2000].

\section{Drawbacks}

The drawback of the closed panel system compared to the modular building system is that more construction processes remain to be completed onsite. The advantages of using 
prefabrication are not transferred over to the rest of the construction processes - primarily the interior finishes. In a panelized system, only the envelope construction process benefits from the advantages of prefabrication. In high performance buildings, this is still reason enough to use it compared to the onsite envelope construction methods. However, in some construction markets where onsite construction costs are high, or areas where there is a shortage of skilled labour, the modular building system takes full advantage of prefabrication for all aspects of the construction process. In contrast, the closed panelized system, only the envelope and potentially some elements of the mechanical, electrical and plumbing systems if they are incorporated into the design take advantage of the interior work environment.

\section{Examples}

The following portion outlines several examples of closed panelized systems that are used in Europe and in North America. First, Figure 2-2 displays a closed panelized system was used in Whistler, BC to deliver a duplex Passive House in 2012 [BC Passive House, 2012]. The windows and doors were left out of the panels. It is speculated that there were concerns about the air barrier transition between the wall and window being damaged during transportation and installation. Previous research shows that many panelized envelope systems in Europe install the windows and doors within the factory [Fazio et al., 2000].

Figure 2-3 displays a stack of closed panelized envelope components [Brute Force, 2013]. The windows were not installed, however the insulation layers were installed in the factory. In Figure 2-4, a closed panelized envelope wall is being installed on site [Brute Force, 2013]. In this section, the windows and doors were installed in the factory. Between the two examples of the closed panelized walls, the level of completeness of the closed panelized systems varies depending on the manufacturer's and installation crew's level of comfort and familiarity with the system. 


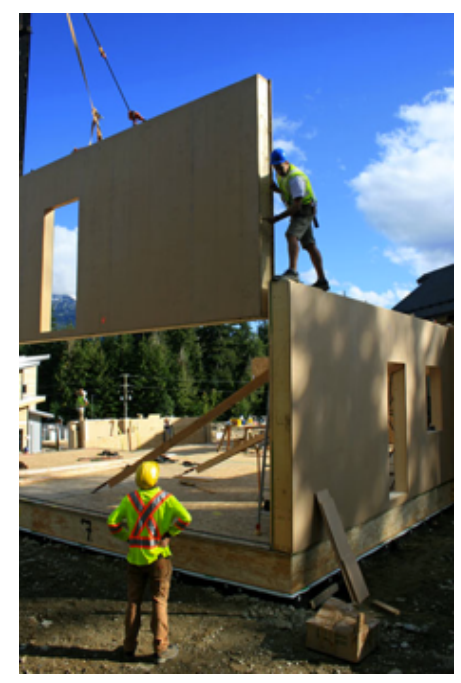

Figure 2-2 - Closed panelized system [BC Passive House, 2012]

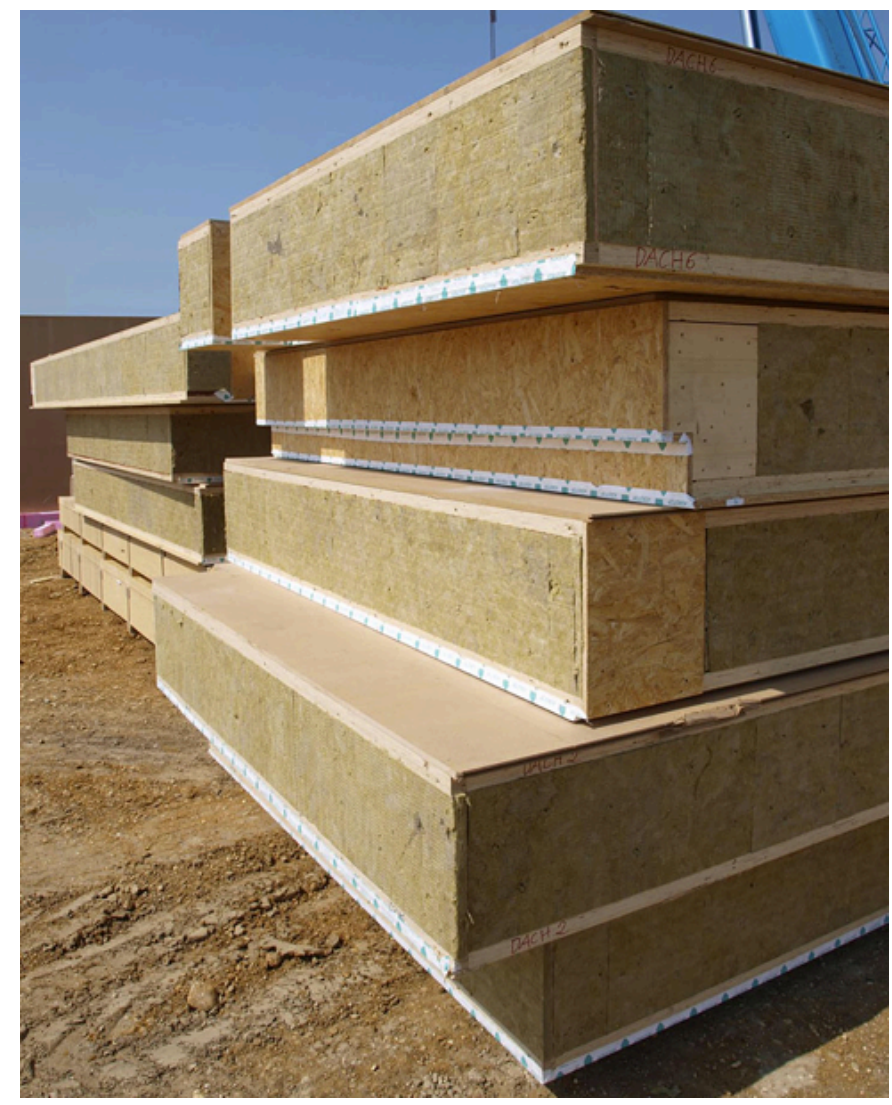

Figure 2-3 - Example of closed panelized envelope components [Brute Force, 2013] 


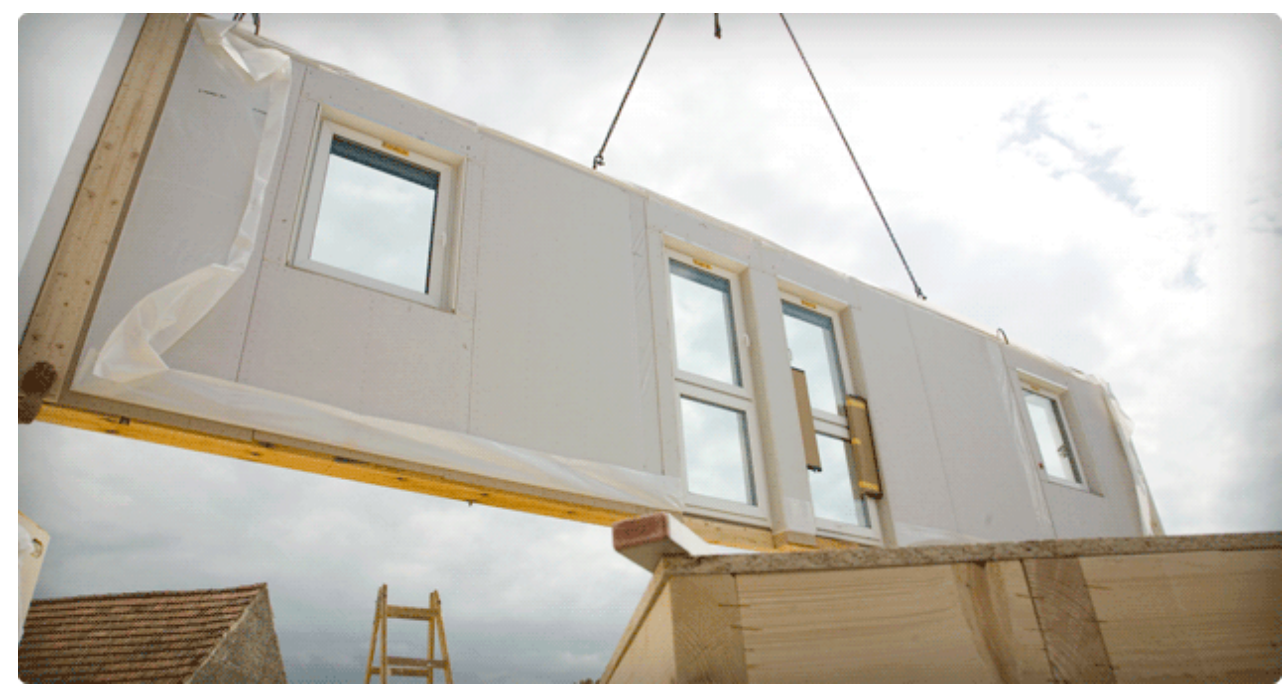

Figure 2-4 - Closed panelized system [Brute Force, 2013]

\section{Structurally Insulated Panels}

This is the most commonly used form of prefabrication for insulated exterior envelopes. Structurally insulated panels [SIPs] have been used in high performance envelope systems because of their high thermal resistance values. The system is a set of panelized components that fit together, forming the building envelope [Brock, 2005]. Typically, a SIP is a piece of foam, often EPS, XPS or polyurethane (but not limited to) and two pieces of oriented strand board secured to both sides with an industrial strength adhesive, staples or wooden spines.

\section{Benefits}

The great advantage of structurally insulated panels is that they can be installed quickly and they provide great thermal resistance as their foam cores have very low conductivity values. As well, they are structurally sound to carry loads, allowing for simple design without the need for additional framing [SIPA, 2012]. 


\section{Drawbacks}

Although there are advantages to SIPs, there are several shortcomings to structurally insulated panels. First, the primary insulating material is heavy petroleum based foam with a high-embodied energy. For example, certain foams can have over a hundred times the embodied energy compared to cellulose insulation [Wilson, 1995]. Next, the foams used in SIPs are costly, especially when the RSI values reach the super insulated levels needed for low energy consuming buildings [Cohen et al., 2013]. Lastly, the connections of SIPs have documented issues with long-term air tightness. Foam, like all building materials, expands and contracts over time due to moisture and temperature changes. These connection points are plentiful in a SIP building system, and have the potential to fail over the long-term, allowing for significant air leakage and heat loss [Lstibruek, 2012, Cohen et al., 2013].

Overall, even with the benefits of SIPs, the shortcomings of using the panels cannot be overlooked. High quality workmanship is needed to ensure all of the seams are accurately installed. Air leakage is one of the main reasons why buildings are not comfortable, not durable and consume a lot of energy. The longevity of the air tightness connections between each SIP and future contraction in the foam are drawbacks to the system. The envelope systems developed in this research will use alternative methods to deliver the high performance prefabricated envelopes.

\subsubsection{Modular building systems}

The modular building system is the most complete form of prefabrication possible within a controlled environment. Modular construction is possible with both wood framed structures and steel framed. However, this research focuses on the wood framed systems. Modular construction is different than the previous forms of prefabrication. In addition to the the exterior envelope, the interior finishes, the plumbing, electrical and mechanical equipment elements are also fabricated. Modular building systems are assembled on site, with connections made onsite for the envelope seams and the internal systems. For example, the exterior cladding may need to 
be installed onsite, or the air barrier and weather resistance membrane will need to be attached between the modules. On the interior side of the installation, the mechanical ductwork, plumbing pipes or electrical wiring may need to be attached between the modules. Interior gypsum repair is another area of onsite installation needed for the modular building system. Not only do the seams between the modules need attention, but also gypsum board is prone to cracking in certain locations on the interior due to the modules flexing during the transportation and installation. Overall, $60-80 \%$ of the building construction processes can be completed within a controlled interior environment by using the modular building system [MBI, 2012].

\section{Benefits}

\section{Concurrent Foundation and Building Processes}

Since the building is constructed off site in an interior environment, the foundation construction process can be completed concurrently with the building of the modules. In Figure $2-5$, an example of a timetable for the modular building system schematically displays how the potential timesaving are gained with a concurrent building process [MBI, 2012]. However, it is possible that the design portion of the modular construction schedule is not accurately displayed as more upfront design work is needed to ensure all of the modules fit together accurately and precisely. The fact that modular building designs take longer than traditional buildings was shown in previous research [Schoenborn, 2012]. Nevertheless, in a modular market research report, it was reported that $66 \%$ of the projects reported having reduced project schedules, and $35 \%$ reported savings 4 weeks or more off the schedule [Berstien et al., 2011]. Undoubtedly, there are time savings to be gained. The time saving varies with every project, and the project's team experience with the system. Once design teams are familiar with the modular building system and recognize the benefits and limitations, design times can be reduced to similar levels of buildings constructed onsite. 


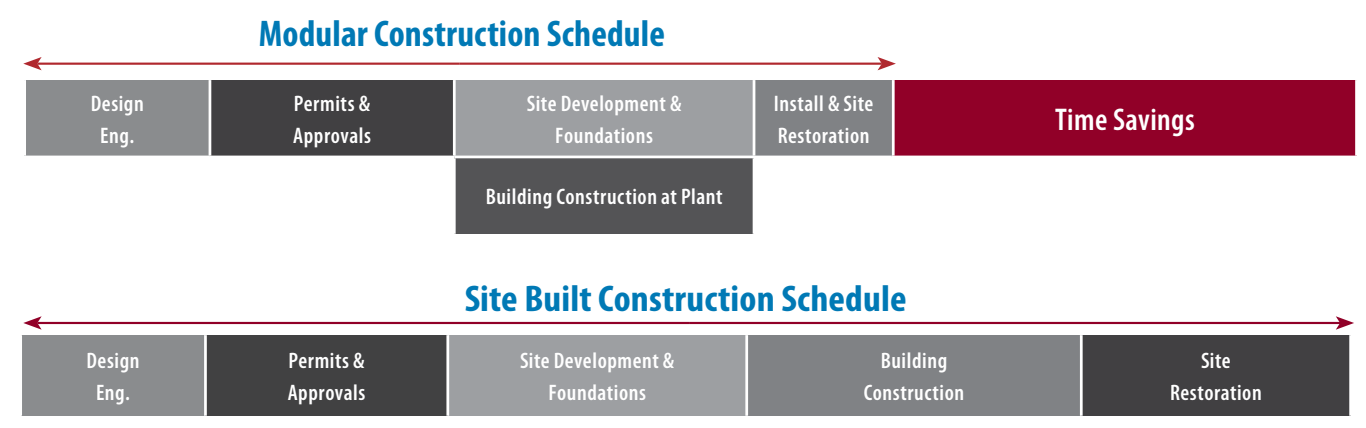

Figure 2-5 - Time Table of Modular Building System [MBI, 2012]

\section{More accurate cost estimates}

In the modular building system, the design must be complete earlier than if the project were to be built onsite with a traditional building system. This is because there are lower construction tolerances and no room for on site installation and design detailing [Schoenborn, 2012]. As a result, the true cost of the project can be determined earlier on with greater accuracy because fewer unknowns and budgetary surprises are experienced with the modular building system than with traditional onsite construction.

\section{Reduced delays due to weather}

Weather can affect project schedules due to precipitation and extreme temperatures. It is estimated that the average construction project loss 20-25 days due to weather related delays over the course of a year [RS Means, 2012]. By moving the majority of the construction process to an interior environment, weather related delays are tremendously reduced. In the vast majority of Canada, daylight is significantly reduced during the winter months, shortening workable time outside, even if the cold is not an issue. In the far north, daylight can be completely reduced for a couple months. However, even with much of the construction process within a controlled interior environment, crews must still contend with the weather during the foundation and onsite installation construction processes. 


\section{Greater control of quality and precision}

Greater quality control is a tremendous advantage of the modular building system [Clapp, 2013]. This benefit is even more attractive for high performance buildings where quality control is necessary, in particular for the air barrier and thermal resistance layers. However, the control of quality and precision is only as good as the system used to inspect and ensure the quality and precision. The systems to ensure quality are made easier in a modular building system compared to onsite because it can be completed during critical moments in the construction process. For example, the attachment of the air barrier from the window to exterior wall, or the transition of the air barrier from the exterior wall to the roof, can be verified right after installation. In onsite construction, to ensure these connections requires greater involvement of the general contractor because these processes are performed by separate sub contracting crews.

Material quality control is also an attractive advantage of the modular building system. Inventories are kept indoors, away from the elements. Precise material quantities can be documented, and the risk of site theft of materials is significantly reduced. Modular manufacturers can also potentially benefit from bulk purchasing of construction materials because they could be sorted within their factory. Although buying materials in bulk can create discounted purchase prices, it does increase inventory, also know as process waste within the context of lean thinking [Womack et al., 1996].

\section{Reduced Cost}

Modular construction has the potential to reduce project costs compared to onsite construction. In a report commissioned for the Philadelphia construction market with regards to using modular construction, it was concluded that the modular building system could provide an urban home for $9-20 \%$ less cost compared to site built construction methods [Building Industry Association of Philadelphia, 2012]. This is mainly due to the high construction cost within the city, which were stated as being $18 \%$ higher than the national average in the United States. This report was commissioned because there is little urban development happening due to low 
building value compared to the high levels of construction costs. That is to say, a building could be constructed and be worth less than the cost to build it, the day after it is commissioned. In markets where construction costs are high, modular offers tremendous advantage in reducing the gap in construction costs and building value.

In the modular building market research report, it was reported that $65 \%$ of those in the survey stated that the modular building system reduced construction costs [Brenstien et al., 2011]. In research conducted by Concordia University into the prefabrication industry, it was noted that the cost savings varied between each company and region. Sometimes companies reported being able to offer modular for less than the normal cost of construction, and other times the use of modular cost more compared to onsite methods [Fazio et al., 2000]. Overall, the modular building system has the potential to reduce construction costs compared to onsite construction, but it depends on regions economic conditions and the modular manufacturer's competitiveness.

\section{Predictable workflow process}

The workflow within the modular building system is more predictable compared to onsite construction because more upfront design work is needed to allow for reduced construction tolerances [Hamzeh et al., 2009]. Onsite field design work is not physically possible with the modular building system. Previous research as shown that the main reason why construction projects take longer to build, and go over budget, is variance in the workflow. The main cause of variance in a project's schedule is related to subcontractors waiting for information, materials or for the preceding installation process to be completed [Wambeke, 2011]. The primary subcontractors that most affect the other trades within the construction process are: interior gypsum, painting, plumbing, electrical, steel fabricators and mechanical. Although this study focused on commercial projects, its results can be used to assess how the modular building system can improve the workflow of residential construction. In the modular building system, designs are more detailed, materials are stored on site in a responsibly sized inventory, and all of trades people are under one roof and can be coordinated with greater precision. If all 
information, materials and labour are less fragmented amongst various companies, there is a greater opportunity to ensure a reliable workflow is possible [Chin 2008, Eriksson 2010]. In previous research that outlines a potential lean production system for a large track homebuilder in Canada, one of the primary aspects of the new lean system was to reduce the number of subcontractors down to five [Yu, 2010]. By reducing the fragmentation, variance in the project schedule is reduced and in turn reduces the potential for projects to experience time and cost overruns.

\section{Potential use of automation}

Automation in the factory manufacturing processes is possible with the modular building system [Han, 2010]. Although it is not necessary for the implementation of a successful modular building system, companies with high levels of demand can use automated systems for the framing processes. This is not a distinct advantage for modular over the other forms of envelope prefabrication because it can also be used in the panelized systems. Automation may also be a lucrative option in a factory with high employee wages. In previous research of prefabricated building envelope systems in Europe, it was documented that a company in Sweden would need to have demand of over 200 homes in order for the investment of the equipment to make economic scene [Fazio et al., 2000]. By using building information modeling systems, the use of automation becomes even more accessible [Hergunsel, 2011].

\section{Process improvements}

Several processes of construction are made easier with the modular building system compared to onsite construction [Han 2010, Van Mulligen, 2012]. It is difficult to quantify the improvement without physically timing the process and comparing it to the same process as if it were completed in the field. Nevertheless, the following examples show construction processes that are made easier with the modular building system. It is important to note that these examples do not necessarily outline improvements in quality, but rather reduced process time and increased productivity. 


\section{Process improvement: Material Handling}

Ease of material handling is vastly improved within a modular manufacturing facility. Large gantries with pulley systems allow for heavy materials, such as entire wall assemblies, to be maneuvered without heavy lifting. The handling of high performance windows is made easier in a factory. High performance windows are significantly heavier than traditional windows, and can often take several people to handle them on site, and negotiating stairs can be a challenge. In a factory, often one worker can handle the window with the aid of a gantry system. The less motion and material handling there is, the more efficient the process will be [Womack et al., 1990]. In Figure 2-6 an example of how walls are moved around with gantries in a factory is displayed. The yellow beam on the ceiling allows for heavy objects to be moved with ease. Only two workers are guiding this wall into place. This photo was taken during a visit to a local modular factory by the researcher.

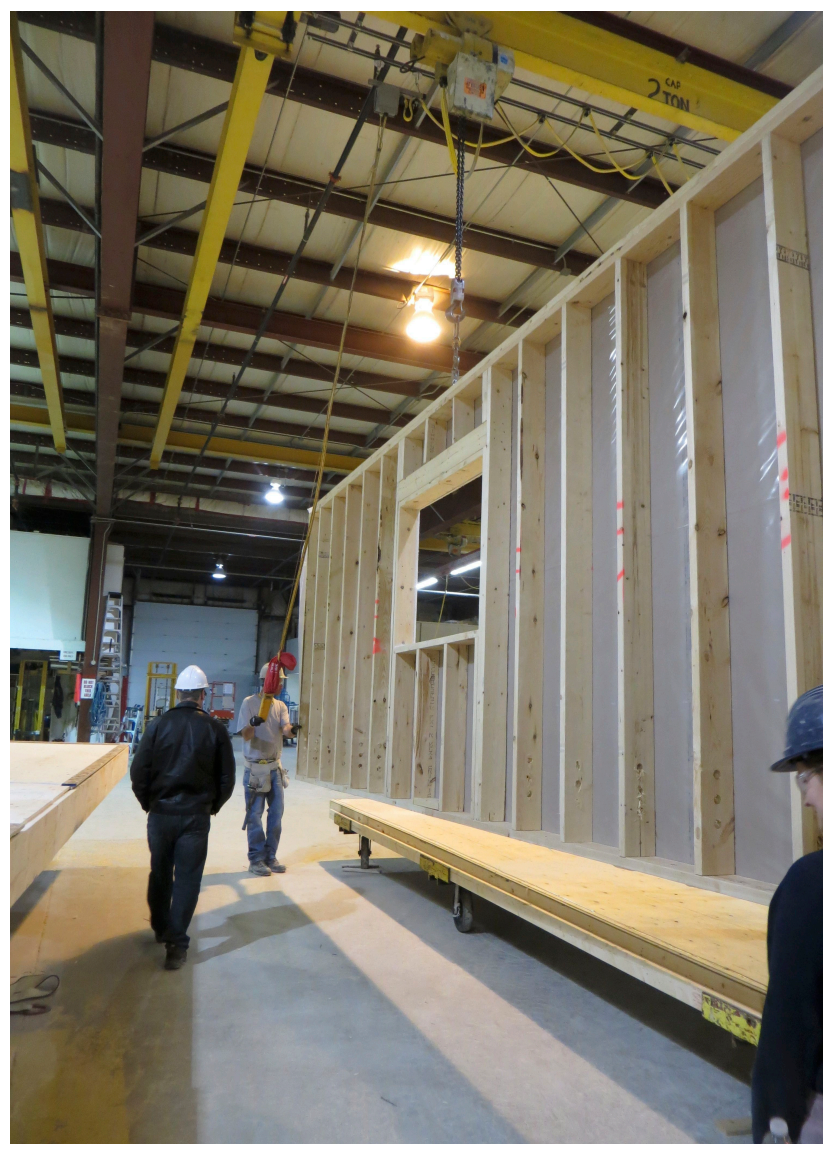

Figure 2-6 Gantry moving a framed wall 


\section{Process improvement: Gypsum Install}

Interior gypsum installation is very time consuming and a messy job. In the field, gypsum must be transported to the construction site and then moved to the location in the building where it will be installed. In most cases for residential construction, gypsum is hand carried into the house unless there is enough space for a forklift. Gypsum is heavy, and is installed on the ceilings and walls by hand. In a modular factory, gypsum board is laid flat on a table, wood framing is placed on top of it, and a spray glue is used to attach the gypsum board to the framing. However, not all modular manufacturers use this practice because the majority installs a polyethylene vapour retarder directly behind the gypsum board [Fazio, 2000 $]$. This prevents a chemical bond to adhere the wood framing to the gypsum. Instead, companies lay the framing on the table and then fasten the gypsum to the framing with screws from the front side. Nevertheless, if an envelope system is designed without a polyethylene vapour barrier, the gypsum board installation process can be potentially improved by using spray glue.

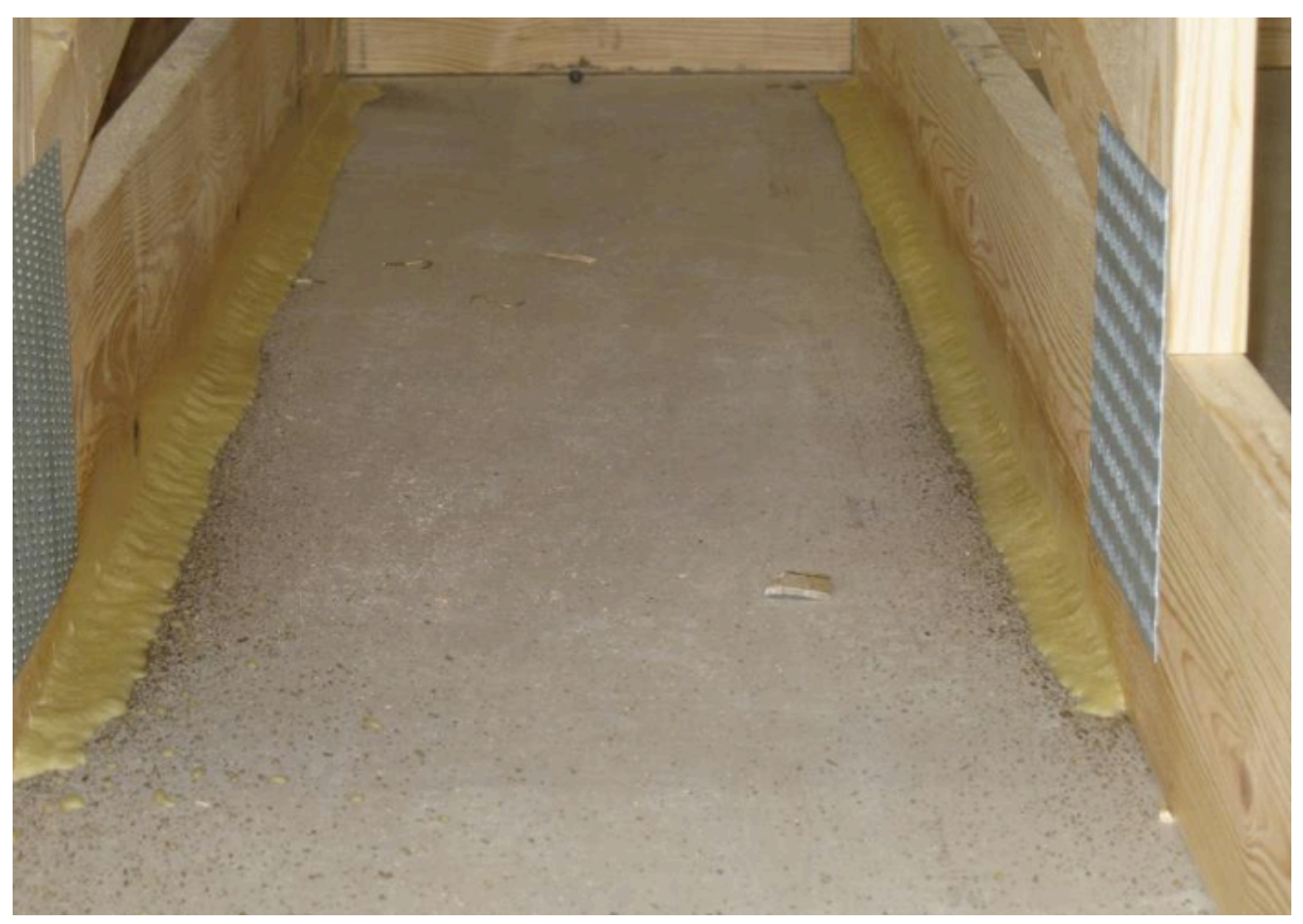

Figure 2-7 View of spray glue of gypsum board to roof truss [Eco Classic Homes, 2013] 


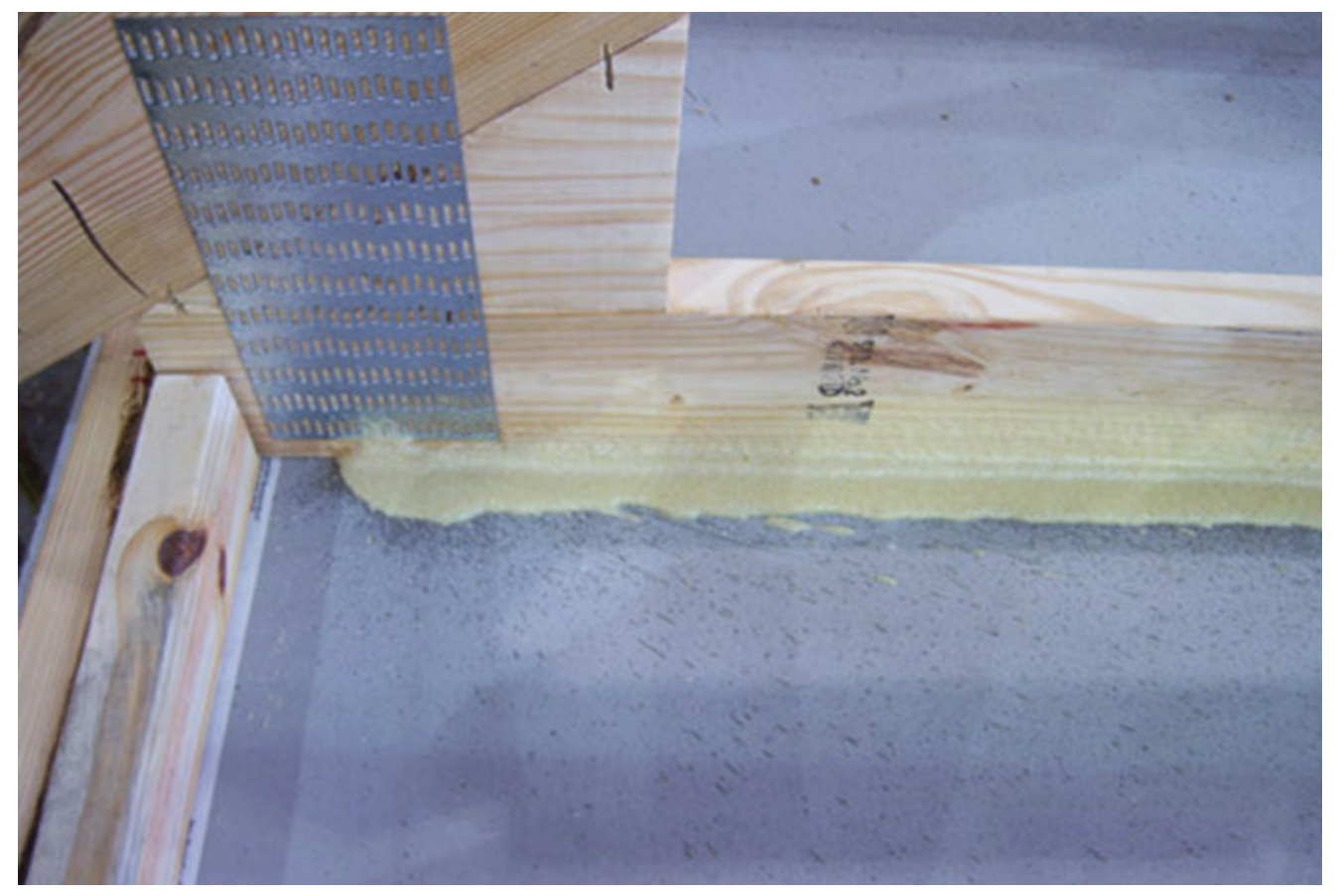

Figure 2-8 View of spray glue of gypsum board to roof truss [Eco Classic Homes, 2013]

\section{Process improvement: Framing}

In an interior environment, the framing process of the wood structure can be potentially improved compared to onsite construction. The use of framing jigs can reduce the need to measure stud and joist spacing. This ensures no extra framing is used, and the spacing is optimized for the length of assembly, without having to continuously measure each stud cavity length. In addition to the framing jigs for the floors, walls and ceiling systems, automated nailing machines can increase productivity of the framing process. Such machines can install subfloor and exterior wall sheathing at a tremendous rate because they are able to shoot multiple nails at the same time, at the precise location of the stud or joist. This reduces the amount of time in the framing process compared to onsite construction. In Figure 2-9, a photo taken during a visit to a modular factory of a framing table is displayed. 


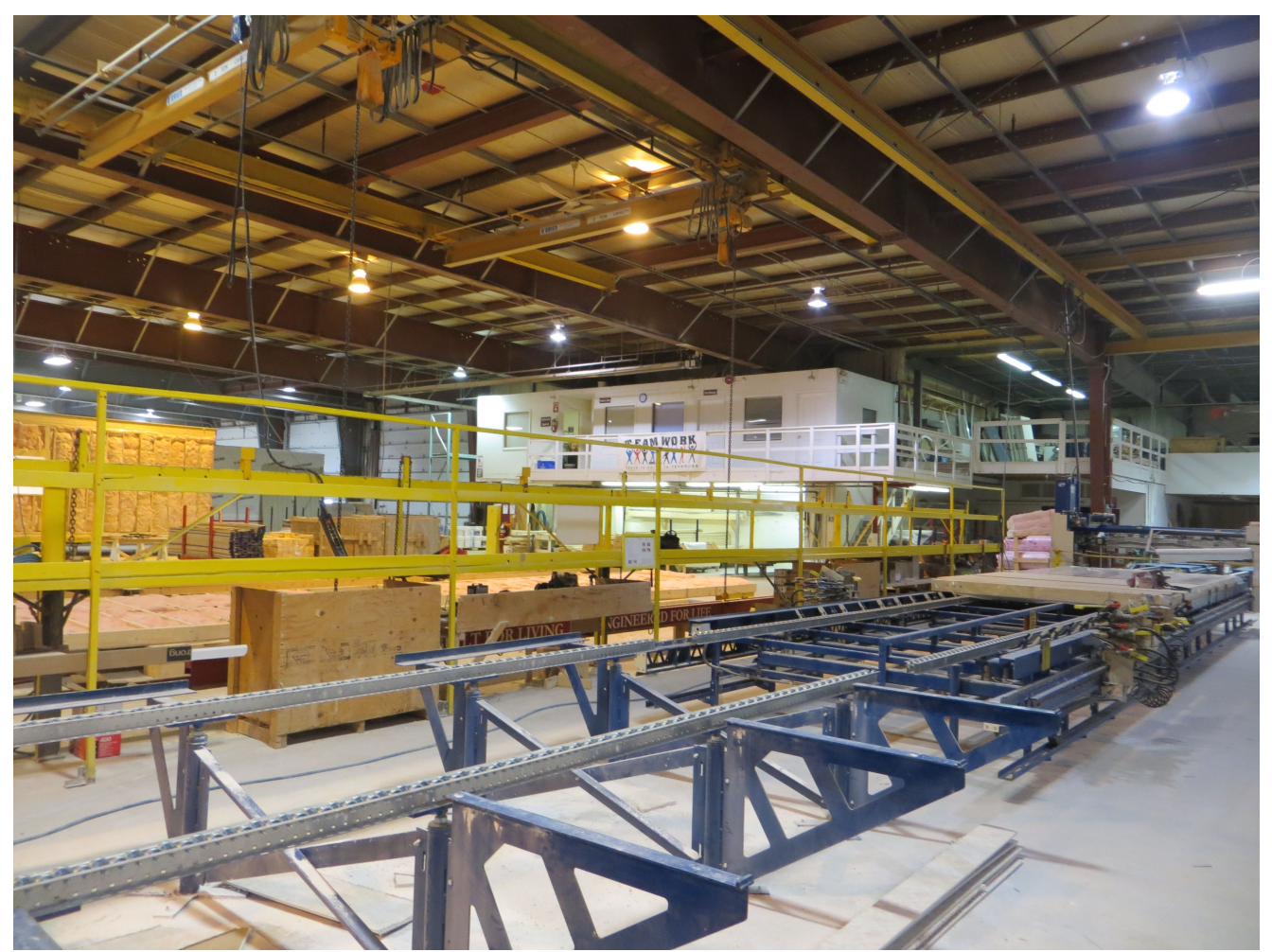

Figure 2-9 View of framing tables

\section{Process improvement: Installation of Mechanical, Electrical \& Plumbing Systems}

The installation processes of MEP systems are made easier with a modular building system [Siggner and Munro, 2011]. Large buildings with complex systems have a greater potential to benefit from this. Certain modules are called 'wet', meaning they are dedicated for plumbing systems and limit the pipe connections between modules. Electrical and mechanical connections are completed on site between the modules, and the connection locations are made accessible without disturbing the interior finishes. In Figure 2-10, the installation of the electrical services can be seen with a view of an outlet installed from the exterior side of the wall. This photo was taken during a visit by the researcher to a local modular factory. 


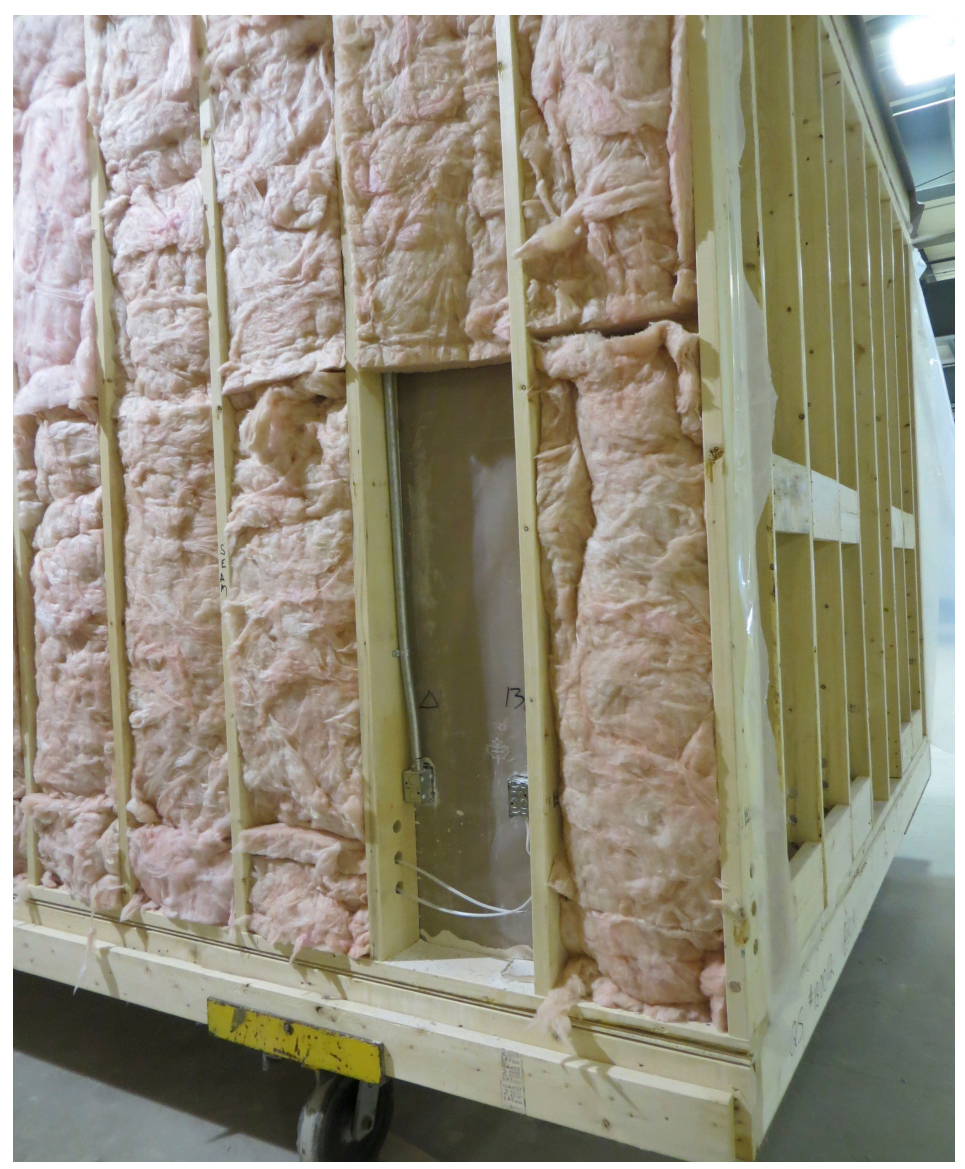

Figure 2-10 View of exterior wall in factory

\section{Reduced site transportation}

Large construction projects in urban centers require a tremendous amount of labor and materials to construct a project in a limited amount of space. If the construction process is moved to a location outside of the urban core, there is less congestion within the city's infrastructure. This is a potential advantage for the modular building system because fewer processes are completed onsite, and as a result, less congestion of the urban core is experienced [Yu, 2010]. 


\section{Challenges Faced by Users of Modular}

Despite all of the advantages of using of prefabrication to deliver the building envelope, it is not common in North America to do so [Fazio, 2000ª. Modular construction is not used on a wide scale in the construction industry and represents only $1.5 \%$ of all new projects in North America [MBI, 2012]. It is clear there are challenges faced by those within the modular building industry, and there are drawbacks and limitations that are viewed as barriers of entry for those not using the system. The following section outlines the potential drawbacks and limitations of modular building in North America.

\section{Architects Lack Experience with Modular}

Architects are often the first point of contact with the design of a building. Previous research has shown a major limitation to the use of modular construction is the lack of knowledge by architects about the possibilities and limitations of the manufacturing process of the modules [Schoenborn, 2012]. To use the modular building system successfully, the architect must design with it from the beginning. It is not practical, and in many cases, not possible, to take an existing design and construct it with a modular building system. It was noted in Schoenborn's research that architects think that the modular building system limits their creative architectural expression and customized designs. This is because modules are perceived to be limited in their shape and ability to produce a unique building. It is also felt by architects that the modular building process puts too much design work on the front end because more detail is needed, and multiple sets of drawings are needed for both the manufacturing and onsite construction processes [Schoenborn, 2012]. Modular companies try and combat this challenge by educating architects about the system, and offer to work with the design team to achieve a constructible system. Using a fully integrated design platform is the best method to do so, but a dedicated team to work together with both the architect and manufacturer is needed in order for this to work successfully [Schoenborn, 2012]. 


\section{Reputation of poor quality from mobile home era}

Modular construction has a poor reputation in the minds of the general public. There are poor lingering images of the manufactured homes from the high production, low quality era of the mobile home industry [Horvat et al., 2001]. This is a major challenge faced by those in the modular industry [Cameron et al., 2007]. The general public must be educated about the differences between mobile homes and permanent modular construction. Along with the general public, developers, architects and policy makers could all help with the image shift of the modular system. This will only be possible if high quality, high performance buildings are constructed using the system to display their true benefits.

\section{Potential transportation constraints}

Modules are large, heavy and cumbersome. They are often box-like in shape: $4.5 \mathrm{~m}$ wide, $3 \mathrm{~m}$ tall and $12 \mathrm{~m}$ long. Although other dimensions are possible, they are limited to the dimensional restrictions imposed on them by the transportation route between the manufacturing facility and the construction site [MBI, 2012]. They can be prone to damage while in transportation [Siggner and Munro, 2011]. This is a major reason why the modular building system is not used in Europe as much as the closed panelized envelope systems [Fazio, 2000 a $]$. The infrastructure in Europe does not allow for wide loads to be transported as easily due to their narrow roads and tightly situated buildings. Another reason why the panelized system is used over the modular system in Europe is because several Northern European countries export them to other countries. It is not practical to build modules and transport air. The panelized systems are smaller, compact, and allow for easy shipping. Although modules offer other advantages over the panelized systems, their size and ease of transportation can be a potential limitation of use in some projects. 


\section{Overhead is consistent, even during periods of low demand}

Using the modular building system, a facility is needed to store the materials, equipment and production line. In addition, the vast majority, if not all, of the trades workers are employees of the manufacturing company. This is substantial overhead that general contractors would not endure. During times of high demand, there is no problem. However, during periods of low demand, the modular building facility could have problems maintaining their overhead and be forced to potentially lay off workers [Cameron et al., 2007]. In periods of low demand, a general contractor also would struggle, but their ability to deal with the reduced demand is more flexible because they subcontract the vast majority of the construction processes to other companies. In addition, traditional general contractors who build onsite do not rent or own a manufacturing facility that would need to be maintained during periods of slow demand.

\section{Manufacturing Production Line}

The majority of modular manufacturers use a production line design that has never changed since the mobile home era [Sloditskie, 2013]. However, there are two vastly distinct characteristics between the current day permanent modular building system compared to the mobile home systems. Mobile homes are uniform - its either a single wide, or a double wide. Every module being processed in the factory requires the same scope of work for completion. In permanent modular construction, various module designs are used to construct the building. The scope of work changes with each module.

The schematic layout of a typical production line used by most modular manufacturers in North America is displayed in Figure 2-11. In positions 1-7, the floor, walls \& ceiling systems will be assembled and joined together to form the structure of the module. Positions 8-17 are used to do the remaining work required - mechanical, electrical, plumbing, interior finishes, exterior finishes and envelope elements. Modules could move between workstations without delaying modules downstream in the production line, or be stalling modules upstream with this system because in the mobile era, each position would take the same amount of time. It is the 
goal of every manufacturing line - to have level flow [Womack et al., 1990, Womack et al., 1996]. Level flow means for each workstation or manufacturing process to take the same amount of time to complete throughout the value stream. In modern modular home designs, often every module is different. Larger buildings allow for greater similarities or repeat modules to be used in the design. This allows the production processes at workstations to take the same amount of time to move at the same rate. Overall, the vast majority of modular home manufacturers use a line design that does not account for varying levels of work scope required by each module in a modern, permanent modular building. This is an area of potential future research - the design and testing or a new production line for a high performance modular building system.

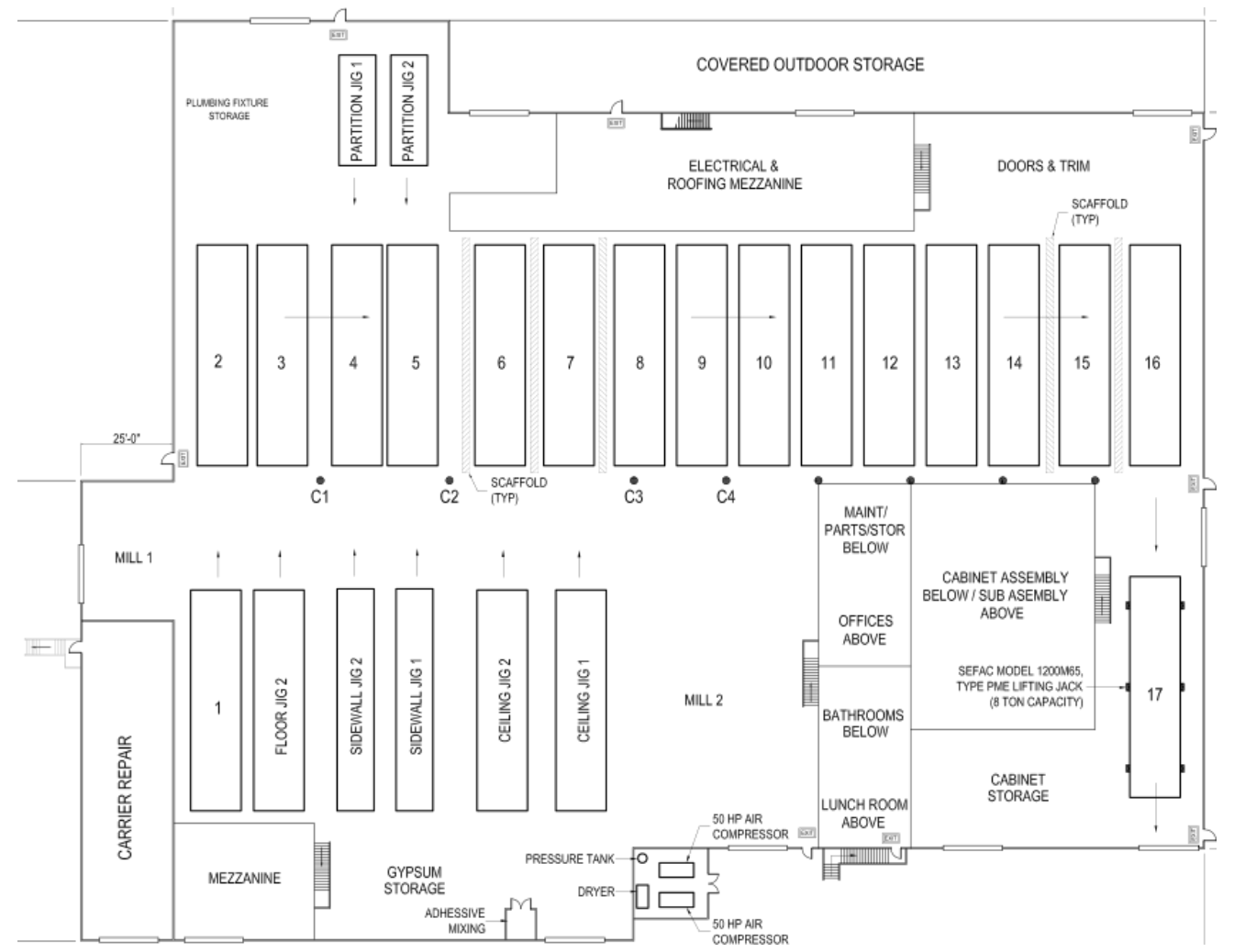

Figure 2-11 - Schematic layout of a typical production line [Sloditskie, 2013] 


\section{Manufacturing facilities consume a lot of energy}

Manufacturing facilities consume a lot of energy. It is commonly stated that the modular building system offers a more environmentally responsible construction process compared to onsite construction [MBI, 2012]. In previous research by Quale, it was cited that this is generally the case. However, the energy consumption characteristics of certain modular factories in North America would tip the balance to a negative environmental impact compared to onsite construction [Quale, 2010]. The cited research concluded that not all modular-manufacturing processes had less environmental impact compared to onsite methods. The primary reason was that certain manufacturing facilities experience tremendous amounts of air infiltration and had very little insulation, if any, in their building envelope. In addition, their plug loads for lighting and mechanical equipment were significant.

\subsection{Modular Building System Examples}

The following section outlines three examples of currently used envelope systems by modular builders in North America. It begins with the most common envelope system used by modular builders. The second example is from a low energy consuming home that was constructed using a modular building system. The third example is a modularly constructed near net-zero energy house, the EcoTerra house project in Quebec. Special attention and discussion was given to the air barrier systems and thermal resistance layers used in the three examples through various construction connection details. Each modular envelope example progressively gets more air tight and more insulated.

\subsubsection{Modular Example \#1}

Figure 2-12 outlines a full section of the most common envelope systems used by modular builders in North America [Sloditskie, 2013]. The full section is of two-story modular house on top of a full height basement attachment. The primary air barrier on the exterior wall is identified as the exterior weather resistance membrane on the outboard side of the structural 
sheathing. The ceiling air barrier is the interior gypsum board layer. These are highlighted with a red line in Figure 2-12. Fiberglass batt insulation is the primary thermal resistance material.

The following list outlines the clear wall thermal resistance values. The air tightness levels are displayed in a range because these details are not taken from a specific project that was tested. The range of air tightness is based on previous investigations into air infiltration rates of homes in North America [Chan et al., 2003].

- $\quad$ Exterior walls $\quad$ RSI 3.4

- Roof RSI 6.7

- Slab RSI 0.15

- $\quad$ Basement walls RSI 0.15

- $\quad$ Air tightness $\quad 3$ to 8 ACH@50 Pascal 


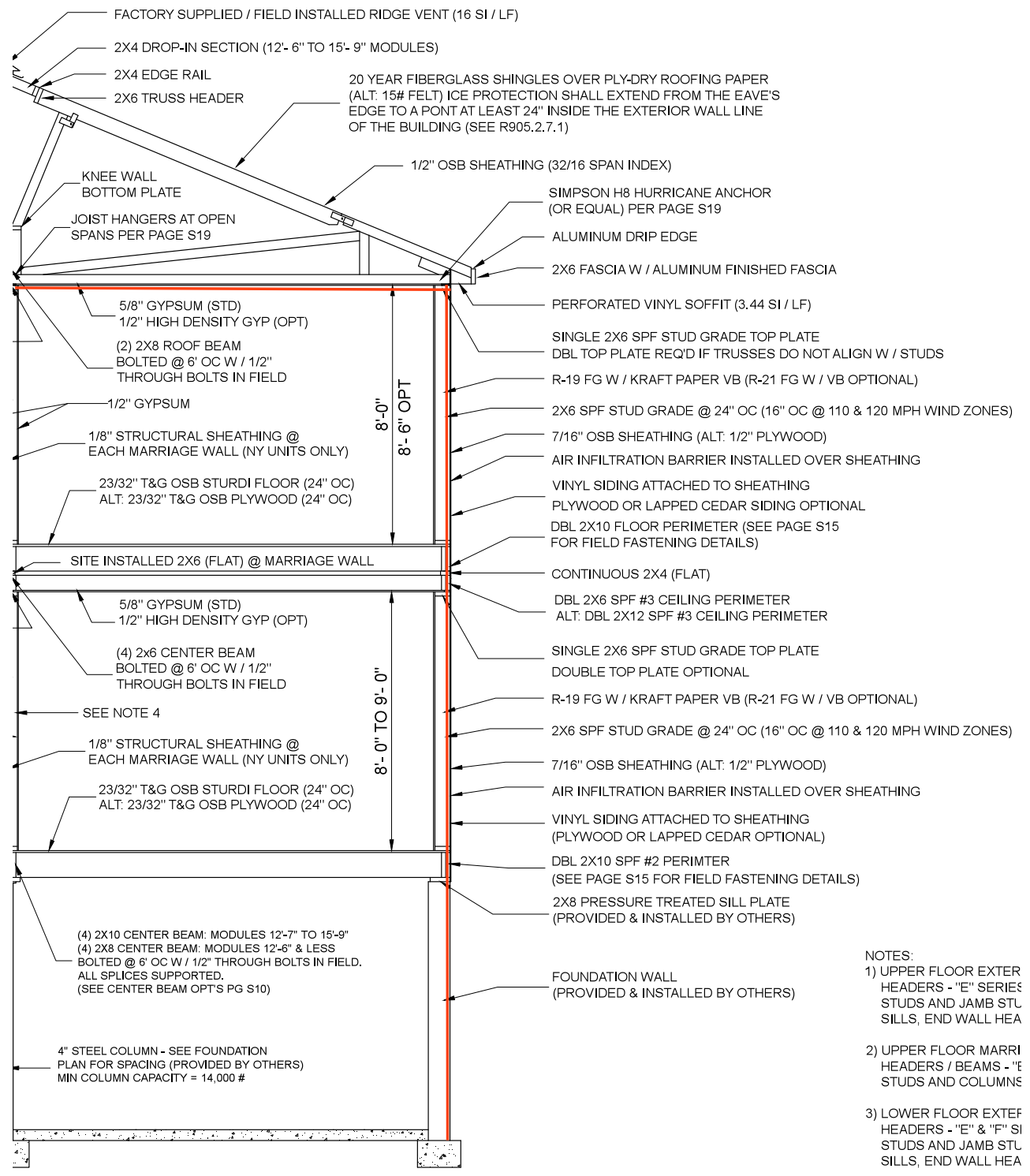

Figure 2-12 Full Section of modular envelope example \#1 [Stoditskie, 2013]

Figure 2-13 shows the connection of the module to the foundation. There is no mention of how a weather resistance membrane transitions to the foundation wall to form a continuous air barrier. The weather resistance membrane is highlighted with a red line in the detail. It is interesting to point out that the foundation system and the sill plate on which the module is placed on, is installed by a separate subcontractor. This is a common location of air leakage in buildings [Knight et al., 2002]. Although modular manufacturers do not perform foundation 
installations, it should be a concern of modular manufacturers on how the modules are connected to below grade foundations. This is not only important for structural purposes, but also for reducing potential air leakage and thermal bridging.

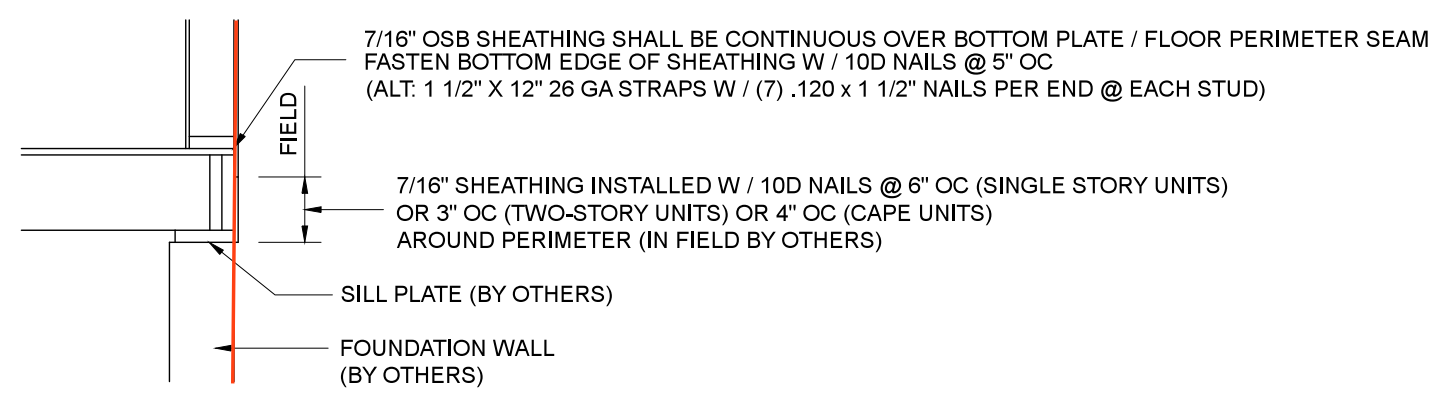

Figure 2-13 Wall to foundation connection from modular example \#1 [Sloditskie, 2013]

In Figure 2-14 the connection between the upper module and lower module is outlined [Sloditskie, 2013]. It is interesting to mention a piece of the exterior OSB sheathing is left off the modules, and then installed onsite. This is to account for variances between the modules [Cohen et al., 2013]. After the OSB is installed, the weather resistance membrane air barrier would be over lapped and then taped onsite [Sloditskie, 2013]. This air barrier is represented with a red line in Figure 2-14. Figure 2-15 shows modules being installed on site with the weather resistance membrane left open.

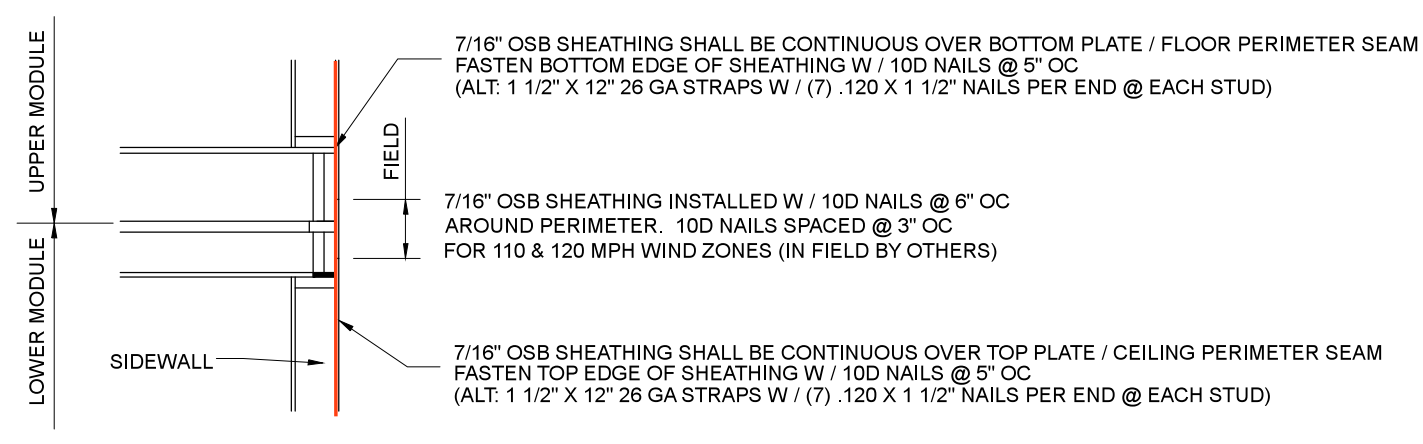

Figure 2-14 Upper \& lower module connection for modular example \#1 [Sloditskie, 2013] 


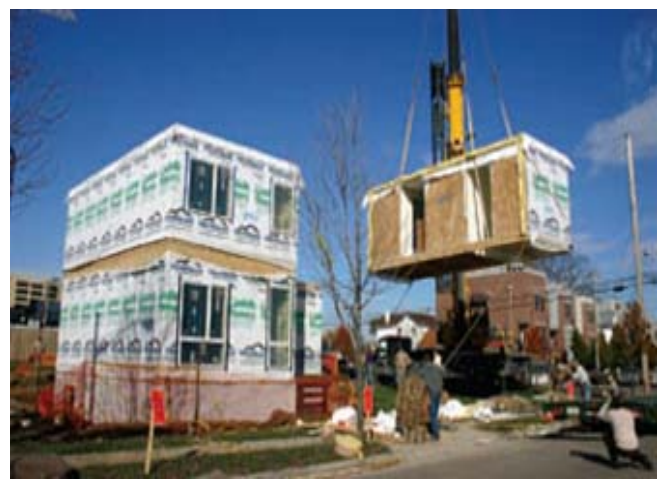

Figure 2-15 Module with WRB left open [NAHB, 2013]

In Figure 2-16 the connection of the wall to the roof is displayed for a typical modular building system in North America [Slodiskie, 2013]. The only material to stop air leakage in the ceiling location is the gypsum board. The weather resistance membrane runs up the sheathing and a compressive strip on the top plate is identified as a possible air barrier transition from the wall to the ceiling. In the ceiling, the air barrier is the gypsum board. This transition is highlighted with a red line.

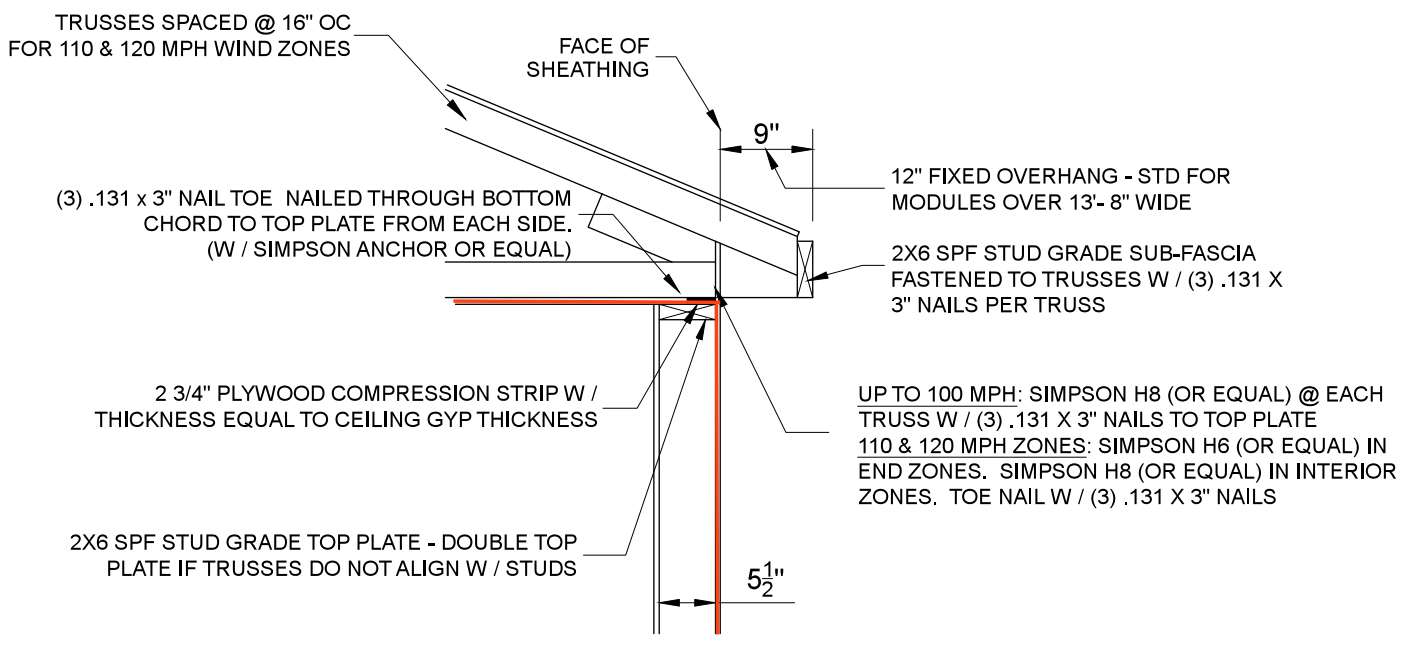

STANDARD 9" FIXED OVERHANG

Figure 2-16 Wall to ceiling detail for modular example \#1 [Slodiskie, 2013] 


\subsubsection{Modular Example \#2}

The following modular building project was constructed in Vermont, United States in 2011 [Biebel, 2011]. It was a custom home, built to be low energy consuming, with above average levels of insulation and air tightness. In Figure 2-17 the modules are shown being installed on site with a crane [Biebel, 2011].

The envelope thermal resistance and air tightness levels are below. The RSI values are represented as clear wall values and the air tightness level was calculated with an onsite blower door test after the house was finished [Biebel, 2011].

- $\quad$ Exterior walls $\quad$ RSI 6.0

- $\quad$ Roof RSI 8.6

- Slab RSI 0.15

- $\quad$ Basement walls RSI 2.1

- $\quad$ Air tightness $\quad 2.66 \mathrm{ACH} @ 50 \mathrm{~Pa}$ [Without basement volume] \& 1.9 ACH@50 [With basement volume]

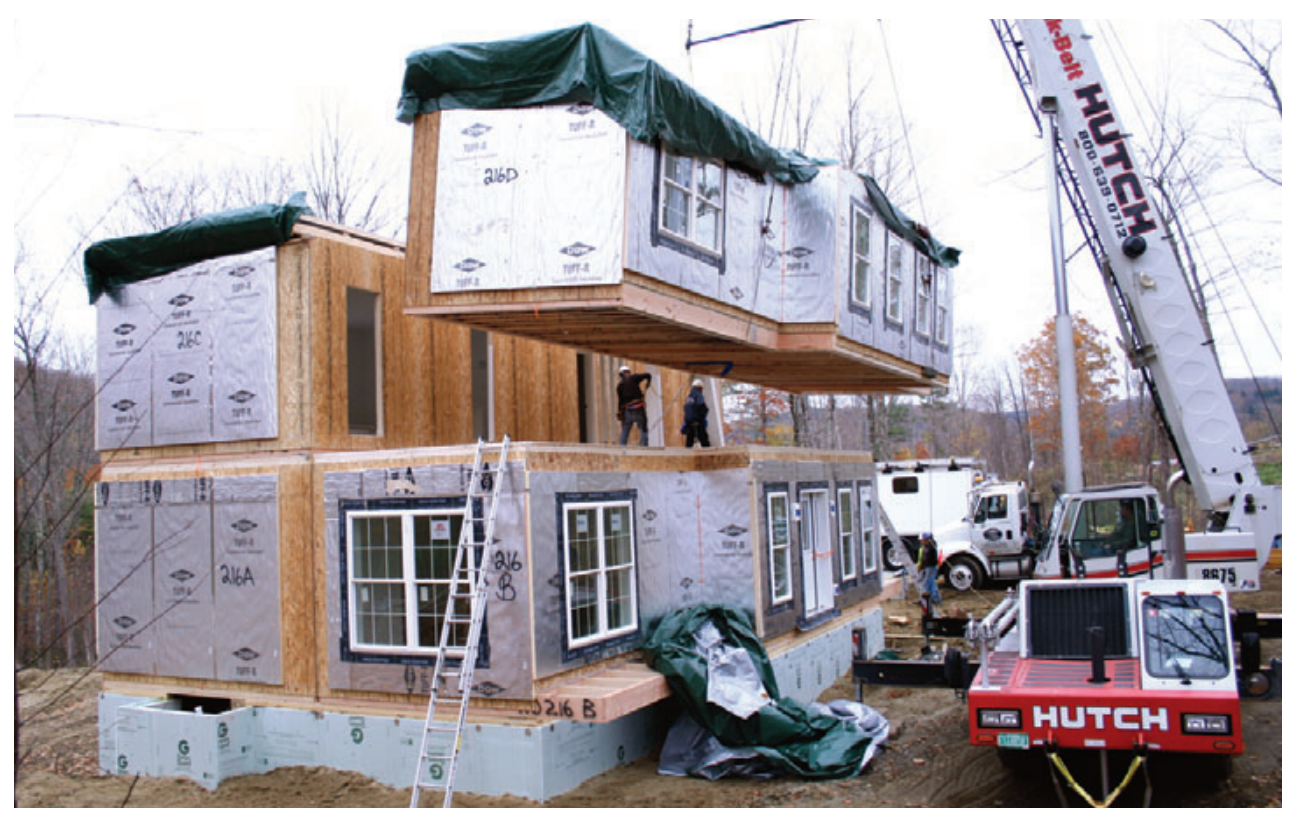

Figure 2-17 Modules installed on site for modular example \#2 [Biebel, 2011] 
Figure 2-18 shows the various connections between the modules are outlined for this particular project. The primary difference between this project and the previous example is the addition of the exterior polyisocyanurate insulation. The air barrier system is the interior gypsum board approach with various compression strips and gaskets to stop air leakage. In Figure 2-19, a black gasket can be seen at the marriage joint of the modules. This was used to limit air leakage between the modules once installed onsite. The rim joist location is displayed in Figure 2-20. The air sealing strategy in this location was described as being the rigid foam board being sealed to the floor joists [Biebel, 2011]. 


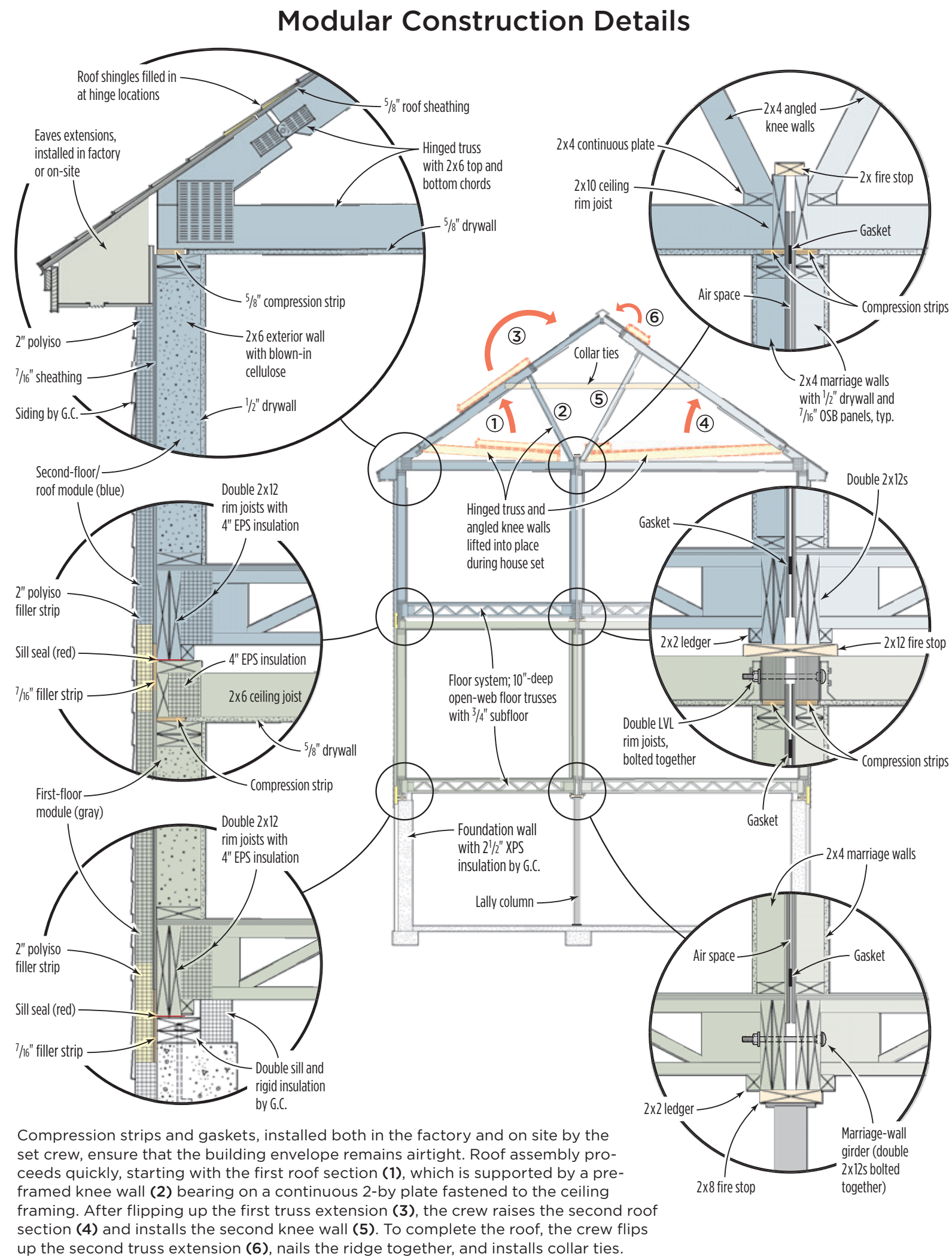

Figure 2-18 Full section detail of modular example \#2 [Biebel, 2012] 


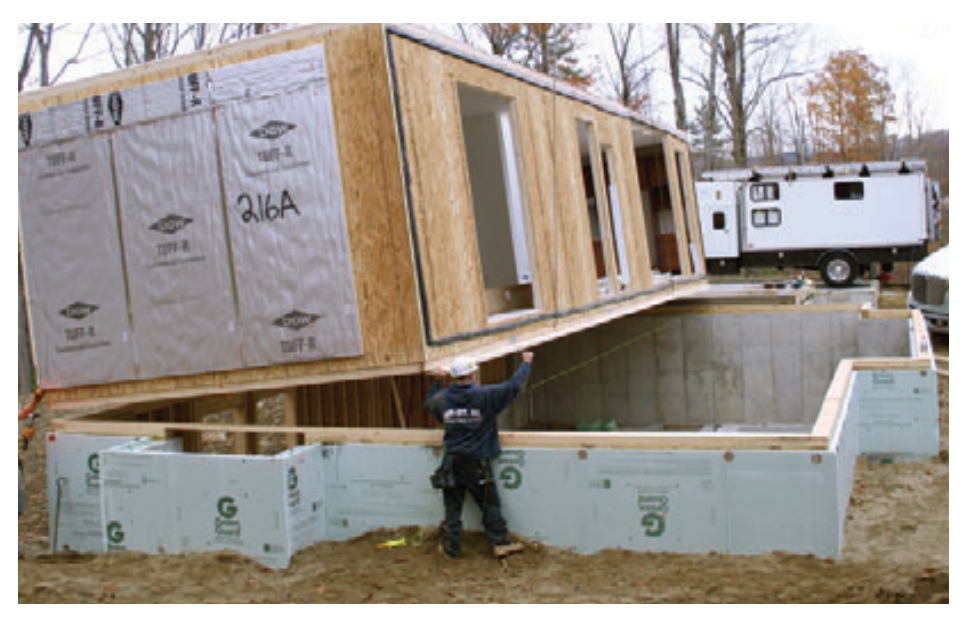

Figure 2-19 View of gasket seal [Biebel, 2012]

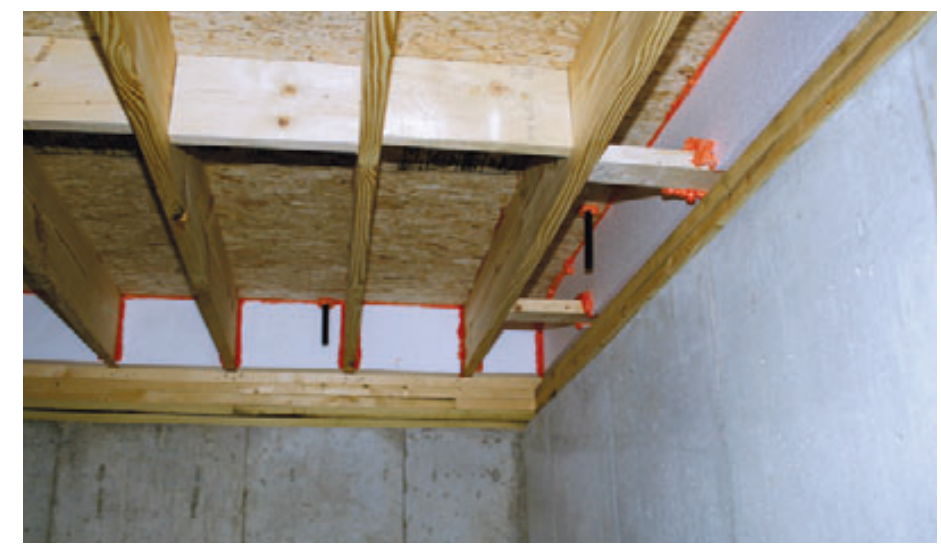

Figure 2-20 View of rim joist [Biebel, 2012]

This example provides insight into current air sealing methods for the building envelope in low energy consuming homes using the modular system. This envelope is better than minimum code requirements, but there are possible improvements to both the air barrier system and the thermal resistance levels to be made to achieve even greater levels of energy conservation and durability. 


\subsubsection{Modular Example \#3}

The EcoTerra project was constructed as part of the Canada Mortgage and Housing Corporation's Equilibrium Sustainable Housing Demonstration Initiative [Doiron, 2011]. The construction team used a modular building system to deliver the home and it was constructed by Alouette Homes in Quebec, Canada. It was designed to demonstrate a method to achieve a netzero energy home.

The envelope system thermal resistance and air tightness levels are outlined in the following list. The RSI values are represented as clear wall values and the air tightness was confirmed with an onsite blower door test [Doiron, 2011].

- Exterior walls $\quad$ RSI 6.4

- Roof RSI $9.2 \& 10.9$

- Slab RSI 1.3

- $\quad$ Basement walls RSI 2.5 [Above grade] \& 5.7 [Below grade]

- $\quad$ Air tightness $\quad 0.85$ ACH@50 Pascal 


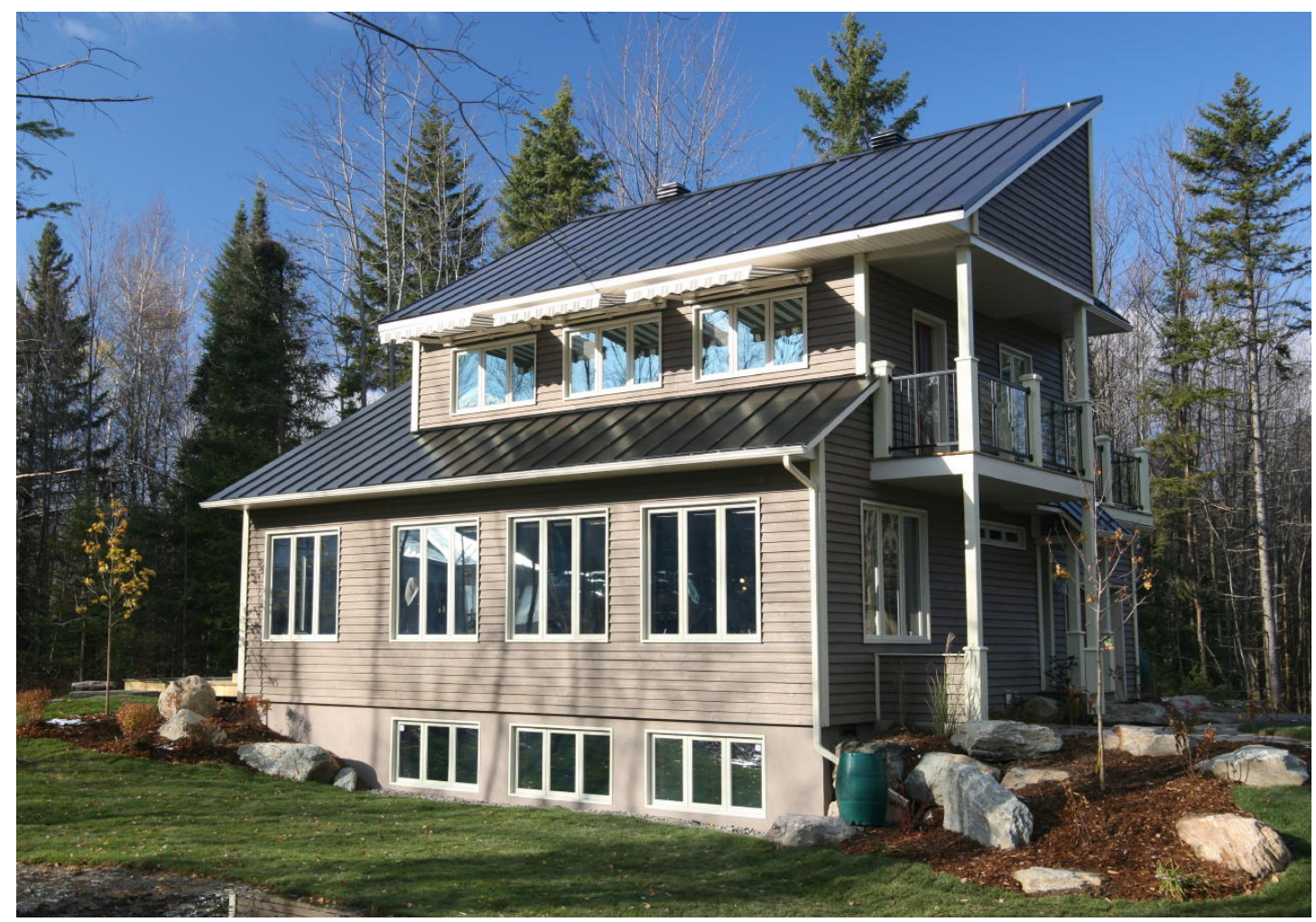

Figure 2-21 EcoTerra house- modular example \#3 [Canadian Mortgage \& Housing Corporation, 2011]

Figure 2-22 shows a full section view of the envelope system from the foundation to the roof. The primary thermal resistance layers are spray applied foam insulation across the entire envelope. The air barrier for the exterior wall portion is a $25 \mathrm{~mm}$ layer of closed cell spray applied foam insulation on the exterior side of the structural studs. The air barrier material for the roof is the $50 \mathrm{~mm}$ layer of closed cell spray applied foam insulation on the exterior side of the gypsum board [Doiron, 2011]. 


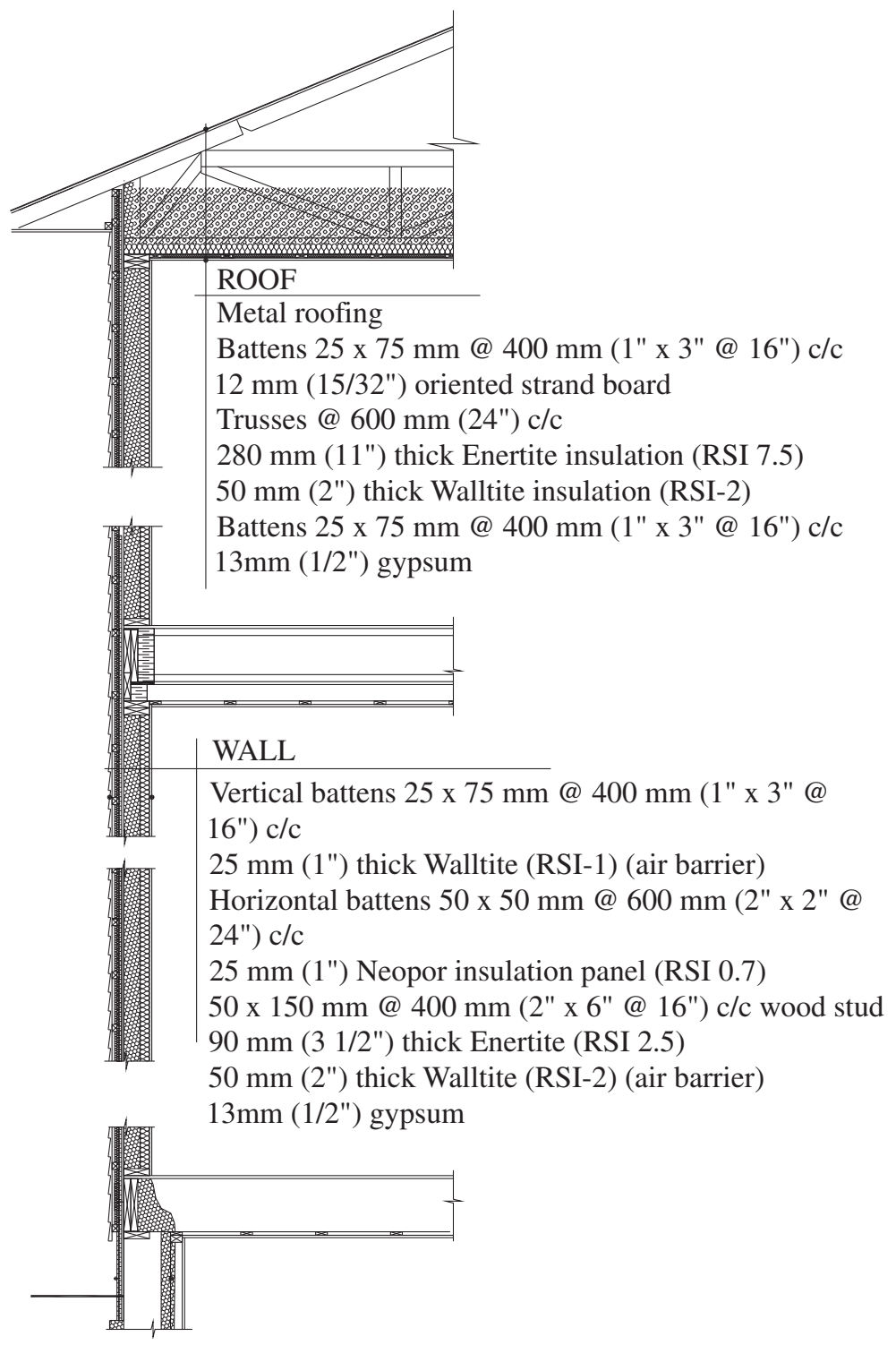

Figure 2-22 Full section detail for modular example \#3 [Chen et al., 2011]

Figures 2-23 \& 2-24 display the exterior wall portion of the envelope as the modules were installed onsite and being delivered [Canadian Mortgage \& Housing Corporation, 2011]. The blue material is the exterior applied spray foam that is acting as the air barrier and has vertical furring strips applied over top to support the exterior cladding. 


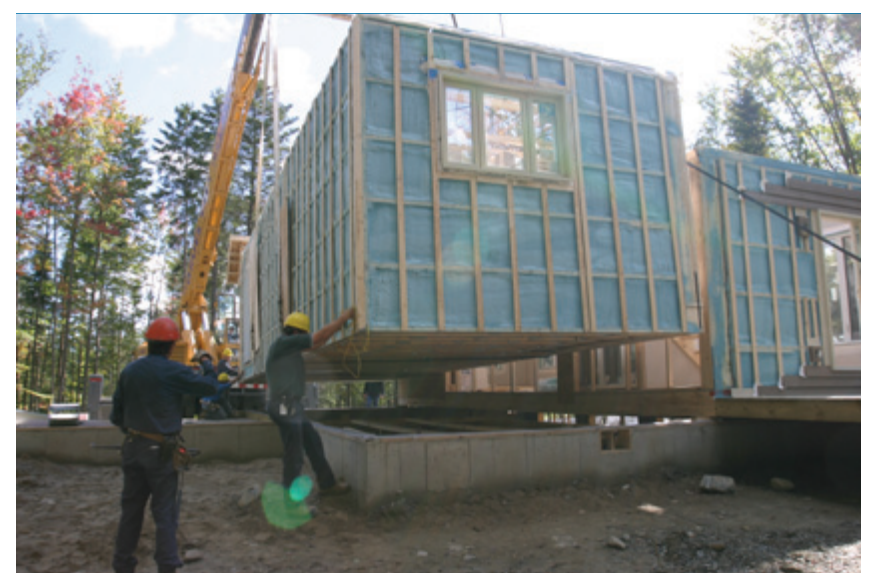

Figure 2-23 Module being installed for EcoTerra house [Canadian Mortgage \& Housing Corporation, 2011]

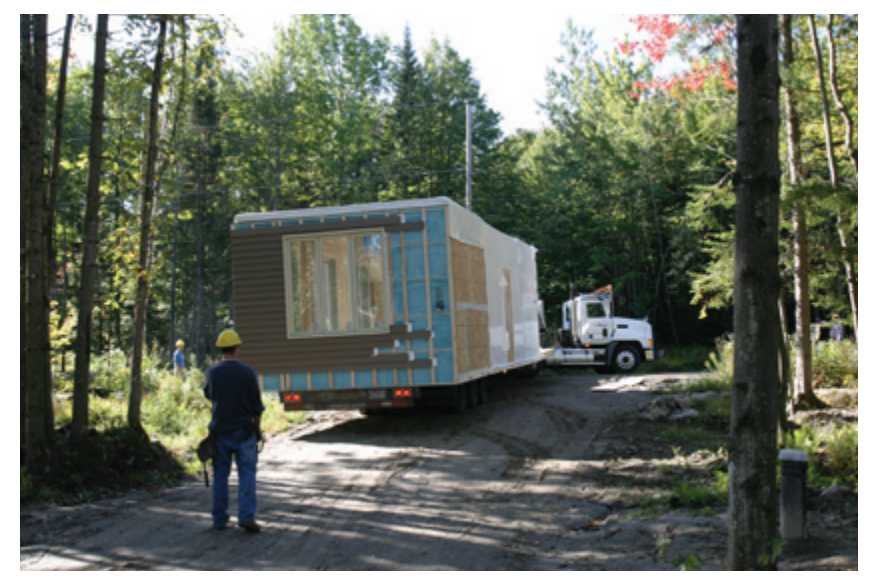

Figure 2-24 Module installed for EcoTerra house [Canadian Mortgage \& Housing Corporation, 2011]

Figure 2-25 illustrates the foundation to exterior wall connection [Doirion, 2011]. In the exterior wall section, the spray applied foam insulation was outlined as the primary air barrier. In this detail, the air barrier transition from the exterior wall to the foundation is made from the exterior layer of spray foam, to the inside of the rim board between the joists and then transitioned to the interior applied spray foam on the concrete foundation wall. This transition is outlined with a red line. 


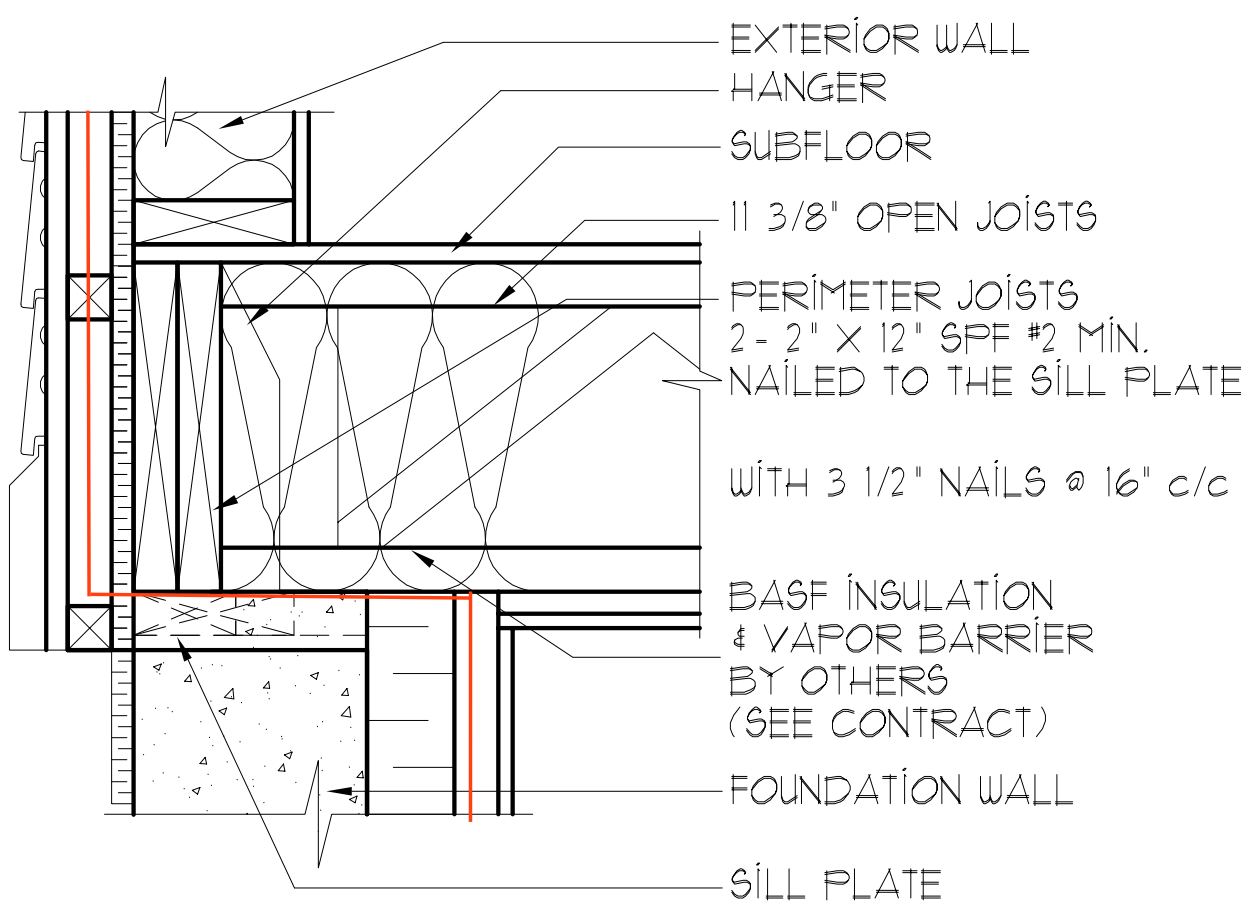

Figure 2-25 Wall to foundation connection for modular example \#3 [Doiron, 2011]

Figure 2-26 displays the rim board connection between the upper and lower modules [Doiron, 2011]. The spray foam on the exterior side of the wall was applied at this seam once the modules were installed onsite. Figure 2-27 shows the plan view of the connection between the modules [Doiron, 2011]. Again, spray foam is used as the primary air sealing method between the units once they are installed onsite. Figure 2-28 displays the air barrier connection from the wall to the ceiling. This made from the exterior applied spray foam, to the spray foam in the ceiling joists. These air barriers are represented with a redline in the details. The blue material in Figure 2-29 is the spray foam layer applied in the factory. 


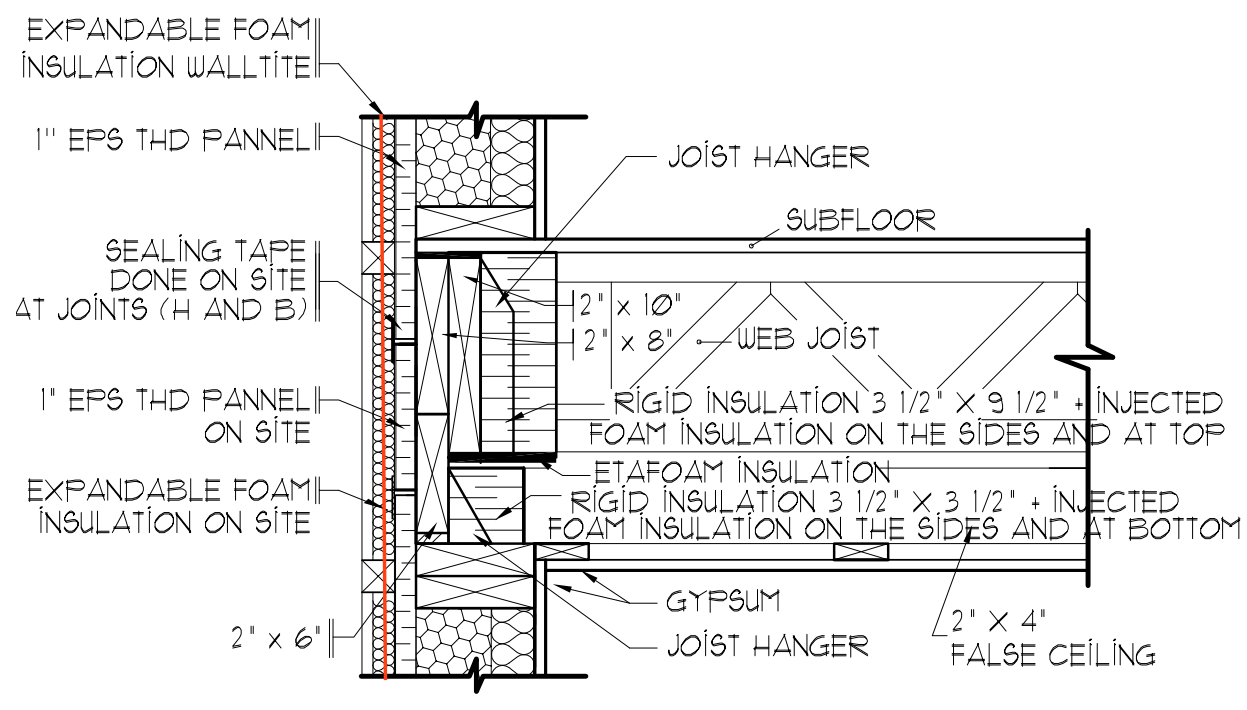

Figure 2-26 Rim joist connection in modular example \#3 [Doiron, 2011]

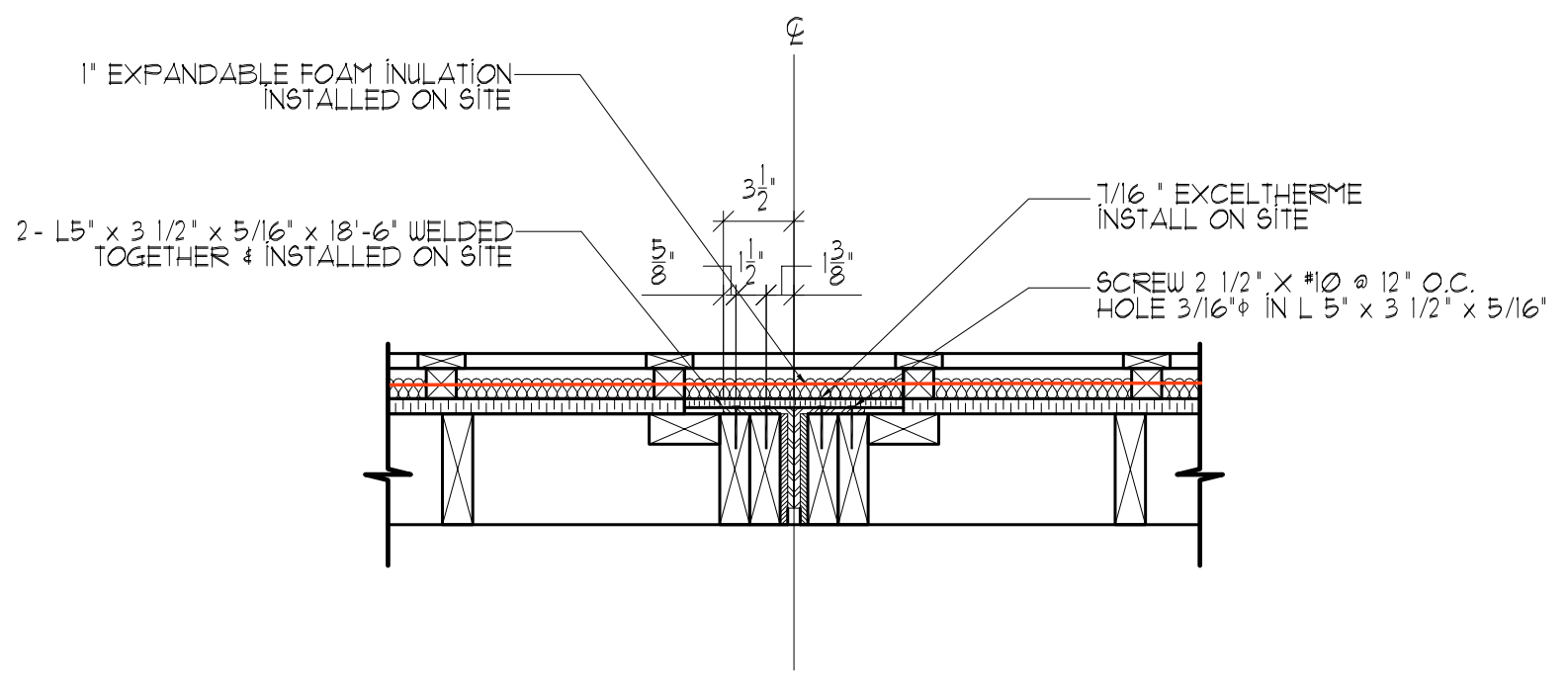

Figure 2-27 Plan view of module connection of modular example \#3 [Doiron, 2011] 


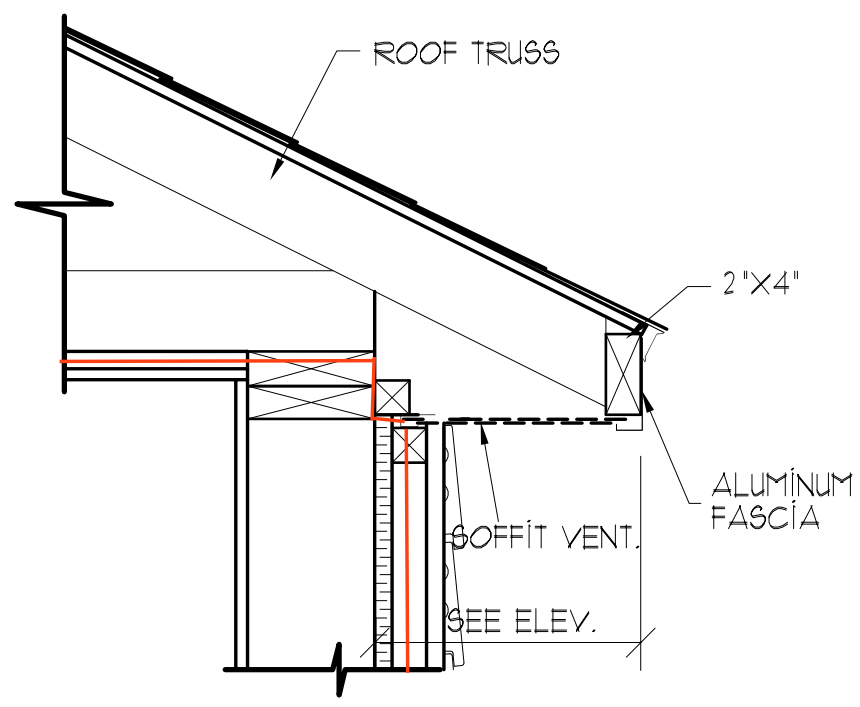

Figure 2-28 Wall to ceiling connection of modular example \#3 [Doiron, 2011]

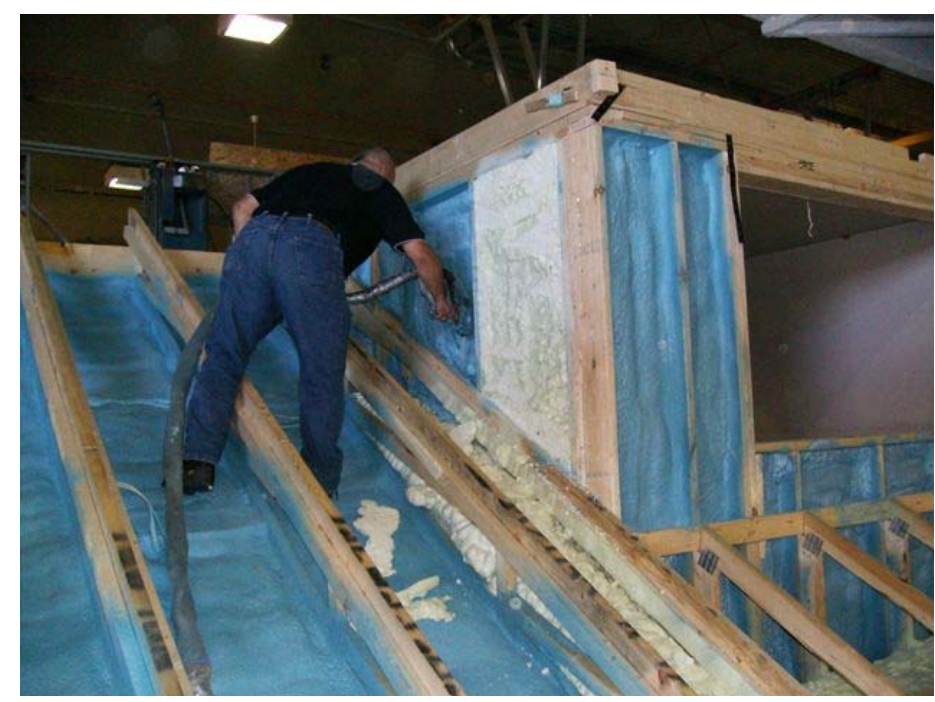

Figure 2-29 View of spray foam insulation in modular example \#3 [Canadian Mortgage \& Housing Corporation, 2011]

The primary difference between the modular examples discussed here is the design of the air barrier system. In these examples, a weather resistance barrier, an interior gypsum board and 
a spray foam insulation methods are used to create an airtight envelope. Based on the blower door test results between the three modular built homes, the interior gypsum board and weather resistance barrier methods of air sealing were less effective than the spray foam approach. Gypsum board is considered to be a possible air sealing method in envelope systems. However, interior gypsum board can be compromised by penetrations from electrical boxes, lighting, hanging cabinets and interior design remodels from the occupants of the home. The weather resistance barrier approach is difficult to make continuous across all of the interfaces and has many seams that are flexible and difficult to tape.

Out of the various air sealing methods displayed in the three modular examples, the spray foam used in the EcoTerra project achieved the lowest blower door test of $0.85 \mathrm{ACH}_{50}$. This is significantly less air leakage than the other two examples. However, there are several issues with this material for its use as an air barrier material. Over the long term, foam insulation will shrink [Bomberg et al., 1999, Listrburek, 2012]. With the expansion and contraction of the materials in the assembly, there is the potential for the foam to develop cracks and develop channel paths for air leakage. Next, spray foam is an expansive insulating material [Aldrich et al., 2012], especially when thick amounts of the material are needed to form a super insulated envelope assembly. Finally, certain closed cell spray foam insulations are manufactured with a heavy petroleum based product that can potentially contain extremely high levels of embodied energy [Harvey, 2007]. Although spray foam was used in this cutting edge modular home and an $\mathrm{ACH}_{50}$ of 0.85 was achieved, the negatives of using this material cannot be ignored.

Overall, this portion of the literature view outlined three examples of currently used envelope systems in modular building systems in North America. The primary air barrier systems varied from interior gypsum board, exterior weather resistance membranes and spray foam. However, none of these materials were specified in any of the developed assemblies in this research as a primary air barrier material. Each of these methods of air sealing has its respective problems and led to the development of an alternative air sealing method to be used in the proposed envelope systems. 


\subsection{High Performance Envelopes}

This section reviews previous envelope systems and insulation materials that provided inspiration for the four high performance envelope systems developed in this thesis. The vertical I-beam [Klingenburg, 2012] and exterior rigid polyisocyanurate insulation assemblies [McDonald, 2012] are developed based on case studies of previous Passive House projects in North America. Mineral wool is the most common insulation material in Northern European climates [Fazio, 2000 $]$ and was used by the researcher and this portion looks into the material properties of the insulation material. Vacuum insulated panels assembly was developed based on current research about the material and its installation practices and some previous literature is reviewed to gain insight into the benefits and drawbacks of using the material.

\subsubsection{Vertical I-Beam Envelope System}

The Smith House, built in 2003 in Urbana, Illinois by Katrin Klingenberg is the first certified Passive House project in North America [Klingenburg, 2012]. This project was built onsite, and the envelope system uses a vertical I-beam to produce a significant cavity for insulation. The vertical I-beam used in this assembly was $281 \mathrm{~mm}$ wide $\left(11^{1 / 4}\right.$ ") for thick amounts of insulation to be installed. Cellulose with a conductivity of $0.4 \mathrm{~W} / \mathrm{m} \cdot \mathrm{k}$, [ASHRAE, 2009 ${ }^{\mathrm{b}}$ ] was used at this thickness to provide a clear wall RSI value of $8\left[\mathrm{~W} / \mathrm{m}^{2} \cdot \mathrm{k}\right]$. This does not include a framing factor, but undoubtedly offers tremendous thermal resistance and has the potential to be produced in a factory setting. I-beams can come in larger sizes if more thermal resistance is needed. The I-beams are convenient because it allows for the cellulose to be installed in sectioned off cavities. This enables for precise density levels to be installed and tested. Figure 2-30 details show how the vertical I-beam is used in an exterior wall system. This type of wall system will be explored for its applicability in using it for a prefabricated modular building envelope system. 


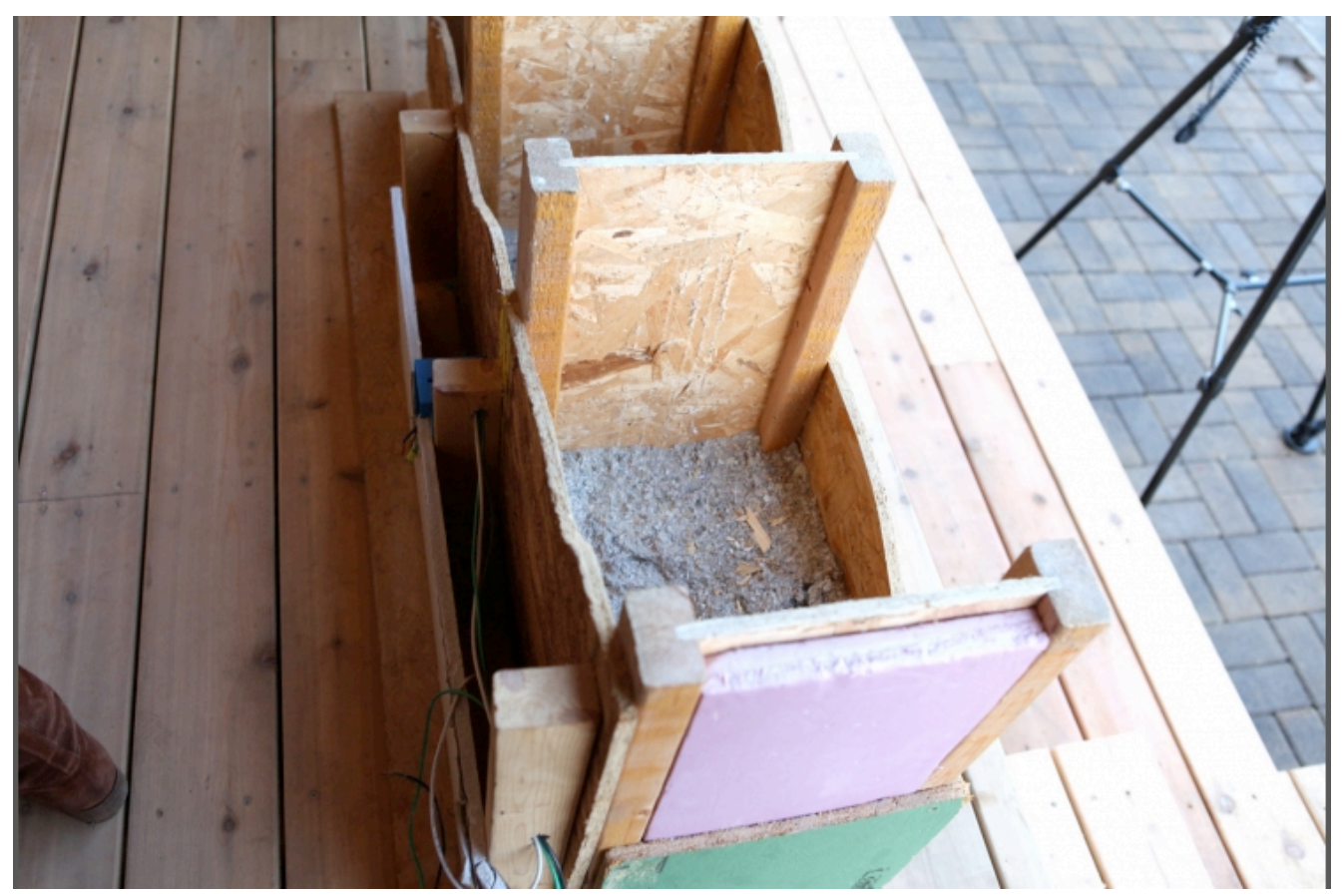

Figure 2-30 - Example of a vertical I-beam assembly [Klingenberg, 2012]

\section{Larson Truss}

The Larson Truss was first developed in Alberta as a means of super insulating a home's exterior wall. First used by John Larson in the 1970s and 1980s, it can be still seen has an appropriate system to super insulate the building envelope. Essentially a second wall is build off of the interior stud wall, allowing for a substantial cavity space to be filled with insulation. Often cellulose is used, but the cavity can be filled with any type of thermal insulation. The following image shows the Larson Truss cavity (looking from the top of the wall, down into the cavity) before insulation is installed. Care must be taken when using this system to ensure that the desired cellulose density levels are achieved consistently through the open cavity [Cohen et al., 2013]. The wider the Larson truss cavity is, the better because workers can physically get into the cavity to compact the cellulose with their hands to the necessary density [Clupp, 2012]. 


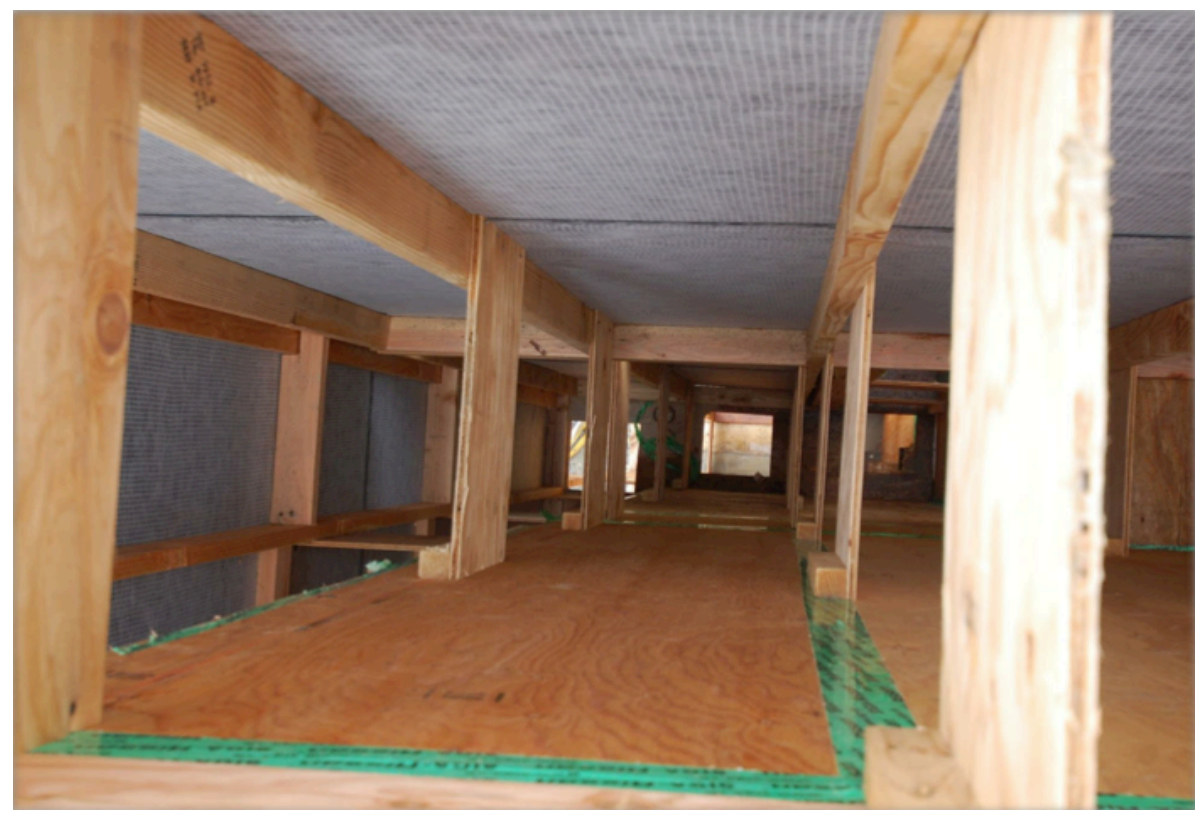

Figure 2-31 View from the top of a larson truss assembly [Clupp, 2012]

\subsubsection{Exterior Rigid Foam}

The exterior insulation strategy greatly reduces the amount of thermal bridging through the studs and simplifies the framing process for the builders without the need for constructing two walls - double stud wall or a vertical I-beam assembly. Rigid foam board and semi-rigid mineral wool can be used for this application [Brock, 2005]. This envelope system influences two of the four proposed designs that were developed and analyzed in this research.

Figures 2-32, 2-33 \& 2-34 outline an example of a built Passive House in Philadelphia that uses the exterior foam insulation envelope strategy in a modular building system application. The envelope is a $139 \mathrm{~mm}$ stud framed wall with $50 \mathrm{~mm}$ of exterior polyisocyanurate, with an effective thermal resistance value of approximately 6 RSI. The project was build as three rowhouse units, consisting of 9 modules in total. The modules were constructed off site in a rural area and then transported into the urban core of Philadelphia and installed in their permanent location. Minimal onsite construction processes were needed to complete the project. The seams of the air barrier and thermal resistance layers between the modules were completed on site, along with the exterior cladding of brick and metal siding [McDonald, 2012]. 


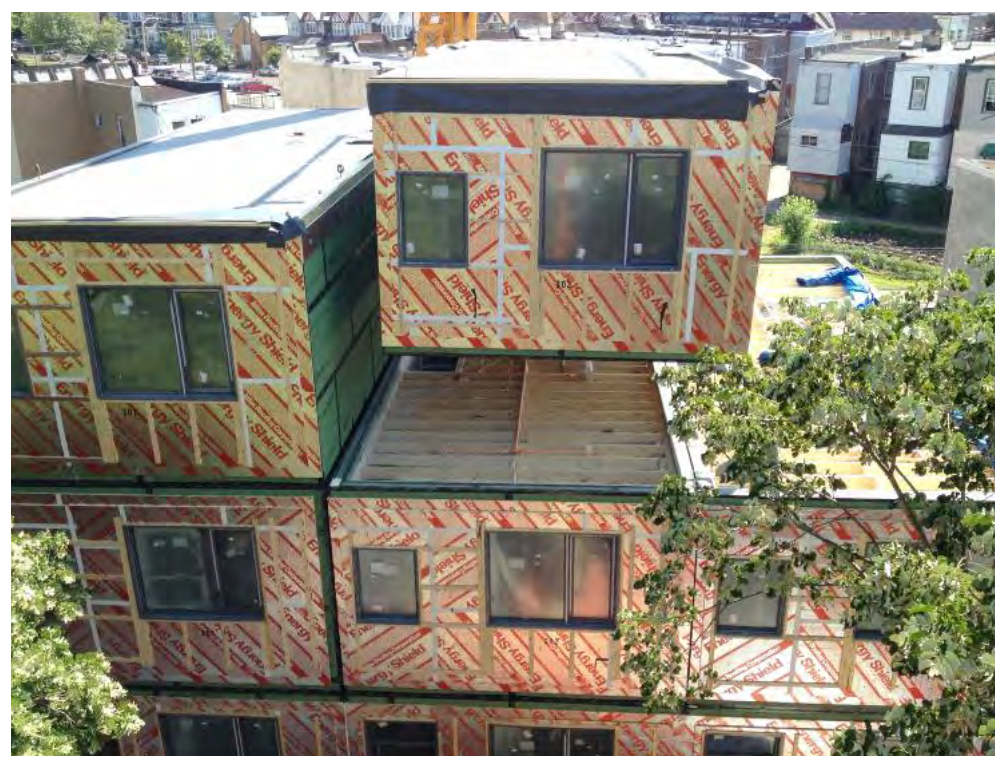

Figure 2-32 View of exterior applied polyisocyanurate assembly [McDonald, 2012]

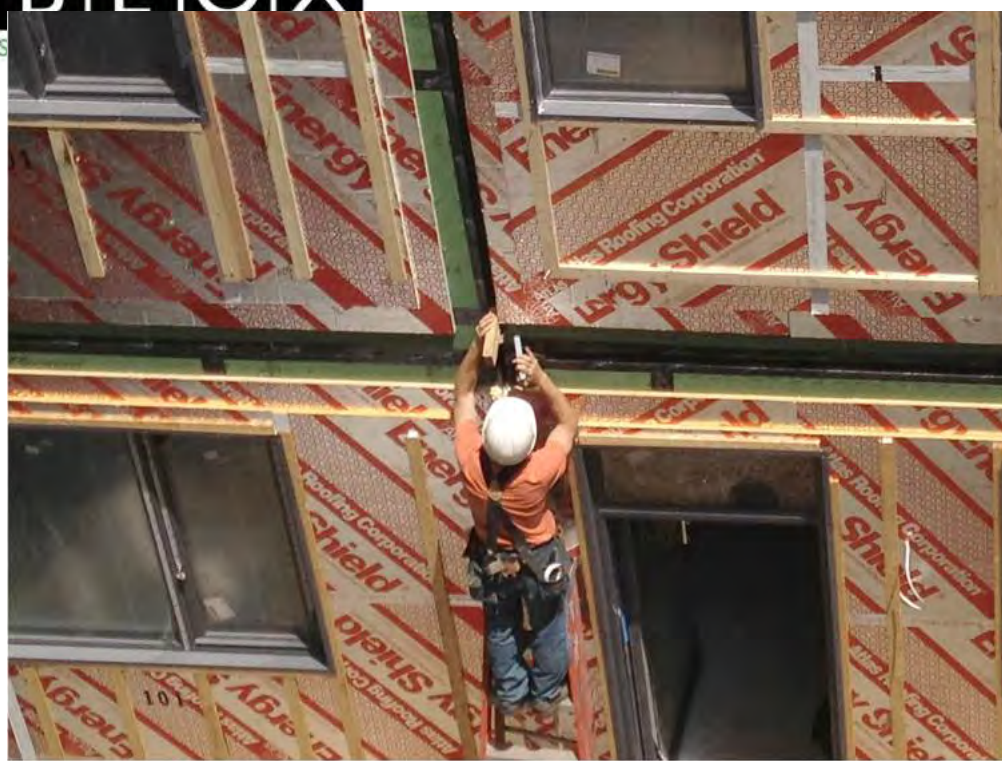

Figure 2-33 View of the exposed modular seams [McDonald, 2012] 


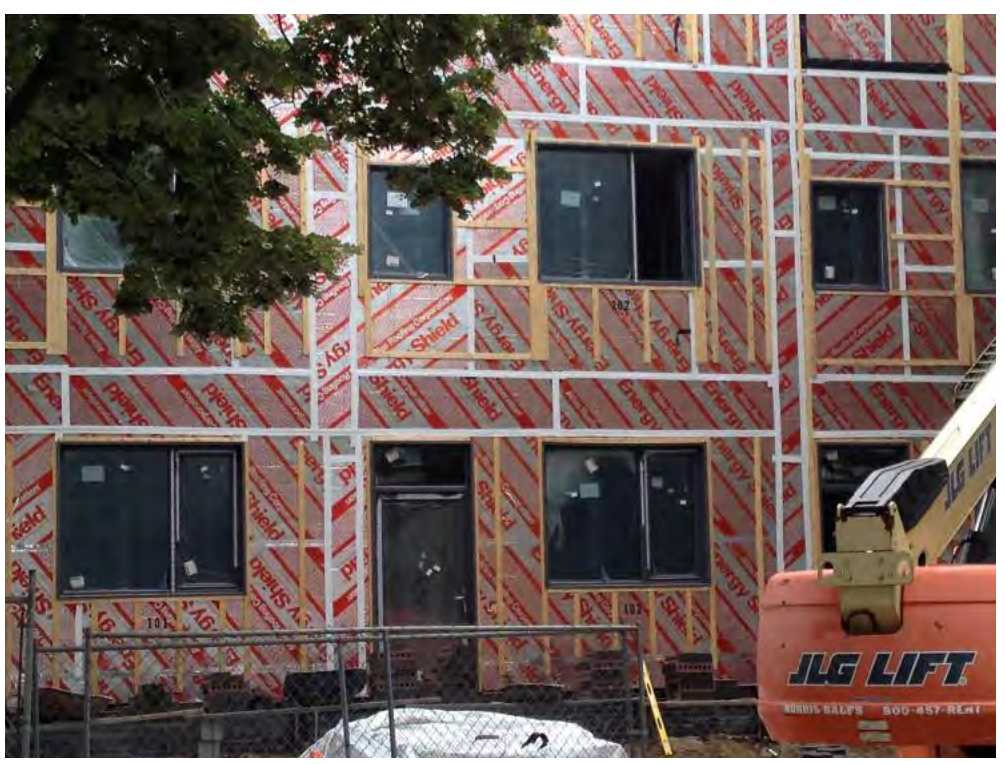

Figure 2-34 View of the seams sealed between the modules [McDonald, 2012]

\subsubsection{Mineral wool}

Mineral wool is extensively used in European envelope systems. Previous research shows the primary insulation material used by companies who manufacture building envelope systems in Europe is mineral wool [Fazio et al., 2000]. Mineral wool is discussed in the literature review because it is the primary insulation material for one of the proposed envelope assemblies.

Mineral wool offers many advantages over other insulation materials. It is fireproof, moisture does not affect its thermal conductivity, is extremely vapour open and offers a similar thermal resistance value to EPS type I foam [Brock, 2005]. Mineral wool is locally produced in the Toronto market. This is another advantage of using the material over other insulations reduced transportation is needed to move the material from the supplier's factory to the modular manufacturing facility. Mineral wool comes in batt and in semi rigid boards. The batts are used in the framing cavities, and the semi rigid boards are used on the exterior side of sheathing, or they can be installed below grade in foundation applications. 


\subsubsection{Vacuum Insulated Panels}

Vacuum insulated panels [VIPs] are the most advanced insulating material in the market. First developed by NASA for their spaceships to reduce heat transfer, the product has been brought to market by several manufacturers from around the world. The core is made from nano sized pore silica materials with a foil or plastic wrapping, where the air has been sucked out, creating a vacuum within the panel. The core is critical to maintaining the shape of the panel while under vacuum conditions. The thermal conductivity values of VIPs vary with every manufacturer and their particular manufacturing processes and material inputs. The typical range is between RSI 6 to 10.5 per $25 \mathrm{~mm}$. [Parekh \& Mattock, 2012]. The thicknesses of 13mm, $25 \mathrm{~mm} \& 38 \mathrm{~mm}$ are the most commonly produced. The product is extremely vapour impermeable. The biggest draw back of the material is cost and questions about the materials long-term durability of the vacuum seal [Parekh \& Mattock, 2012, Haavi et al., 2012]. If the sealed wrapping is ruptured, and the vacuum is released, the material loses a significant portion of its insulating properties. This could happen during installation or overtime with a faulty seal. It has been reported that when installed with OSB or plywood, chards have the potential to rupture the VIP membrane [Parekh \& Mattock, 2012]. Fiberglass coated panels have been documented as being the most durable for construction usage [Cohen et al., 2013]. The material is being tested by several agencies around the world with different nano pore materials and sealing methods [Mukhopadhyaya et al., 2011].

\section{Placement of the Vacuum Insulated Panel}

There are three options when placing the vacuum insulated panel in the exterior wall assembly: on the interior side of the structural studs, on the exterior side of the structure, or in the structural framing cavity. Each option is discussed with pictures from a study on the incorporation of vacuum insulation panels in a Wood Frame Net Zero Energy Home [Parekh \& Mattock, 2012]. 
In Figure 2-35, it can be seen that the VIPs have been installed on the interior side of the framing. The pink bracing around the panels hold them in place, and tape is applied at the VIPs seams. In Figure 2-36, there is an additional interior frame built, forming a cavity for spray foam insulation to be applied. This protects the VIPs from the building occupants, and adds additional thermal resistance. However, this technique makes the wall thicker, which is the main reason why it is not used. Also, the framing of two walls seems to be more time consuming, and the use of spray foam was avoided in all of the designed wall assemblies.

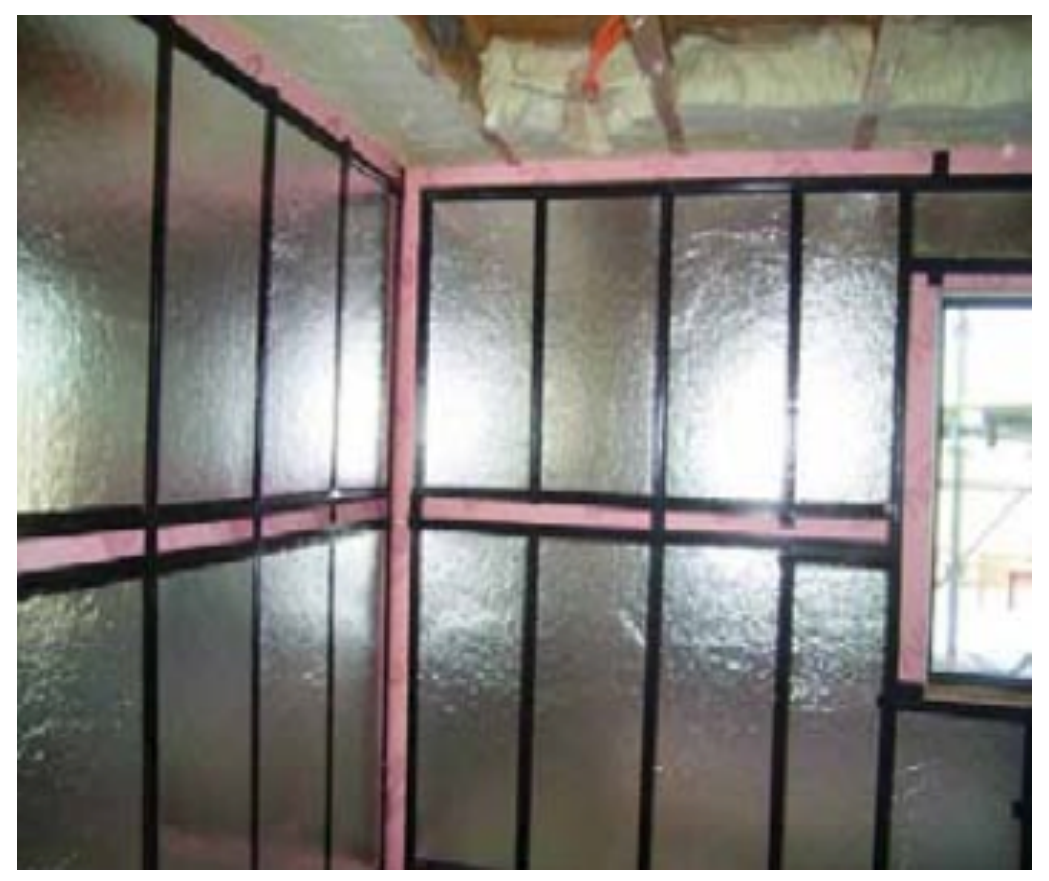

Figure 2-35 View of VIPs on interior side studs [Parekh \& Mattock, 2012] 


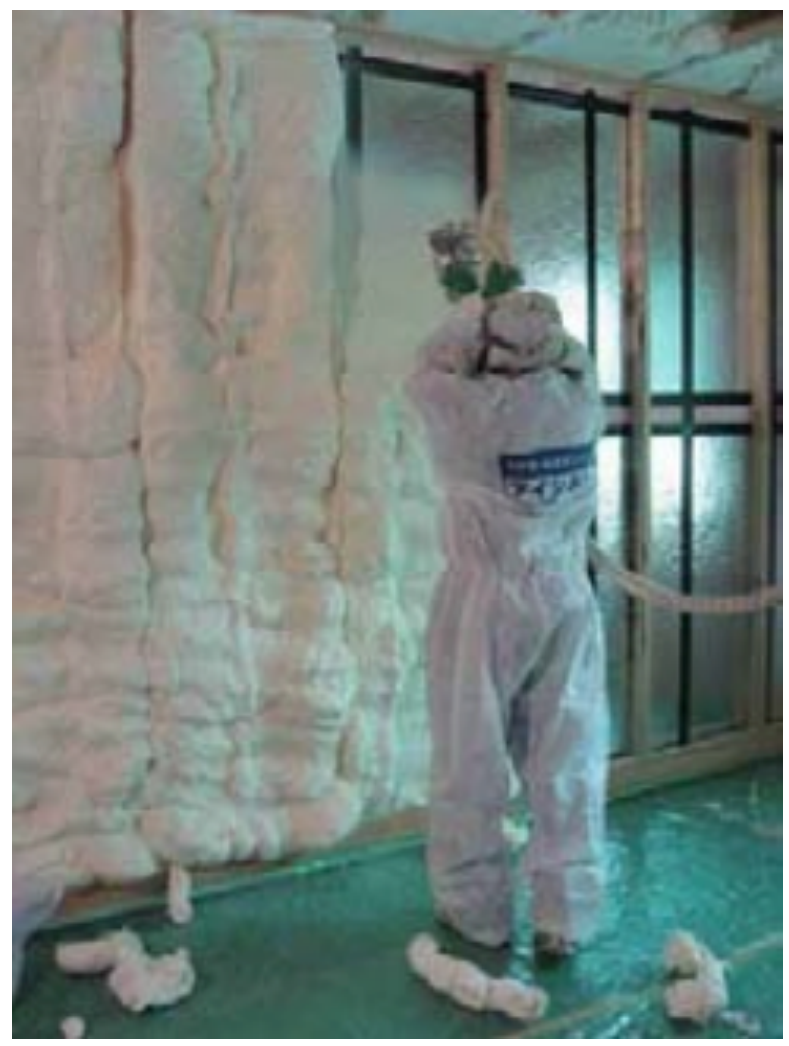

Figure 2-36 View of the spray foam over top of the VIPs [Parekh \& Mattock, 2012]

\section{- Located on the Exterior Side of the Studs}

In Figure 2-37, the VIPs are installed on the exterior side of the sheathing. Vertical holding straps are used to hold the panels without using mechanical fasteners that would otherwise puncture the material. This significantly reduces the thermal bridging effect of the stud framing. There are concerns of placing an extremely vapour closed material on the most exterior side, but the ultra high thermal resistance keeps the sheathing air barrier well above dew point temperatures, unless the seal fails and thermal resistance values are reduced. Overall, this method was not used because the installation of the exterior holding straps was seen has an extra step in the manufacturing process that could be removed. In addition, there are concerns of the rupturing of the panels once the exterior cladding material is applied. The installation of the cladding was not discussed with clarity in the research, and would significantly influence this options appeal. 


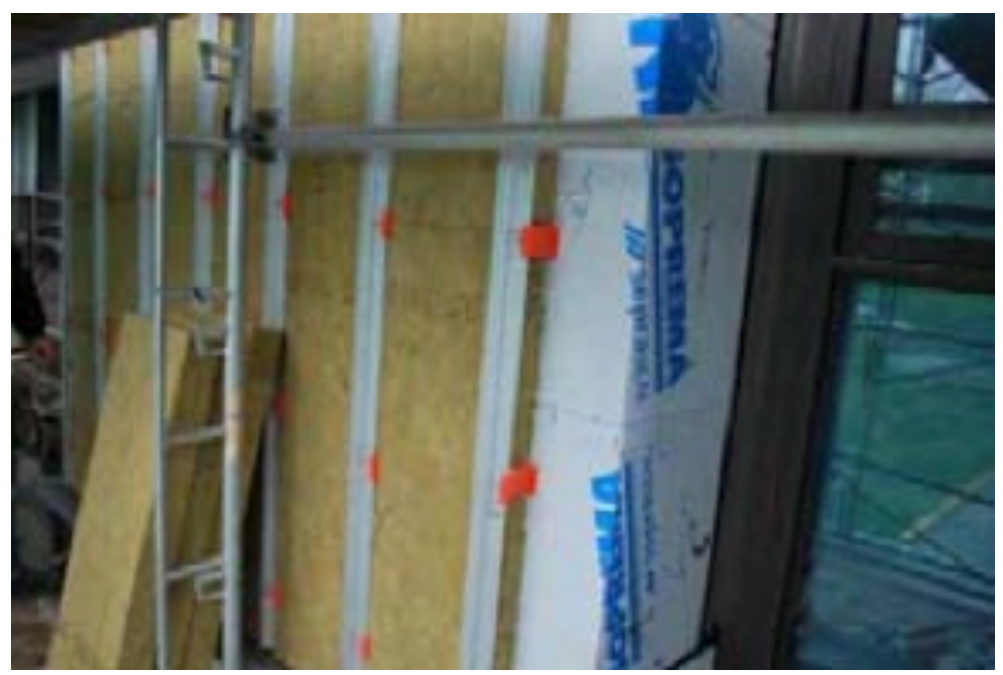

Figure 2-37 View of exterior applied VIP system [Parekh \& Mattock, 2012]

\section{- Located Within the Stud Cavity}

In Figure 3-38, the VIPs are installed within the middle of the cavity. It can be noted that the panel was installed right against the exterior plywood sheathing layer. In the research, it was mentioned that the wood sheathing could potentially rupture the material [Parekh \& Mattock, 2012]. It also outlines that this assembly has the greatest thermal bridging out of the three options, and in supported in other literature about this type of framing strategy for VIPs [Haavi, 2012]. In addition, the framing must be very accurate, because the panels cannot be cut, but they can be manufactured for a variety of widths. This caters to the modular building system where all stud cavities are precisely outlined because the manufacturing process begins. Overall, the installation of the VIP within the middle of the framed cavity was selected because it is protected from the interior occupants, the potential puncturing affects of the exterior cladding installation and the fact that only a single framed wall is needed. 


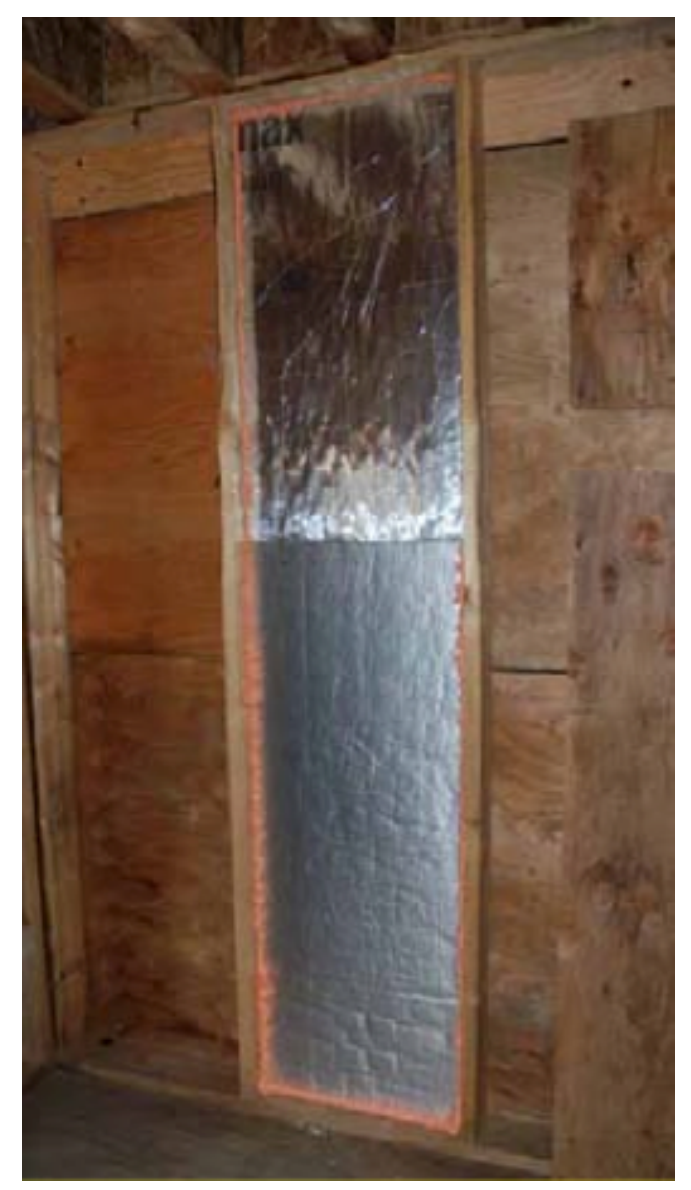

Figure 2-38 View of VIP located within the framed cavity [Parekh \& Mattock, 2012]

\subsection{Overview}

The literature review outlined several important areas of background information for this research. First, various forms of exterior building envelope prefabrication were discussed: open panel, closed panel and the modular building system. The various benefits and drawbacks of using each envelope delivery system were discussed in detail. This provided insight into the potential options for a prefabricated high performance envelope system. It was clear a modular building system offered more advantages over the other two, mainly because more of the construction process benefits from the advantages of moving the process into a controlled interior environment, not just the envelope construction. Also, this is of particular interest for the Canadian climate because there are remote geographical areas with a limited skilled labour force, 
areas of extreme climate (too cold to work outside and limited daylight). Also, the limitation of narrow roads (this limits the use of modular in European markets) is not an issue with North American infrastructure systems. The modular building system offers the best opportunity in North America to allow future high performance modular buildings to be constructed for the same or less than standard site built construction. This research does not aim to test this hypothesis, but rather aims to develop envelope assemblies and connection details that future modular buildings can use in the Southern Ontario context.

Next, the current state of modular envelopes was discussed by outlining three different envelope systems. These examples were shown because they highlight the current state of modular building envelopes in North America. The examples show what elements of the building envelope can be improved: insulation thickness and the air barrier system. Air barrier systems that utilize interior gypsum board, weather resistance membranes, polyethylene sheets and spray applied polyurethane foam have problems with continuity, long term durability and high embodied energy.

Finally, the discussion of high performing Passive House envelope systems provides a benchmark for the proposed envelope systems. None of the existing modular envelope systems achieve the RSI levels and air infiltration rates of the Passive house standard. The literature on Passive House systems also provides justification for material selection and design options for the insulation and air tightness layers of the proposed envelope systems to be explored in the next chapter. 


\section{Chapter 3 - Methodology}

\subsection{Scope}

This research is focused on the development of four super insulated, airtight envelope assemblies that are designed specifically for modular construction processes. The assemblies will be designed based on their: 1) thermal resistance, 2) vapour control and 3) air permeability characteristics. The assemblies will also be analyzed for their hygrothermal performance, thermal resistance of interfaces and their impact on the annual heating demand in cold climates using industry standard testing methodologies. The relative constructability of the four assemblies and their use in modular and traditional building processes will also be discussed.

\subsection{Criteria for Design}

The four assemblies were designed based on several considerations in terms of material selection and material placement for the super insulation, air barrier and vapour control layers. Each of these elements are discussed in the following with rationale for its selection, and how it compares to common building practice.

\subsubsection{Thermal resistance}

Four different insulation materials were used in the assemblies. Each of the materials were selected based on a list of criteria - to have a clear wall of RSI $10\left[\mathrm{~m}^{2} \cdot \mathrm{k} / \mathrm{W}\right]$ and to use an insulating materials that has industry wide acceptance.

The assemblies were designed to represent a clear wall thermal resistance value of RSI 10 $\left[\mathrm{m}^{2} \cdot \mathrm{k} / \mathrm{W}\right]$. This is within a range of thermal resistance that has been used to meet the Passive House standard in similar annual heating day climates as Toronto [Jacobson, 2012]. Clear wall RSI values are used as a benchmark because it allows the analysis to highlight how each framing method and insulation type affect the overall effective thermal resistance value once all factors 
are accounted for. Other research into insulation levels describes RSI $10\left[\mathrm{~m}^{2} \cdot \mathrm{k} / \mathrm{W}\right]$ as an appropriate level of super insulation for a cold climate [Nisson \& Dutt 1985, Shurcliff 1988].

Previous super insulated envelope systems described in the literature review used four insulation types used by designers and builders in the industry: foam based insulation (both spray applied and rigid board) [McDonald 2012, Dorion 2012], semi-rigid batt [Fazio, 2000ª , loose fill [Klingenberg, 2012] and advanced insulation [Parekh \& Mattock 2012, Mukhopadhyaya et al., 2011]. Each of the assemblies used of one of these insulation types, and the methodology of selecting the specific insulating material within the group is discussed in the following.

\section{Foam Insulation}

Rigid board polyisocyanurate insulation is used in the design of one of the assemblies. Table 3-1 shows that polyisocyanurate offers the lowest conductivity level out of all the rigid foam board options used in industry. Spray applied polyurethane insulation was an option, but it was not selected for two reasons. First, spray applied foam applications have been known to cause health risks associated with respiratory systems for installers [Wayne 2012], and the space where the material is installed must be well ventilated [US EPA, 2014]. In a modular context, this would require the factory to have a separate room for spray applied polyurethane installation, and for it to be well ventilated. The typical existing modular factory does not have such facilities because spray foam is not commonly used [Fazio 2000a, Slodiske 2013], and would require additional upgrades to factories. Overall, rigid board was deemed a more appropriate choice for the foam insulation material because a modular manufacturing facility would need to account for the ventilation needed for the use of spray foam. Also, factory workers are at a reduced risk of respiratory illness by avoiding spray applied foam. 
Table 3-1 Conductivity values of foam [Conductivity values: ASHRAE, 2009 ${ }^{\mathrm{b}}$ ]

\begin{tabular}{|c|c|}
\hline Insulation Type & $\begin{array}{c}\text { Conductivity } \\
{[\mathbf{W} / \mathbf{m} \cdot \mathbf{k}]}\end{array}$ \\
\hline Expanded polystyrene & 0.038 \\
\hline Extruded polystyrene & 0.029 \\
\hline Polyisocyanurate & 0.023 \\
\hline Polyurethane & 0.028 \\
\hline
\end{tabular}

\section{Mineral Wool Insulation}

Semi-rigid batt insulation is used in one of the assembly designs. This option has advantages compared to other forms of insulation in a modular building system because semirigid batts can be manually applied without the use of a machine or blowers to install the material. This allows for a simpler installation process, and less capital investment in the factory.

When it comes semi rigid batt insulation, there are two primary materials available in the market, fiberglass and mineral wool [Wilson, 1995]. Fiberglass batt is the most popular variety of insulation used in modular residential construction in North America [Fazio, 2000a]. However, it is not specified in any of the proposed envelope assemblies. Instead, mineral wool batt insulation was selected because it more vapour permeable than fiberglass and allows for greater drying potential of the envelope [ASHRAE, 2009 ${ }^{\mathrm{b}}$ ]. In addition, the conductivity value of mineral wool is not affected by moisture, whereas the conductivity less of fiberglass is increased with moisture [Brock, 2005]. For these reasons, mineral wool batt was selected over fiberglass to represent the semi rigid batt insulation category. 


\section{Cellulose}

Cellulose has been a very popular insulating material used in North American Passive house construction [Klingenberg, 2012]. The primary reason for its popularity in Passive house construction is because it offers the lowest embodied energy out of all the industry accepted building insulations [Harvey, 2007]. In Table 3-2, cellulose is compared to the other insulations used in the assemblies in term of embodied energy $[\mathrm{MJ} / \mathrm{kg}]$. Cellulose is made from recycled newspaper and treated with boric acid to provide fireproofing characteristics. The insulation is installed with a blower to high densities in framing cavities and to lower densities in attic spaces [Brock, 2005].

Table 3-2 Embodied energy of insulation materials [Harvey, 2007]

\begin{tabular}{|c|c|}
\hline Insulation Type & $\begin{array}{c}\text { Embodied } \\
\text { Energy [MJ/kg] }\end{array}$ \\
\hline Cellulose & 3.3 \\
\hline Mineral wool & 19.2 \\
\hline Fiberglass & 30.3 \\
\hline Polyisocyanurate & 137 \\
\hline Expanded Polystyrene & 107 \\
\hline
\end{tabular}

\section{Advanced Insulation}

The final insulation selected was an insulating material with the lowest conductivity levels available in the market, the vacuum insulated panel. VIPs are the most advanced type of insulation in the market and have been looked at by researchers and industry professionals as the insulation material of the future [Mukhopadhyaya et al., 2011]. Other research in the field investigated the placement of the VIP within the assembly [Parekh \& Mattock, 2012]. The VIP installation process can benefit from a modular building system because the material is very 
sensitive to handling, and within a modular factory it can be handled with greater care than compared to onsite installation and handling methods.

\subsubsection{Moisture management layers}

The moisture management layers were designed to deal moisture in both forms: bulk moisture, and water vapour.

The the bulk moisture management is first dealt with a $18 \mathrm{~mm}$ ventilated rain screen. This system was used because it is a durable method of allowing rain that penetrates the cladding material to drain and dry [Salonvarra et al., 2007]. All assemblies use designed with a weather resistance membrane because it protects the exterior insulation, and with the exterior mineral wool assembly, it provides a smooth drainage plain to promote drainage with gravity. For the vertical I-beam assembly the weather resistance membrane is a special material that does not bulge or deform from the cellulose in the cavity. This this WRB material was used instead of a sheathing layer because it is more vapour permeable [ASHRAE, 2009 ], allowing for more drying potential of the thick amounts of cellulose in the vertical I-beam cavity.

The vapour control layer is designed with a $13 \mathrm{~mm}$ orientated strand board layer with a factory applied weather resistance membrane. Orientated strand board [OSB] is considered to be a class II vapour retarder [ASHRAE, 2009 ]. It was selected for two primary reasons - for ease of construction in a modular context and for maximum drying potential.

In terms of ease of construction in a modular context, this material was used instead of a polyethylene sheet because it allows for the interior gypsum board layer to be attached to the structural framing with spray glue. If a polyethylene sheet were to be used behind the gypsum finish, spray glue would not be able to secure the seam between the backside of the interior gypsum board and the wood framing. Secondly, thick superinsulated assemblies need to allow for more drying potential of the assembly to the interior during the summer months. This is a critical aspect of a super insulated assembly because moisture has a longer way to travel to escape the assembly due to increased thickness [Klingenberg, 2012]. The most common vapour 
retarder material used by homebuilders in Canada is a polyethylene sheet [Fazio, 2000 ${ }^{\mathrm{a}}$ and it is considered to be a class I vapour retarder [ASHRAE, 2009b] . However, none of the proposed envelope systems specified this material as a vapour control layer because it does not allow spray glue to be used during the modular process, and it does not allow the assembly to dry to the interior during the summer months.

\subsubsection{Air Barrier}

The air barrier is critical for a high performance envelope system. The air barrier design is based on several criteria - the material must allow for expansion and contraction of the assembly without comprising the integrity of air barrier material, it is to be placed in the middle of the assembly and the continuity of the air barrier must be visible during the modular process.

The air barrier material is a OSB layer with taped seams. OSB is used because it is durable, structurally supported and impermeable to air movement. The seams are sealed with a flexible tape that allows for movement, while maintaining its adhesiveness to the OSB layer. Next, the air barrier is placed in the middle of the assembly because it is protected from the building occupants. In all of the assemblies, the air barrier is located on the exterior side of the structural framing. This reduces the chance of puncture during interior remodels or interior decorating. Finally, the air barrier cannot be fully tested in the modular factory until it is installed onsite. It is important to have an air barrier system that can be visually inspected to control quality. All of the exterior envelope surfaces use sheathing layers with taped seams. This allows for all of the exterior surfaces of a module to be visually inspected in the factory.

Previous examples in the literature review revealed that the vast majority of modular builders use a weather resistance membrane [Sloditskie, 2013], an interior polyethylene sheet behind the gypsum [Fazio 2000a , Fazio 2000 b] spray foam insulation [Doiron, 2012] or the interior gypsum board [Beibel, 2012] as the primary air barrier system. However, none of these are appropriate for the proposed assemblies. Weather resistance membranes are difficult to make continuous around the entire envelope, polyethylene sheets and interior gypsum board are 
vulnerable to puncturing from building occupants and during future remodels, spray applied foam insulation shrinks overtime and will not provide a longterm air barrier due to expansion and contraction of building components.

Figure 3-1 displays common air leakage pathways in envelopes [Conservation technology, 2008]. (A) Mixing of interior and exterior air can mix in the attic space. (B) Air leakage into the framing cavity through the top plate and interior gypsum board. (C) Wind washing into the framing cavity. (D) Interior electrical boxes that penetrate the interior gypsum board. (E) Air leakage through the bottom plate into the framing cavity from the interior and exterior. (F and G) Voids in air sealing around windows at the header and sill. (H) Air movement between the wall and foundation connection. All of these common air leakage locations are detailed in the following section and were selected because of their vulnerability to air leakage. 


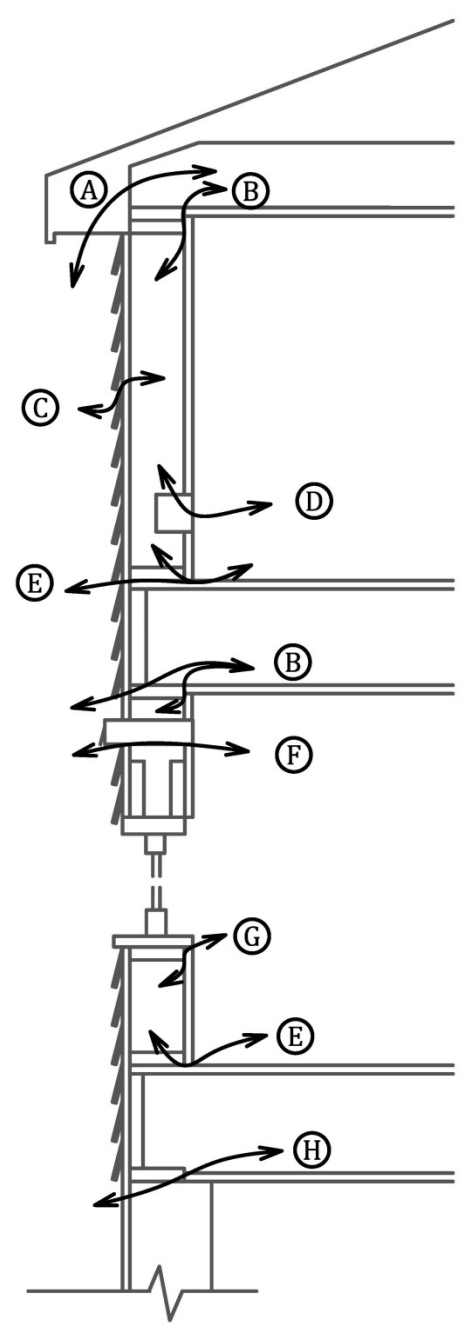

Figure 3-1 Common air leakage pathways [Conservation Technology, 2008]

\subsection{Thermal, Hygrothermal \& Energy Modeling Analysis}

Thermal performance, hygrothermal and energy modeling analysis were performed to assess the assemblies in the contexts of a cold climate. This analysis was performed based on industry standard testing methodology and software programs used by professionals and researchers in the building science industry. 


\section{Thermal Resistance Performance}

Effective thermal resistance values were calculated to assess the true RSI value of the assemblies. Two dimensional heat transfer analysis was performed on three interface locations: rim joist, wall to roof and wall to foundation. The analysis was based on the International Organization of Standardization [ISO] protocol EN 10211-2007 testing methodology for assessing thermal bridging using two-dimensional heat transfer in building construction [ISO, 2007]. This was used to determine the specific linear thermal bridge Psi factor of the various envelope transitions.

\section{Hygrothermal Analysis}

Hygrothermal analysis was performed using one-dimensional heat and moisture transfer WUFI ${ }^{\circledR}$ software. The analysis is based on testing methodology from ASHRAE standard 160P in terms of moisture content for wood [ASHRAE, 2009a]. Moisture content [MC] levels of the exterior sheathing were assessed for their long-term drying potential and condensation risk in each of the four assemblies. Special attention was given to the MC of the sheathing layer because it is structural, and it is the primary air barrier material in the assemblies. Various parametric elements were changed to assess how the interior and exterior conditions affected the MC of the structural sheathing.

\section{Energy Modeling Analysis}

The various envelope systems were run in an energy modeling software, Passive House Planning Package [PHPP] [Feist, 2007], and compared to an envelope assembly with thermal resistance values that are code compliant with Ontario Building Code 2012 [OBC] [OBC, 2012]. A generic building was modeled using the software, and only the RSI values of the envelope components and infiltration rates were changed in each simulation. The analysis was performed to assess how the proposed envelope systems affect the annual heating demand of a building compared to a code compliant envelope assembly. 


\section{Chapter 4 - Connection Details \& Construction Process}

\subsection{Overview}

\section{Chapter research questions:}

What options can be developed for a modular manufacturer to produce a super insulated, airtight building envelope system for a wood framed modular building system in a cold climate context?

a) How can the design of the air barrier made continuous across the wall to roof, rim joist and wall to foundation transitions without the use of typical air sealing methods used in the modular industry?

b) How are the various assemblies constructed differently using the modular building system compared to onsite methods, and what are the advantages gained by constructing these developed assemblies with the modular system over onsite methods?

In the following chapter, connection details are shown for the foundation to wall, rim joist and wall to roof connections. In addition, a window header and sill detail were developed, along with a window jamb detail for each of the assemblies. Several marriage connection details were developed to give context how the air barrier transitions between the modules then they are installed onsite. One of each detail connection is displayed with comments in this chapter and the remaining details are outlined in the appendices A,B,C and D. Also outlined in this chapter are the specific construction processes needed to deliver the four assemblies and the benefits gained for each process as a result of using the modular building system instead of using onsite methods. This provides context to the differences between onsite and modular in terms of constructing each of the assemblies. 


\subsection{Proposed Envelope Assemblies}

The following is a list of the four assemblies that were designed, analyzed and detailed.

Exterior Polyisocyanurate Assembly-

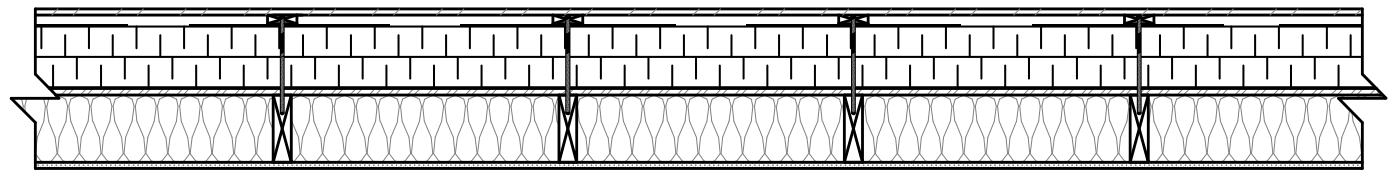

- 13mm Interior gypsum board (Interior finish)

- 38mm x 139mm SPF framing filled with dense pack cellulose to $55 \mathrm{~kg} / \mathrm{m}^{3}$ (Structural framing, Thermal resistance)

- 13mm Exterior sheathing taped at seams with factory applied weather resistance barrier (Air barrier, Secondary drainage plane, Vapour control layer)

- 140mm Exterior applied polyisocyanurate rigid foam board, attached in two layers of $70 \mathrm{~mm}$ with offset vertical and horizontal seams taped (Thermal resistance)

- Weather resistance barrier (Primary drainage plane)

- 18mm Vertical furring strips \& vented rain screen (Vented air cavity)

- 13mm Exterior fiber cement board cladding (Exterior cladding)

Table 4-1 Clear wall RSI value for polyisocyanurate assembly [Conductivity values: ASHRAE, 2009']

\begin{tabular}{|l|c|c|c|c|}
\hline \multicolumn{1}{|c|}{ Material } & Conductivity & Thickness & Conductance & RSI Value \\
\cline { 2 - 6 } & {$[\mathbf{W} / \mathbf{m} \cdot \mathbf{k}]$} & {$[\mathbf{m}]$} & {$\left[\mathbf{W} / \mathbf{m}^{2} \cdot \mathbf{k} /\right]$} & {$\left[\mathbf{m}^{\mathbf{2}} \cdot \mathbf{k} / \mathbf{W}\right]$} \\
\hline Interior air film & - & - & - & 0.12 \\
\hline Gypsum board & 0.160 & 0.013 & 12.308 & 0.081 \\
\hline Cellulose & 0.038 & 0.139 & 0.273 & 3.658 \\
\hline OSB sheathing & 0.140 & 0.013 & 12.308 & 0.081 \\
\hline Polyisocyanurate & 0.023 & 0.140 & 0.166 & 6.034 \\
\hline Exterior air film & - & 0.018 & - & 0.030 \\
\hline Cladding & - & 0.013 & - & 0 \\
\hline \multicolumn{1}{c|}{ Total } & & $\mathbf{0 . 3 3 6}$ & & $\mathbf{1 0 . 0}$ \\
\hline
\end{tabular}


Mineral Wool Assembly-

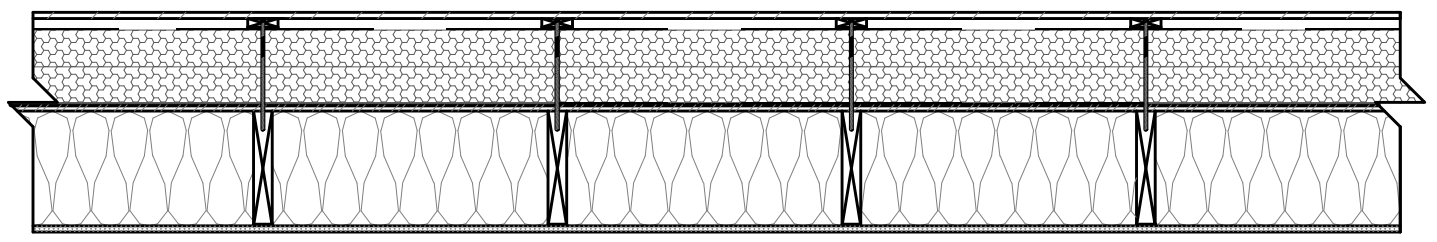

- 13mm Interior gypsum board (Interior finish)

- 38mm x 185mm SPF framing filled with mineral wool batt

(Structural framing, Thermal resistance)

- 13mm Exterior sheathing with factory applied weather resistance barrier

(Air barrier, Secondary drainage plane, Vapour control layer)

- 150mm Exterior applied semi-rigid mineral wool board (Thermal resistance)

- Weather resistance barrier (Primary drainage plane)

- 18mm Vertical furring strips \& vented rain screen (Vented air cavity)

- 13mm Exterior fiber cement board cladding (Exterior cladding)

Table 4-2 Clear wall RSI value for mineral wool assembly [Conductivity values: ASHRAE, 2009]

\begin{tabular}{|l|c|c|c|c|}
\hline \multicolumn{1}{|c|}{ Material } & Conductivity & Thickness & Conductance & RSI Value \\
\cline { 2 - 5 } & {$[\mathbf{W} / \mathbf{m} \cdot \mathbf{k}]$} & {$[\mathbf{m}]$} & {$\left[\mathbf{W} / \mathbf{m}^{\mathbf{2}} \cdot \mathbf{k} /\right]$} & {$\left[\mathbf{m}^{\mathbf{2}} \cdot \mathbf{k} / \mathbf{W}\right]$} \\
\hline Interior air film & - & - & - & 0.12 \\
\hline Gypsum board & 0.160 & 0.013 & 12.308 & 0.081 \\
\hline Mineral Wool & 0.035 & 0.185 & 0.186 & 5.362 \\
\hline OSB sheathing & 0.140 & 0.013 & 12.308 & 0.081 \\
\hline Mineral Wool & 0.035 & 0.150 & 0.230 & 4.348 \\
\hline Exterior air film & - & 0.018 & - & 0.030 \\
\hline Cladding & - & 0.013 & - & 0 \\
\hline Total & & $\mathbf{0 . 3 9 2}$ & & $\mathbf{1 0 . 0}$ \\
\hline
\end{tabular}


Vertical I-Beam Assembly-

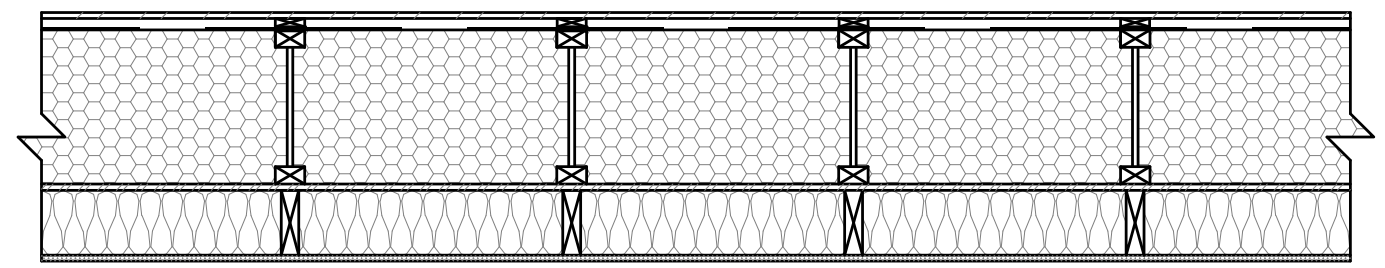

- 13mm Interior gypsum board (Interior finish)

- $38 \mathrm{~mm}$ x $139 \mathrm{~mm}$ SPF framing filled with dense pack cellulose to $55 \mathrm{~kg} / \mathrm{m}^{3}$

(Structural framing, Thermal resistance)

- 13mm Exterior sheathing with factory applied weather resistance barrier

(Air barrier, Secondary drainage plane, Vapour control layer)

- $235 \mathrm{~mm}$ Vertical TJI filled with dense pack cellulose to $55 \mathrm{~kg} / \mathrm{m}^{3}$ (Thermal resistance)

- Weather resistance barrier that resists the compressed cellulose layer within the cavity (Primary drainage plane)

- 18mm Vertical furring strips \& vented rain screen (Vented air cavity)

- 13mm Exterior fiber cement board cladding (Exterior cladding)

Table 4-3 Clear wall RSI value for vertical I-beam assembly [Conductivity values: ASHRAE, 2009']

\begin{tabular}{|l|c|c|c|c|}
\hline \multicolumn{1}{|c|}{ Material } & Conductivity & Thickness & Conductance & RSI Value \\
\hline Interior air film & {$[\mathbf{W} / \mathbf{m} \cdot \mathbf{k}]$} & {$[\mathbf{m}]$} & {$\left[\mathbf{W} / \mathbf{m}^{2} \cdot \mathbf{k} /\right]$} & {$\left[\mathbf{m}^{2} \cdot \mathbf{k} / \mathbf{W}\right]$} \\
\hline Gypsum board & - & - & - & 0.12 \\
\hline Cellulose & 0.160 & 0.013 & 12.308 & 0.081 \\
\hline OSB sheathing & 0.140 & 0.139 & 0.276 & 3.620 \\
\hline Cellulose & 0.038 & 0.235 & 0.164 & 0.081 \\
\hline Exterior air film & - & 0.018 & - & 0.113 \\
\hline Cladding & - & 0.013 & - & 0.030 \\
\hline \multicolumn{1}{c|}{ Total } & & $\mathbf{0 . 4 3 1}$ & & $\mathbf{1 0 . 0}$ \\
\hline
\end{tabular}


Vacuum Insulated Panel Assembly-

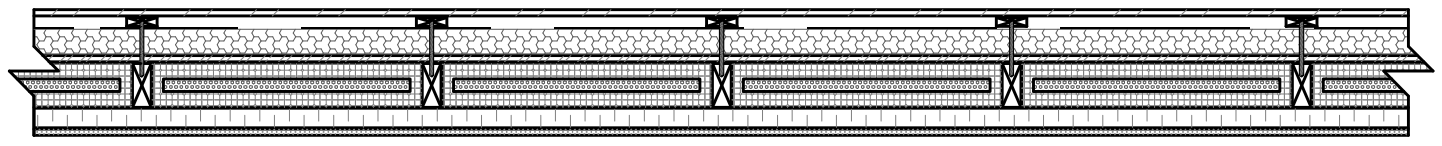

- 13mm Interior gypsum board (Interior finish)

- 38mm Horizontal strapping with mineral wool (Thermal resistance)

- 32mm x 89mm SPF framing (Structural framing)

- 38mm Rigid EPS foam board within framing cavity (Thermal resistance)

- 25mm Vacuum insulated panel (Thermal resistance, Vapour control layer)

- 32mm Rigid EPS foam board within framing cavity (Thermal resistance)

- 13mm Exterior sheathing with factory applied weather resistance barrier (Air barrier, Secondary drainage plane)

- 50mm Exterior applied semi-rigid mineral wool board (Thermal resistance)

- Weather resistance barrier (Primary drainage plane)

- 18mm Vertical furring strips \& vented rain screen (Vented air cavity)

- 13mm Exterior fiber cement board cladding (Exterior cladding)

Table 4-4 Clear wall RSI value for vacuum insulated panel assembly [Conductivity values: ASHRAE 2009 Mukhopadhyaya et al., 2011*]

\begin{tabular}{|l|c|c|c|c|}
\hline \multirow{2}{*}{ Material } & Conductivity & Thickness & Conductance & RSI Value \\
\cline { 2 - 5 } & {$[\mathbf{W} / \mathbf{m} \cdot \mathbf{k}]$} & {$[\mathbf{m}]$} & {$\left[\mathbf{W} / \mathbf{m}^{\mathbf{2}} \cdot \mathbf{k} / \mathbf{l}\right.$} & {$\left[\mathbf{m}^{\mathbf{2}} \cdot \mathbf{k} / \mathbf{W}\right]$} \\
\hline Interior air film & - & - & - & 0.120 \\
\hline Gypsum board & 0.160 & 0.013 & 12.308 & 0.081 \\
\hline Mineral wool & 0.035 & 0.038 & 0.921 & 1.086 \\
\hline EPS & 0.035 & 0.032 & 0.921 & 0.914 \\
\hline VIP & $0.005^{*}$ & 0.025 & 0.200 & 5.319 \\
\hline EPS & 0.035 & 0.032 & 0.921 & 0.914 \\
\hline OSB sheathing & 0.160 & 0.013 & 12.308 & 0.081 \\
\hline Mineral wool & 0.035 & 0.050 & 0.690 & 1.449 \\
\hline Exterior air film & - & 0.018 & - & 0.030 \\
\hline Cladding & - & 0.013 & - & 0 \\
\hline \multicolumn{1}{r|}{ Total } & & $\mathbf{0 . 1 5 3}$ & & $\mathbf{1 0 . 0}$ \\
\hline
\end{tabular}




\subsection{Full Section}

Figure 4-1 displays the various locations of the details developed for the modular building envelope system. Each envelope system was developed with a wall to foundation, rim joist, wall to roof and window detail. In addition, the various marriage joint details that are made onsite for the modules to be connected are also presented. Several details of each connection location are presented, and majority of the details are presented in the appendix. The details are significant to show how the various assemblies go together and detailed descriptions are given to ensure an accurate installation.

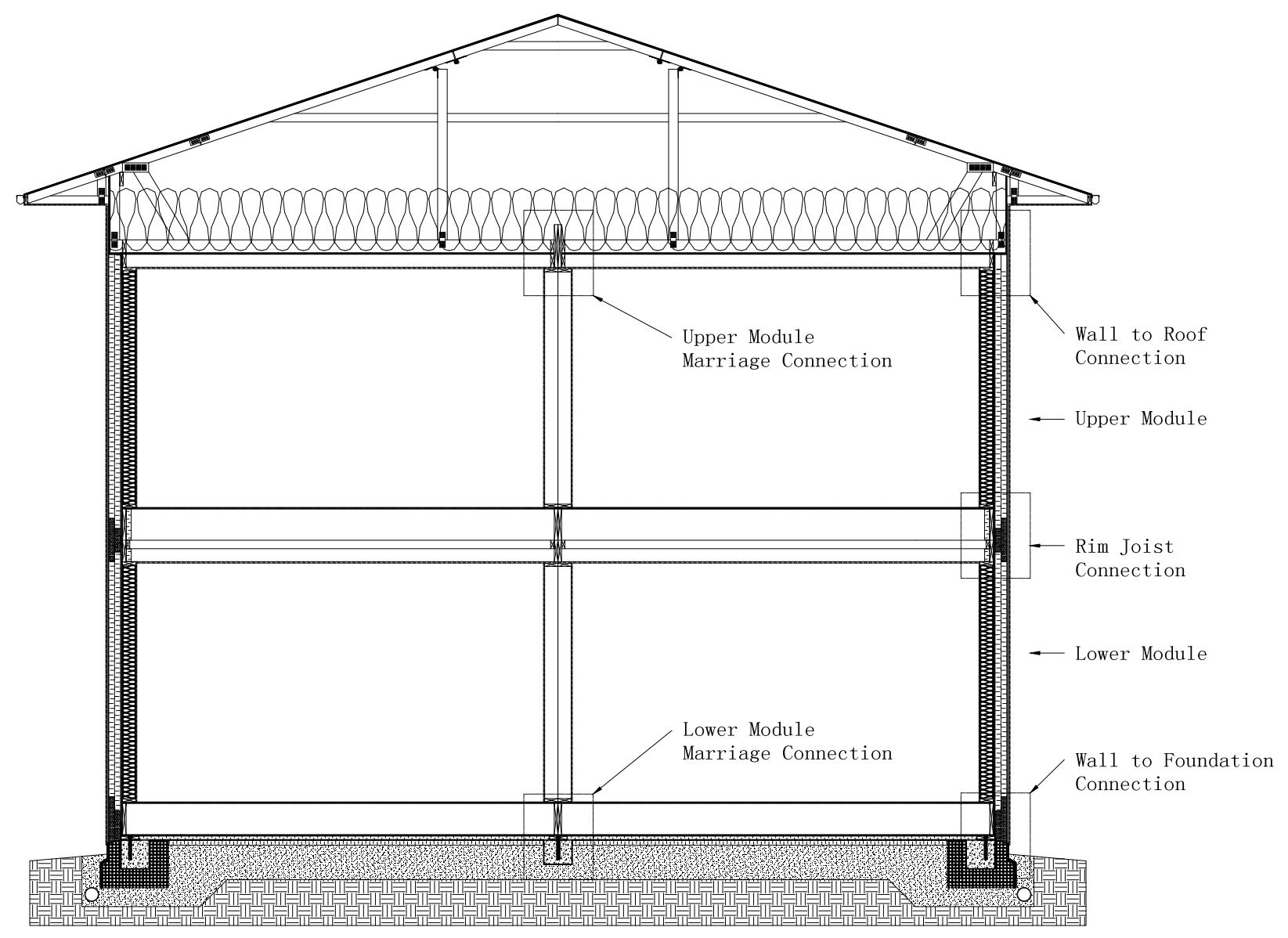

Figure 4-1 Full section detail of modular building 


\subsection{Wall to Roof Connection}

Figure 4-2 shows the roof to wall connection for the vertical I-beam assembly. In this detail, it is important to point out how the roof truss extends out over the top of the vertical Ibeam assembly to provide a continuous layer of thermal resistance. The air barrier connection is made with a continuous layer of sheathing. This connection would be made in the modular factory and is critical to maintain a continuous air barrier system at this commonly leaky location. The sheathing is installed on top of the modules' ceiling and is taped and sealed before the roof truss is placed on top and secured to the structure. Tape is made continuous on the exterior side of the sheathing, allowing for one crew or installer to make all of the seams of the wall and ceiling tight at one time. This air tight sheathing layer is represented with a red line in Figure 4-2. 


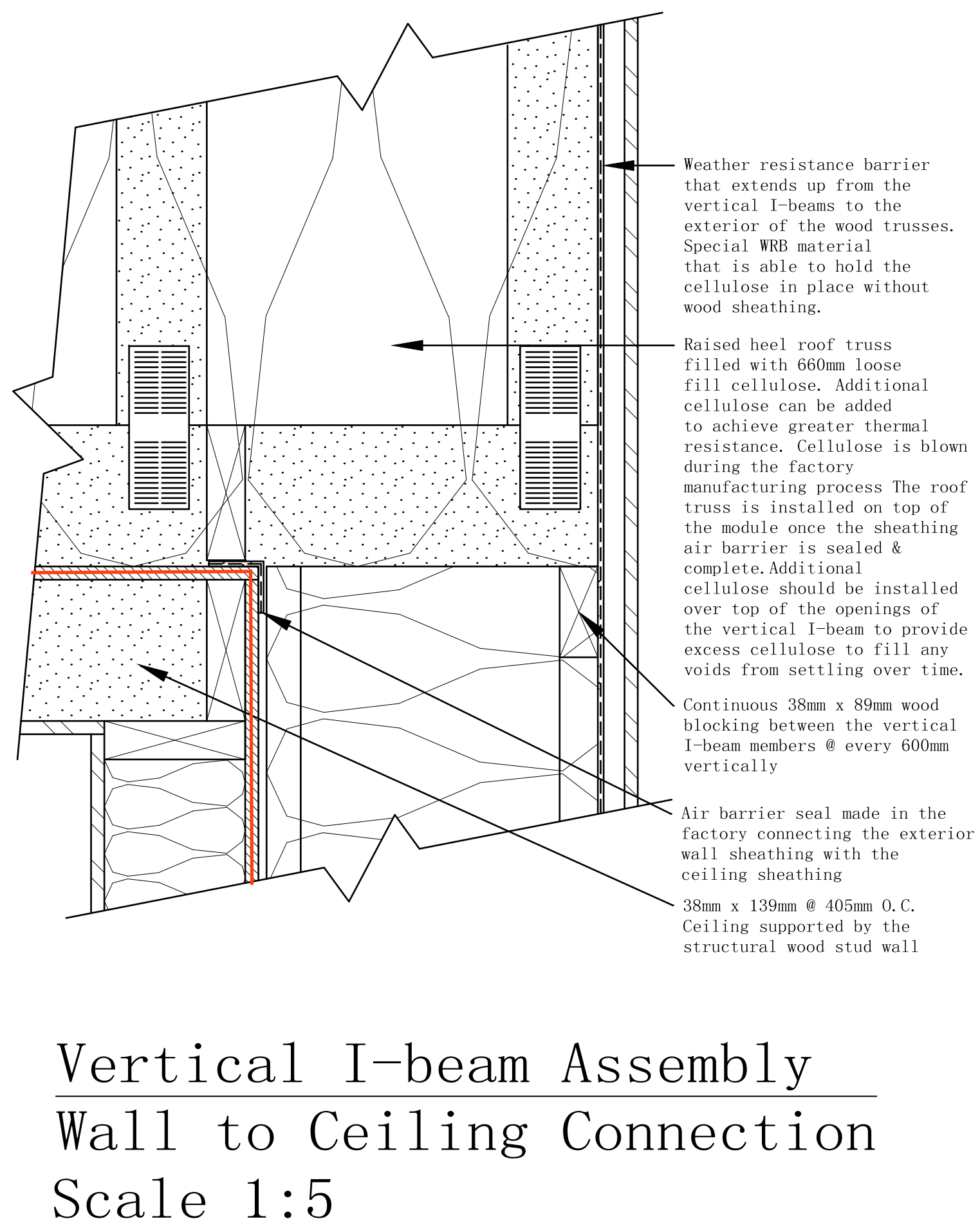

Figure 4-2 Wall to roof connection for the vertical I-beam assembly 


\subsection{Rim Joist Connection}

In Figure 4-3, the rim joist of the vertical I-beam assembly is displayed. This detail is a unique air sealing strategy for the rim joist location. The air barrier is the structural sheathing, however, in order to make continuous when the modules are installed in the field, installation crews will not have clear access this location. The vertical I-beams will be covering it, and cellulose insulation will be an obstacle.

In the beginning of the design phase, it was first thought that a void in the vertical I-beam could be left open and then be filled in later during the installation in the field. This would leave access to physically tape the air barrier system between both modules. However, it is the goal of the modular building system to get as much work done inside the factory as possible, so an alternative air sealing method was designed. Instead, $100 \mathrm{~mm}$ wide pieces of sheathing are turned inside from the exterior structural sheathing, and a layer of expanding foam tape is used between the modules and applied in the field. This is represented with a red line in Figure 4-3. This is also a practical way of air sealing between modules if each unit has a separate conditioned air space, as is the case in a row house situation. 


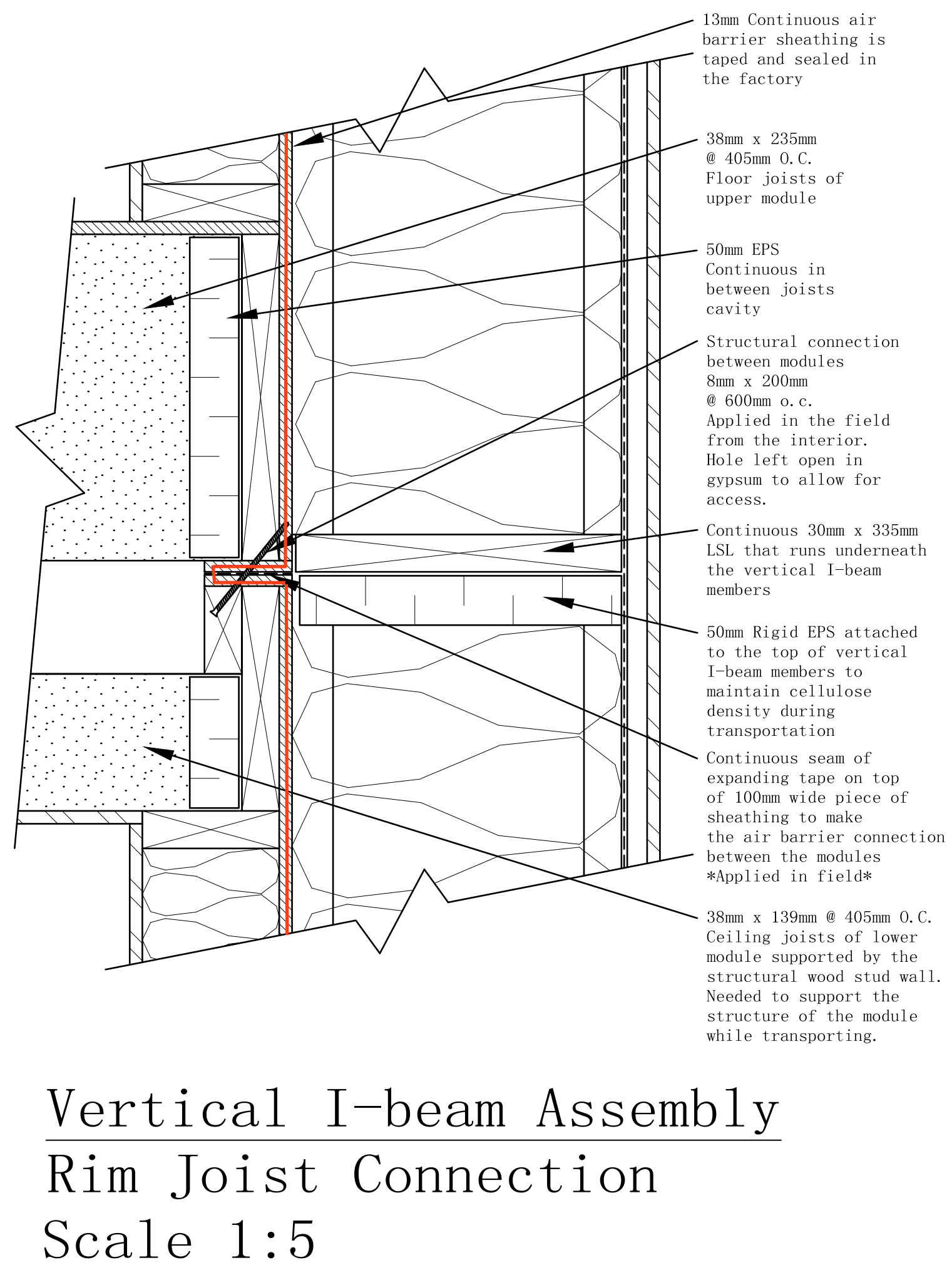

Figure 4-3 Rim joist connection for the vertical I-beam assembly 


\subsection{Wall to Foundation Connection}

In Figure 4-4, the connection between the modular wall and foundation is displayed for the exterior applied polyisocyanurate assembly. This is an interesting connection location because it outlines how the modules are attached to the site built foundation system. Again, the air barrier system is the structural sheathing on the exterior side of the framing. For the ground contact location, the air barrier is the taped sheathing on the bottom side of the joists. This layer of sheathing is also needed to support the blown-in cellulose within the floor joists. This connection is made continuous, and sealed in the factory. This air tight layer is displayed with a red line in Figure 4-4. The module is structurally secured to the foundation with a $8 \mathrm{~mm}$ screw is attached through the module framing into the foundation blocking. To do so, a void in the exterior insulation is needed to allow for this connection to be made. The void in the insulation is installed in the field and is represented in Figure 4-4 with a different hatch in the exterior polyisocyanurate layer. Another design feature that the void in the exterior insulation allows for is the attachment of the polyethylene vapour barrier to the exterior sheathing. This adds another element of air tightness of the module to foundation connection. With this technique, two materials are attaching to the exterior sheathing to make the air barrier system continuous from the ground contact to the exterior air locations of the envelope. Placed overtop of the polyethylene attachment is a flexible piece of flashing to promote drainage off the sheathing and to protect the foundation insulation from bulk moisture.

Figure 4-5 shows how the module would be attached if a foundation wall was used instead of an on-grade approach. The attachment of the module would be the same, but the transition of the air barrier is different. The air barrier materials are the taped sheathing for the wall, and the liquid applied water proof membrane on the concrete wall. The transition is made with a liquid applied sealant over top of both materials, completing the air barrier. This transition is made with a liquid applied sealant because it allows for movement, and is compensate for tolerances between the module and foundation wall dimensions. The air barrier layer is shown with a red line in Figure 4-5. 


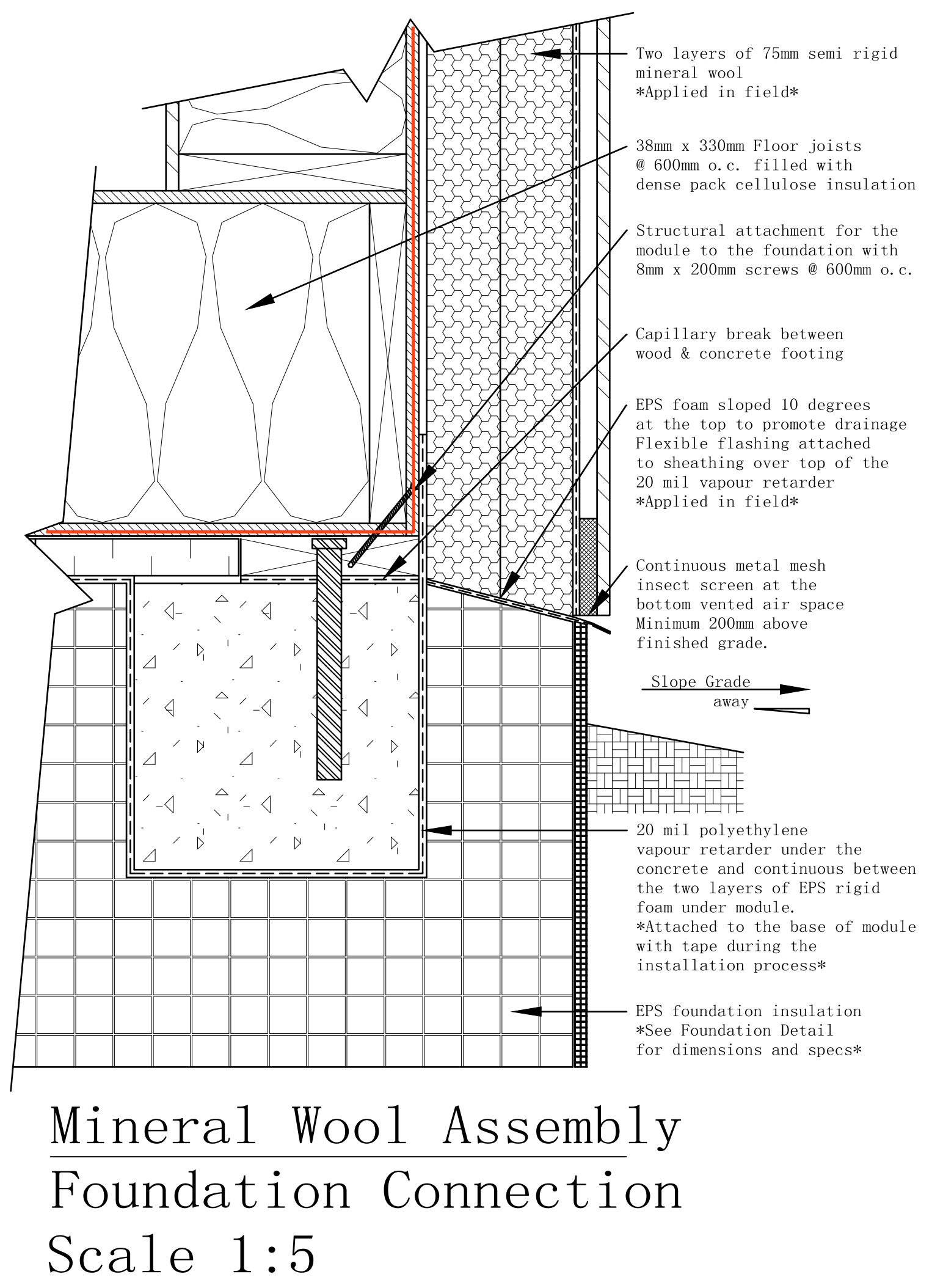

Figure 4-4 Wall to foundation connection for the mineral wool assembly 


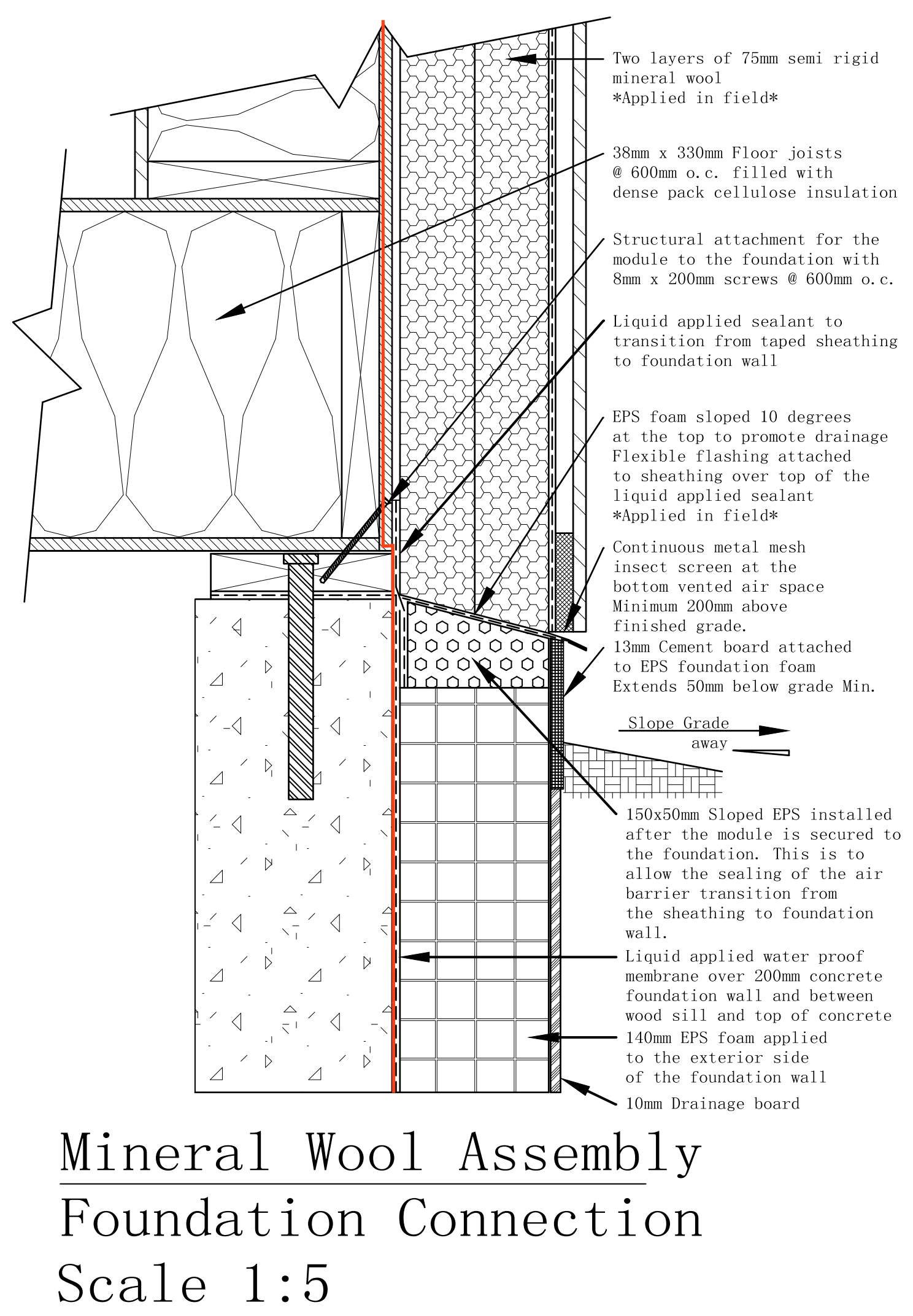

Figure 4-5 Wall to foundation connection for the mineral wool assembly 


\subsection{Window Header, Sill \& Jamb}

Figures 4-7 and 4-8 show the window header detail, along with the sill and jamb detail of the vertical I-beam assembly. These details are significant to show how the air barrier system ties into the window frame, and also how the window frames are over insulated. The significant material in these details is the application of a liquid applied membrane that coats the sheathing, and is continuous around the window buck and into the rough opening. This air barrier is represented with a red line in Figures 4-7 and 4-8. This material is preferred for this application because it eliminates the complicated three-dimensional transitions of a peel and stick membrane [Cohen et al., 2013]. The air barrier is then transitioned with a backer rod and sealant to the window frame, or a high quality double-sided tape could also be used instead of the sealant. In essence, the air barrier system goes from, exterior sheathing to liquid applied membrane, to backer rod/sealant (or tape), to the window frame.

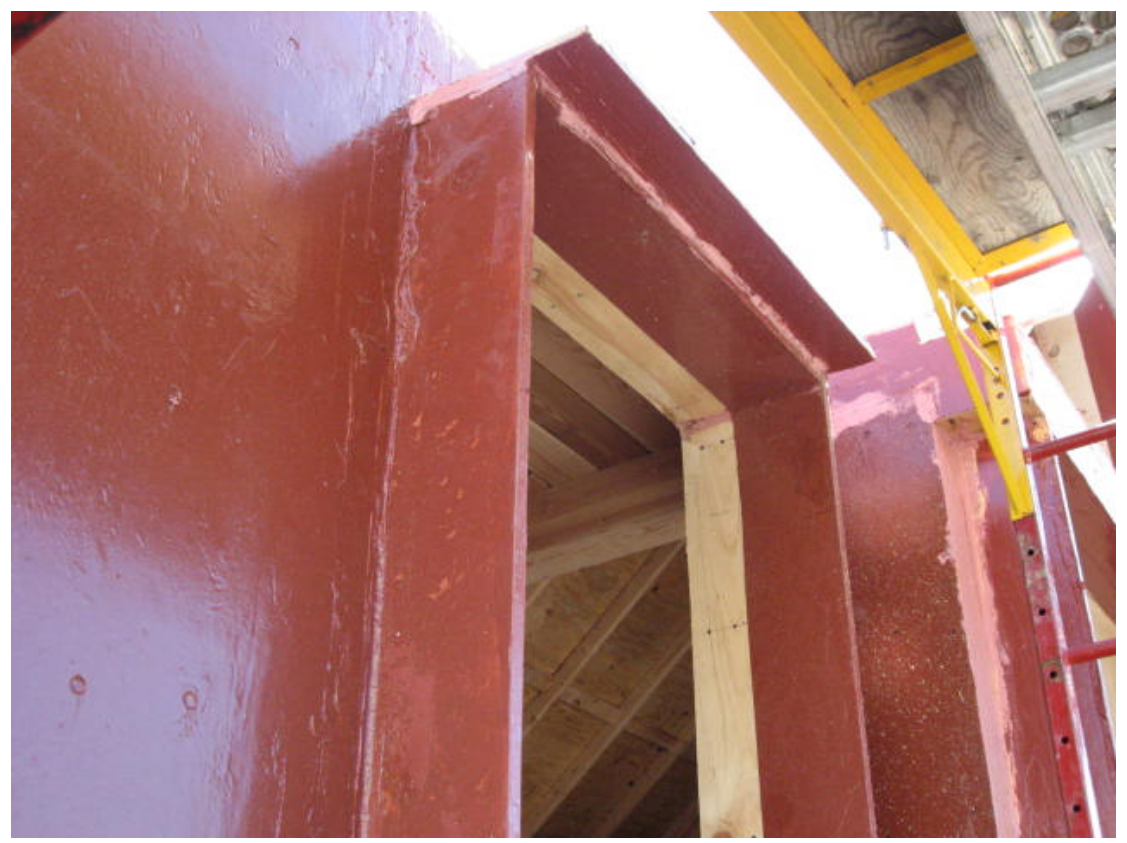

Figure 4-6 Liquid applied flashing around window buck [Prosoco, 2013]

The other interesting element to these window details is the location of the window, and the over insulation of the frame. To minimize heat loss through the window, the window frame is 
best located in the middle of the thermal insulation layer and over insulated on the interior and exterior side of the frame [Klingenberg, 2012]. Polyisocyanruate pieces are installed to achieve this design feature. The exterior weather resistance barrier is taped to the window frame and protects the polyisocyanurate over insulation layer. At the sill and header locations, the window buck is sloped to the exterior to promote drainage. This slope at the header made with a cant placed on top of the buck. Once the cant is installed, it would be coated with the liquid applied membrane. The slope at the sill is provided with a sloped piece of laminated veneer lumber attached to the framing. In the vertical I-beam assembly, the sill portion is attached to the sidepieces of the window buck, and then once the liquid applied flashing is applied, the I-beams are cut on an angle to support the sill buck from below. The sill is not over insulated because water drainage could potentially be disrupted if foam was installed at this location. The metal sill pan is attached to the window frame and has end dams that fold up behind the fascia trim on the jambs. 


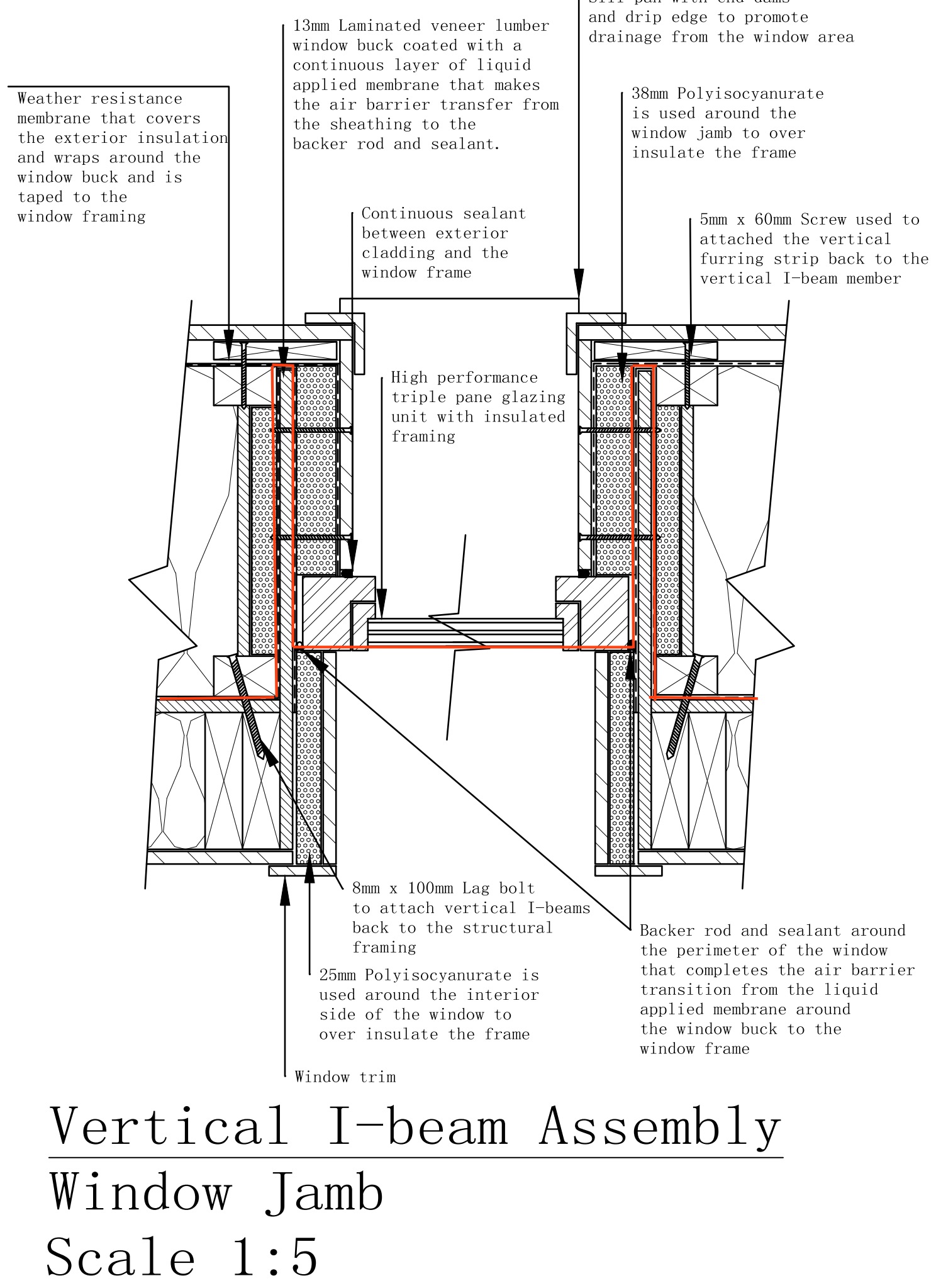

Figure 4-7 Window jamb detail of the vertical I-beam assembly 


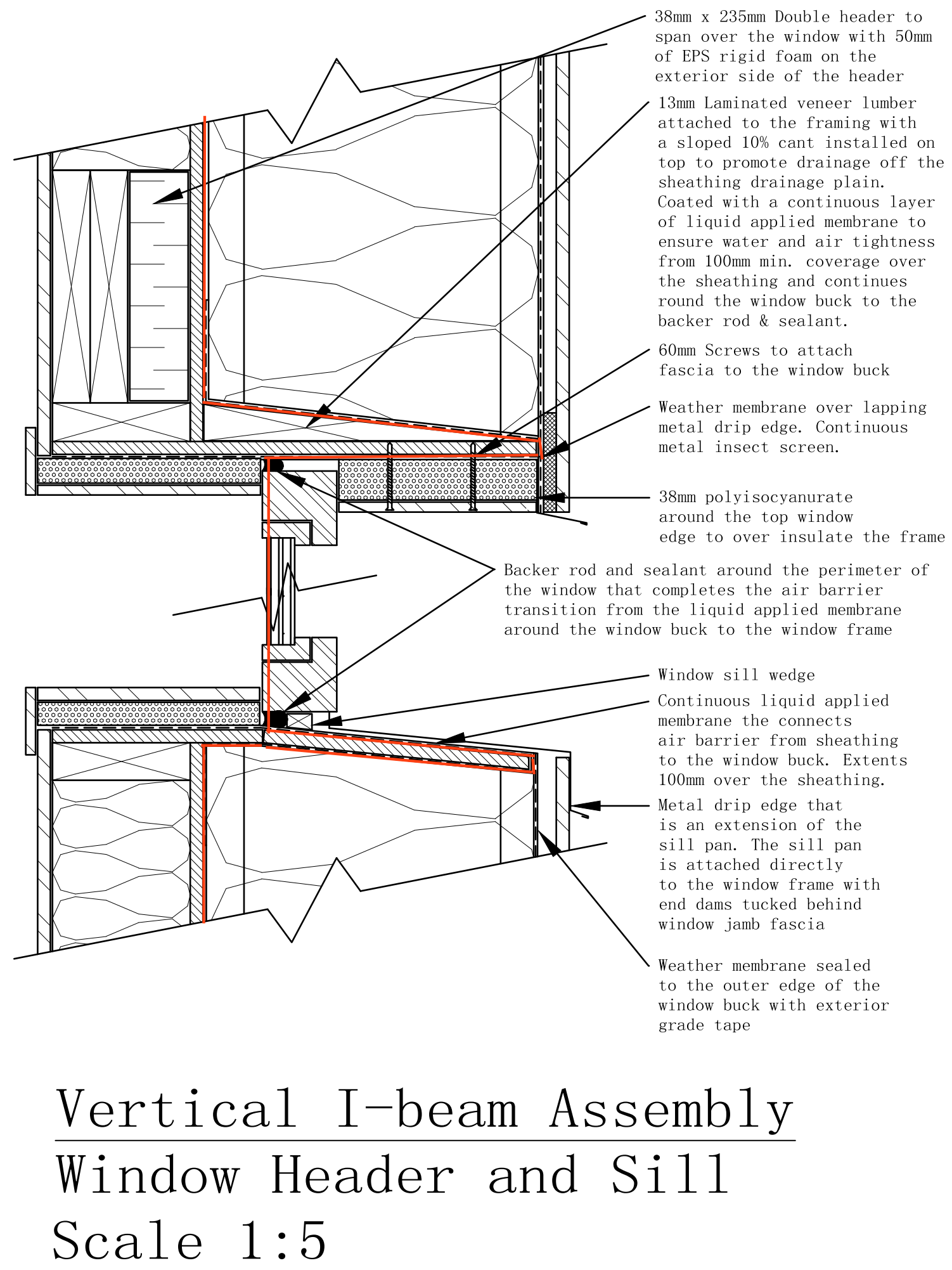

Figure 4-8 Window header and sill detail of the vertical I-beam assembly 


\subsection{Hinged Roof Truss}

The roof system is the same for each assembly. The roof is to be attached in the factory to the upper most module section to reduce the amount of fieldwork. The roof would be installed once the sheathing air barrier is complete on the ceiling of the upper model. The roof truss is designed with a moveable-hinged system. This allows the height of the roof to be lowered. The eaves trough is also hinged to reduce the width of the modules during transportation.

Figure 4-8 displays how the roof would fold down for transportation, and how it would appear once installed in the field. The left portion represents the finally installed assembly, and the portion of the schematic on the right displays how the roof would look during transport, and a set of arrows show how it would unfold for installation in the field. The only items that are added on site are a horizontal cord across the truss and a vent at the top of the roof seam once the roof is erected. 

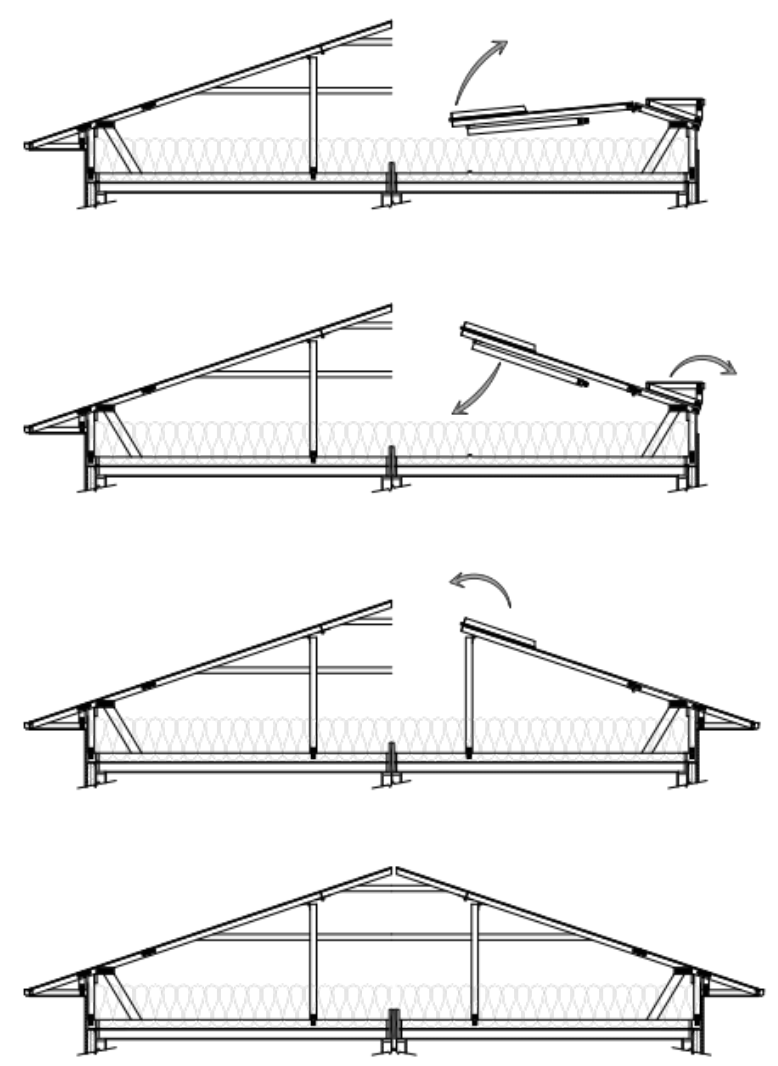

Figure 4-9 Schematic view of hinged roof truss.

\subsection{Foundation}

The foundation is designed as a slab on grade. The main structural component of the foundation is the continuous reinforced concrete footing around the perimeter of the modules and expanded polystyrene is used to insulate the footings. The structural loads are transferred from the concrete, to the foam and finally to the ground. The structural grade EPS foam is necessary to limit the thermal bridging of the foundation connection. Continuous EPS foam is also used under the module to increase the thermal resistance to the ground. Between the concrete footing and the EPS there is a continuous vapour retarder to provide a capillary break from the ground. The vapour retarder is placed in this location to prevent the situation of the EPS foam sitting in a 'bathtub' of water that could accumulate during the construction process from rain. The above 
grade portion of the geofoam footing is covered with a frost shield to protect it from the elements. In Figure 4-10 a section view of the footing is displayed.

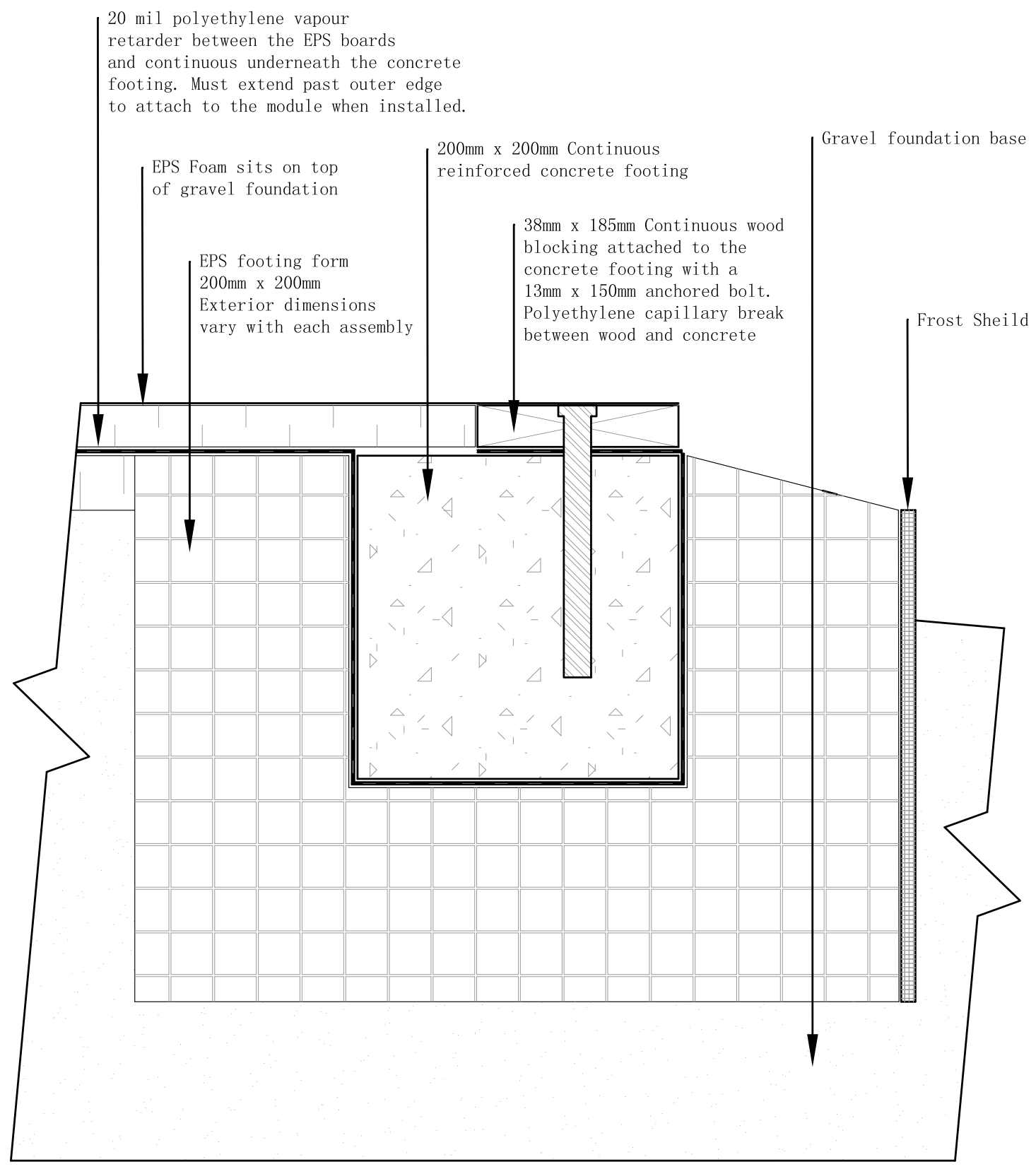

Figure 4-10 Schematic section view of footing with EPS foam 


\subsection{Construction Processes for the Proposed Envelope Systems}

The construction processes needed to deliver the four envelope systems differs with onsite construction methods and modular. The construction processes of delivering the envelopes were divided into steps. The various steps in the wall construction process are outlined for each of the developed envelopes: interior finish, structural framing, insulation, exterior cladding, weatherization, air sealing and window installation. Each of the steps is described for two scenarios: the proposed envelope using the modular system, and using a traditional onsite stick build method. This provides insight into the benefits of using the modular building system to deliver the developed high performance envelopes.

Not only are construction processes different, but the procurement of the materials and tools needed for the processes. The differences between each step are described and the potential benefits of using the modular system are outlined in regards to worker productivity, increased safety and ability to control quality of the materials and work produced from each construction step. These benefits are based on previous literature about the benefits and drawbacks of the modular building system outlined in chapter two. This portion of the research does not aim to quantify the advantages gained, but rather to qualify which steps benefit from the modular system, how they benefit from the modular system compared to onsite methods and how the assembly process differs from onsite methods Each of the construction processes are discussed individually, and within each step, the four envelope assemblies are described.

\subsubsection{Interior Finish}

When installing the interior gypsum finish, the modular building system reduces the amount of material handling compared to the onsite method. Gypsum board is merely placed flat onto the ground or worktable, and the framing [both exterior walls \& ceiling joists] is placed on top and secured. Onsite construction methods would involve far more maneuvering of the material to secure it in place. Hoisting gypsum board and attaching it to the ceiling would be more time consuming for an installer than it would be for a worker in a factory. In addition, the 
absence of a polyethylene sheet behind the interior finish, allows the gypsum board to be attached to the wall and ceiling framing with spray glue. Spray glue is another reason why the workers can install the material with greater ease. In addition, the spray glue provides another layer of air sealing for the interior by sealing the back side of the interior gypsum [in addition to the mud and tape used on the interior side of the gypsum], although it does rely on the gypsum board as an air barrier. The process of installing the interior finish for the high performance envelope system is improved from onsite methods because there is less material handling and use of spray glue is possible because a polyethylene sheet is not used. Traditional envelope systems built in a modular system use a polyethylene vapour retarder, and the use of spray glue is not possible to attach the gypsum to the framing.

\subsubsection{Structural framing}

The structural framing used in modular is different than onsite methods. The modular system reduces the amount of material handling by the workers and it increases the precision of the framing process. Floor and ceiling joists, and stud members are placed into framing jigs for accurate spacing without having to continuously measure the spacing between the framing members. This is important for high performance walls because the amount of framing is accounted for in the energy model of the building. A framing jig allows for the correct amount of studs to be installed into the walls, floors and ceilings. Additional wood studs and joists would reduce the effective thermal resistance value and alter the predicted energy use of the building.

Once the stud wall is ready (including the gypsum board being secured to the interior side of the studs), it is hoisted into place on top of the floor joists with a gantry. Onsite methods would require the carpenters to physically raise the wall into place, often requiring several people. In the modular factory, this is performed with one or two people and minimal physical effort is needed because the gantry is doing the heavy lifting.

After the framed exterior walls are placed onto the floor system, the ceiling joists (with ceiling gypsum board attached) are placed on top of the walls. The additional ceiling joists make 
the structural 30\% stronger [Fazio et al., 2000]. If this assembly were to be built onsite, there would be no ceiling joists (unless a 139mm cavity below the sheathing air barrier is desired for recessed lighting fixtures). On site methods would instead have $38 \times 38 \mathrm{~mm}$ furring strips that separate the ceiling sheathing layer from the interior gypsum layer for electrical wiring. This would mean the order of assembly for the onsite method would be: apply sheathing to the underside of the roof trusses and seal the seams, attach the furring strips to allow for wiring and attach the ceiling gypsum board. This is a tremendous about of work to be performed above the workers head. This is an awkward working position for onsite workers that is avoided by using the modular building system.

With the vertical I-beam assembly, the $38 \times 139 \mathrm{~mm}$ stud wall is the same, but there is the addition of the vertical I-beam to the exterior side of the studs. In the modular factory, the vertical I-beam is installed once the cavity insulation and sheathing layers are finished. It is first toe nailed to the stud, and then secured back to the structural stud framing with screws. The holes are pre-drilled for the screws so that the wood does not split. With onsite methods, the I-beam would be installed before any cavity insulation is installed. The window rough opening will be cut open, and a window buck installed with the liquid applied membrane before the attachment of the vertical I-beams. The bottom of the window buck sill is nailed to the side bucks of the window opening, and is then supported by the I-beam once the buck is flashed with a liquid applied membrane and the vertical members are installed. The process in the field would be the same. The modular process benefits from having vertical I-beams that are shorter in length compared to onsite construction methods because the members would only span one story. Onsite methods would use longer pieces to span the entire height of the envelope. The shorter pieces are easier to handle in the factory, and the workers can also benefit from working at lower heights while attaching the I-beams to the structure. The I-beam framing also benefits from the possibility of gantries moving the heavy pieces of wood.

For the vacuum insulated panel assembly, the $38 \times 89 \mathrm{~mm}$ stud assembly process is the same as the previously described envelope construction processes. However, the vacuum insulated panel envelope has the addition of a horizontal strapping layer between the studs and 
the gypsum layer. Its primary purpose is to provide additional depth from the interior finish to the vacuum insulated layer. The installation process of the strapping differs between onsite and modular methods. In the modular process, the strapping would be attached to the studs and then placed on top of a gypsum layer. The gypsum would be attached with spray glue to the straps from the backside of the interior finish. With onsite methods, the strapping is applied from the interior side once the exterior walls are erected and the cavity is installed with the EPS and VIP insulation layers, followed by the gypsum board. The modular process allows the strapping to be attached while the studs are in a framing jig. This reduces material handling by the workers in the factory, and reduces fragmentation within the framing process compared to onsite methods. Onsite methods require the stud cavity to be filled with insulation first because the EPS and VIP layers are not flexible, and require the cavity to be filled accessible. If strapping is installed before the cavity insulation, this restricts the rigid insulation install process.

\subsubsection{Structural sheathing}

The structural sheathing is a critical layer for the high performance assembly because it is the primary air barrier material for the floor joists, walls and ceiling.

In the modular factory, the floor systems (of the lower module) are framed with the sheathing layer secured to the joists and the seams are sealed. Next, it is then flipped over with a butterfly table or a gantry system to access the joist cavity to install blown insulation. Once the floor joists are insulated, they are sheathed on top with the sub floor, and exterior walls can be placed on top. If this assembly were to be built onsite, it would have a slab on grade, and there would be no floor joists needed for the bottom floor.

The sheathing layers for the walls and ceiling are installed at the same time in the modular system. The cavity insulation, and any electrical wiring would be installed before the sheathing layers are attached and nailed. By attaching them at the same time, this allows a visual inspection of the sealed seams to be conducted at the same time for both the walls and ceiling. With onsite methods, the sheathing on the walls and the sheathing underneath the roof trusses 
would be attached at different stages. This means additional quality control inspection steps. A critical advantage of using modular is that the ceiling sheathing can be installed over the top plate of the framed wall. This allows for the sheathing to be continuously installed at once. With onsite methods, the wall and ceiling sheathing are installed at different times, and additional steps would be needed to seal the sheathing transition from the walls to the ceiling.

\subsubsection{Insulation}

\section{Polyisocyanurate Assembly}

The order of assembly for the insulation layers is different for the modular system and for built onsite construction processes. In the modular system, the stud cavity insulation would be installed from the exterior side, with the interior gypsum giving backing to it, and a screen mesh would be needed to keep it in place on the exterior side. If this were to be constructed on site, the sheathing would be the backing and the insulation would be blown in from the interior side. The advantage of the modular process is that the interior gypsum board can begin its taping and mudding process, while work on the exterior is being completed at the same time. Also, the exterior sides of the walls are more easily accessible by the workers and their blowing equipment because they do not need to run hoses a great distance from the hopper to the blowing location.

The exterior applied foam insulation is attached once the sheathing layer is sealed and the roof truss is secured for both the onsite and modular system. The only difference is that there is a gap left at the rim joist location to allow for the sheathing layer to be sealed on site. The layer of polyisocyanurate insulation is applied in two layers, and the seams are offset both vertically and horizontally. The foam is secured with screws that attach back to the sheathing layer, and is then further secured with the vertical furring strips.

There are a couple advantages the modular system offers for the installation of the blownin cellulose and the exterior applied polyisocyanurate. First, the cellulose within the cavity can be installed while the interior gypsum is being finished, allowing for concurrent construction processes. Next, the polyisocyanurate layer can be installed without being exposed to rain or 
solar radiation. Excessive moisture, or long periods of sun exposure can jeopardize the integrity of the foam. With onsite methods, the foam has the potential to be damaged from the elements. The cellulose in both cases is installed in a dry environment (in the factory from the exterior side of the studs, and onsite from within in the home). In addition, the foam can be installed in a modular factory at a more comfortable height than if it were to be installed in the field. The workers in the factory will never have to install foam on the exterior of the sheathing at heights greater than one story. In the field, workers would need to work at greater heights to install the foam using a ladder, scaffolding or a skylift. Finally, modular manufacturers have the potential to benefit from bulk purchases of insulation because they the capacity to warehouse the material. This is unlikely to be the case with onsite construction methods because most builders do not have the capabilities of warehousing large stockpiles of materials onsite.

\section{Mineral Wool}

The installation of the mineral wool differs for modular systems and onsite construction. In modular building, the mineral wool batt in the cavity would be applied from the exterior side of the wall. This allows for the time consuming gypsum finishing processes to be completed at the same time. With onsite methods, the mineral wool batt is applied from the interior side of the wall and restricts possible concurrent steps in the envelope process. The exterior applied semirigid mineral wool is applied in the field with both building methods because the modular processes of transporting and hoisting the modules with a crane have the potential to dent the semi-rigid material. This is a possible reason why rigid foam might be preferred over semi-rigid mineral wool in terms of reducing construction processes in the field since foam can be installed within a factory and resist the impact of transportation and crane straps.

\section{Vertical I-beam}

The $38 \times 139 \mathrm{~mm}$ stud cavity is filled in the same manner as the polyisocyanurate stud cavity. Cellulose is blown from the exterior side of the studs in the modular system, using the 
interior gypsum board and a mesh screen to support the material. In the field, the cellulose is applied from the interior side, and supported by the sheathing and mesh screen. The vertical Ibeam cavity is attached to the studs on the exterior side of the sheathing. This is the same way for both modular and onsite construction methods. After the weather resistance membrane is applied to the exterior side of the vertical I-beams, holes are made to allow the hose for the blown-in cellulose to enter into the cavity. The primary difference between the modular system and onsite methods for filling the I-beam with cellulose is the size of the cavity to be filled. Since modules are only one story, insulation is installed for one story at a time. On site methods would fill the entire cavity, spanning over two or three stories, all at once. The advantage to a shorter cavity is that installation crews can more accurately ensure the proper density levels are achieved. In large cavities, there is a greater possibility of the cellulose having air pockets. Potential air gaps, or improper density levels will cause settling over time and reduced thermal resistance levels.

\section{Vacuum Insulated Panel}

The insulation install processes vary significantly between the modular and onsite methods needed to delivery the vacuum insulated panel assembly. Like all of the assemblies, the VIP assembly is built from the inside out, allowing gypsum and cavity processes to happen concurrently. However, there is the addition of a horizontal strapping layer between the studs and gypsum board, and the cavity insulation is rigid and cannot be flexed, nor can the VIP be cut to fit. In the modular process, the first layer of insulation is the mineral wool batt installed between the horizontal strapping. This is accessible from the exterior side of the wall and the batt insulation is flexible to be maneuvered into place. Next, an EPS layer would be installed and attached to the horizontal strapping with screws. Next, the VIP would be applied with an adhesive to the first layer of EPS, and then another EPS layer would go over top. The exterior mineral wool layer would be applied onsite once the modules are secured. When constructed with onsite methods, the cavity insulation would be installed first, and then the strapping applied, followed by the mineral wool in the strapping. 


\subsubsection{Exterior cladding, furring strips \& WRB}

The installation of the exterior cladding is the same for both the modular building system and onsite construction methods. It is preformed onsite, with the same tools and installation methods. However, with the modular system the vertical furring strips and weather resistance barrier can be installed in the factory setting. The furring strips are secured back to the framing with long screws [length varies with exterior insulation thickness]. As exterior insulation is applied, there are lines marked as to where the studs are located. This is an advantage for the installation crews because they never have to install it at a height taller than one story. This is similar to the advantage of installation of the rigid foam within the factory setting - safer and faster working conditions for the workers.

For the vertical I-beam assembly, the WRB is installed before the cellulose is installed. This is the only assembly where the WRB is applied before exterior insulation is applied. This is a different WRB than any of the other assemblies. It is a special material that is resistant to tearing and bulging from the dense packed cellulose. It is stapled to the I-beam members, and is then secured with the installation of vertical furring strips. The furring strips are secured to the vertical I-beam members. This is the same process as it would be in the field. However, the modular process benefits from lower working heights for the installers than compared to this process happening in the field.

\subsubsection{Air sealing}

The air sealing process is different between onsite and modular construction methods. In the modular system, the primary air barrier is the sheathing layer for the ground, walls and ceiling. With onsite methods, the ground contact air barrier would be a polyethylene sheet and is then taped to the exterior side of the sheathing [or below grade foundation walls if a basement is used]. The sheathing transition from the wall to ceiling is made easier in the factory because it can it applied at once, and is made continuous over the top plate and the ceiling joists. The seams can be all taped on the exterior side of the sheathing, and visually inspected for continuity at 
once. With onsite construction, the taped seams are not on the same side for the exterior wall and ceiling sheathing layers. The walls are taped from the exterior, and the ceiling is taped from the interior. This means extra time and attention must be given to sealing the sheathing transition at the top plate location and divides the visual inspection of the taped seams into two steps.

The rim joist location cannot be air sealed in the factory. This is why a gap is left open in the exterior insulation layer - to allow the taping of the sheathing layer once the upper and lower modules are installed on site. In the field, this location is made airtight by having the sheathing layer laid continuously on the exterior side of the floor joists and studs. For the vertical I-beam assembly, the rim joist location for air sealing is distinct when it is constructed modularly. Since the I-beams are on the exterior side of the sheathing, and they are made continuous from the top of the module to the bottom, it does not allow for a void to be left open to allow the sheathing layer to be taped. Instead, pieces of sheathing are turned over and under the rim joist to create a smooth clean surface for a layer of expanding foam tape to be attached. This tape is applied right before the modules are placed on top of each other.

For all of the assemblies, the foundation to wall air sealing transition can be made in the modular factory because sheathing is used to provide support of the cellulose in the floor joists. The same workers in the factory are responsible for the two layers of sheathing. With onsite methods, the sub slab polyethylene sheet to the exterior side of the sheathing makes the foundation to wall air sealing transition. This means there are two crews that need to work together to ensure this interface is airtight - the foundation crew needs to provide enough polyethylene that extends out past the outer edge of the slab, and the carpenters to apply it to the sheathing. This is a fragmentation of the air sealing process that is avoided with the modular process.

\subsubsection{Window installation}

The window installation is a significant process for low energy buildings. The window install begins with the cutting of the sheathing to make a rough opening. In the modular process, 
the interior gypsum also needs to be cut at the same time. In the field, the rough opening is cut the same way, once the sheathing layer is installed. The window bucks are installed into the rough opening and the liquid applied flashing is applied over the bucks. The liquid applied flashing membrane starts from $100 \mathrm{~mm}$ over the sheathing and extends into the rough opening. Once the rough opening and window buck are coated, the window is placed into the opening and secured to the structural framing. The air barrier transitions to the window frame from the window buck with tape or sealant and backer rod. In a modular setting, installing a window is always no higher than one story above the ground. In the field, this is performed at higher elevations above grade by using ladders, scaffolding or skylifts. The primary advantage of this step in the modular process is the use of a gantry with suction cups to maneuver and install the window. High performance windows are extremely heavy, but only one person is needed to move them around if a gantry is used. When they are installed onsite, they must be maneuvered by hand, and moving them up staircases can be difficult. Another advantage the modular process offers for the window installation step is the ability to store the high performance windows in a secured location. Often, high performance windows are imported from overseas and can arrive at an inopportune moment in the construction process due to scheduling inaccuracies or delays in shipment [Cohen et al., 2013]. With onsite methods, builders can be left without a place to store them, and are forced to move the heavy window several times before actually installing them.

\subsubsection{Primary Advantages Gained with Modular}

The following is a summarized list of the advantages gained from using the modular building system over onsite methods to produce the four designed high performance envelope systems. It was not the goal of this research to quantify the advantages gained, but rather to identify and qualify them. Future research into measuring the process times of the various construction steps and involved costs can be done to quantify these advantages gained.

- Interior gypsum layer can be installed with less material handling and is installed without a polyethylene vapour retarder layer, allowing spray glue to be used to secure it to the studs. 
- Framing factors are controlled more accurately because crews can use jigs with predetermined stud spacing. This prevents additional framing in the walls that can negatively affect the thermal resistance performance of the assemblies.

- Reduced lifting and hoisting of walls and window with gantries. This is especially helpful with thicker walls and high performance windows because they are heavier than traditional walls/windows to lift for workers onsite.

- Many processes such as applying exterior insulation, vertical furring strips, weather resistance barriers, attaching vertical I-beams and windows can be installed at heights no greater than one story.

- Bulk purchases of insulation at reduced rates are possible with the modular building system because they can be stored within the factory.

- The air barrier transitions of the wall to ceiling and wall to foundation can be made within the factory, and are preformed by the same crews. This reduces fragmentation in the air sealing process

- Sensitive materials such as the vacuum insulated panels and high performance windows benefit from the modular process because they can be handled with greater care and have a place to be stored securely away from the elements. 


\section{Chapter Five - Thermal Performance Analysis}

\subsection{Overview}

\section{Chapter research questions:}

How do the proposed envelope systems perform in terms of thermal resistance?

a) What are the effective RSI values of the assemblies once framing is accounted for?

b) Do the wall to roof, ceiling to floor and wall to foundation transitions of the proposed envelope details have a linear thermal resistance value $<0.01[\mathrm{~W} / \mathrm{m} \cdot \mathrm{k}]$ ?

The following chapter reviews the thermal resistance performance of the four super insulated exterior wall assemblies. The computer software THERM 6.1, a two-dimensional heattransfer modeling program, is used to assess the thermal conductivity values of the envelope systems and the various joint locations for thermal bridging potential.

First, a plan view simulation is run to assess the effective $U$-value with a $15 \%$ framing factor. This will provide the most realistic analysis of the true U-values for the various envelope designs. A tolerance factor for error was set at $5 \%$ for all of the models. Next, the effective Uvalues were used to create a fictitious material in the database for each of the assemblies to perform the thermal bridging analysis of the various connection joints. This was to determine the linear $\Psi$-values of the connections and interface transitions that are outlined later in this chapter. 


\section{Material Conductivity Values}

Table 5-1 represents the conductivity values for the material inputs. All of these are taken from the material database, except for the vacuum insulated panel, which is taken from previous research into the material.

Table 5-1 Conductivity values of material inputs for THERM models

*Conductivity of VIP [Parekh \& Mattock, 2012]

\begin{tabular}{|l|c|}
\hline \multicolumn{1}{|c|}{ Material } & $\begin{array}{c}\text { Conductivity } \\
{[\mathbf{W} / \mathbf{m} \cdot \mathbf{k}]}\end{array}$ \\
\hline Mineral Wool & 0.038 \\
\hline Expanded Polystryene & 0.038 \\
\hline Cellulose & 0.040 \\
\hline Polyisocyurante & 0.022 \\
\hline Lumber \& Sheathing & 0.140 \\
\hline Vacuum Insulated Panel & $0.005^{*}$ \\
\hline
\end{tabular}




\subsection{Effective Thermal Resistance}

\section{Exterior Polyisocyanurate Assembly}

The exterior polyisocyanurate assembly was calculated to have a clear wall RSI value of 10. Once accounting for framing, it was reduced to an effective RSI value of 9.7. This was the smallest drop in thermal resistance due to framing. This can be attributed to the exterior applied polyisocyurante. Figure 5-1 displays a screen shot of the assembly in plan view in a THERM model. It shows the isotherms and the energy flux through the wall. Overall, the heat flux through the studs peaks at roughly $7 \mathrm{w} / \mathrm{m}^{2}$. In Figure 5-1, this can be noticed with the red color in the flux screen shot.
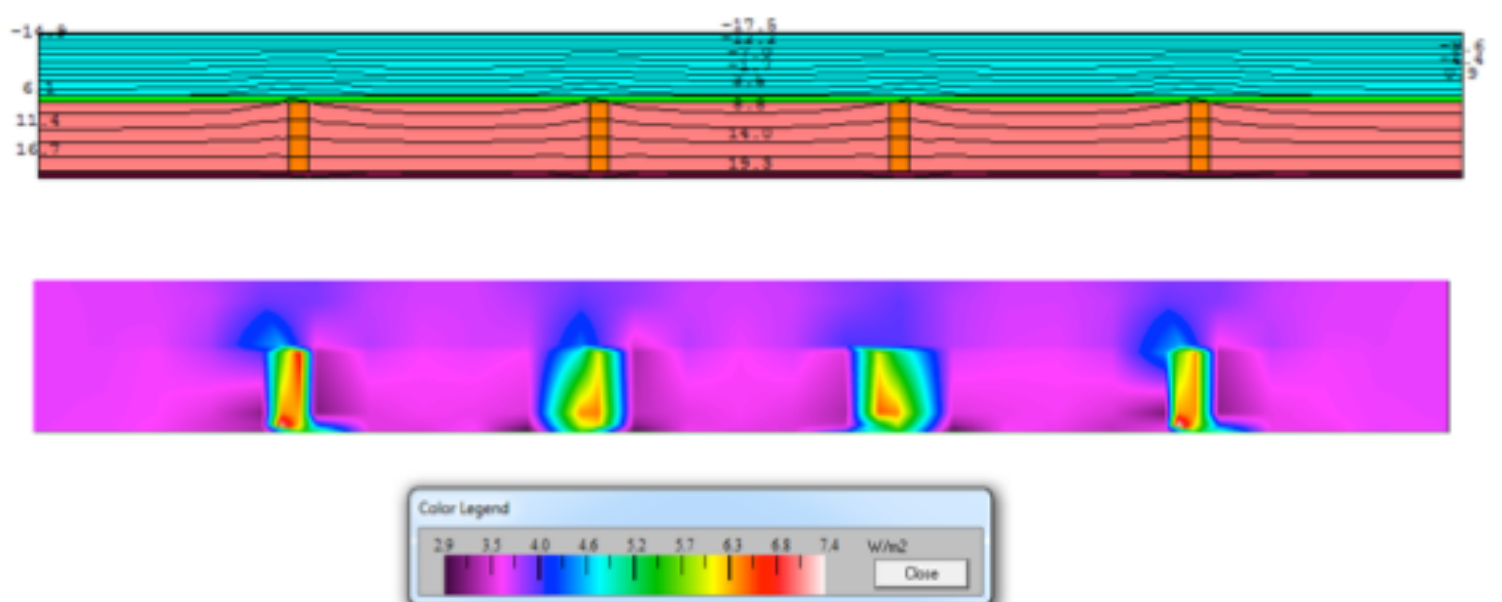

Figure 5-1 THERM screen shot the polyisocyanurate assembly 


\section{Exterior Mineral Wool Assembly}

The exterior mineral wool assembly is calculated to have a clear wall RSI value of 10 . Once accounting for framing, it was reduced to an effective RSI value of 8.4. This is a difference of $16 \%$. This is a higher percentage drop in RSI value compared to the polyisocyurante assembly because the mineral wool has a high conductivity value, and does not reduce thermal transmittance as well as the foam. Nevertheless, a substantial effective RSI value is obtained. Figure 5-2 is a screen shot of the assembly in plan view in the THERM model. The heat flux through the stud peaks at $8 \mathrm{w} / \mathrm{m}^{2}$.
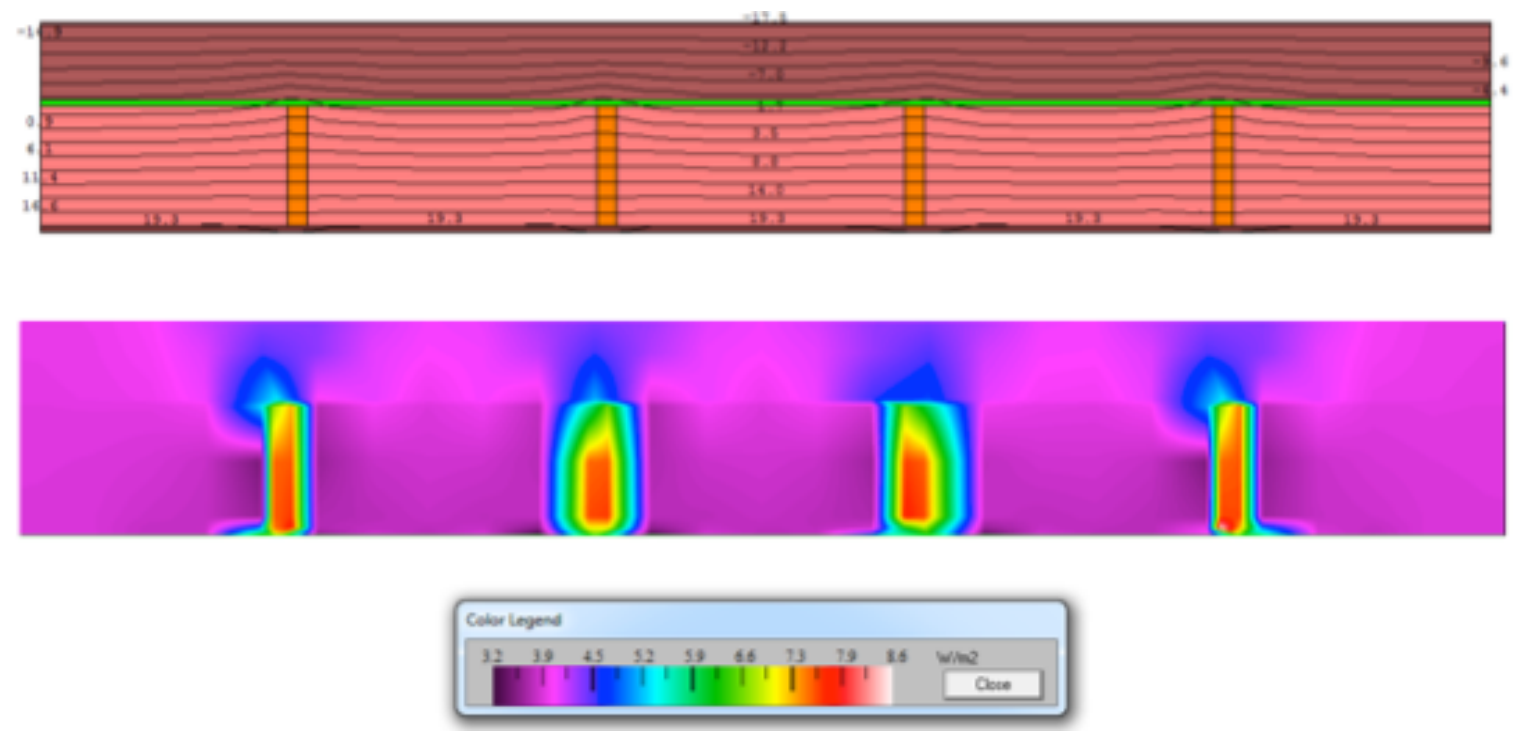

Figure 5-2 THERM screen shot of the mineral wool assembly 


\section{Vertical I-Beam Assembly}

The vertical I-beam assembly is calculated to have a clear wall RSI value of 10 . Once accounting for framing, it is reduced to an effective RSI value of 9.3. This is a difference of 7\%. This is higher than the polyisocyurante assembly, but less than the mineral wool assembly. This is because the exterior cavity is $260 \mathrm{~mm}$ thick of cellulose, and the I-beam are made of $13 \mathrm{~mm}$ oriented strand board for the web portion. Both of these characteristics reduce the thermal bridging effect. In Figure 5-3, a screen shot of the assembly in plan view taken from the THERM model is displayed. The heat flux through the studs peaks at roughly $9 \mathrm{w} / \mathrm{m}^{2}$.
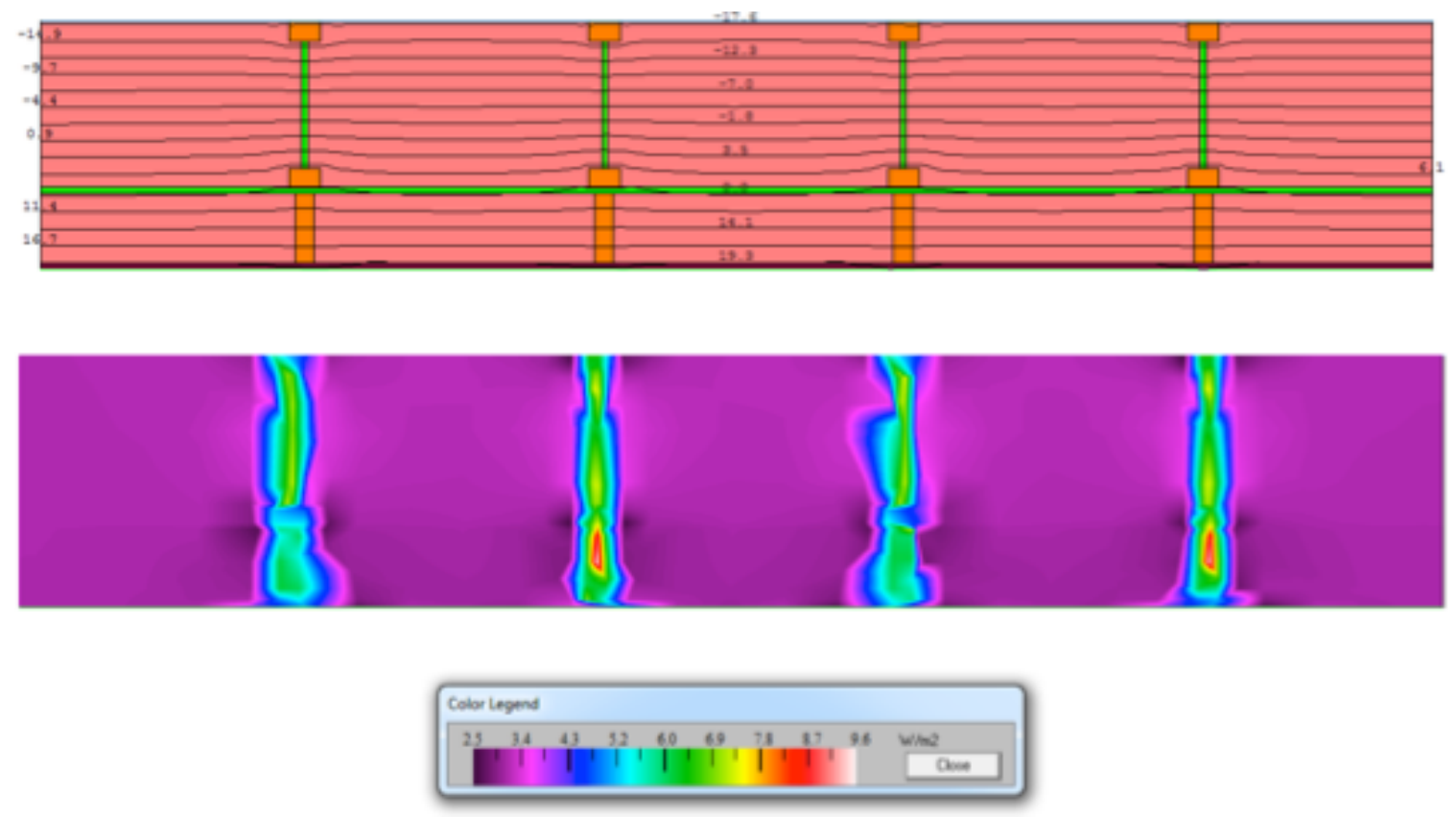

Figure 5-3 THERM screen shot of the vertical vertical I-beam assembly 


\section{Vacuum Insulated Panel Assembly}

The vacuum insulated panel assembly is calculated to have a clear wall RSI value of 10 . Once accounting for framing, it is reduced to an effective RSI value of 6.5. This is a difference of $35 \%$. This is by far the greatest drop in RSI value once framing is accounted for. The exterior insulation is only at 50mm, and does not slow down the bridging effect enough. In Figure 5-4, a screen shot of the assembly in plan view is displayed and shows the isotherms and the energy flux through the wall. The heat flux through the studs peaks at roughly $18 \mathrm{w} / \mathrm{m}^{2}$, ranking the highest amongst all of the proposed assemblies developed in this report.
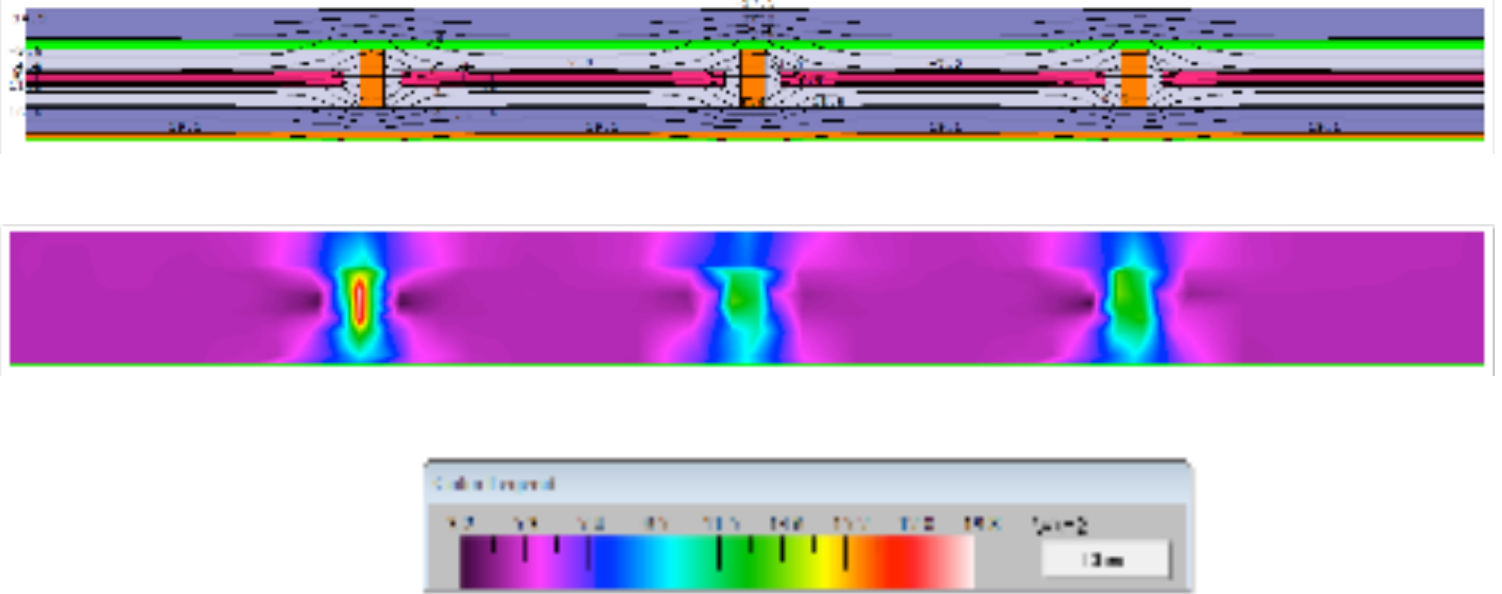

Figure 5-4 THERM screen shot of the vacuum insulated panel assembly

The results of the plan view THERM simulations are shown in Table 5-2 in U-value and RSI value. These values are used to calculate the thermal bridging at the various module connection interfaces. Thickness values are taken from the interior finish to the exterior edge of the thermal envelope. It can be noted that the polyisocyurante has the lowest percentage drop from a clear wall RSI value to an effective value. The greatest difference is the vacuum insulated panel assembly with a $35 \%$ drop. This is significant because it shows that insulating the exterior side of the studs is the best method of reducing the thermal bridging effect. For the vacuum 
insulated panel assembly, it is recommended to place the vacuum insulated panels in the middle of a double stud wall, or to be attached continuously on the exterior side of the studs [Parekh \& Mattock, 2010]. Each technique has its own respective benefits and drawbacks. Placing the VIP the exterior side of the framing allows for less thermal bridging, but an increased risk of rupture for the panel and a more complicated installation process because special fasteners are needed. If placed within the cavity, thermal bridging is increased, but it is in a safer location for reduced risk of rupturing the VIP [Parekh \& Mattock, 2010]. For this research, the goal of this assembly is to get the wall as thin as possible, and to protect the vacuum insulated panel from rupture during installation, hence why it was placed in the middle of the cavity. At the beginning of the research, it was not anticipated that such a drop in thermal resistance was going to happen.

Table 5-2 Summary of the clear wall and effective RSI values

\begin{tabular}{|l|c|c|c|c|c|c|}
\hline & $\begin{array}{c}\text { Clear Wall } \\
\text { RSI }\end{array}$ & $\begin{array}{c}\text { Clear Wall } \\
\text { U-Value }\end{array}$ & $\begin{array}{c}\text { Effective } \\
\text { RSI }\end{array}$ & $\begin{array}{c}\text { Effective } \\
\text { U-Value }\end{array}$ & $\begin{array}{c}\text { Drop from } \\
\text { Clear }\end{array}$ & Thickness \\
\hline & {$[\mathrm{m} \cdot \mathrm{k} / \mathrm{W}]$} & {$[\mathrm{W} / \mathrm{m} \cdot \mathrm{k}]$} & {$[\mathrm{m} \cdot \mathrm{k} / \mathrm{W}]$} & {$[\mathrm{W} / \mathrm{m} \cdot \mathrm{k}]$} & & {$[\mathrm{mm}]$} \\
\hline Polyisocyanurate & $\mathbf{1 0}$ & $\mathbf{0 . 1}$ & $\mathbf{9 . 7}$ & $\mathbf{0 . 0 9 9}$ & $\mathbf{3 \%}$ & $\mathbf{2 9 0}$ \\
\hline Mineral Wool & $\mathbf{1 0}$ & $\mathbf{0 . 1}$ & $\mathbf{8 . 4}$ & $\mathbf{0 . 1 0 9}$ & $\mathbf{1 6 \%}$ & $\mathbf{4 1 1}$ \\
\hline Vertical I-beam & $\mathbf{1 0}$ & $\mathbf{0 . 1}$ & $\mathbf{9 . 3}$ & $\mathbf{0 . 0 8 8}$ & $\mathbf{7 \%}$ & $\mathbf{5 0 0}$ \\
\hline VIP & $\mathbf{1 0}$ & $\mathbf{0 . 1}$ & $\mathbf{6 . 5}$ & $\mathbf{0 . 1 8 5}$ & $\mathbf{3 5 \%}$ & $\mathbf{2 0 4}$ \\
\hline
\end{tabular}




\subsection{Linear Thermal Bridges}

Three primary linear $\Psi$ thermal bridge values were calculated for all of the assemblies and are outlined in the following portion of this chapter. The locations were at the wall to roof connection, the rim joist, and the foundation connection. The linear $\Psi$ thermal bridge values for all four assemblies are displayed in Table 5-4 at the end of the chapter. These locations are significant because they are vulnerable to thermal bridging and experiencing cold interior surface temperatures [Klingenberg, 2012].

\section{Thermal Bridge Calculation Method}

Linear thermal bridge calculations are done with two-dimensional heat transfer software to estimate the heat loss through connection locations within an assembly [Klingenberg, 2012]. In Figure 5-4, the calculation methodology of a linear $\Psi$ is displayed. The coloured portion of the Figure on the left shows the two-dimensional heat transfer calculation through the connection. Heat transfer is calculated with an area, and that area is taken from the exterior edge of a surface. If we look at the middle portion of Figure 5-4, there is 'double counting' of the heat transfer at the corner. In other words, the heat loss of the corner was over estimated because the area of the exterior surface was counted twice. Therefore, the $\Psi$ value of the connection is the twodimensional heat transfer of the connection modeled in THERM, minus the manual calculation using the exterior surface area values. If the $\Psi$ value is negative, it means the manual calculation overestimated the heat loss. This is the case for several of the connection details in this research. If it is a positive number, it means the heat transfer is underestimated in the manual calculation and a linear $\Psi$ must be assigned to the thermal bridge. Anything with a $\Psi>0.01 \mathrm{~W} / \mathrm{m} \cdot \mathrm{k}$ is considered to be a thermal bridge [Klingenberg, 2012]. 


\section{THERM Model Value}

$\mathrm{U}=\mathrm{U}$ value for THERM model for Interface $\left[\mathrm{W} / \mathrm{m}^{2} \cdot \mathrm{k}\right]$

$\mathrm{L}=$ Length $[\mathrm{m}]$

$\mathrm{T}=$ Temperature $[\mathrm{k}]$

\section{Simplified Component A}

$\mathrm{U}_{\mathrm{a}}=\mathrm{U}$ value from THERM Model of component A [W/m².k]

$\mathrm{L}_{\mathrm{a}}=$ Length $[\mathrm{m}]$

$\mathrm{T}_{\mathrm{a}}=$ Temperature $[\mathrm{k}]$

\section{Simplified Component B}

$\mathrm{U}_{\mathrm{b}}=\mathrm{U}$ value from THERM Model of component B $\left[\mathrm{W} / \mathrm{m}^{2} \cdot \mathrm{k}\right]$

$\mathrm{L}_{\mathrm{b}}=$ Length $[\mathrm{m}]$

$\mathrm{T}_{\mathrm{b}}=$ Temperature $[\mathrm{k}]$

Linear Psi $\Psi[W / m \cdot k]=\left[(U \cdot L \cdot \Delta T)-\left[\left(U_{a} \cdot L_{a} \cdot \Delta T_{a}\right)+\left(U_{b} \cdot L_{b} \cdot \Delta T_{b}\right)\right]\right] / \Delta T$
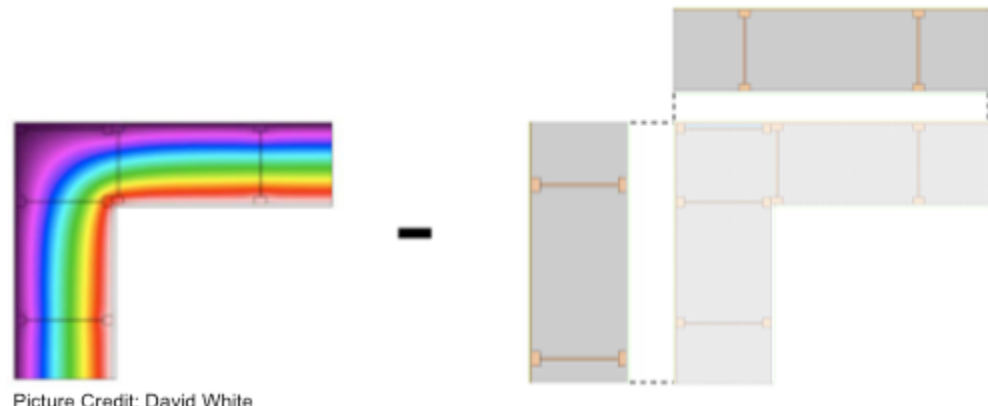

$=\Psi$

Figure 5-5 Linear thermal bridge $\Psi$ calculation methodology [Klingenberg, 2012] 


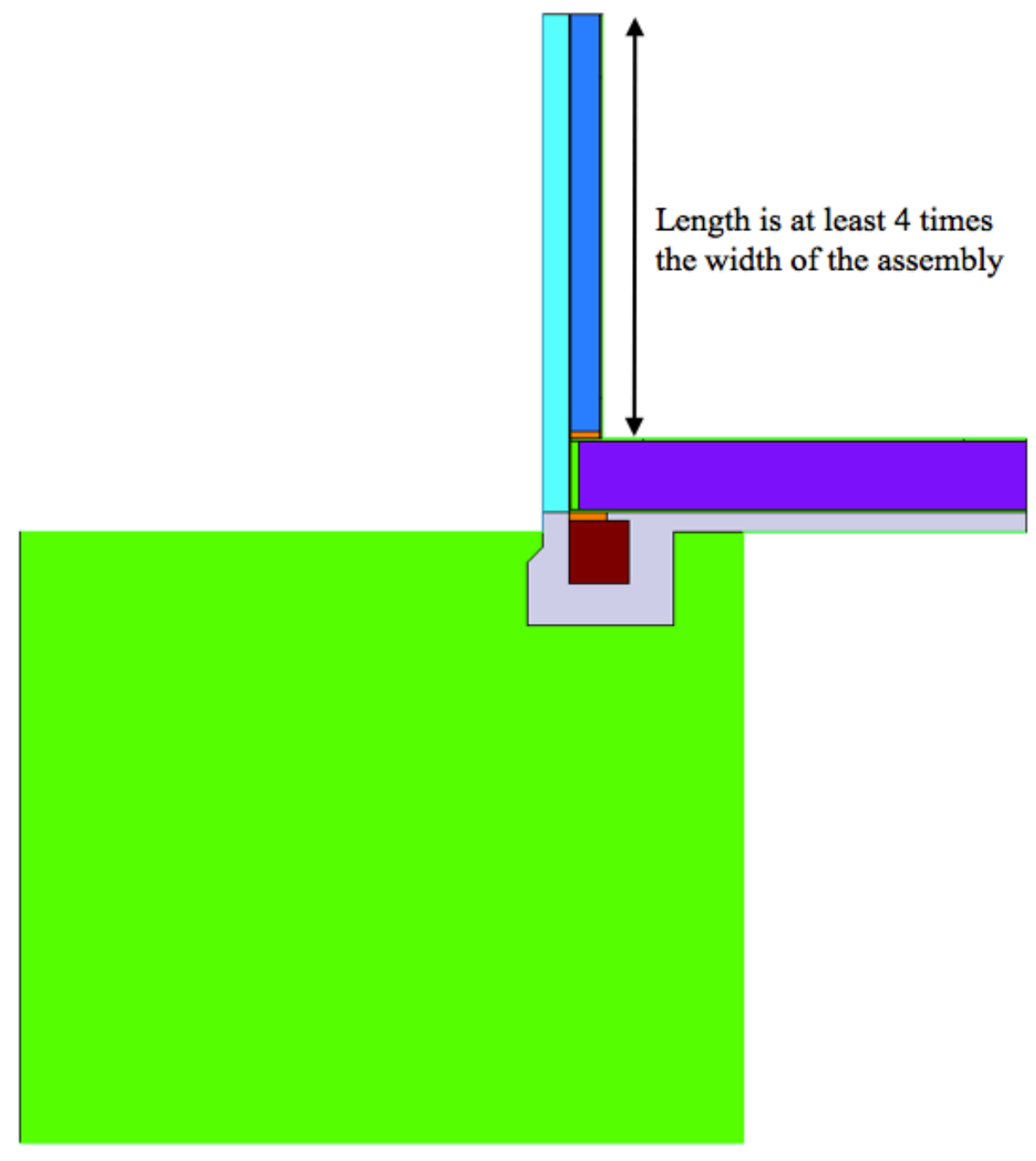

Figure 5-6 Screen shot from THERM model

\section{Surface Film Coefficients \& Temperatures}

The various surface film coefficients and temperatures are set in the THERM model to represent the boundary conditions for the different interfaces locations. The temperatures vary for three conditions - the ground, the interior and the exterior. These values are seen in Figure $5-7$, along with the several surface film coefficients used in the models. The only surface film coefficient that is not represented in the Figure is the exposed exterior surface film, which was used on the ground and the exposed slab on grade footing. Table 5-3 has a summarized list the 
surface film coefficients and temperatures used in the THERM models for the various conditions.

Table 5-3 Surface film coefficients $\&$ surface temperatures [ISO, 2007]

\begin{tabular}{|l|c|c|}
\hline & $\begin{array}{c}\text { Surface Temperature } \\
{\left[{ }^{\circ} \mathrm{C}\right]}\end{array}$ & $\begin{array}{c}\text { RSI Thermal Resistance } \\
{\left[\mathrm{m}^{2} \cdot \mathrm{k} / \mathrm{W}\right]}\end{array}$ \\
\hline Interior Surface & 21 & 0.13 \\
\hline Interior Corner & 21 & 0.2 \\
\hline Interior Downward & 21 & 0.17 \\
\hline Interior Upward & 21 & 0.11 \\
\hline Exterior Surface Screened & -13 & 0.08 \\
\hline Exterior Surface Non-Screened & -13 & 0.04 \\
\hline Ground Exposed to Air & -13 & 0.03 \\
\hline Ground Non-exposed & 4 & None \\
\hline
\end{tabular}




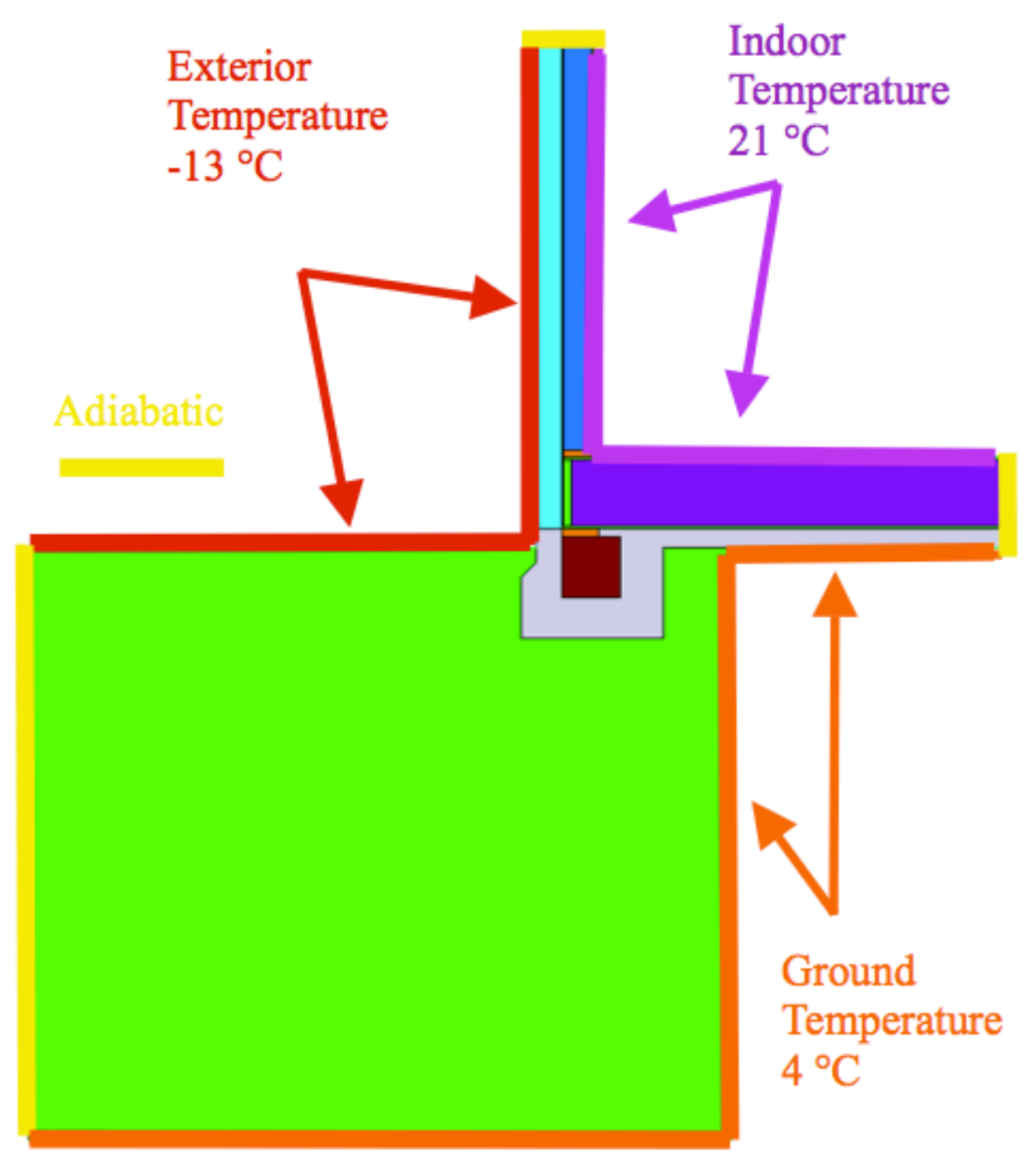

Figure 5-7 Surface temperatures for THERM models

\section{Wall to Roof}

The wall to roof connection is a critical location in envelope assemblies to manage cold interior surface temperatures and control heat loss [Klingenberg, 2012]. In traditional residential construction, this location experiences significant thermal bridging due to decreased roof insulation levels at the edges. The reduced thermal insulation layer is due to roof trusses not having enough vertical space for continuous insulation to the outer edge. This can be a significant problem in terms of thermal bridging and condensation risk on interior surfaces [Klingenberg, 2012]. In the research, all of the assemblies have a negative linear $\Psi$ thermal 
bridging value at the wall and roof location. This is because the roof assemblies are super insulated and the insulation extends to the outer most edge of the assembly. This is important because it will ensure that all interior surface temperatures are not at risk of condensation.

The following is an example of how the linear Psi $\Psi[\mathrm{W} / \mathrm{m} \cdot \mathrm{k}]$ values were calculated for the wall to roof interface for the polyisocyanurate assembly.

\section{THERM Model Value}

$$
\begin{aligned}
& \mathrm{U}=\mathrm{U} \text { value of Wall to Roof Interface }\left[\mathrm{W} / \mathrm{m}^{2} \cdot \mathrm{k}\right] \\
& \mathrm{L}=\text { Length }[\mathrm{m}] \\
& \mathrm{T}=\text { Temperature }[\mathrm{k}]
\end{aligned}
$$

\section{Simplified Component A}

$\mathrm{U}_{\mathrm{a}}=\mathrm{U}$ value of Wall $\left[\mathrm{W} / \mathrm{m}^{2} \cdot \mathrm{k}\right]$

$\mathrm{L}_{\mathrm{a}}=$ Length $[\mathrm{m}]$

$\mathrm{T}_{\mathrm{a}}=$ Temperature $[\mathrm{k}]$

\section{Simplified Component B}

$$
\begin{aligned}
& \mathrm{U}_{\mathrm{b}}=\mathrm{U} \text { value of Roof }\left[\mathrm{W} / \mathrm{m}^{2} \cdot \mathrm{k}\right] \\
& \mathrm{L}_{\mathrm{b}}=\text { Length }[\mathrm{m}] \\
& \mathrm{T}_{\mathrm{b}}=\text { Temperature }[\mathrm{k}]
\end{aligned}
$$

$$
\begin{aligned}
\text { Linear Psi } \Psi[W / m \cdot k]= \\
\left.\left.=I(U \cdot L \cdot \Delta T)-I\left(U_{a} \cdot L_{a} \cdot \Delta T_{a}\right)+\left(U_{b} \cdot L_{b} \cdot \Delta T_{b}\right)\right]\right] / \Delta T \\
=[(0.1353 \cdot 3.487 \cdot 38)-[(0.1376 \cdot 2.675 \cdot 38)+(0.0616 \cdot 2.037 \cdot 38)]] / 38 \\
=-0.0218[W / m \cdot k]
\end{aligned}
$$




\section{Wall to Foundation}

The wall to foundation connection is a critical point in all construction assemblies. In traditional residential construction, this location experiences significant thermal bridging due to decreased foundation insulation levels, or no insulation at all. This can be a problem in terms of thermal bridging and condensation risk on interior surfaces. All of the designed foundation connections were well insulated and do not experience thermal bridging.

Table 5-3 displays the summarized values of the various linear thermal bridge values. It can be noticed that all of the assemblies have a negative thermal bridge value. This because the thermal resistance layer is continuous, and the concrete footing itself is super insulated as well.

The following is an example of how the linear Psi $\Psi[\mathrm{W} / \mathrm{m} \cdot \mathrm{k}]$ values were calculated for the wall to foundation interface for the mineral wool assembly.

\section{THERM Model Value}

$$
\begin{aligned}
& \mathrm{U}=\mathrm{U} \text { value of Wall to Foundation Interface }\left[\mathrm{W} / \mathrm{m}^{2} \cdot \mathrm{k}\right] \\
& \mathrm{L}=\text { Length }[\mathrm{m}] \\
& \mathrm{T}=\text { Temperature }[\mathrm{k}]
\end{aligned}
$$

\section{Simplified Component A}

$$
\begin{aligned}
& \mathrm{U}_{\mathrm{a}}=\mathrm{U} \text { value of Wall }\left[\mathrm{W} / \mathrm{m}^{2} \cdot \mathrm{k}\right] \\
& \mathrm{L}_{\mathrm{a}}=\text { Length }[\mathrm{m}] \\
& \mathrm{T}_{\mathrm{a}}=\text { Temperature }[\mathrm{k}]
\end{aligned}
$$

\section{Simplified Component B}

$$
\begin{aligned}
& \mathrm{U}_{\mathrm{b}}=\mathrm{U} \text { value of Foundation }\left[\mathrm{W} / \mathrm{m}^{2} \cdot \mathrm{k}\right] \\
& \mathrm{L}_{\mathrm{b}}=\text { Length }[\mathrm{m}] \\
& \mathrm{T}_{\mathrm{b}}=\text { Temperature }[\mathrm{k}]
\end{aligned}
$$




\section{Linear Psi $\Psi[W / m \cdot k]=$ \\ $=\left[(\boldsymbol{U} \cdot \boldsymbol{L} \cdot \Delta \boldsymbol{T})-\left[\left(\boldsymbol{U}_{a} \cdot \boldsymbol{L}_{a} \cdot \Delta \boldsymbol{T}_{a}\right)+\left(\boldsymbol{U}_{b} \cdot \boldsymbol{L}_{b} \cdot \Delta \boldsymbol{T}_{b}\right)\right]\right] / \Delta T$ \\ $=[(0.1604 \cdot 4.749 \cdot 38)-[(0.1942 \cdot 3.458 \cdot 38)+(0.0909 \cdot 2.584 \cdot 38)]] / 38$ \\ $=-0.1447[\mathrm{~W} / \mathrm{m} \cdot \mathrm{k}]$}

Rim Joist

The rim joist is another critical location that is often neglected in terms of thermal resistance in traditional envelope systems [Klingenberg, 2012]. In the four assemblies designed in the research, the VIP assembly has the most significant thermal bridge in this location because the insulated panel is not on the exterior side of the rim joist. Although there is exterior mineral wool in this location, it does not sufficiently control the heat loss in this location. The VIP rim joist detail can be seen in Figure 5-8. This is the only assembly that experienced thermal bridging above $0.1>[\mathrm{W} / \mathrm{m} \cdot \mathrm{k}]$. In Figure 5-9, the rim joist of the mineral wool assembly is displayed. This is better performing than the VIP rim joist because there is $150 \mathrm{~mm}$ of exterior mineral wool on the exterior side.

It was the goal of all the assemblies to provide as much exterior insulation as possible in this location. However, due to limitations of the VIP assembly design, this was not possible. It should also be noted that each of the rim joists have a piece of EPS foam, $50 \mathrm{~mm}$ thick, installed in the joist cavity. This is again to limit the heat transfer in this location. Spray foam is an alternative option in this, but it was not used in these details. 
The following is an example of how the linear Psi $\Psi[\mathrm{W} / \mathrm{m} \cdot \mathrm{k}]$ values were calculated for the rim joist interfaces. This calculation is of the wall to roof interface for the vacuum insulated panel assembly. The equation is slightly adjusted because there is only one simplified component, the interior wall. The length of the wall is taken from the exterior wall, and the length of the interface is taken from the interior walls, ceiling and floor between the rim joist.

\section{THERM Model Value}

$$
\begin{aligned}
& \mathrm{U}=\mathrm{U} \text { value of Rim Joist Interface }\left[\mathrm{W} / \mathrm{m}^{2} \cdot \mathrm{k}\right] \\
& \mathrm{L}=\text { Length }[\mathrm{m}] \\
& \mathrm{T}=\text { Temperature }[\mathrm{k}]
\end{aligned}
$$

\section{Simplified Component A}

$$
\begin{aligned}
& \mathrm{U}_{\mathrm{a}}=\mathrm{U} \text { value of Wall }\left[\mathrm{W} / \mathrm{m}^{2} \cdot \mathrm{k}\right] \\
& \mathrm{L}_{\mathrm{a}}=\text { Length }[\mathrm{m}] \\
& \mathrm{T}_{\mathrm{a}}=\text { Temperature }[\mathrm{k}]
\end{aligned}
$$

$$
\begin{aligned}
\text { Linear Psi } \Psi[W / m \cdot k]= \\
=\left[(U \cdot L \cdot \Delta T)-\left(U_{a} \cdot L_{a} \cdot \Delta T_{a}\right)\right] / \Delta T \\
=[(0.791 \cdot 5.672 \cdot 38)-[(0.8476 \cdot 3.384 \cdot 38)] / 38 \\
=1.6183[\mathrm{~W} / \mathrm{m} \cdot \mathrm{k}]
\end{aligned}
$$


The linear thermal bridge of the vacuum insulated rim joist was calculated at $1.62[\mathrm{~W} / \mathrm{m} \cdot \mathrm{k}]$. The linear length of the rim joist around a house would be multiplied by this value, and the annual heating degree-days, to calculate the additional heat loss over one year at this thermal bridge location. The following is an example of how much heat loss can happen with this location in a climate with 4500 HDD and a rim joist of 50 linear meters:

Additional Heat Loss $=\boldsymbol{P s i} \cdot \boldsymbol{H D D} \cdot$ Linear Length

Additional Heat Loss $=1.6183[\mathrm{~W} / \mathrm{m} \cdot \mathrm{k}] \cdot 4500[\mathrm{k}] \cdot 50[\mathrm{~m}]$

Additional Heat Loss $=364118 \mathrm{~W}$ or $364 \mathrm{~kW}$ 


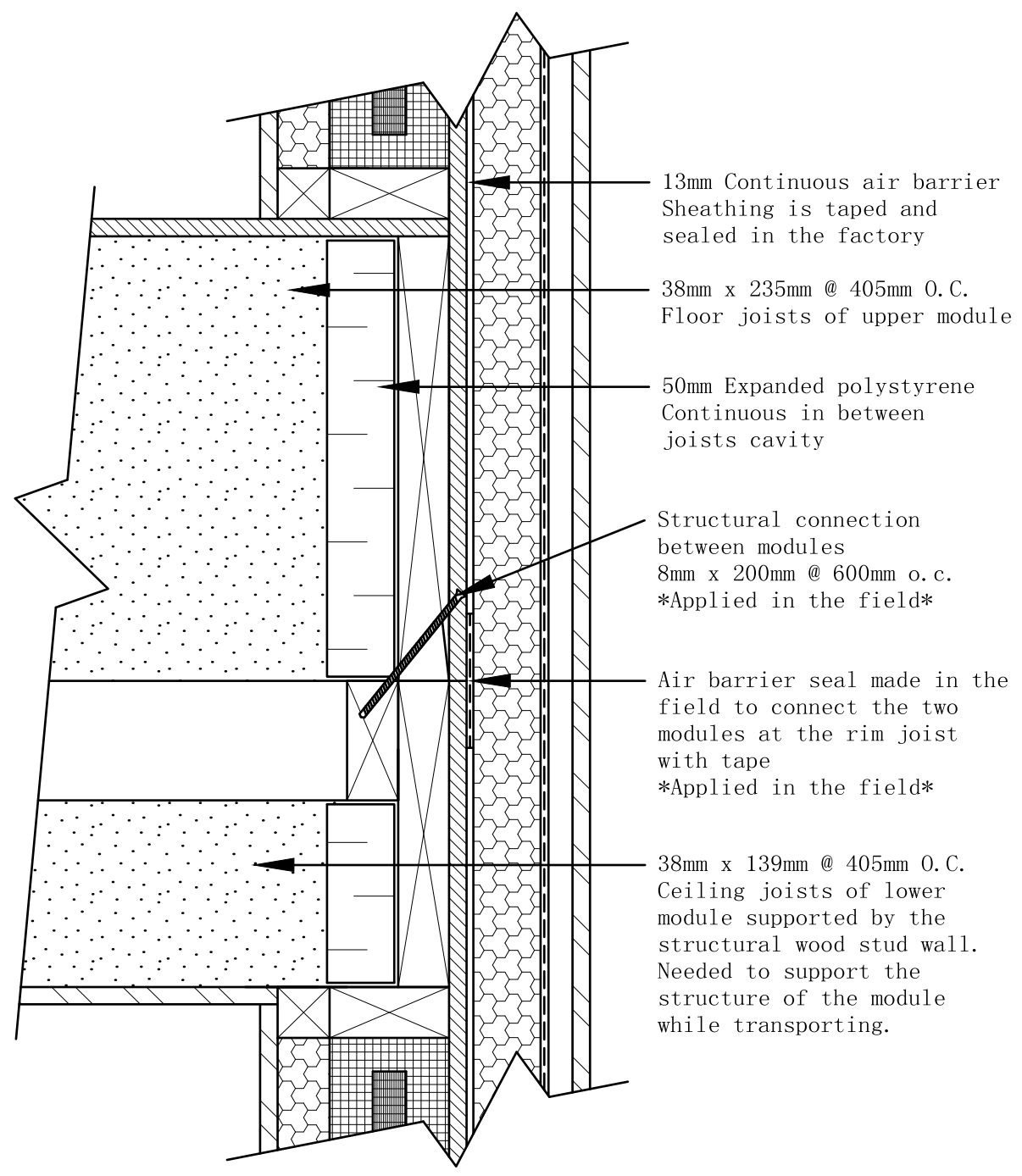

\section{VIP Assembly \\ Rim Joist Connection Scale 1:5}

Figure 5-8 Vacuum Insulated panel rim joist 


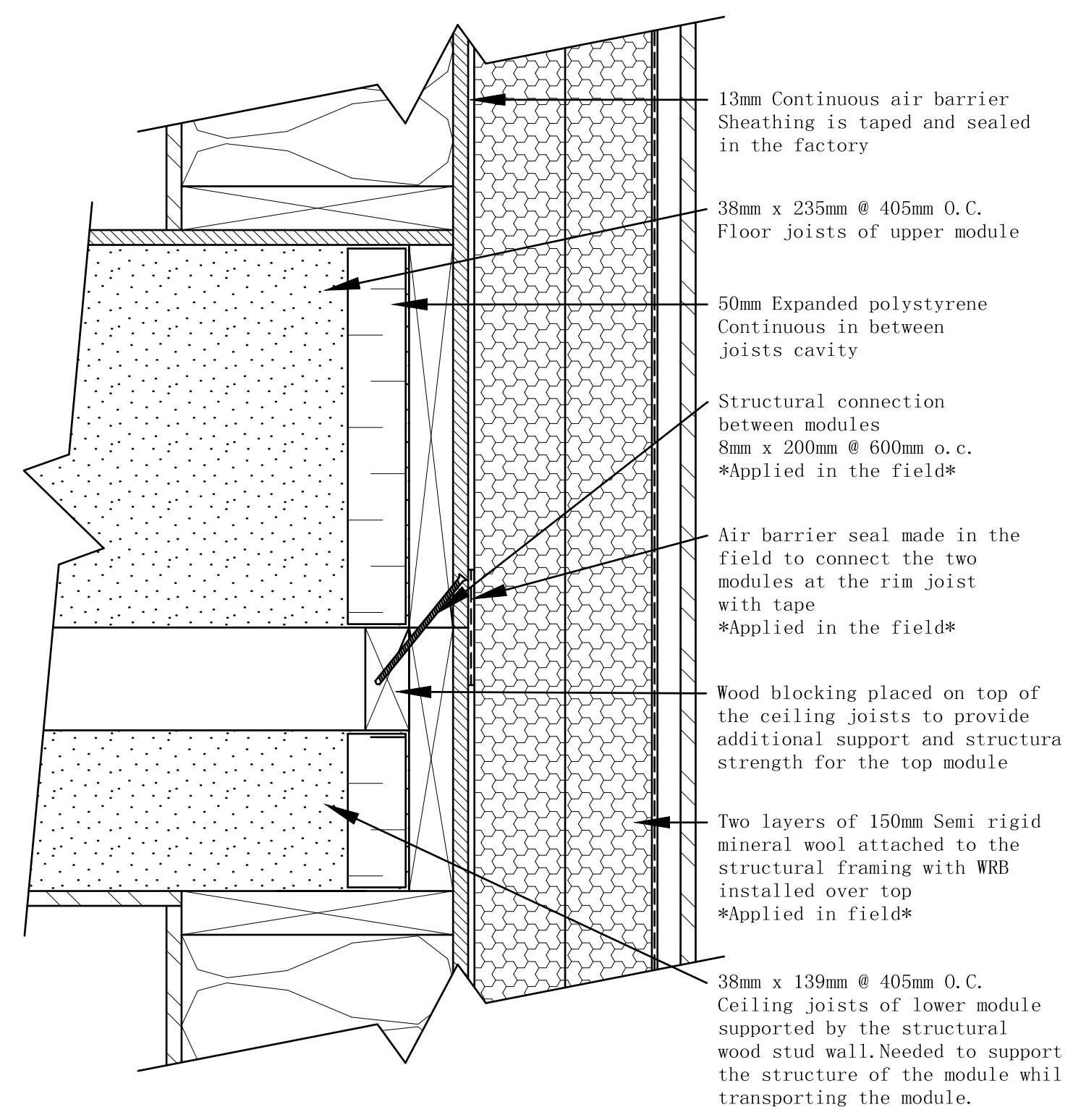

\section{Mineral Wool Assembly \\ Rim Joist Connection \\ Scale 1:5}

Figure 5-9 Mineral wool assembly rim Joist detail 
Table 5-4 displays the summarized results of the linear thermal bridging analysis of the various envelope systems. The rim joist of the VIP assembly experiences the worst performance because the greatest thermal resistance material is located within the framing, and not on the exterior side. Negative values mean that the heat loss is not as great as if each of the envelope components were to be calculated separately. It is not accurate to say that the lowest negative value is the best performing because it depends on the two envelope components that come together. The negative values are always relative to the two components used to calculate the linear thermal bridging. The red highlighted boxes show which connections were calculated as a thermal bridge.

Table 5-4 Summarized table of the linear thermal bridges for all four assemblies

\begin{tabular}{|c|c|c|c|}
\hline Envelope Type & $\begin{array}{c}\text { Eaves } \\
\text { Linear } \Psi[\mathbf{W} / \mathbf{m} \cdot \mathbf{k}]\end{array}$ & $\begin{array}{c}\text { Rim Joist } \\
\text { Linear } \Psi[\mathbf{W} / \mathbf{m} \cdot \mathbf{k}]\end{array}$ & $\begin{array}{c}\text { Foundation } \\
\text { Linear } \Psi[\mathbf{W} / \mathbf{m} \cdot \mathbf{k}]\end{array}$ \\
\hline Polyisocyanurate & -0.0218 & 0.0062 & -0.0518 \\
\hline Mineral Wool & -0.1021 & 0.0129 & -0.1447 \\
\hline Vertical I-Beam & -0.0787 & -0.2263 & -0.1901 \\
\hline VIP & -0.5854 & 1.6183 & -1.3454 \\
\hline
\end{tabular}




\section{Chapter 6 - Hygrothermal Performance Analysis}

\subsection{Overview}

Chapter research question:

How do the proposed envelope systems perform in terms hygrothermal performance?

a) Does the moisture content level of the OSB sheathing layer go above $16 \%$ and for how many hours do the interior and exterior surfaces of the OSB layer experience conditions with relative humidity above $80 \%$ and surface temperature above $5^{\circ} \mathrm{C}$ during one year?

WUFI ${ }^{\circledR}$ Pro 5.3 was used to assess the hygrothermal performance criteria of the various exterior walls [Kunzel, 2006]. The analysis methods were based on criteria and recommendations made by ASHRAE 160 with regards to moisture content limits for the structural sheathing layer and relative humidity levels of surfaces [ASHRAE, 2009ª]. The primary layer of focus was the structural OSB sheathing and used the following criteria.

- $\quad$ Moisture content of wood shall not exceed 16\%

- $\quad 30$-day running average surface $\mathrm{RH}>80 \%$ when the 30-day running average surface temperature is between $5^{\circ} \mathrm{C}$ and $40^{\circ} \mathrm{C}$.

- $\quad$ 7-day running average surface $\mathrm{RH}>98 \%$ when the 30 -day running average surface temperature is between $5^{\circ} \mathrm{C}$ and $40^{\circ} \mathrm{C}$.

- $\quad$ 24-hour running average surface $\mathrm{RH}>100 \%$ when the 24-hour running average surface temperature is between $5^{\circ} \mathrm{C}$ and $40^{\circ} \mathrm{C}$.

Based on these four performance criteria items, the moisture content of the middle of the OSB layer were calculated for each assembly and the the RH at the interior and exterior edges of the OSB were simulated.

An overview of the hygrothermal simulations are displayed in Table 6-1. There were two primary case sets modeled in WUFI ${ }^{\circledR}$, one using standard ASHRAE 160 moisture sources and $\mathrm{ACH}$ rates in the ventilated cavity, and the other was an intensified set of cases to test the limits 
of the assemblies. The difference between the two sets are variations in moisture sources and $\mathrm{ACH}$ rates in the ventilated cavity.

- Mid. SE: Middle of OSB with southeast orientation

- Mid. N: Middle of OSB with north orientation

- Ext. SE: Exterior edge of OSB with southeast orientation

- Ext. N: Exterior edge of OSB with north orientation

- Int. SE: Interior edge of OSB with southeast orientation

- Int. N: Interior edge of OSB with north orientation

Table 6-1 WUFI ${ }^{\circledR}$ simulation matrix

\begin{tabular}{|c|c|c|c|c|c|c|c|c|c|c|c|c|c|c|c|c|c|c|c|c|c|c|c|c|}
\hline \multirow{2}{*}{\begin{tabular}{|c}
$\begin{array}{c}\text { Interior RH } \\
\text { Level }\end{array}$ \\
$\begin{array}{c}\text { OSB \& } \\
\text { Orientation }\end{array}$
\end{tabular}} & \multicolumn{6}{|c|}{ Low } & \multicolumn{6}{|c|}{ Medium } & \multicolumn{6}{|c|}{ High } & \multicolumn{6}{|c|}{ Extreme } \\
\hline & \begin{tabular}{l|l} 
Mid. \\
SE
\end{tabular} & $\begin{array}{ll}\text { Mid. } \\
\text { N }\end{array}$ & \begin{tabular}{l|l} 
Ext. \\
SE
\end{tabular} & :xt. $\begin{array}{ll}\text { int } \\
\text { SE }\end{array}$ & \begin{tabular}{l|l} 
nt. \\
EE
\end{tabular} & \begin{tabular}{l|l} 
nt. \\
$\mathrm{v}$.
\end{tabular} & $\begin{array}{c}\text { Mid. } \\
\text { SEE }\end{array}$ & \begin{tabular}{c|l} 
Mid. & E \\
$\mathbf{N}$
\end{tabular} & \begin{tabular}{l|l} 
Ext. & Ex \\
SE & $N$
\end{tabular} & :xt. $\begin{array}{l}\text { Int } \\
\text { SE }\end{array}$ & \begin{tabular}{l|l} 
nt. & In \\
EE & $N$
\end{tabular} & nt. & $\begin{array}{l}\text { Mid. } \\
\text { SE }\end{array}$ & Mid. & \begin{tabular}{l|l} 
Ext. & E \\
SE & N
\end{tabular} & \begin{tabular}{l|l} 
Ext. & In \\
$N$ & s
\end{tabular} & $\begin{array}{l}\text { Int. } \\
\text { sE }\end{array}$ & Int. & \begin{tabular}{|l|l} 
Mid. \\
SEE
\end{tabular} & $\begin{array}{l}\text { Mid. } \\
\text { N }\end{array}$ & \begin{tabular}{l|l} 
Ext. & E \\
SE & N
\end{tabular} & \begin{tabular}{l|l} 
Ext. & In \\
N & \\
$s$
\end{tabular} & $\begin{array}{l}\text { Int. } \\
\text { SE }\end{array}$ & Int. \\
\hline $\begin{array}{l}\text { Polyisocyanurate } \\
\text { ASHRAE } 160\end{array}$ & & & & & & & & & & & & & & & & & & & & & & & & \\
\hline $\begin{array}{l}\text { Polyisocyanurate } \\
\text { Intensified }\end{array}$ & & & & & & & & & & & & & & & & & & & & & & & & \\
\hline $\begin{array}{l}\text { Mineral Wool } \\
\text { ASHRAE } 160\end{array}$ & & & & & & & & & & & & & & & & & & & & & & & & \\
\hline $\begin{array}{c}\text { Mineral Wool } \\
\text { Intensified }\end{array}$ & & & & & & & & & & & & & & & & & & & & & & & & \\
\hline $\begin{array}{l}\text { Vertical I-beam } \\
\text { ASHRAE } 160\end{array}$ & & & & & & & & & & & & & & & & & & & & & & & & \\
\hline $\begin{array}{l}\text { Vertical I-beam } \\
\text { Intensified }\end{array}$ & & & & & & & & & & & & & & & & & & & & & & & & \\
\hline $\begin{array}{c}\text { VIP } \\
\text { ASHRAE } 160\end{array}$ & & & & & & & & & & & & & & & & & & & & & & & & \\
\hline $\begin{array}{c}\text { VIP } \\
\text { Intensified }\end{array}$ & & & & & & & & & & & & & & & & & & & & & & & & \\
\hline
\end{tabular}




\subsection{Model Inputs}

\section{Material Properties}

All of the materials entered into the model were taken from the WUFI ${ }^{\circledR}$ material database except for one, the vacuum insulated panel. There is no VIP material in the database, a new material was development in the software. Permeance values can vary greatly for VIPs depending on the manufacturer, coating, core pressure and age of the panel. Metallic foil that coats the VIP core is very impermeable to moisture vapour [Garnier et al., 2011] and is equivalent to a polyethylene sheet. The vacuum insulated panel conductivity values were entered manually with a conductivity of $0.005[\mathrm{~W} / \mathrm{m} \bullet \mathrm{k}]$ based on previous research [Mukhopadhyaya et al., 2011]. The OSB sheathing with a factory applied weather resistance membrane was modeled as a layer of oriented strand board with a layer of spun bonded polyolefin on the exterior side.

\section{Moisture \& Air Sources}

The standard case used a $1 \%$ of driving rain simulated in $5 \mathrm{~mm}$ the air cavity and is used as a typical moisture source behind the cladding [ASHRAE, 2009a]. The exterior rain screen cavity was simulated with $200 \mathrm{ACH}$ in the $10 \mathrm{~mm}$ air cavity. Since the envelope is designed with a ventilated air cavity at the top and bottom, this is a realistic ACH value [Salonvarra et al., 2007]. In the intensified case set, $3 \%$ of driving rain was simulated in $5 \mathrm{~mm}$ the air cavity. The exterior rain screen cavity was simulated with $3 \mathrm{ACH}$ in the $10 \mathrm{~mm}$ air cavity. In addition, a $1 \%$ driving rain moisture source was placed in the outer $25 \mathrm{~mm}$ of the exterior insulation. These values are shown in Table 6-2. 
Table 6-2 WUFI ${ }^{\circledR}$ case sets

\begin{tabular}{|c|l|l|}
\hline & \multicolumn{1}{|c|}{ Moisture Source } & \multicolumn{1}{c|}{ ACH in air cavity } \\
\hline Standard Case & $\begin{array}{l}-1 \% \text { of driving rain within the air } \\
\text { cavity }\end{array}$ & $\begin{array}{l}-200 \text { air changes within the air } \\
\text { cavity }\end{array}$ \\
\hline \multirow{3}{*}{ Intensified Case } & $\begin{array}{l}-3 \% \text { of driving rain within the air } \\
\text { cavity } \\
-1 \% \text { of driving rain in outer } \\
\text { cavity } \\
25 \mathrm{~mm} \text { of exterior insulation }\end{array}$ & \\
\hline
\end{tabular}

\section{Exterior Boundary Conditions}

Exterior conditions were taken from WUFI ${ }^{\circledR}$ climate data for a cold winter weather file in Toronto. This is because the coldest year will have the greatest vapour drive to the exterior and the exterior surfaces temperatures are the lowest, and the most prone to condensation. The orientation used in the case studies was to the southeast direction to simulate the hardest driving rains, and to the north to simulate the lack of sun hitting the exterior. The southeast orientation was used because all of the moisture sources are directly related to the driving rain amount, and the model attempted to simulate the worst-case scenario. The north orientation was used to assess how the assembly performs with reduced drying from solar radiation.

\section{Interior Boundary Conditions}

The relative humidity was simulated at four levels: low, medium, high and extreme. They are displayed in Figure 6-1 below. Extreme and high RH levels are not likely to happen in homes with dehumidification and/or air conditioning systems, but were used to test the upper limits of the drying potential for the assemblies [ASHRAE, 2009ª]. Interior temperature was assigned a maximum value of $22^{\circ} \mathrm{C}$ during the summertime and a minimum value of $20^{\circ} \mathrm{C}$ during the winter months. 


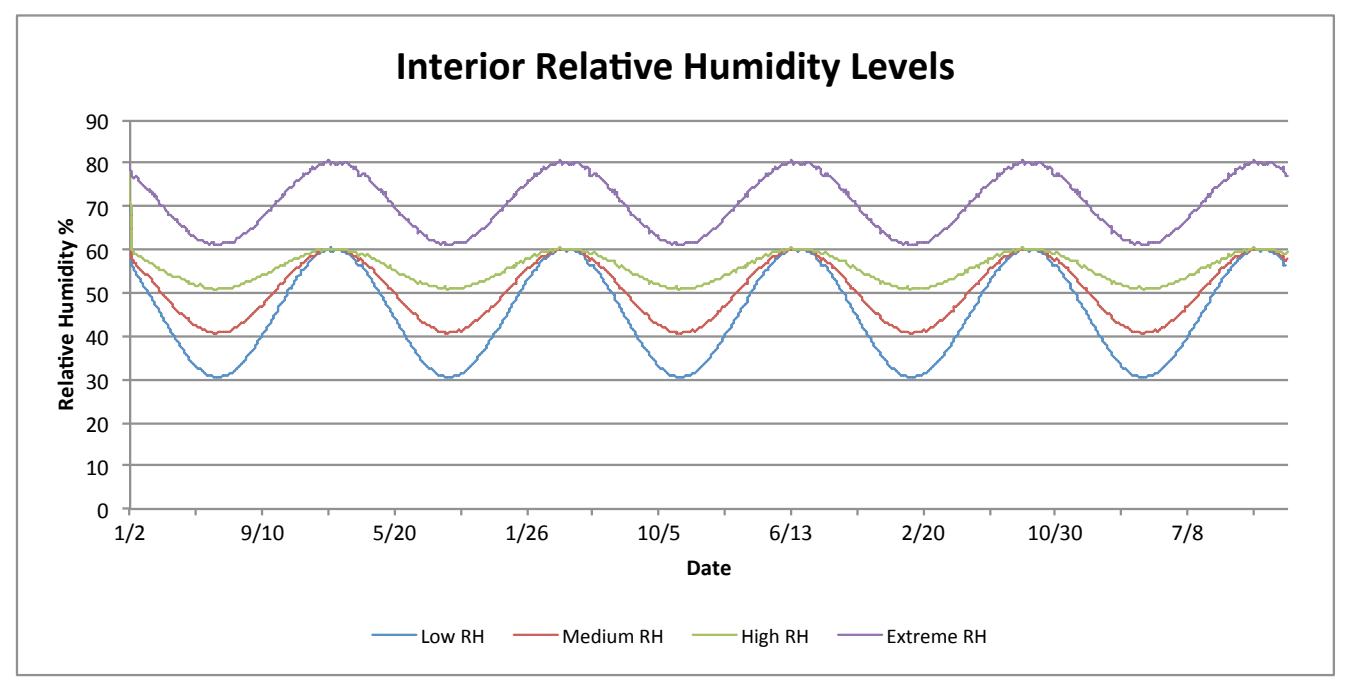

Figure 6-1 Interior relative humidity testing values

\subsection{Results from WUFI ${ }^{\circledR}$ Cases}

The WUFI ${ }^{\circledR}$ results are discussed and analyzed in the following portion of the research. Each assembly is represented with the following outputs from the hygrothermal simulations. The simulated moisture content of the OSB layers are shown in graphs for each assembly. The graphs that show the RH levels of the interior and exterior edges of the OSB layer are in Appendix F, G, $\mathrm{H}$ and I. Interesting graphs from the RH simulations are brought forward for discussion. The final summarized results are displayed at the end of the section in Table 6-3. The graphs are displayed with dates, and each interval is 5000 hours on the $\mathrm{X}$-axis.

\section{Exterior Polyisocyanurate}

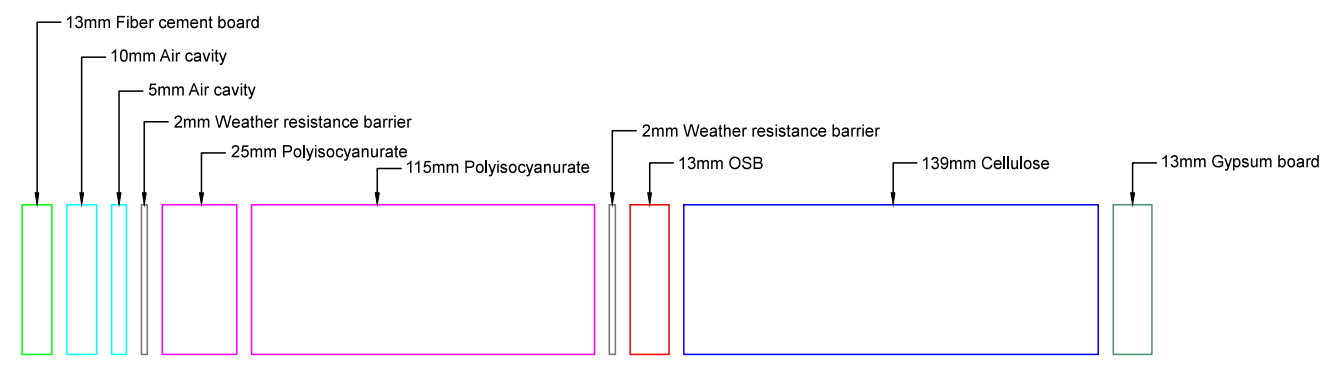

Figure 6-2 WUFI ${ }^{\circledR}$ material layers for polyisocyanurate assembly 
Figure 6-2 shows the material layers for the polyisocyanurate assembly simulation. For the standard case, the $1 \%$ driving rain is located in the exterior $5 \mathrm{~mm}$ air cavity and $\mathrm{ACH} 200$ is located in the $10 \mathrm{~mm}$ air cavity For the intensified case, the $3 \%$ driving rain is located in the exterior $5 \mathrm{~mm}$ air cavity, a $1 \%$ driving rain is located in the outer $25 \mathrm{~mm}$ of insulation and $\mathrm{ACH} 3$ is located in the $10 \mathrm{~mm}$ air cavity. This is the same for all of the remaining simulations.

Figures 6-3 and 6-4 show the moisture content of the structural sheathing layer with southeast and north orientations for the standard case. Figures 6-5 and 6-6 show the moisture content of the structural sheathing layer with southeast and north orientations for the intensified case.

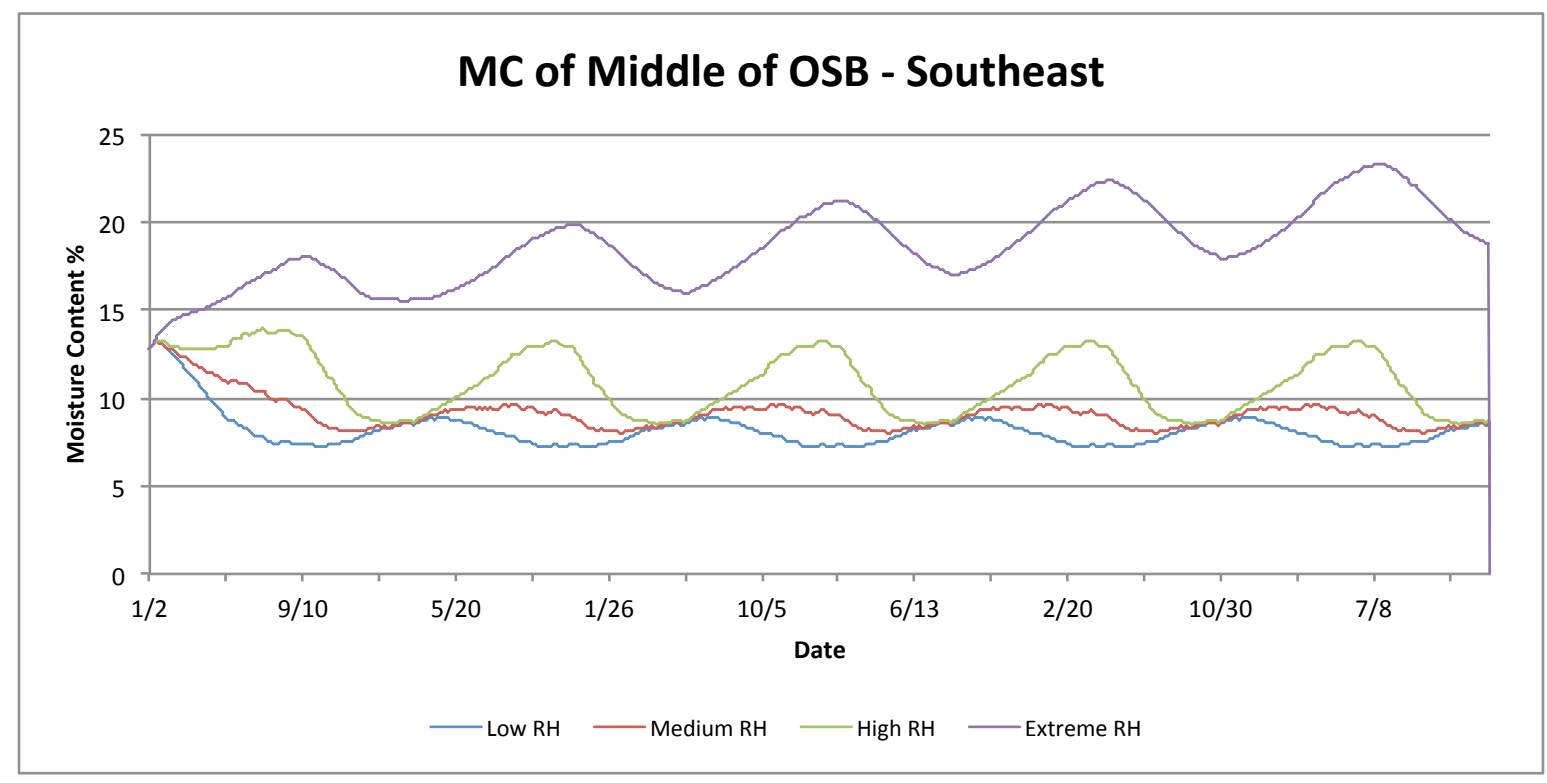

Figure 6-3 MC of middle of OSB layer for polyisocyanurate assembly - Standard Case 


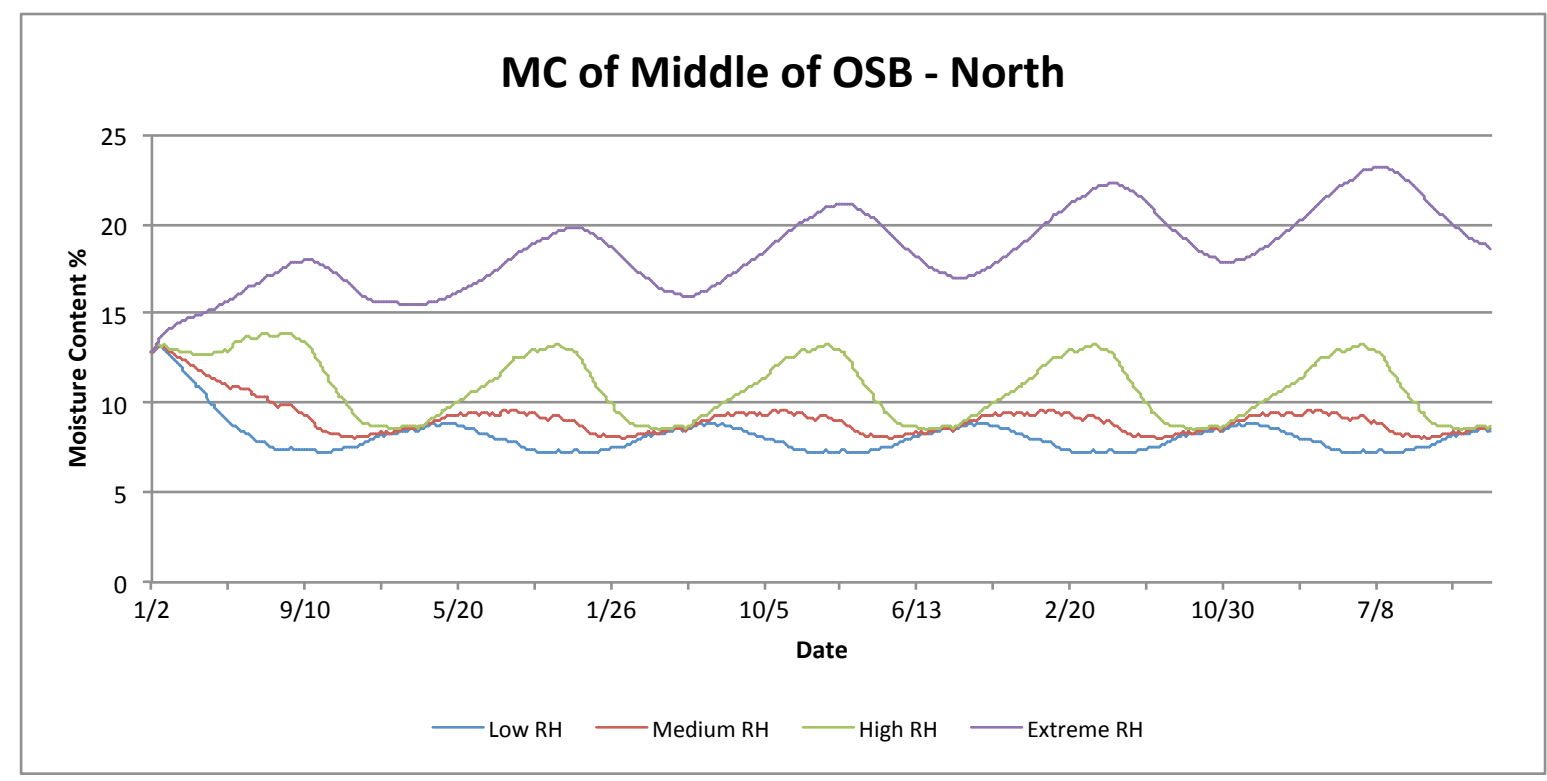

Figure 6-4 MC of middle of OSB layer for polyisocyanurate assembly - Standard Case

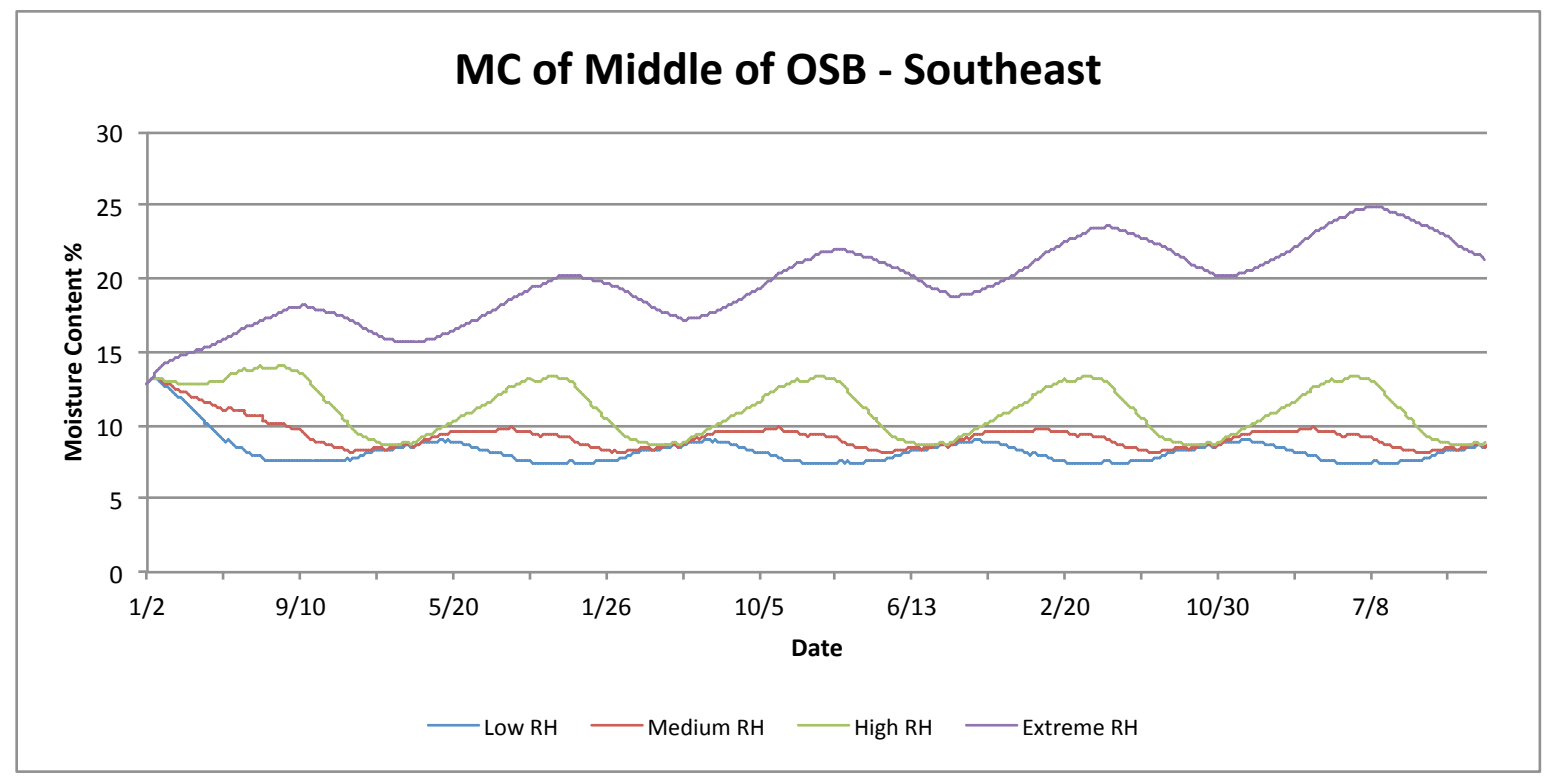

Figure 6-5 MC of middle of OSB layer for polyisocyanurate assembly - Intensified Case 


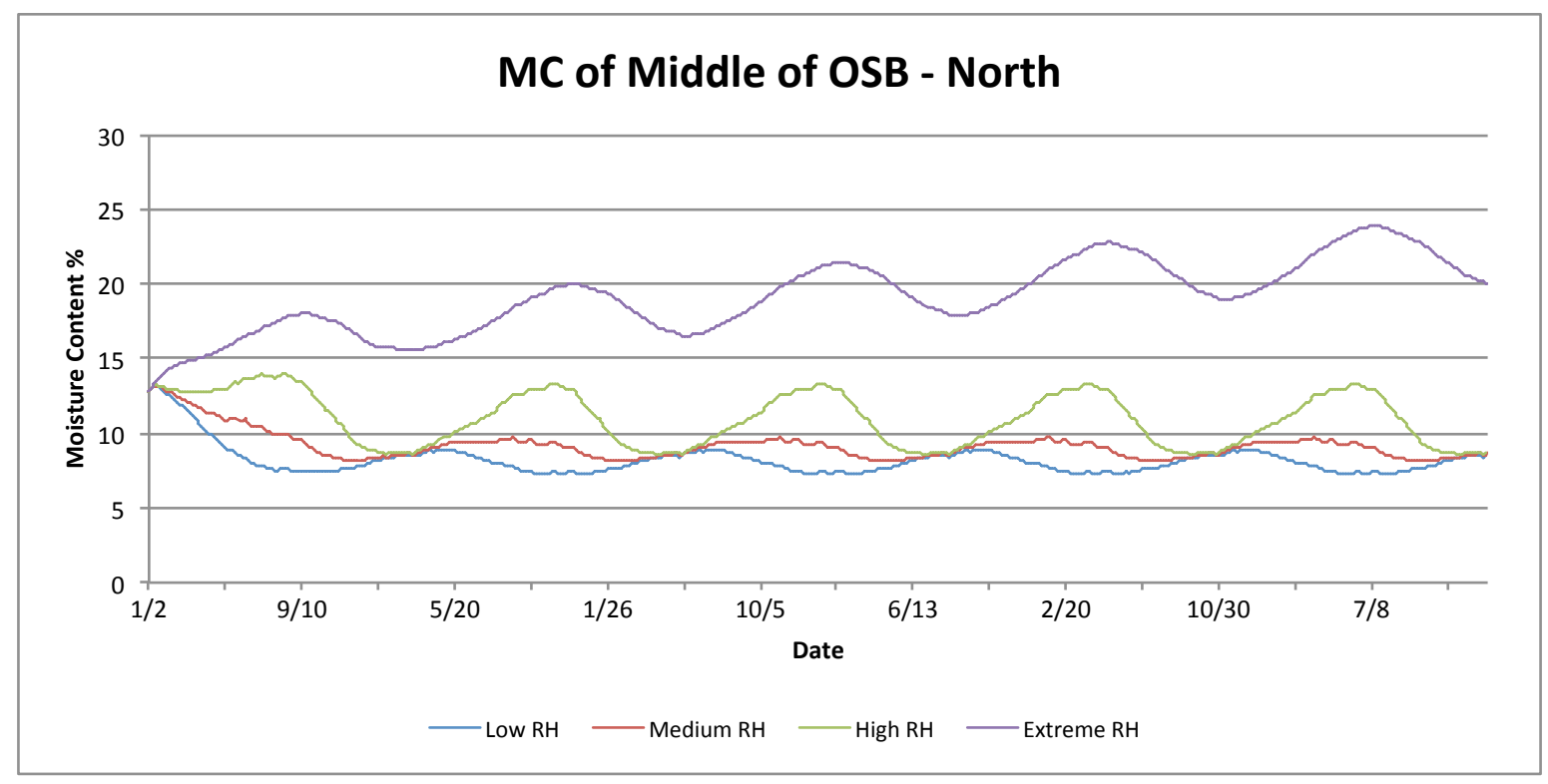

Figure 6-6 MC of middle of OSB layer for polyisocyanurate assembly - Intensified Case

All four levels of interior RH are represented in the graphs. Only the extreme interior RH resulted in sheathing $\mathrm{MC}$ levels above 16\%. Low, medium and high interior RH levels results in below 16\% MC levels for both the southeast and north orientations, and both standard and intensified cases.

In this assembly, the polyisocyanurate insulation is the least permeable material and is located on the exterior side of the OSB. Therefore, there is more capacity for the OSB to dry towards the interior than the exterior. However, when the interior air's moisture content is high, there is less ability for the OSB layer to dry to the interior. That is why the MC peaks in the summertime when the interior $\mathrm{RH}$ is set high, whereas the MC of the OSB with low interior RH peaks in the wintertime. When the winter vapour drive is to the exterior, and the interior RH is set low, there is not a lot of moisture driven into the assembly. In contrast, when the interior $\mathrm{RH}$ is set high, more moisture is driven into the wall and cannot travel past the OSB layer because of the exterior polyisocyanurate. This creates a build up of moisture in the OSB layer, until the vapour drive reverses towards the interior during the summertime and is able to dry towards the interior. 
Figure 6-7 and 6-8 show the RH levels of the interior edge of the OSB sheathing layer with the standard and the intensified cases.

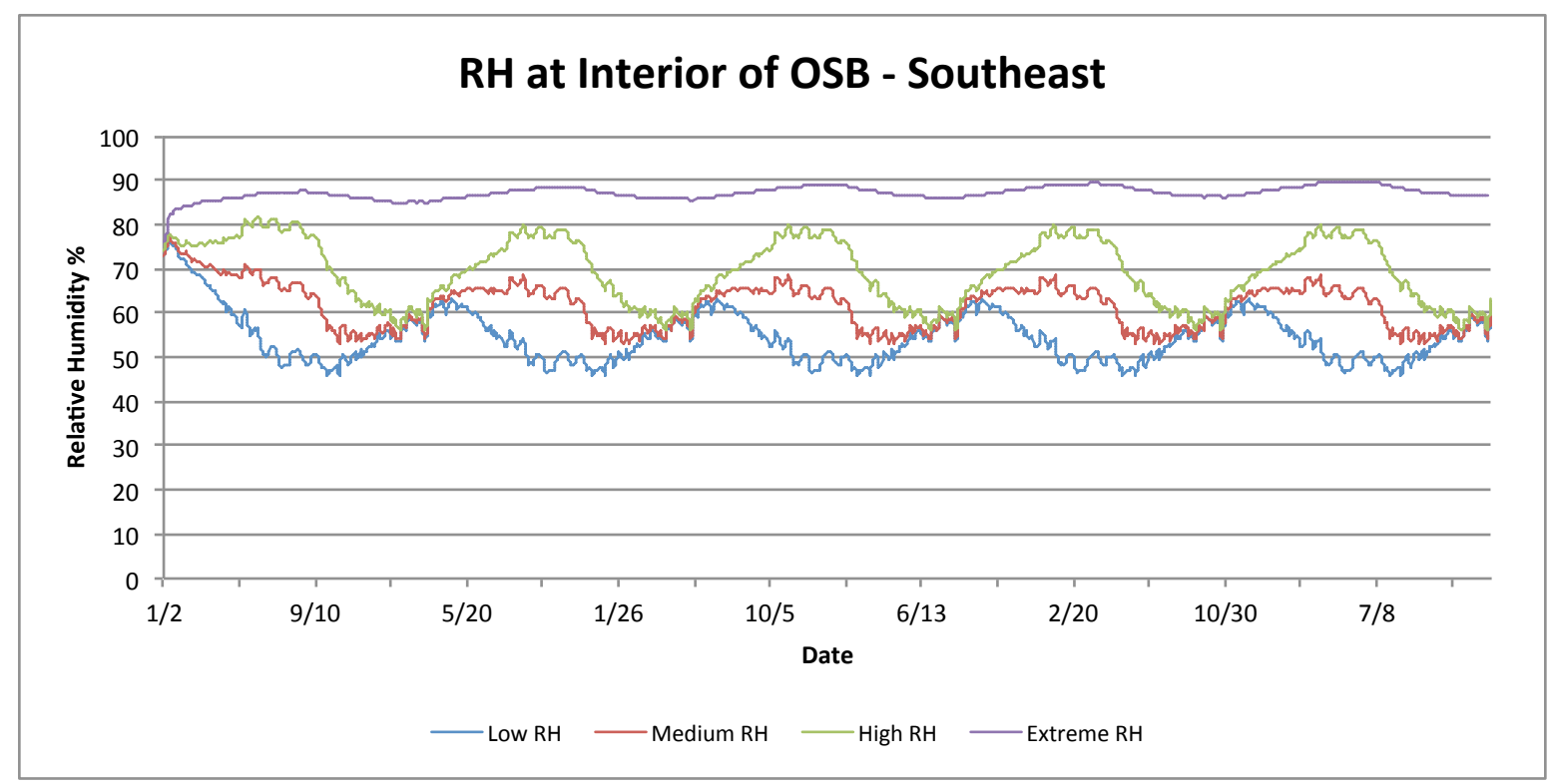

Figure 6-7 RH of interior OSB edge of polyisocyanurate assembly - Standard Case

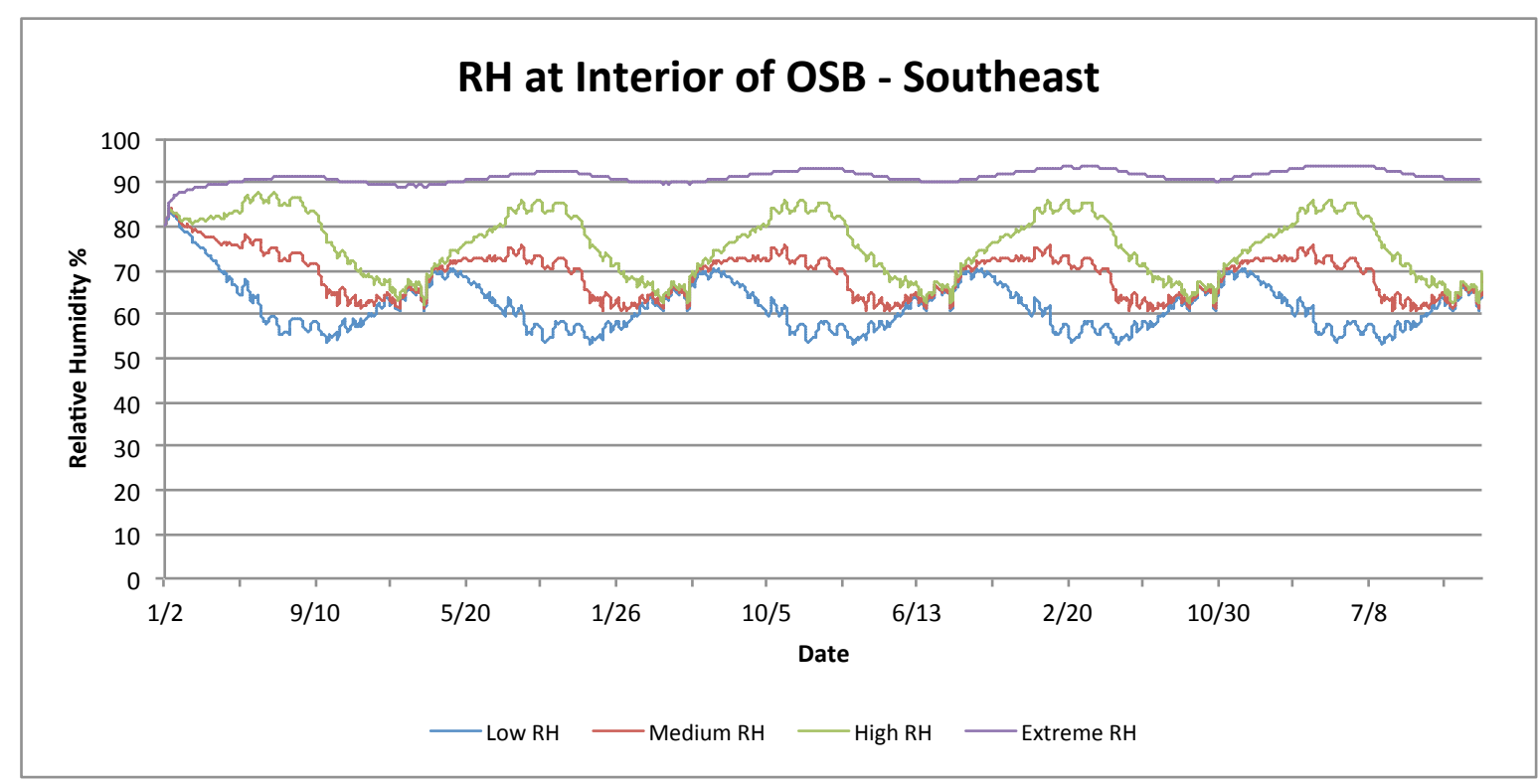

Figure 6-8 RH of interior OSB edge of polyisocyanurate assembly - Intensified Case

The RH levels of the interior edge of the OSB sheathing are consistently above $80 \%$ when extreme interior RH is used in the simulation. High interior RH experiences a brief period 
above $80 \% \mathrm{RH}$ in the first year, but then is below that level for the remainder of the simulation. When high interior RH was used in the intensified case, $\mathrm{RH}$ above $80 \%$ was also experienced for periods during the simulation. Low and medium interior $\mathrm{RH}$ levels displayed below $80 \% \mathrm{RH}$ levels of the interior edge of the OSB layer for the low and medium interior RH levels. The remaining graphs for the polyisocyanurate assembly are in Appendix F.

\section{Exterior Mineral Wool}

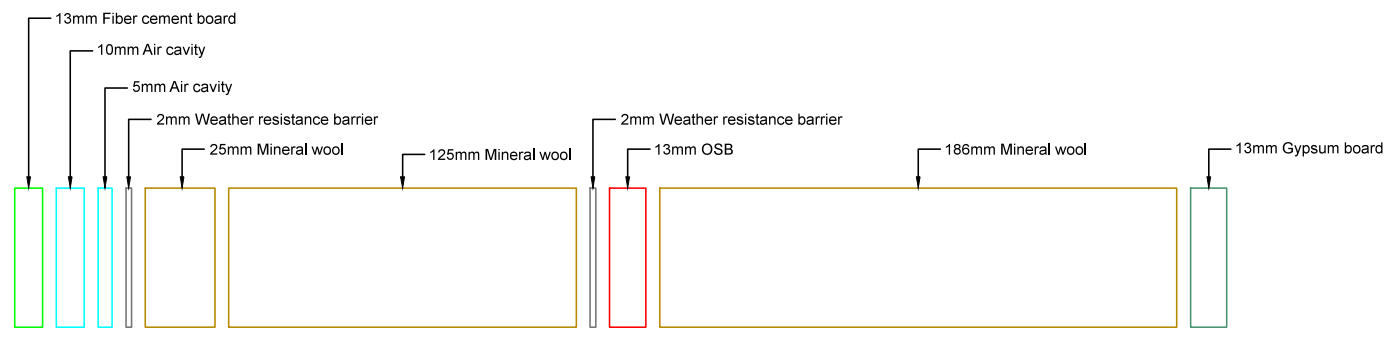

Figure 6-9 WUFI ${ }^{\circledR}$ material layers for mineral wool assembly

Figure 6-9 shows the material layers for the mineral wool assembly simulation. Figures 6-10 and 6-11 display the moisture content of the structural sheathing layer with southeast and north orientations with the standard case, and Figures 6-12 and 6-13 for the intensified case. 


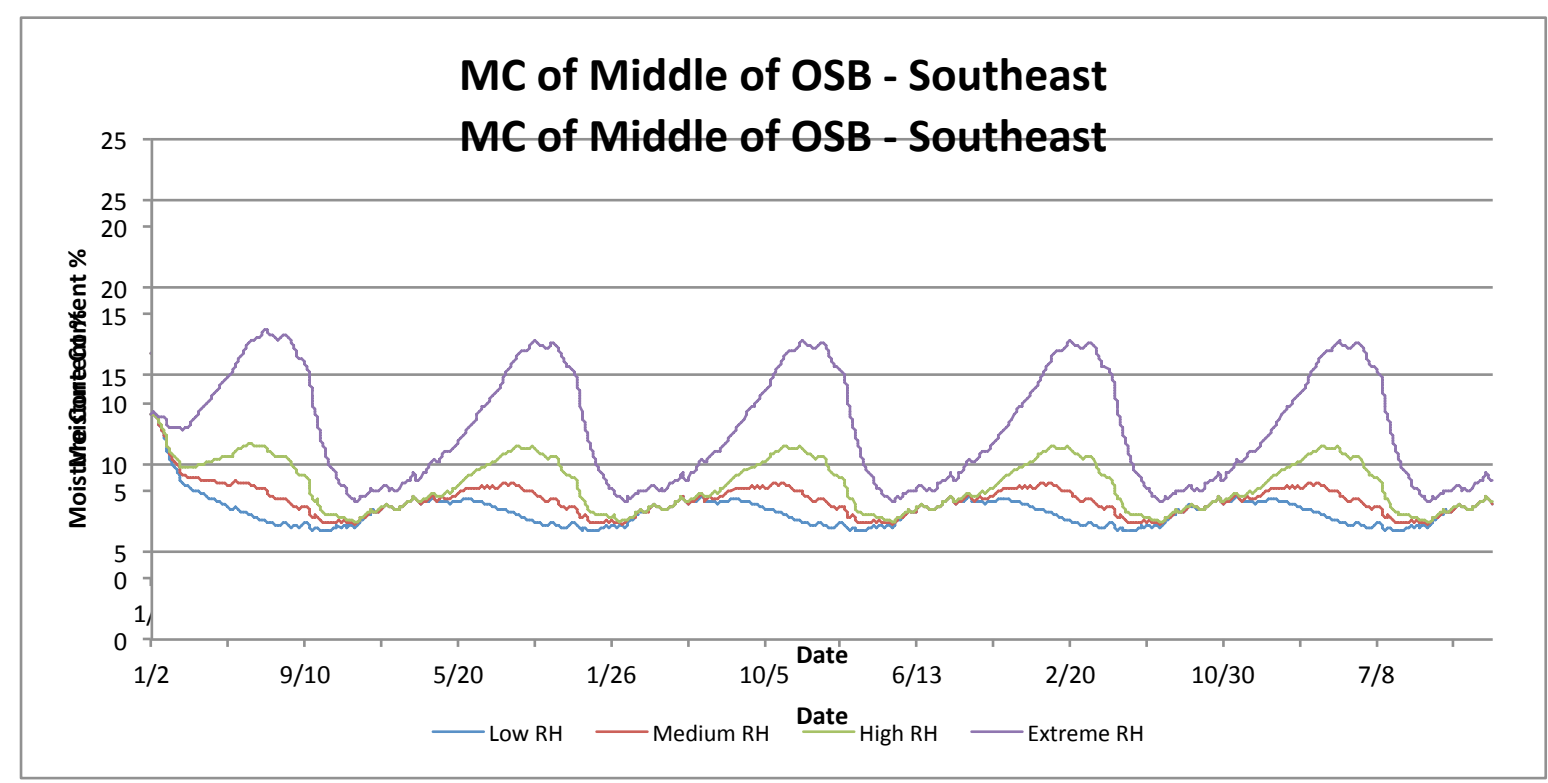

Figure 6-10 MC of middle of OSB layer for mineral wool assembly - Standard Case

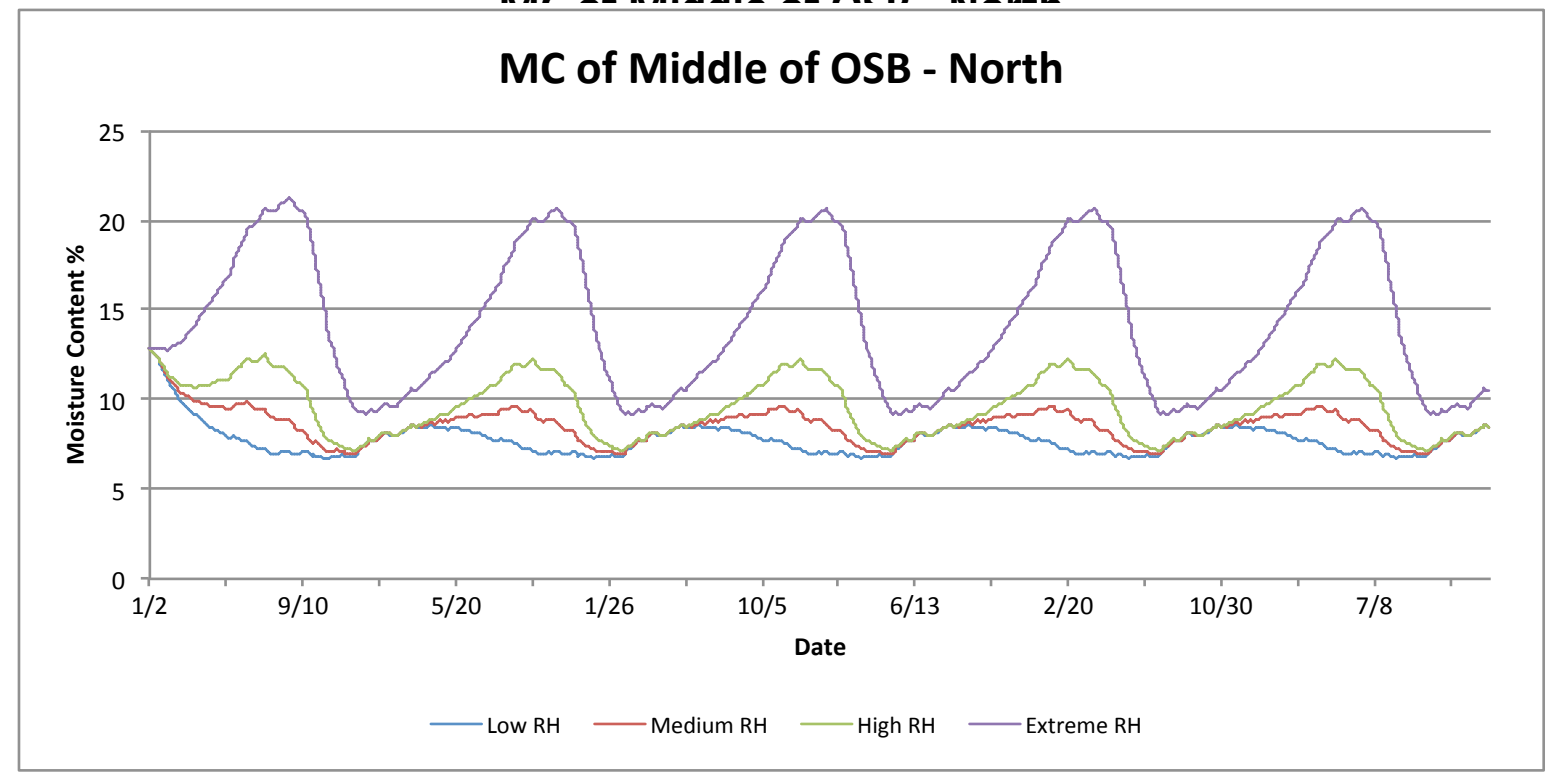

Figure 6-11 MC of middle of OSB layer for mineral wool assembly - Standard Case 


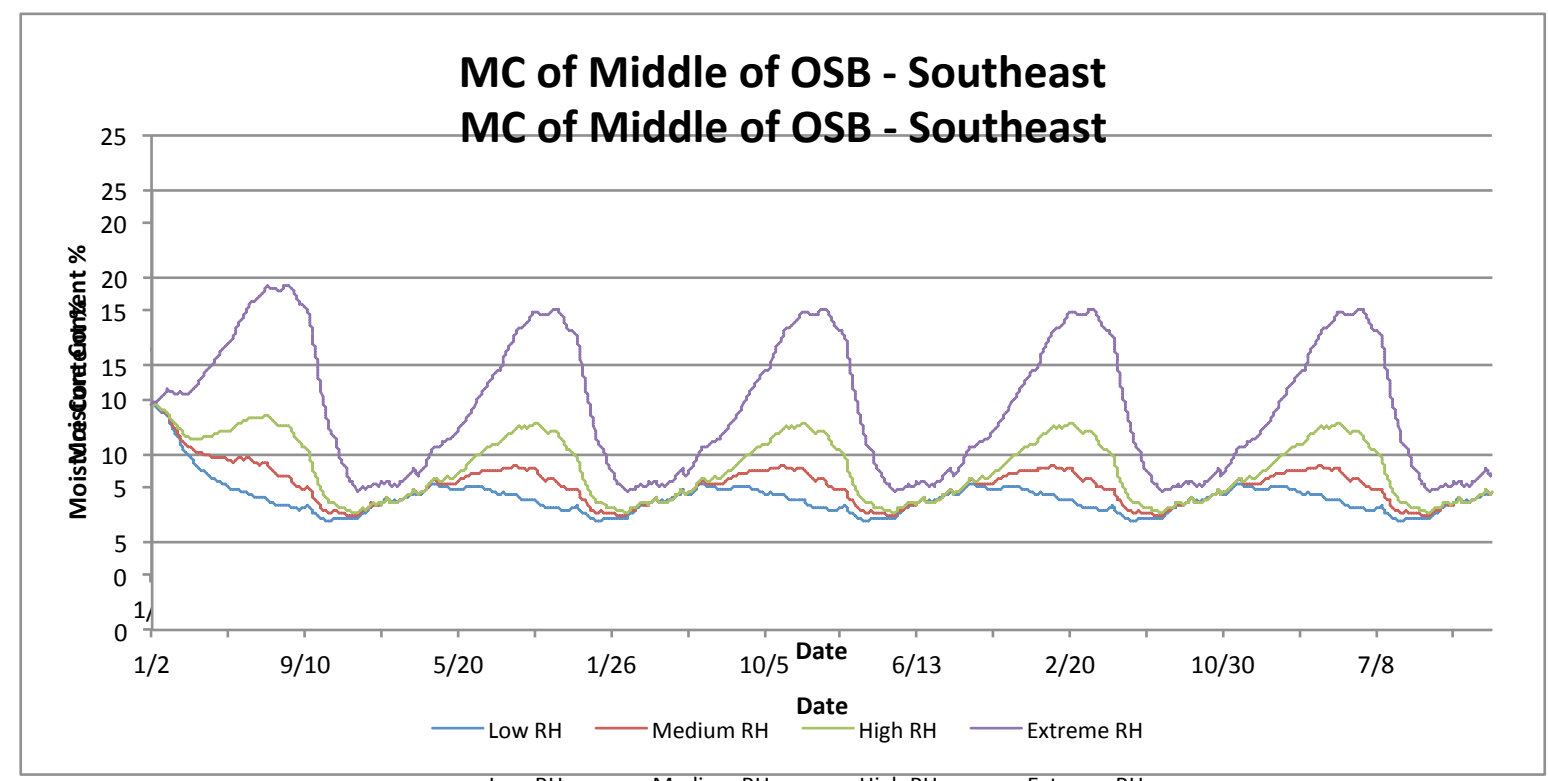

Figure 6-12 MC of middle of OSB layer for mineral wool assembly - Intensified Case

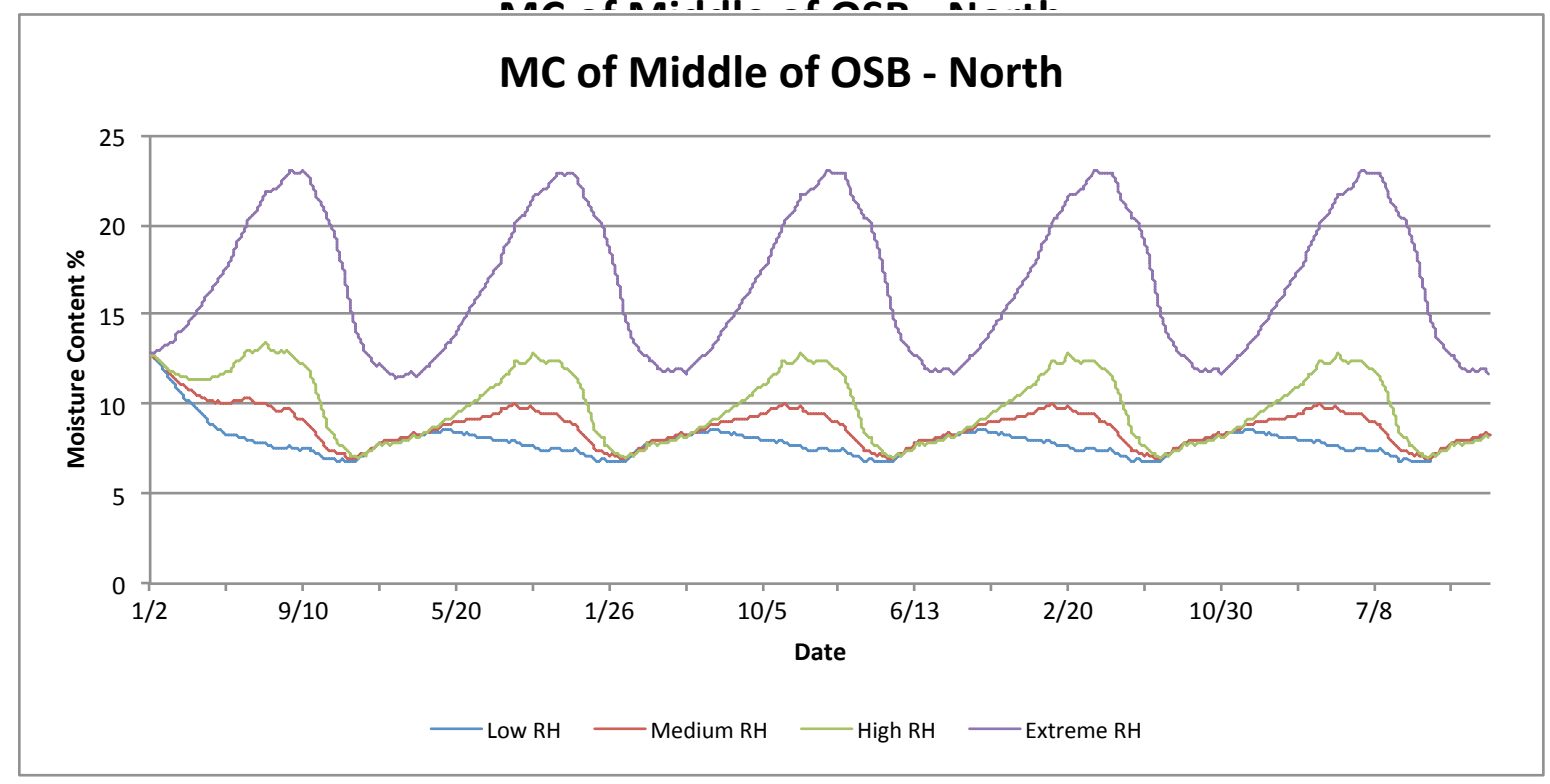

Figure 6-13 MC of middle of OSB layer for mineral wool assembly - Intensified Case

The structural OSB sheathing layer within the mineral wool assembly showed consistent moisture content levels below 16\% when the interior RH levels were set at low, medium and high for both the standard and intensified cases. When extreme interior RH levels were 
simulated, the MC of the middle of the OSB layer exceeded $16 \%$ for both the southeast and north orientations in both cases.

In the mineral wool assembly, the OSB layer is the least vapour permeable material. Unlike the polyisocyanurate assembly, the mineral wool layer applied on the exterior side of the OSB allows for the assembly to dry towards the exterior. This is the primary reason why the MC levels of the OSB layer are below that of the polyisocyanurate assembly for high levels of interior RH.

Figure 6-14 show the RH levels of the interior edge of the OSB sheathing layer with southeast orientation for the intensified case.

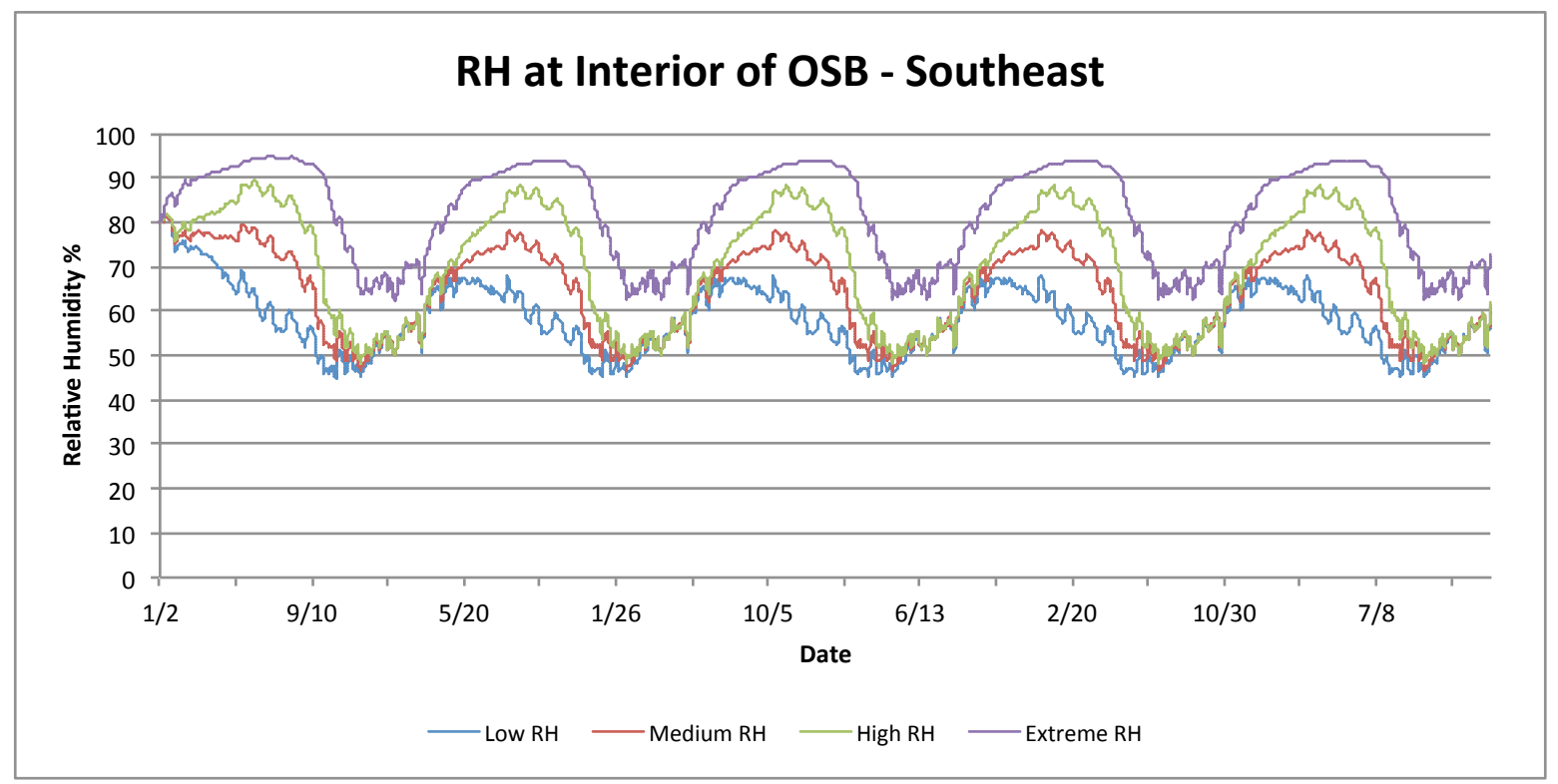

Figure 6-14 RH of interior OSB edge of mineral wool assembly - Intensified Case

The RH levels of the interior edge of the OSB sheathing with southeast orientation do exceed $80 \%$ when extreme and high interior RH were used in the simulation. This was the same for the north orientation. However, with the standard case, the RH levels were below $80 \%$ during periods of above $5^{\circ} \mathrm{C}$, except for when the interior $\mathrm{RH}$ was set to extreme levels. The rest of the RH graphs are displayed in Appendix G and the results are summarized in Table 6-3. 


\section{Vertical I-Beam}

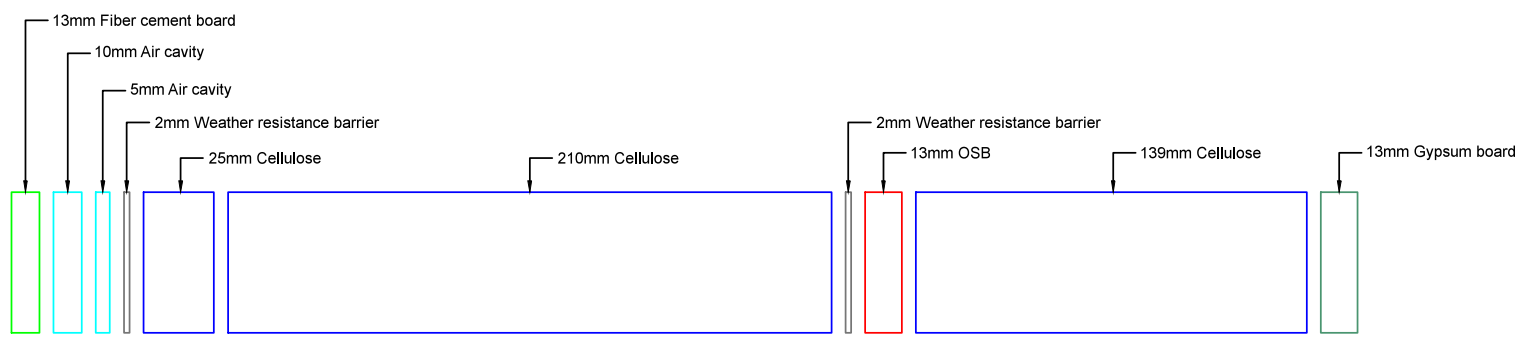

Figure 6-15 WUFI ${ }^{\circledR}$ material layers for vertical I-beam assembly

Figure 6-15 shows the material layers for the vertical I-beam assembly simulation. Figures 6-16 and 6-17 represent the moisture content of the structural sheathing layer with southeast and north orientations for the standard case, and Figures 6-18 and 6-19 for the intensified case.

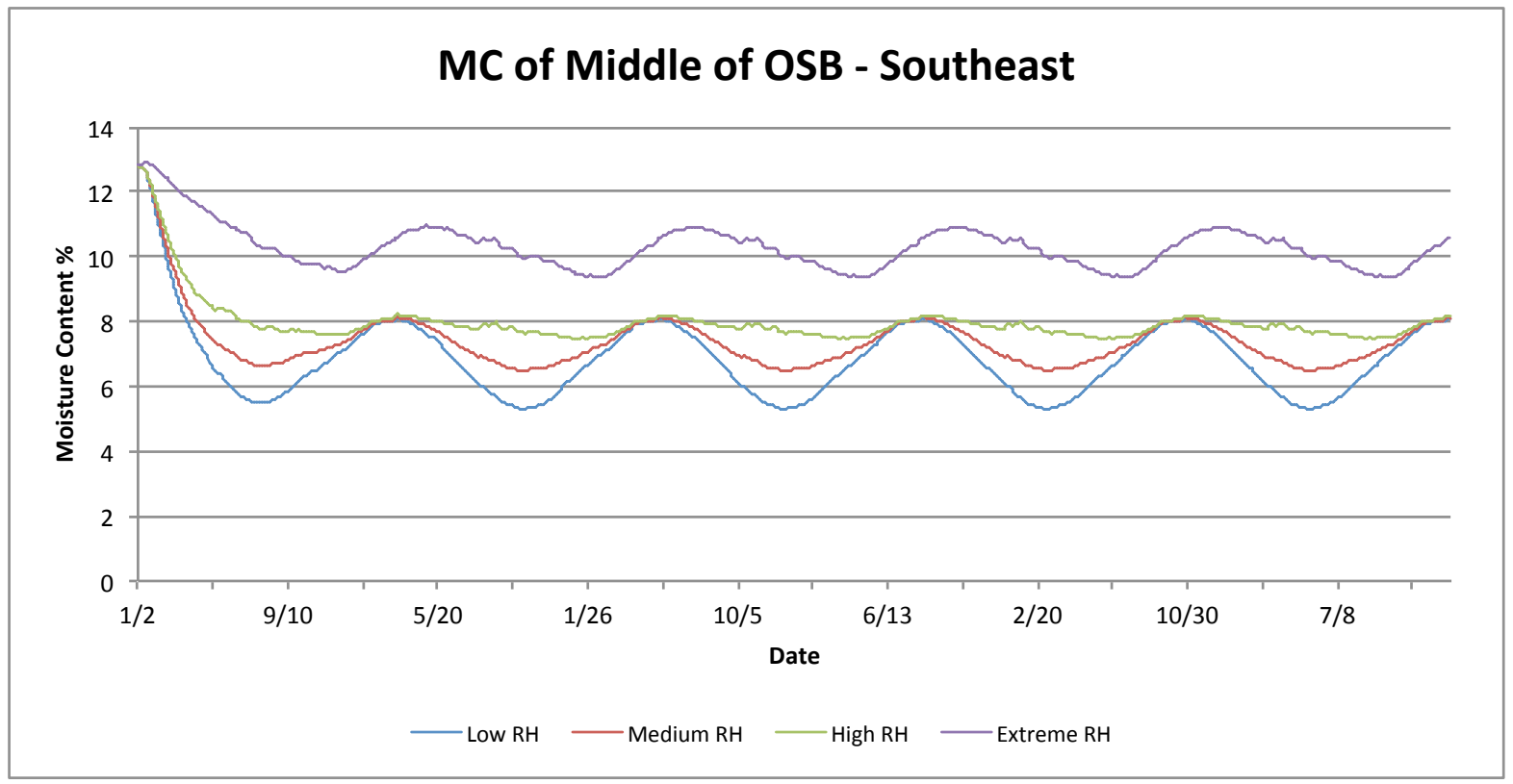

Figure 6-16 MC of middle of OSB layer for vertical I-beam assembly - Standard Case 


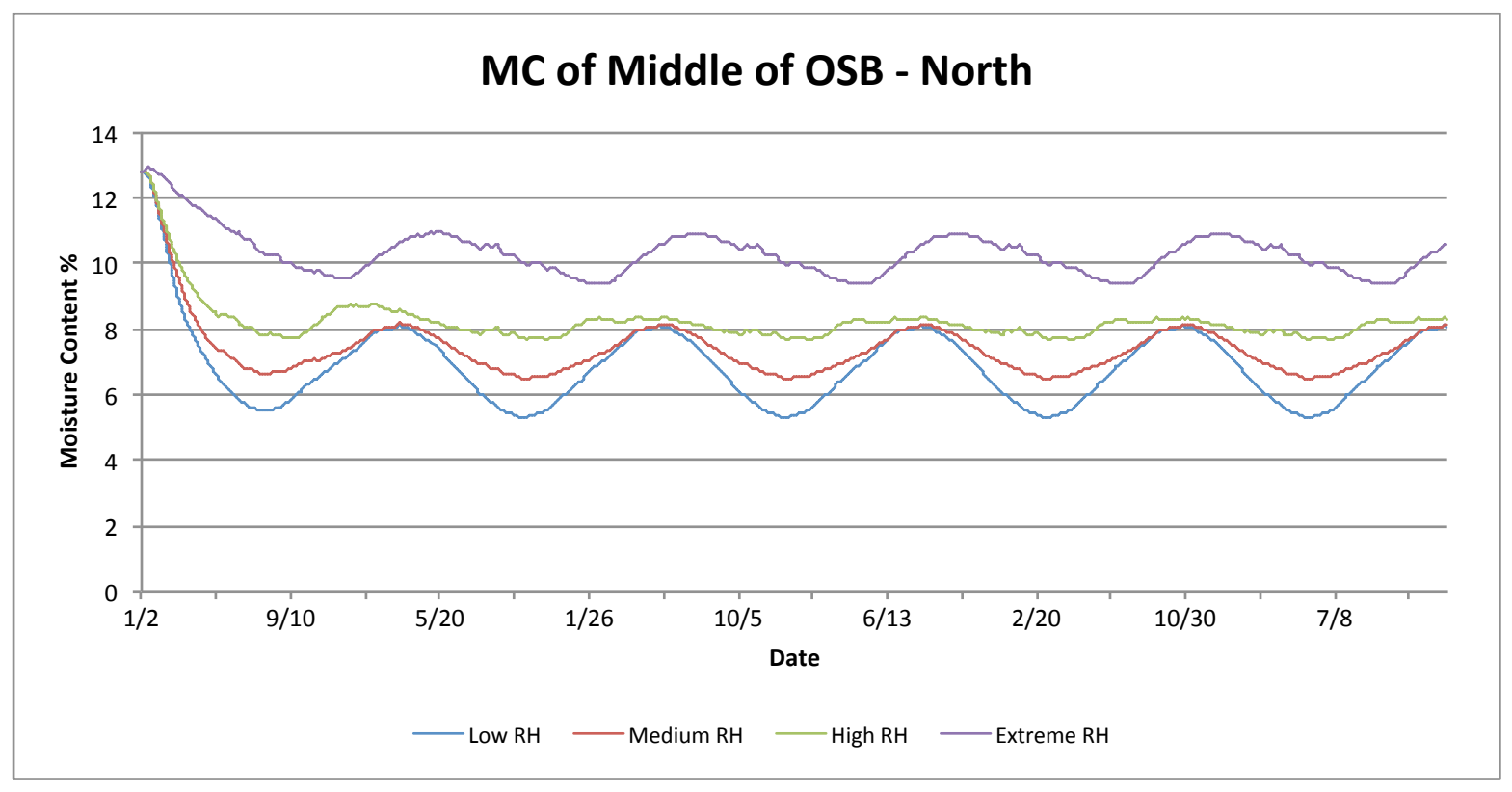

Figure 6-17 MC of middle of OSB layer for vertical I-beam assembly - Standard Case

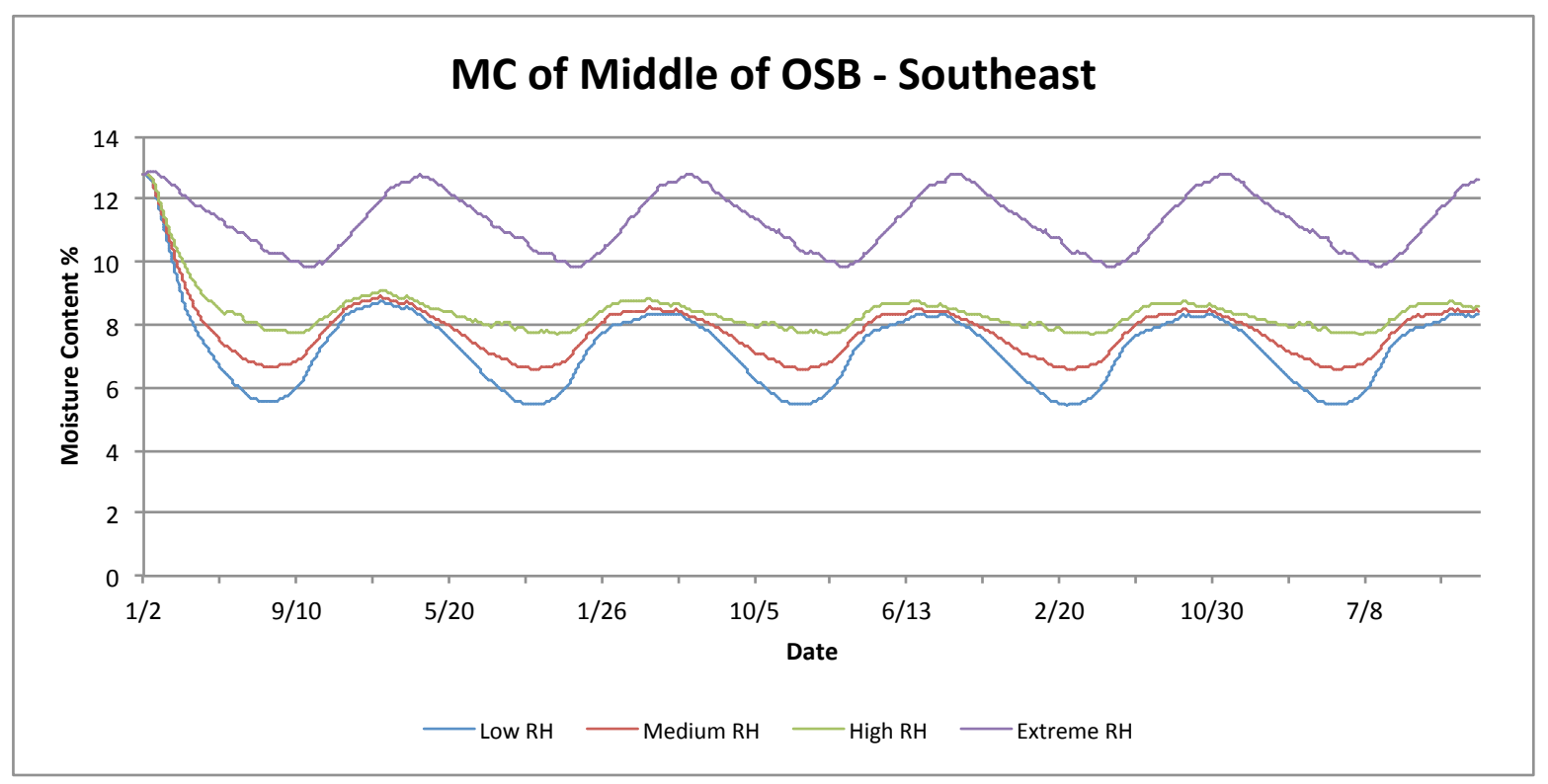

Figure 6-18 MC of middle of OSB layer for vertical I-beam assembly - Intensified Case 


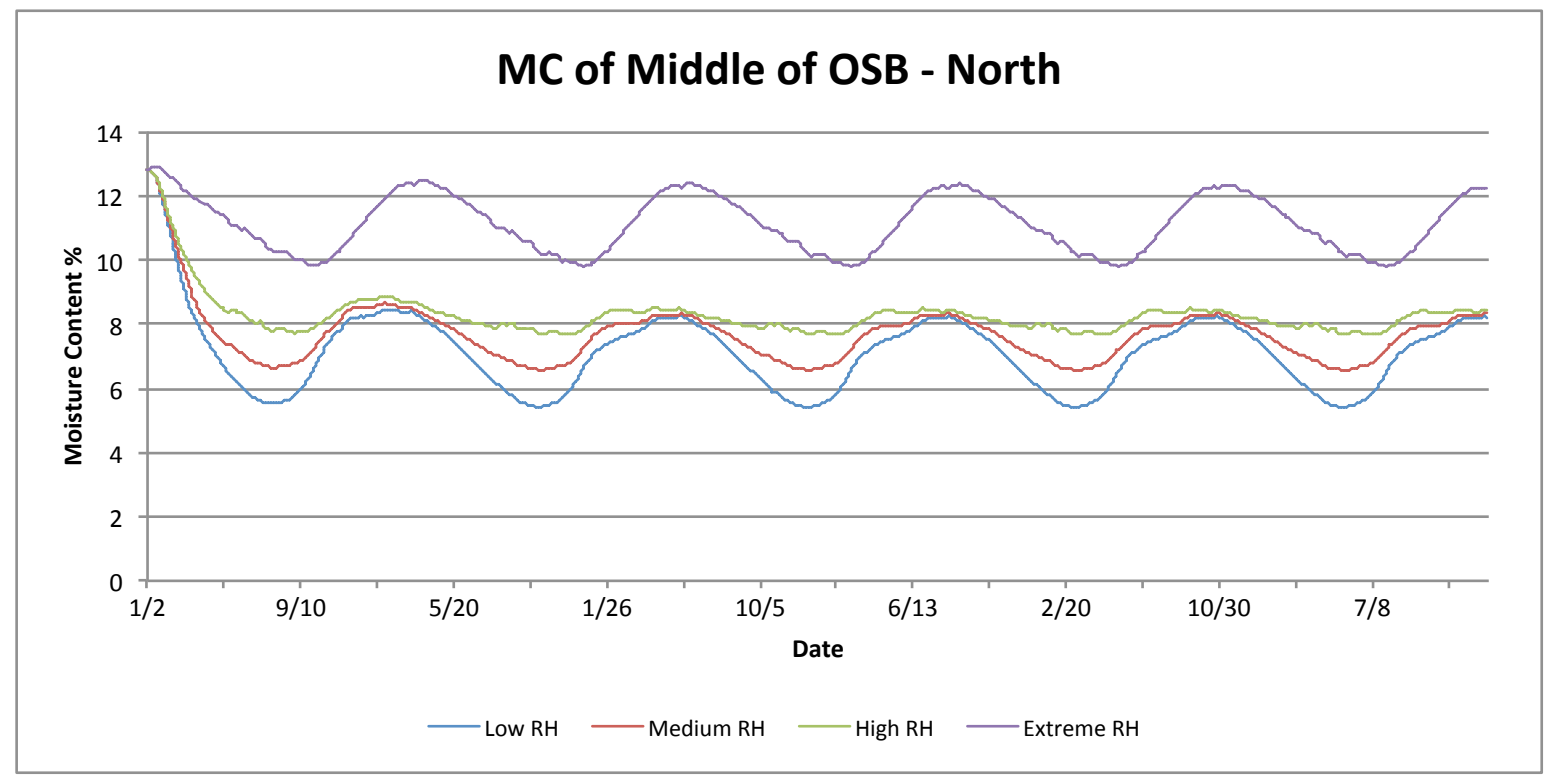

Figure 6-19 MC of middle of OSB layer for vertical I-beam assembly - Intensified Case

The structural sheathing layer within the vertical I-beam assembly showed acceptable moisture content levels when interior RH was set at all four levels for both the standard and intensified cases. The cellulose is able to absorb the additional moisture and then release it during the drying periods. Out of the four assemblies, the MC of the OSB layer in the vertical Ibeam assembly is the lowest. This is because the OSB has the greatest amount of insulation on the exterior side out of the four assemblies, keeping the temperature higher and the relative humidity lower throughout the year.

Figure 6-20 and 6-21 show the RH levels of the exterior and interior edge of the OSB sheathing layer with varying interior relative humidity levels for the vertical I-beam assembly in the intensified case. 


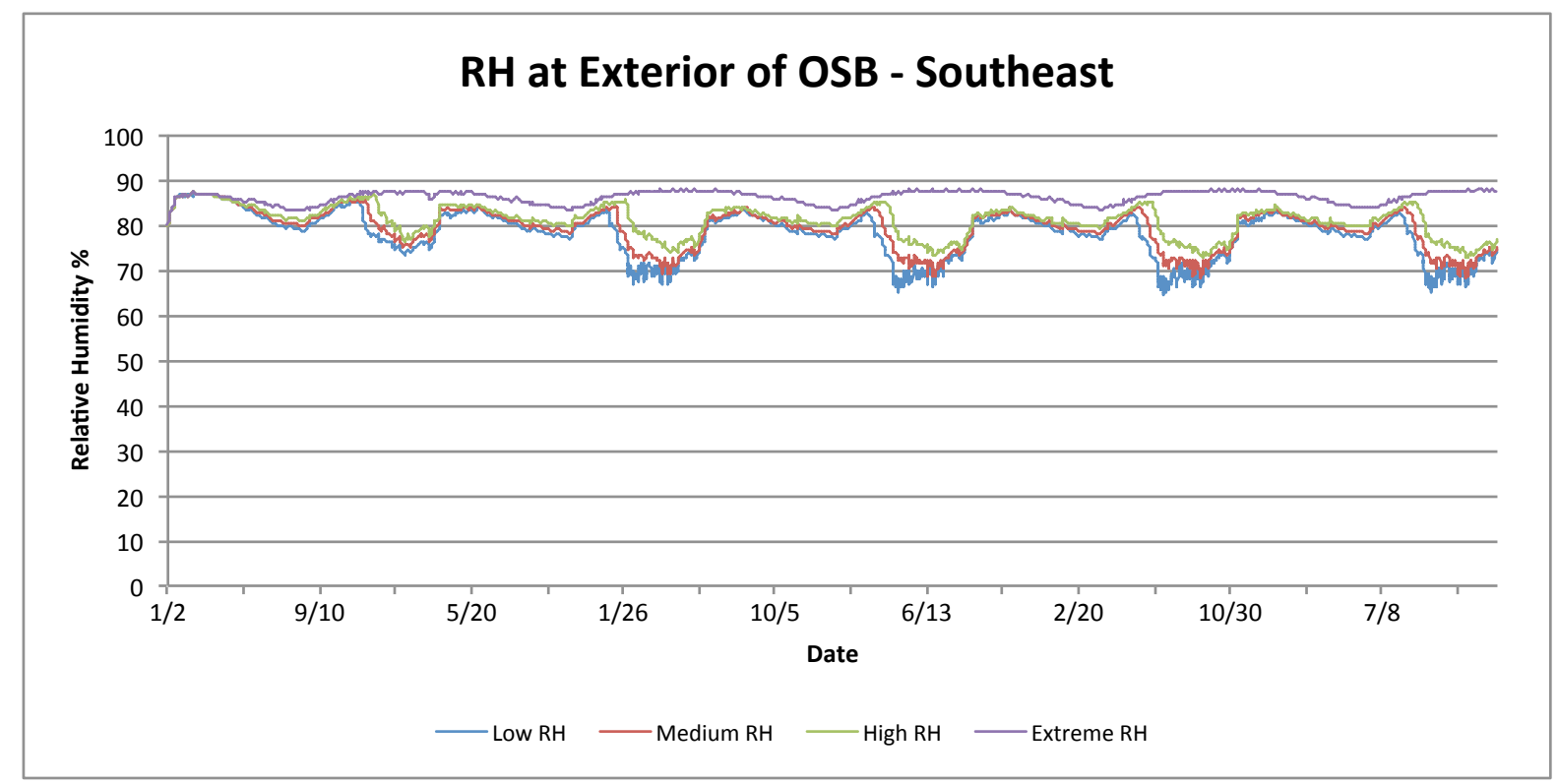

Figure 6-20 H of exterior OSB edge of vertical I-beam assembly - Intensified Case

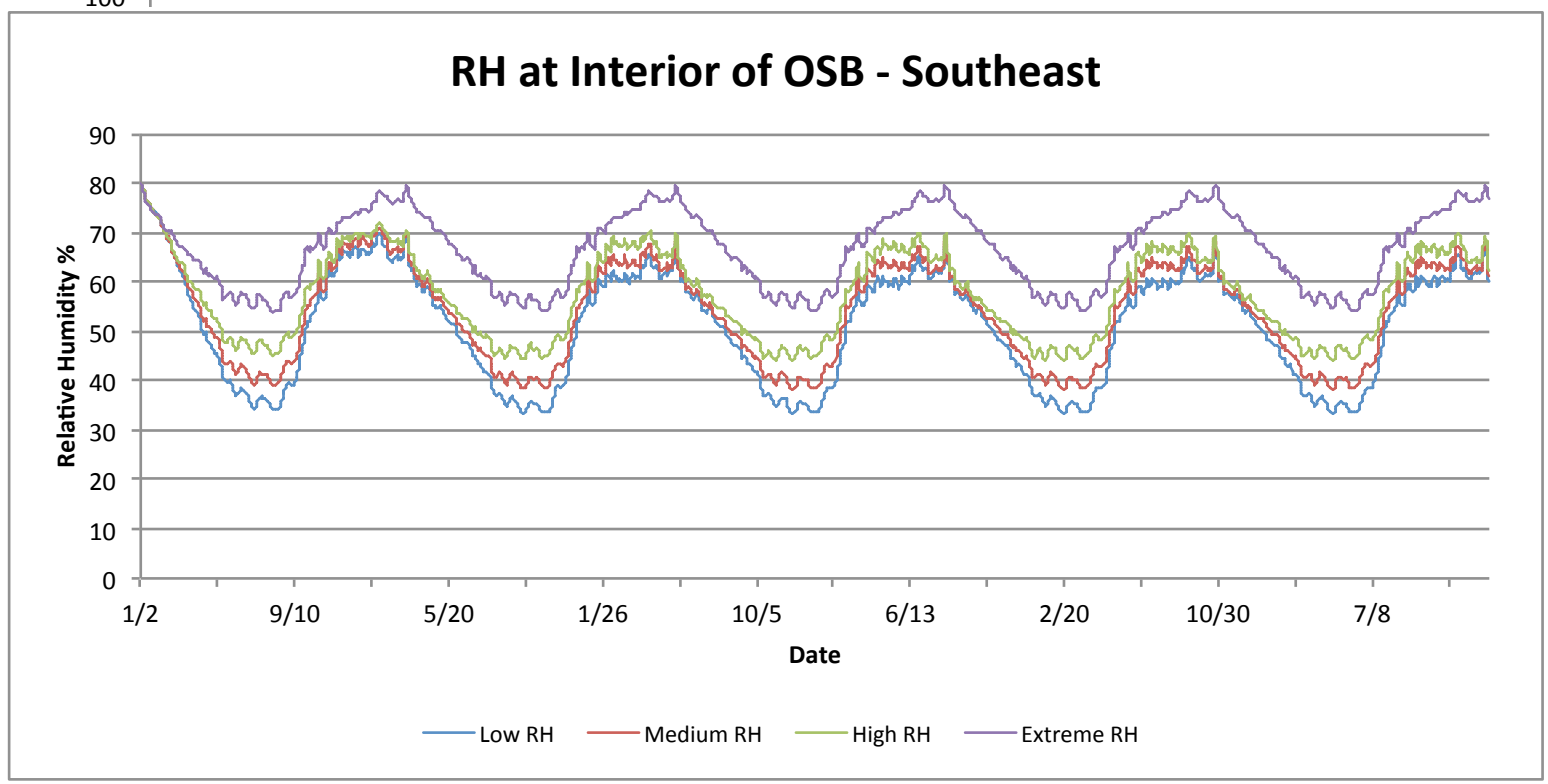

Figure 6-21 RH of interior OSB edge of vertical I-beam assembly - Intensified Case

The RH on the exterior edge of the OSB behaves very differently compared to the interior edge of the OSB layer in the vertical I-beam assembly. This is linked to the ability of the thick cavity of cellulose to absorb and hold moisture. The exterior edge is more closely linked to the 
wetting of the cavity and outer $25 \mathrm{~mm}$ of the cellulose during rain (moisture sources in cavity are $3 \%$ of driving rain, and outer $25 \mathrm{~mm}$ of cellulose is $1 \%$ of driving rain). The rain is sporadic, and is not an evenly distributed curve and results in a more sporadic RH at the exterior edge of the OSB compared to the interior edge. The interior edge is dominated by the interior RH levels. For the interior edge, it is consistently below $80 \% \mathrm{RH}$, even when interior RH levels are extreme. This again is linked to the cellulose's ability to hold moisture, and that the OSB is kept at warm temperatures. The remaining RH graphs for the vertical I-beam assembly are shown in Appendix $\mathrm{H}$ and the summarized results in Table 6-3.

\section{Vacuum Insulated Panel}

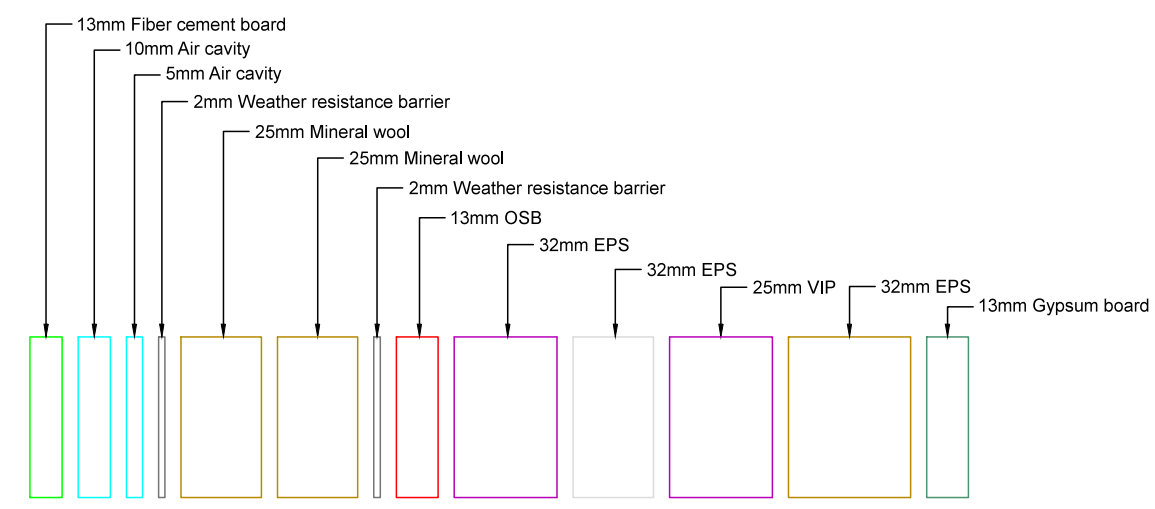

Figure 6-22 WUFI ${ }^{\circledR}$ material layers for VIP assembly

Figure 6-22 shows the material layers for the vacuum insulated assembly simulation.

Figures 6-23 and 6-24 represent the moisture content of the structural sheathing layer with southeast and north orientations for the standard case, and Figures 6-25 and 6-26 for the intensified case. 


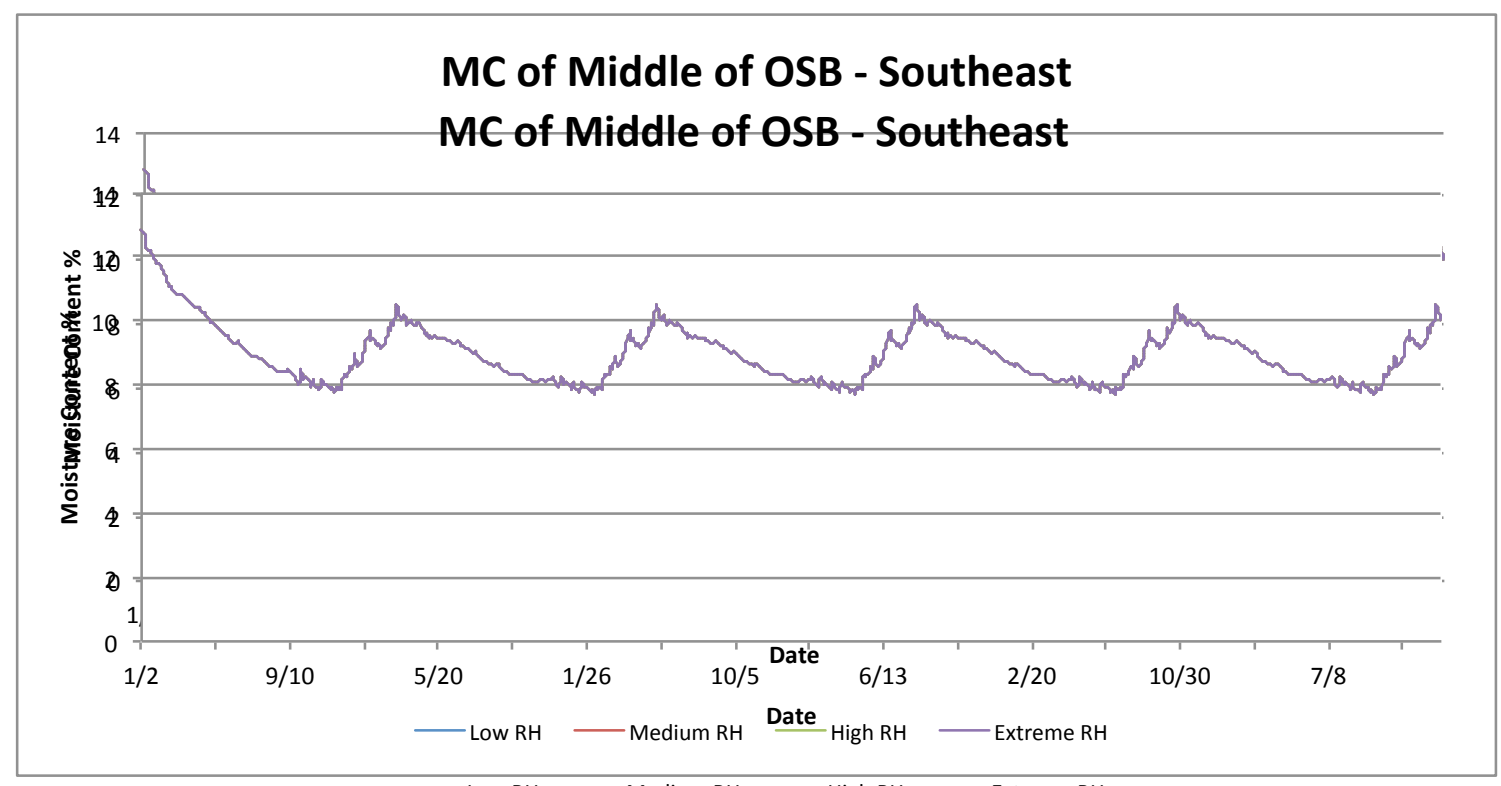

Figure 6-23 MC of middle of OSB in the VIP assembly - Standard Case

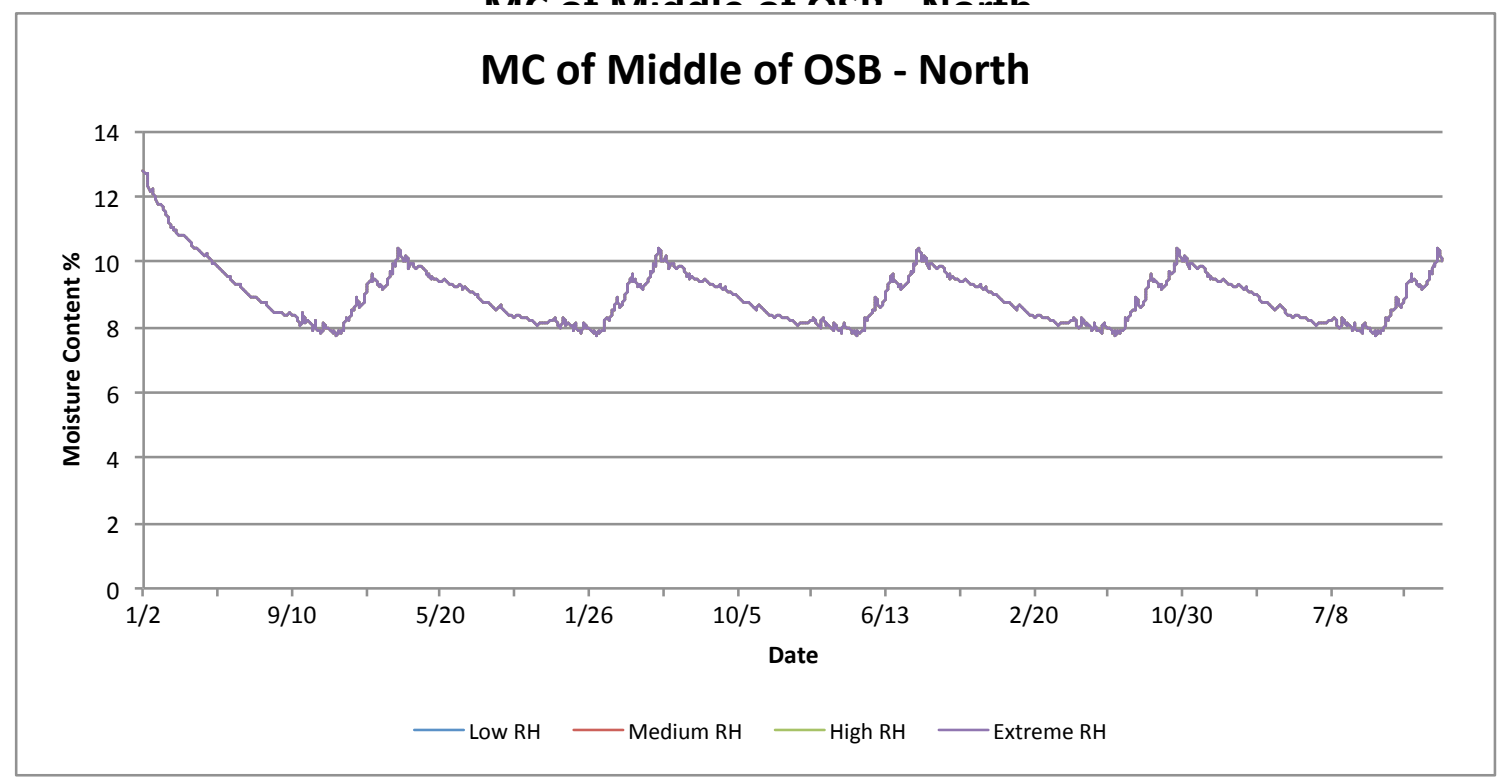

Figure 6-24 MC of middle of OSB in the VIP assembly - Standard Case 


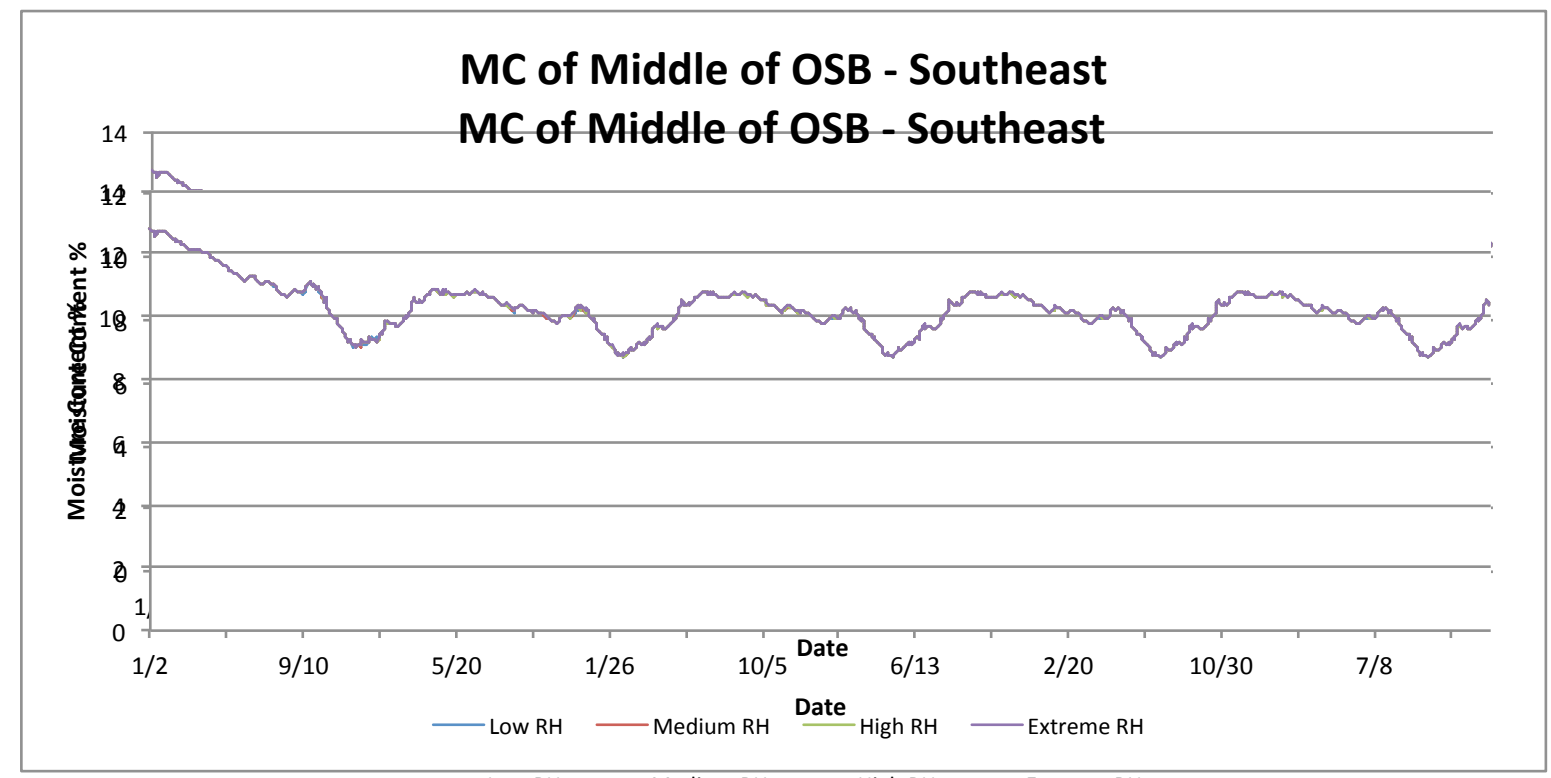

Figure 6-25 MC of middle of OSB in the VIP assembly - Intensified Case

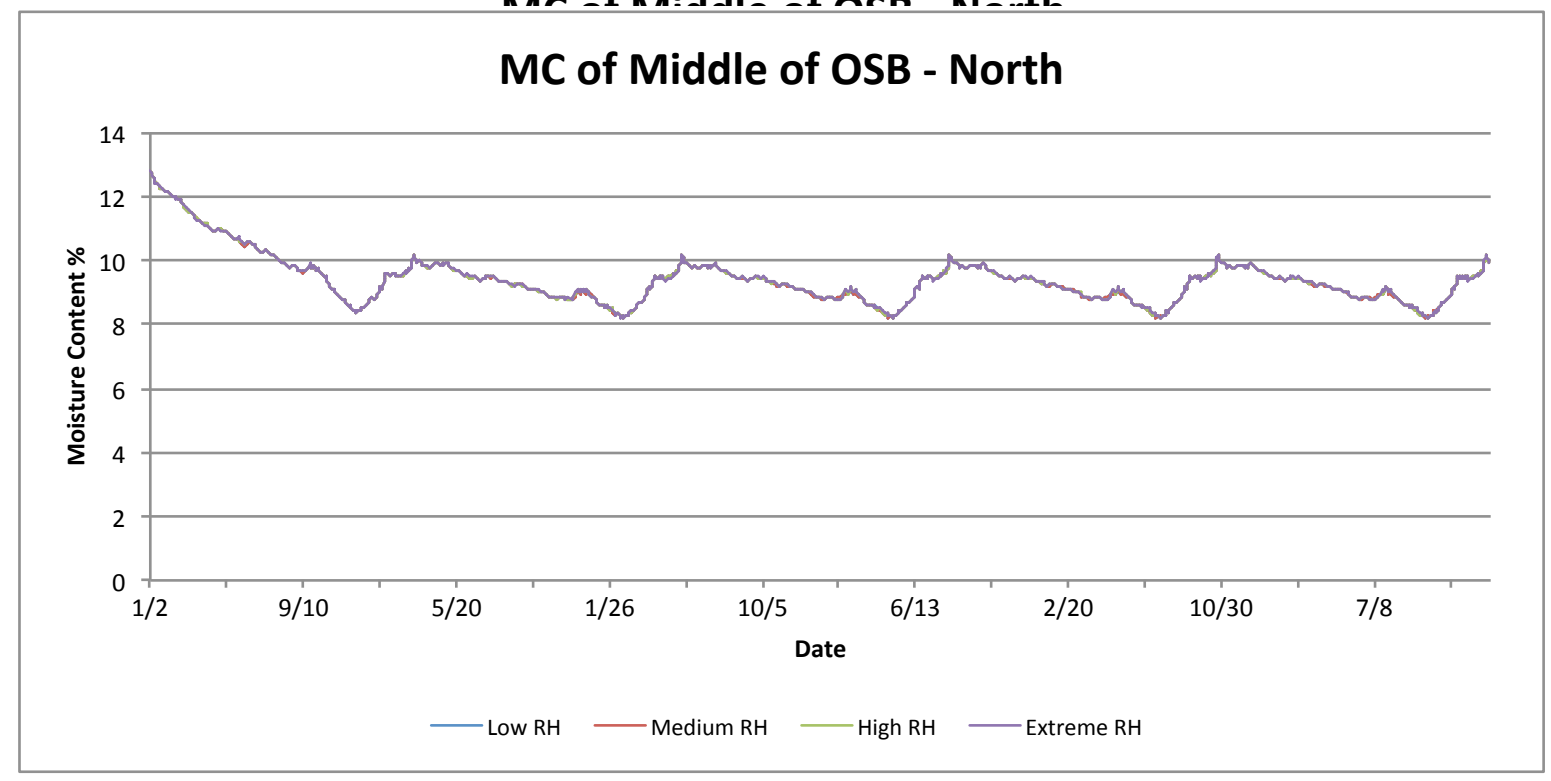

Figure 6-26 MC of middle of OSB in the VIP assembly - Intensified Case

The structural sheathing layer within the VIP assembly showed acceptable moisture content levels when interior RH were set at all levels. The MC of the OSB is the same for all of the interior RH levels - this is unlike any of the other assemblies. The vacuum insulated panel itself is the least permeable material out of any of the assemblies. This is because the metal foil 
used to create the vacuum in the panel is impermeable to vapour movement and slows interior vapour from reaching the OSB layer. The assembly is also the thinest out of the four, so moisture within the assembly does not have far to travel to escape.

The RH results are displayed in Appendix I and the summarized results in Table 6-3.

\subsection{WUFI ${ }^{\circledR}$ Conclusions}

WUFI ${ }^{\circledR}$ Pro 5.3 was used to assess the long-term hygrothermal performance of the four proposed assemblies for the Toronto climate. The goal of the analysis was to assess the long-term moisture content of the OSB sheathing layer and to measure the RH of the interior and exterior edge of the OSB surfaces. Criteria set forth by ASHRAE 160 in regards to safe moisture content levels for wood and surface RH levels were used to assess critical levels of potential mold growth and decay.

Table 6-3 shows a summarizes the OSB surfaces and orientations that experienced conditions with $\mathrm{RH}$ above $80 \%$ and temperatures greater than $5^{\circ} \mathrm{C}$. None of the assemblies experienced surface RH levels greater than 98\%. The green boxes signify a RH level below $80 \%$ with temperatures above $5^{\circ} \mathrm{C}$ or an $\mathrm{RH}$ level above $80 \%$ with temperatures below $5^{\circ} \mathrm{C}$ for the OSB edges. Green also means shows that MC levels were below $16 \%$ for the middle of the OSB layer. The red boxes signify the opposite.

- Mid. SE: Middle of OSB with southeast orientation

- Mid. N: Middle of OSB with north orientation

- Ext. SE: Exterior edge of OSB with southeast orientation

- Ext. N: Exterior edge of OSB with north orientation

- Int. SE: Interior edge of OSB with southeast orientation

- Int. N: Interior edge of OSB with north orientation 
Table 6-3 Condensation risk of assemblies

\begin{tabular}{|c|c|c|c|c|c|c|c|c|c|c|c|c|c|c|c|c|c|c|c|c|c|c|c|c|}
\hline $\begin{array}{c}\text { Interior RH } \\
\text { Level }\end{array}$ & \multicolumn{6}{|c|}{ Low } & \multicolumn{6}{|c|}{ Medium } & \multicolumn{6}{|c|}{ High } & \multicolumn{6}{|c|}{ Extreme } \\
\hline $\begin{array}{c}\text { OSB \& } \\
\text { Orientation }\end{array}$ & \begin{tabular}{l|l}
$\operatorname{Mid}$ \\
$\mathrm{SE}$
\end{tabular} & & xt. & xt. & Int. & Int. & $\begin{array}{l}\text { Mid. } \\
\mathrm{SE}\end{array}$ & Mid. & $\begin{array}{l}\text { Ext. } \\
\text { SE }\end{array}$ & Ext. & $\begin{array}{l}\text { Int. } \\
\text { SE }\end{array}$ & Int. & $\begin{array}{l}\text { Mid. } \\
\mathrm{SE}\end{array}$ & Mid. & $\begin{array}{l}\text { Ext. } \\
\text { SEE }\end{array}$ & Ext. & $\begin{array}{l}\text { Int. } \\
\text { SE }\end{array}$ & int. & $\begin{array}{l}\text { Mid. } \\
\text { SE }\end{array}$ & Mid. & $\begin{array}{l}\text { Ext. } \\
\text { SE }\end{array}$ & $\begin{array}{l}\text { Ext. } \\
\text { N }\end{array}$ & $\begin{array}{l}\text { Int. } \\
\text { SE }\end{array}$ & $\begin{array}{l}\text { Int. } \\
\mathrm{N}\end{array}$ \\
\hline $\begin{array}{l}\text { Polyisocyanurate } \\
\text { Standard }\end{array}$ & & & & & & & & & & & & & & & & & & & & & & & & \\
\hline $\begin{array}{c}\text { Polyisocyanurate } \\
\text { Intensified }\end{array}$ & & & & & & & & & & & & & & & & & & & & & & & & \\
\hline $\begin{array}{l}\text { Mineral Wool } \\
\text { Standard }\end{array}$ & & & & & & & & & & & & & & & & & & & & & & & & \\
\hline $\begin{array}{c}\text { Mineral Wool } \\
\text { Intensified }\end{array}$ & & & & & & & & & & & & & & & & & & & & & & & & \\
\hline $\begin{array}{l}\text { Vertical I-beam } \\
\text { Standard }\end{array}$ & & & & & & & & & & & & & & & & & & & & & & & & \\
\hline $\begin{array}{l}\text { Vertical I-beam } \\
\text { Intensified }\end{array}$ & & & & & & & & & & & & & & & & & & & & & & & & \\
\hline $\begin{array}{c}\text { VIP } \\
\text { Standard }\end{array}$ & & & & & & & & & & & & & & & & & & & & & & & & \\
\hline$\underset{\text { Intensified }}{\text { VIP }}$ & & & & & & & & & & & & & & & & & & & & & & & & \\
\hline
\end{tabular}

\begin{tabular}{|l|l|}
\hline Does not meet performance criteria & \\
\hline Does meet performance criteria & \\
\hline
\end{tabular}

For both the standard and intensified cases, the only period the middle of the OSB layer experienced MC levels above 16\% was with extreme interior RH levels [60-80\%]. Only the polyisocyanurate and mineral wool assemblies exceeded this threshold. It should be noted that the polyisocyanurate assembly had increasing MC levels year after year, whereas the mineral wool assembly was able to lower below $16 \%$ during its drying cycle. The vertical I-beam assembly never experienced MC levels above $16 \%$ in the middle of the OSB layer because the vast majority of the cellulose is on the exterior side of it, keeping the temperature high. The vacuum insulated panel assembly did not experience higher than $16 \%$ either because the VIP itself is extremely vapour impermeable, and did not allow extreme interior RH levels to affect it.

The RH levels of the interior and exterior edges were predominately maintained within the safe range, expect for when extreme interior RH levels were introduced, and with the intensified case. The mineral wool assembly showed mold risk when the interior RH level was 
set to high during the intensified case. The only standard case that experienced mold risk was the polyisocyanurate assembly at the interior surface edge with high interior RH levels. The vertical I-beam assembly experienced period of mold risk with low and medium interior RH levels

during the intensified case. This is linked to the additional moisture sources in the outer $25 \mathrm{~mm}$ of the cellulose.

\section{Condensation Risk Hours for Intensified Cases}

Only the intensified case showed condensation risk. The standard case showed only condensation risk during extreme interior RH levels and when high interior RH was simulated for the polyisocyanruate assembly at the interior OSB surface. The intensified case is unlikely to happen, but was used to test the assemblies under extreme conditions.

Figure 6-26 shows the quantity of hours that were experienced in one year with surface conditions of the OSB with $\mathrm{RH}<80 \%$ and temperatures above $5^{\circ} \mathrm{C}$. The 5 th year of values were used for the comparison between each assembly because an equilibrium has been established at this period. The high and extreme interior relative humidity simulations are reviewed in separate graphs for the polyisocyanurate, mineral wool and vertical I-beam assemblies. Only the vertical I-beam experienced this level of RH and temperature at low and medium interior relative humidity values. 
Exterior-SE $\square$ Exterior-N $\mathrm{N}$ Interior-SE $\square$ Interior-N

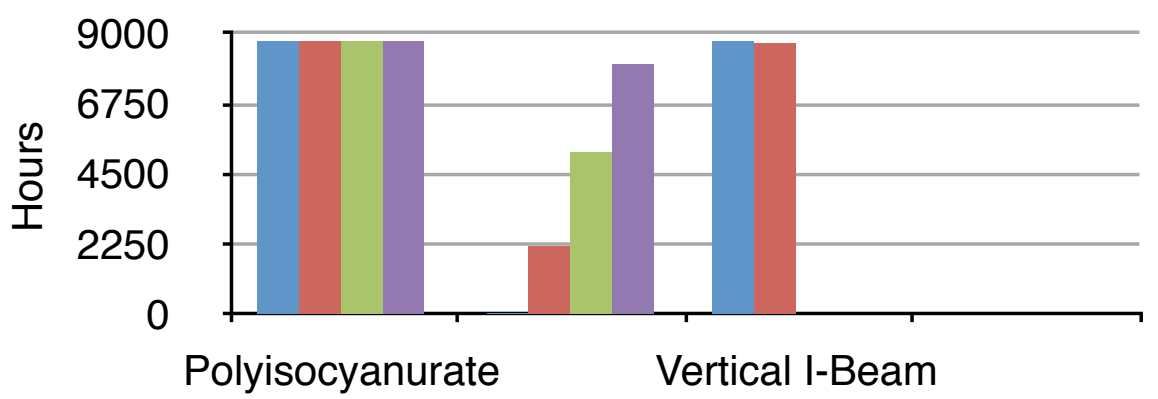

Figure 6-27 Condensation risk hours with extreme RH levels
Exterior-SE
Exterior- $\mathrm{N}$
Interior-SE
Interior- $\mathrm{N}$

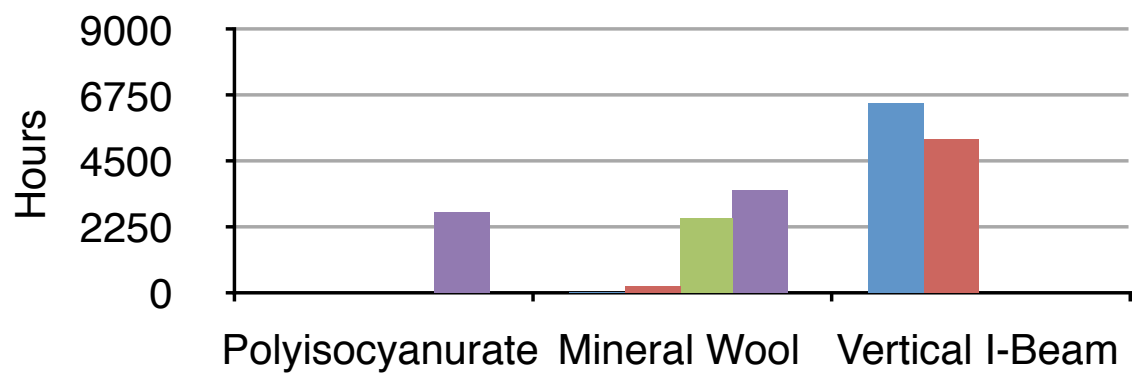

Figure 6-28 Condensation risk hours with high RH levels
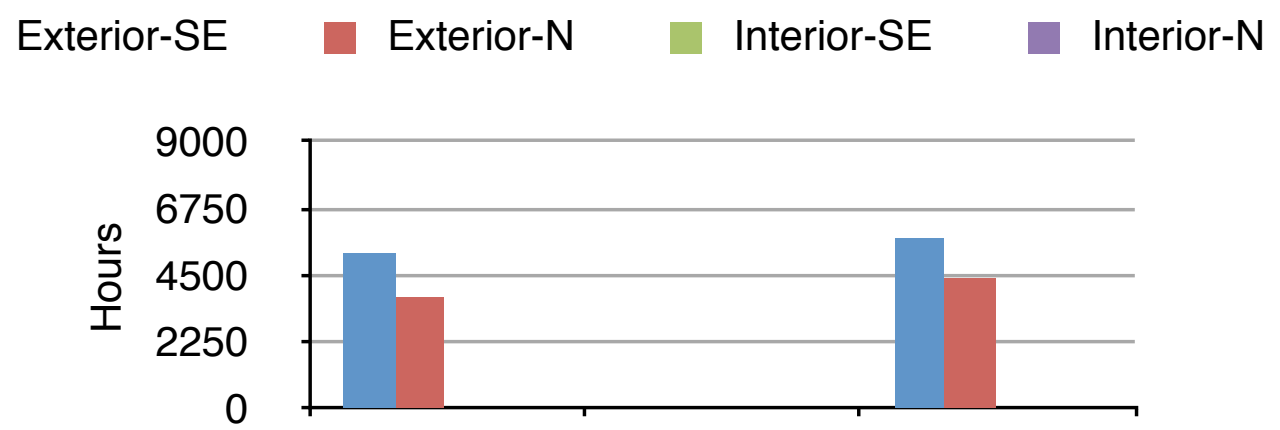

Vertical I-beam - Low RH Vertical I-Beam - Medium RH

Figure 6-29 Condensation risk hours for vertical I-beam scenarios with low \& medium RH levels 
The RH levels of the interior and exterior surface each were assessed for the four assemblies using four levels of interior RH. The hours in the 5th year of the simulations were totaled and listed in Figures 6-26, 6-27 and 6-28. This year was used because the moisture content had reached equilibrium levels. The polyisocyanurate assembly experienced the highest number of hours with extreme interior RH. The mineral wool assembly experienced this condition with high and extreme interior RH values on both the interior and exterior OSB surface. The vertical I-beam assembly only experienced this condition on the exterior side of the OSB, and did so for all of the interior RH levels. This is linked to the cellulose's tremendous ability to hold moisture. The vacuum insulated panel did not experience any hours with the prescribed conditions. None of the assemblies experienced surface RH levels above $98 \%$. 


\section{Chapter 7 - Energy Consumption Model}

\subsection{Overview}

Research Question:

By how much do the proposed super-insulated and airtight envelope systems reduce the annual heating demand by compared to a standard OBC 2012 code built envelope system?

The following chapter reviews the results from the PHPP energy model. It shows the change in annual heating demand for a traditional modular home compared to that of the proposed modular envelope systems. It was not the goal of this energy model to assess the specific primary energy demand of the home because this value will vary based on mechanical systems and occupants behavior. Instead, it was the goal of this portion of the research to give insight into the difference between each assembly, and how it compares to the baseline assembly, in terms of annual heating demand.

\subsection{Assumptions \& Limitations}

This section outlines the assumptions and limitations of the building energy model used to assess the annual heating demand. Table 7-1 displays the dimensions that were entered into the PHPP. It should be noted that all of the envelope areas are kept the same for each model.

Table 7-1 Envelope areas entered into the PHPP model

\begin{tabular}{|l|c|}
\hline Building Component & Area $\mathbf{~ m}^{2}$ \\
\hline Roof & $\mathbf{1 6 5}$ \\
\hline Exterior Wall & $\mathbf{5 2 0}$ \\
\hline Foundation & $\mathbf{1 6 5}$ \\
\hline Windows & $\mathbf{5 2}$ \\
\hline
\end{tabular}

All interior area and exterior dimensions are kept the same for all models. The interior floor area of the home is $440 \mathrm{~m}^{2}$, but the treated floor area [TFA] entered into the model is $415 \mathrm{~m}^{2}$. 
There was no floor plan developed for the home, as it was outside the scope of this research, so the TFA was estimated at a reduced value. All energy totals were based on the TFA value.

All window sizes were kept the same for all models. Each elevation was given a percentage of glazing as follows: southern $50 \%$, east/west $20 \%$ and north $10 \%$. The windows were assigned as multiple single windows with varying sizes to achieve these percentage values for each elevation. All orientations were assigned on cardinal axis lines. All window installation $\Psi$ factors were kept the same for all models.

The shading inputs were kept the same for all of the models. General shading was assigned at $75 \%$, meaning that the only $75 \%$ of the solar radiation hit the glazing surface. Summer shading value was also assigned at $75 \%$.

The ventilation inputs were kept the same for all of the simulations. The efficiency of the ventilation is significant for the annual heat demand. The HRV efficiency was $72 \%$ once all losses from the intake and outtake outlets were accounted for. This efficiency rating was arbitrarily selected. All heat losses were kept the same through the ventilation system.

All domestic hot water, electricity, auxiliary electricity, ground conditions, and occupant inputs were kept the same for all of the models. The climate conditions were taken from PHPP weather file for Toronto. All of these elements can affect the heating demand of the building. Since all of these values were kept the same, they do not have any impact on the percentage change between each of the PHPP simulations.

\subsection{Model Variations of Inputs}

This portion outlines the variances in the inputs for each of the PHPP simulations. As seen in Table 7-2, the entered RSI values for the exterior envelope do vary and the ACH between the high performance and baseline are different. The $\mathrm{ACH}$ for the high performance is taken from Passive Houses minimum air infiltration requirement. Although it cannot be physically verified, the air barrier system has been influenced from previously successful PH designs that 
have achieved $<0.6 \mathrm{ACH}_{50}$. The baseline air leakage value was used at $3 \mathrm{ACH}_{50}$ based on industry experts investigations into average air leakage rates in residential homes [Chan et al., 2003]. As well, Table 7-3 outlines the performance specifications of the high performance windows used, and the baseline windows.

Table 7-2 Envelope RSI values \& ACH values assigned in PHPP model

\begin{tabular}{|l|c|c|c|c|}
\hline & Wall [RSI] & Roof [RSI] & Slab [RSI] & ACH \\
\hline Polyisocyanruate & 9.7 & 15 & 10.5 & 0.6 \\
\hline Mineral Wool & 8.6 & 15 & 10.5 & 0.6 \\
\hline TJI & 9.3 & 15 & 10.5 & 0.6 \\
\hline VIP & 6.5 & 15 & 10.5 & 0.6 \\
\hline Baseline & 4.2 & 9.2 & 0.18 & 3 \\
\hline
\end{tabular}

Table 7-3 Window performance specifications for PHPP inputs

\begin{tabular}{|c|c|c|c|}
\hline & U-value cog & $\begin{array}{c}\text { U-value } \\
\text { frame }\end{array}$ & SHGC \\
\hline High Performance & 0.68 & 0.74 & 0.33 \\
\hline $\begin{array}{c}\text { High Performance } \\
\text { Southern Glazing }\end{array}$ & 1.02 & 0.74 & 0.55 \\
\hline Baseline & 1.67 & 2.18 & 0.35 \\
\hline $\begin{array}{c}\text { Baseline } \\
\text { Southern Glazing }\end{array}$ & 1.67 & 2.18 & 0.63 \\
\hline
\end{tabular}

\subsection{Results of the PHPP Energy Models}

Table 7-4 Summarized results from PHPP models

\begin{tabular}{|l|c|c|}
\hline & $\begin{array}{c}\text { Annual Heating Demand } \\
{\left[\mathrm{kWh} / \mathrm{m}^{2} / \mathrm{yr}\right]}\end{array}$ & \% Reduction from Baseline \\
\hline Baseline & 50 & - \\
\hline Polyisocyanurate & 15 & $69 \%$ \\
\hline Mineral Wool & 17 & $67 \%$ \\
\hline Vertical I-beam & 15 & $69 \%$ \\
\hline VIP & 19 & $64 \%$ \\
\hline
\end{tabular}


The results of the PHPP simulations of the annual heating demand are displayed in Table 7-4. It shows the reduction in the annual heating demand with the high performance envelopes compared to the baseline envelope. The reduction in annual heating demand varied between 64-69\%. It should be noted that even the VIP, the lowest effective RSI value out of all the developed assemblies, still achieved reductions of $64 \%$ in annual heating demand compared to the baseline. The only differences between the five PHPP models were the changes in RSI values of the slab, wall and roof, the window specifications and air infiltration rates. Between these changes, a reduction of up to $69 \%$ in annual heating demand was simulated. 


\section{Chapter 8 - Conclusions}

\subsection{Conclusions}

Heating represents the largest energy consumer in homes in Southern Ontario. High performance envelope systems that are super-insulated and airtight are the most effective way to reduce the energy consumption in homes in Toronto. Modular building systems have the potential to construct such envelope systems with increased quality and reduced time of construction. The research aimed to answer several questions in regards to designing and analyzing high performance envelopes for a modular building system in a cold climate context. The following outlines the research questions, and the conclusions drawn to answer them.

\section{What options can be developed for a modular manufacturer to produce a super insulated,} airtight building envelope system for a wood framed modular building system in a cold climate context?

a) How can the design of the air barrier made continuous across the wall to roof, rim joist and wall to foundation transitions without the use of typical air sealing methods used in the modular industry?

Currently, the air barrier used in modular construction relies on one of several strategies: interior gypsum board, polyethylene vapour retarder behind the gypsum board, weather resistance barrier or by using spray foam insulation. However, each of these air sealing strategies has a fault. Interior gypsum board and vapour retarders are not durable materials and are prone to puncture during remodels of the home over its lifetime. The weather resistance barrier approach is difficult to make continuous around the entire envelope, especially at the connection to the roof. Spray foam insulation is prone to shrinking overtime and could be a potential source of air leakage. Also, spray foam is expensive and is a heavy petroleum based product with a highembodied energy content.

The assemblies designed in this research do not rely on any of these air-sealing strategies. Instead, a continuous layer of sheathing with sealed seams is used. The air barrier layer is made with the same material across the various outlined interface transitions. This allows for a visual 
inspection of the air barrier in the modular manufacturing facility before it is shipped to site for installation. Any seams between the modules at the rim joist and vertical seams can be made on site with tape, expanding foam tape or with rubber gaskets.

Window details were also developed for the various assemblies. Window installations were designed with a continuous application of a liquid applied membrane to make the transition from the sheathing layer to the window frame, and to complete the transition from the membrane to the frame, a backer rod and sealant is used (or double sized window tape). In essence, the air barrier moves from the sheathing layer, to the liquid applied membrane, to the sealant, to the window frame, to the window glazing. Overall, the only way to air test a modular structure is with a blower door test in the field once the building is installed onsite.

b) How are the various assemblies constructed differently using the modular building system compared to onsite methods, and what are the advantages gained by constructing these developed assemblies with the modular system over onsite methods?

The following is a summarized list of the advantages offered by the modular building system that were identified to be helpful when delivering the proposed four envelope systems. These benefits were based on previous research, and were assessed for their applicability to the high performance envelopes designed for this research.

- Framing factors are controlled more accurately because crews can use jigs with predetermined stud spacing. This prevents additional framing in the walls that can negatively affect the thermal resistance performance of the assemblies.

- Interior gypsum layer can be installed with less material handling and is installed without a polyethylene vapour retarder layer, allowing spray glue to be used to secure it to the studs.

- Reduced lifting and hoisting of walls and window with gantries. This is especially helpful with thicker walls and high performance windows because they are heavier than traditional walls/windows to lift for workers onsite. 
- Many processes such as applying exterior insulation, vertical furring strips, weather resistance barriers, attaching vertical I-beams and windows can be installed at heights no greater than one story.

- Bulk purchases of insulation at reduced rates are possible with the modular building system because they can be stored within the factory.

- The air barrier transitions of the wall to ceiling and wall to foundation can be made within the factory, and are preformed by the same crews. This reduces fragmentation in the air sealing process.

- Sensitive materials such as the vacuum insulated panels and high performance windows benefit from the modular process because they can be handled with greater care and have a place to be stored securely away from the elements.

2. How do the proposed envelope systems perform in terms of thermal resistance and overall heating energy consumption?

a) Do the wall to roof, ceiling to floor and wall to foundation transitions of the proposed envelope details have a linear thermal resistance value $<0.01[\mathrm{~W} / \mathrm{m} \cdot \mathrm{k}]$ ?

The various connection locations for each of the assemblies for the wall to roof, rim joist and wall to foundation were evaluated for thermal bridging. THERM two-dimensional heat transfer software was used to assess if any connection had a linear thermal bridge value $<0.01[\mathrm{~m} \cdot \mathrm{k} / \mathrm{W}]$. The only location where thermal bridging was observed was at the rim joist location for two assemblies, the VIP and mineral wool envelope systems. The thermal bridge was more dramatic with the VIP assembly because the primary insulating material was not continuous on the exterior side of the framing. The wall to roof and wall to foundation connections were negative linear thermal bridge values for all of the assemblies, meaning that a manual calculation using the exterior surface area of the envelope would overestimate the amount of heat loss in those transition interfaces. 
b) By how much do the proposed super-insulated and airtight envelope systems reduce the annual heating demand by compared to a standard OBC 2012 code built envelope system?

Energy modeling software PHPP was used to estimate the reduction in annual heating demand the developed envelope systems could offer compared to code compliant envelope systems. Strictly increasing thermal resistance levels of walls, roof, foundation, windows, and reducing air infiltration to Passive House levels achieved reductions of $64-69 \%$ in annual heating demand. All of the other variables were maintained through all the energy simulations to provide evidence on the direct impact of the changes to the insulation and air tightness had on heating consumption.

3. How do the proposed envelope systems perform in terms hygrothermal performance?

a) Does the moisture content level of the OSB sheathing layer go above $16 \%$ and for how many hours do the interior and exterior surfaces of the OSB layer experience conditions with relative humidity above $80 \%$ and surface temperature above $5^{\circ} \mathrm{C}$ during one year?

The various assemblies were modeled for their long-term hygrothermal performance using WUFI® one-dimensional software. Special attention was given to the structural wood sheathing. ASHRAE 160P was used as a guideline for assessing critical levels of moisture content of the wood sheathing layer and RH levels for the exterior and interior surfaces of the OSB layer. Interior relative humidity levels were set at four levels, and the orientation was set to southeast and north to perform parametric analysis on the walls.

None of the wood sheathing layers experienced periods of moisture content in excess of $16 \%$ when interior relative humidity was set at low, medium and high. It was not until the interior $\mathrm{RH}$ was set at extreme, did the $\mathrm{MC}$ of the sheathing exceed $16 \%$ for the polyisocyanurate and mineral wool assemblies for both the southeast and north orientations. This was the same for both the standard and intensified cases.

The surface RH levels for the exterior and interior edges of the OSB layer were also assessed for their levels using ASHRAE 160P as a guideline for performance. Figure 8-2 shows 
the summarized simulations, and red means there was condensation risk in that particular scenario, and green means there was not. None of the assemblies experienced RH levels above $98 \%$ at any point, so the condensation risk is $\mathrm{RH}>80 \%$ while temperatures are between $5^{\circ} \mathrm{C}$ and $40^{\circ} \mathrm{C}$.

The polyisocyanurate displayed safe levels of moisture and surface $\mathrm{RH}$, until extreme interior RH levels were introduced. The interior surface OSB edge with northern orientation during periods of high interior RH also exceed the safe limit.

With the intensified case, the vertical I-beam assembly on the exterior surface consistently experienced $\mathrm{RH}$ levels above $80 \%$, and this is linked to the thick amounts of cellulose in the exterior cavity and the hydroscopic nature of the material, and the leak that was used throughout the simulations. Whereas, with the standard case, the vertical assembly consistently had RH levels within the safe range. With the mineral wool assembly, the exterior wetting of the intensified case made RH surface levels at risk.

The VIP assembly did not experience any moisture risk in any of the simulations.

\subsection{Future Research}

This chapter discusses possible future research. First, these and other high performance envelopes could be physically constructed and analyzed for their constructability in the modular construction process and compared to how they would be built on site. The design of high performance envelope systems is a consistent evolution that changes with material science, climate conditions, worker familiarity, performance and economics. The design of other assemblies that use the vacuum insulated panel are of particular interest once the material becomes more reliable and costs are reduced.

Field testing the assemblies for their hygrothermal performance and ability to deal with varying climates is of interest. These are very thick assemblies, and little research as been done in the field on the impacts the environment have on their long term durability and performance. 
Cost estimating high performance building envelopes is an area of future research. There are few field examples of such construction that are well documented. There is limited academic research into the actual field costs of high performance construction. Future research could partner up with local designers and builders of high performance buildings to generate such costs for various economic regions. This can lead to the development of a true comparison between modular and onsite construction costs to deliver a high performance building envelope.

The quantification of improvements from to the modular factory system is of great interest for future research. This can only be done by actually timing the process time in the factory, and compare it to in the field process times. This research investigated the processes that could be done faster and more safely in a factory than compared to the field, but these were not quantifiable. Future research could investigate these process improvements and allow for more accurate estimates of modular construction to be made.

Finally, further improvements of the modular building system are still possible. In the name of lean thinking, continuous improvement should be used. New materials, new factory design, better processes, better tools and equipment, better design for construction and improvement to the integrated design process from the very beginning stages to better optimize for construction. 


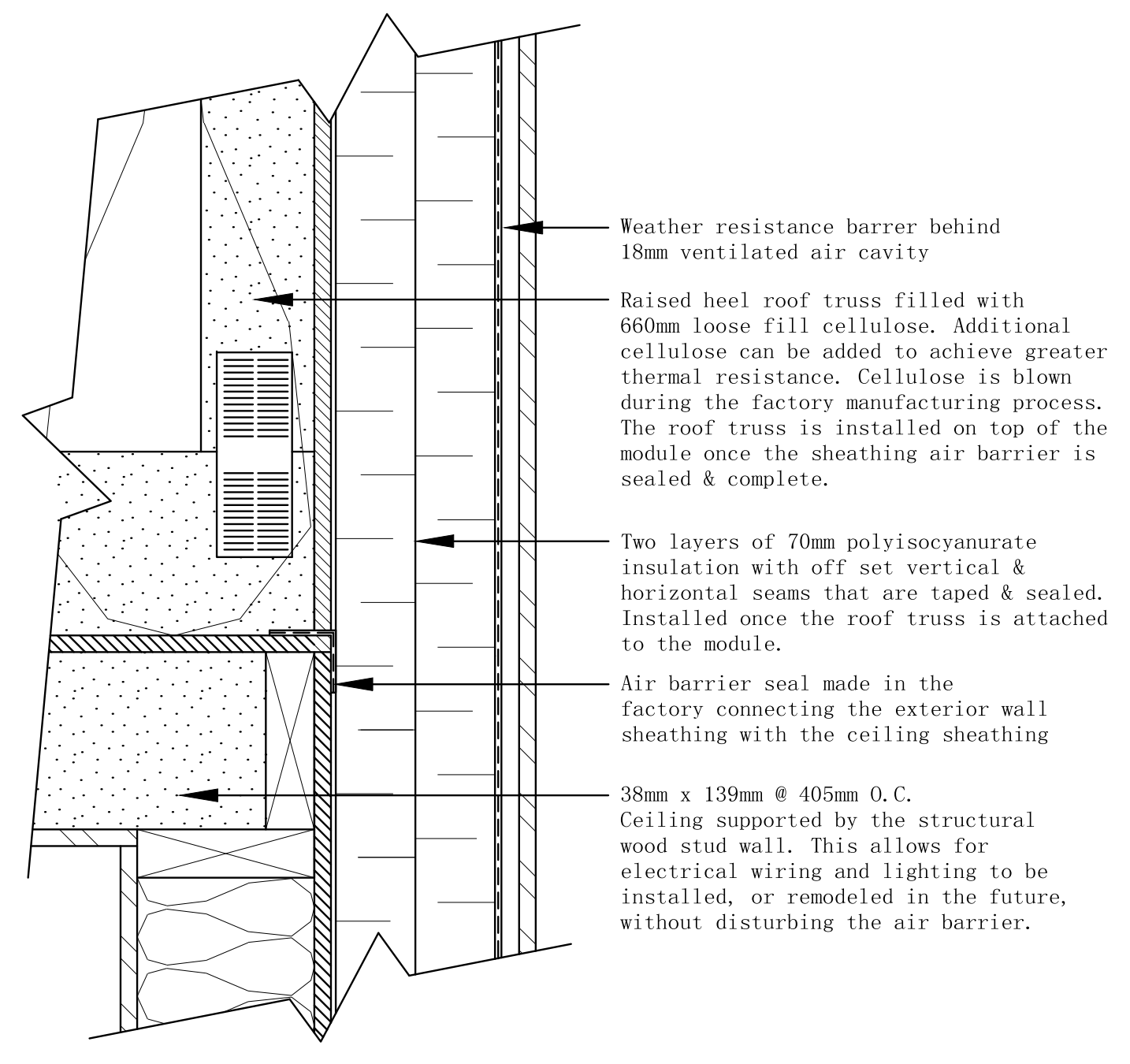

\section{Polyisocyanurate Assembly Wall to Ceiling Connection Scale 1:5}




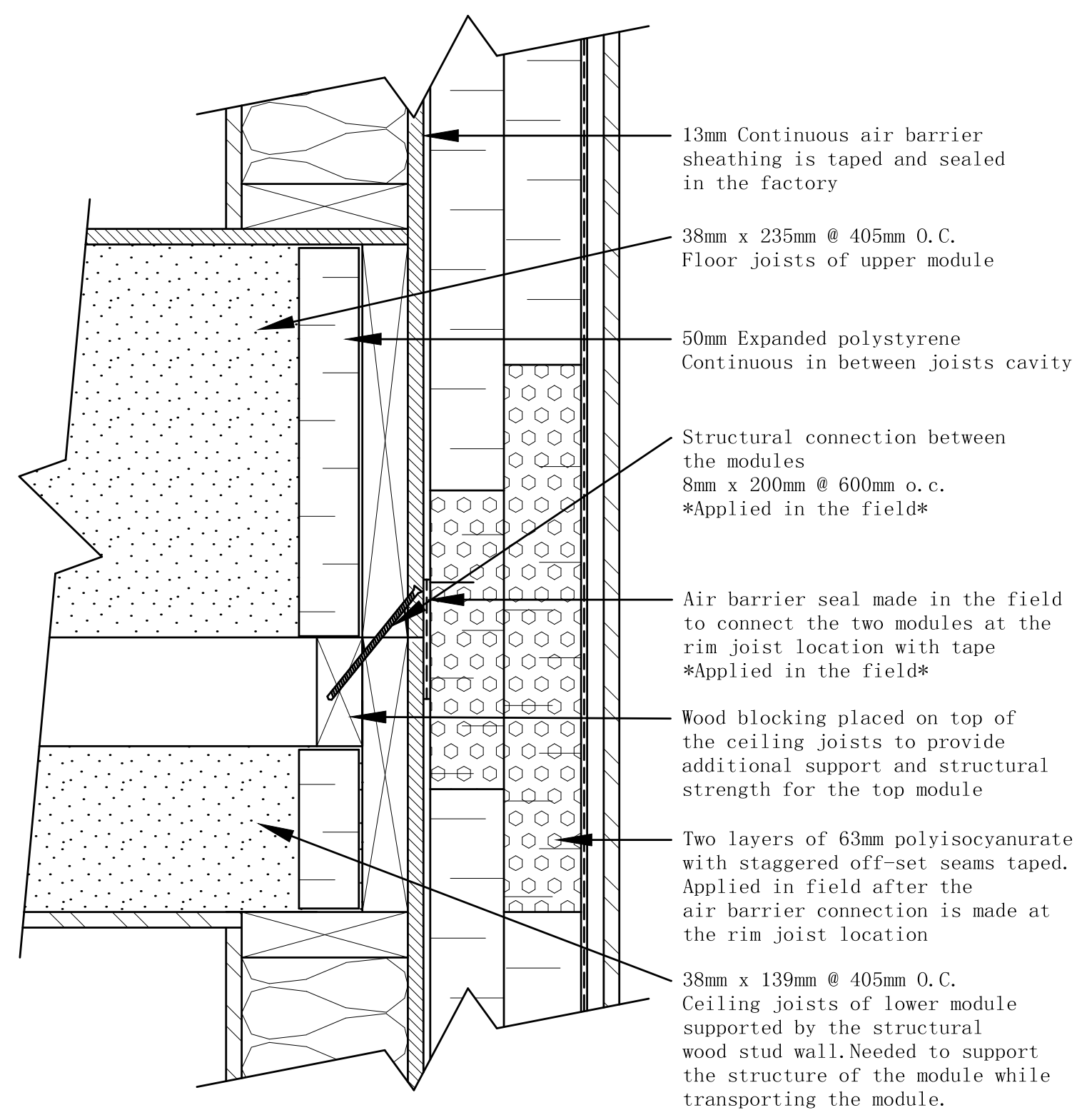

\section{Polyisocyanurate Assembly Rim Joist Connection Scale 1:5}




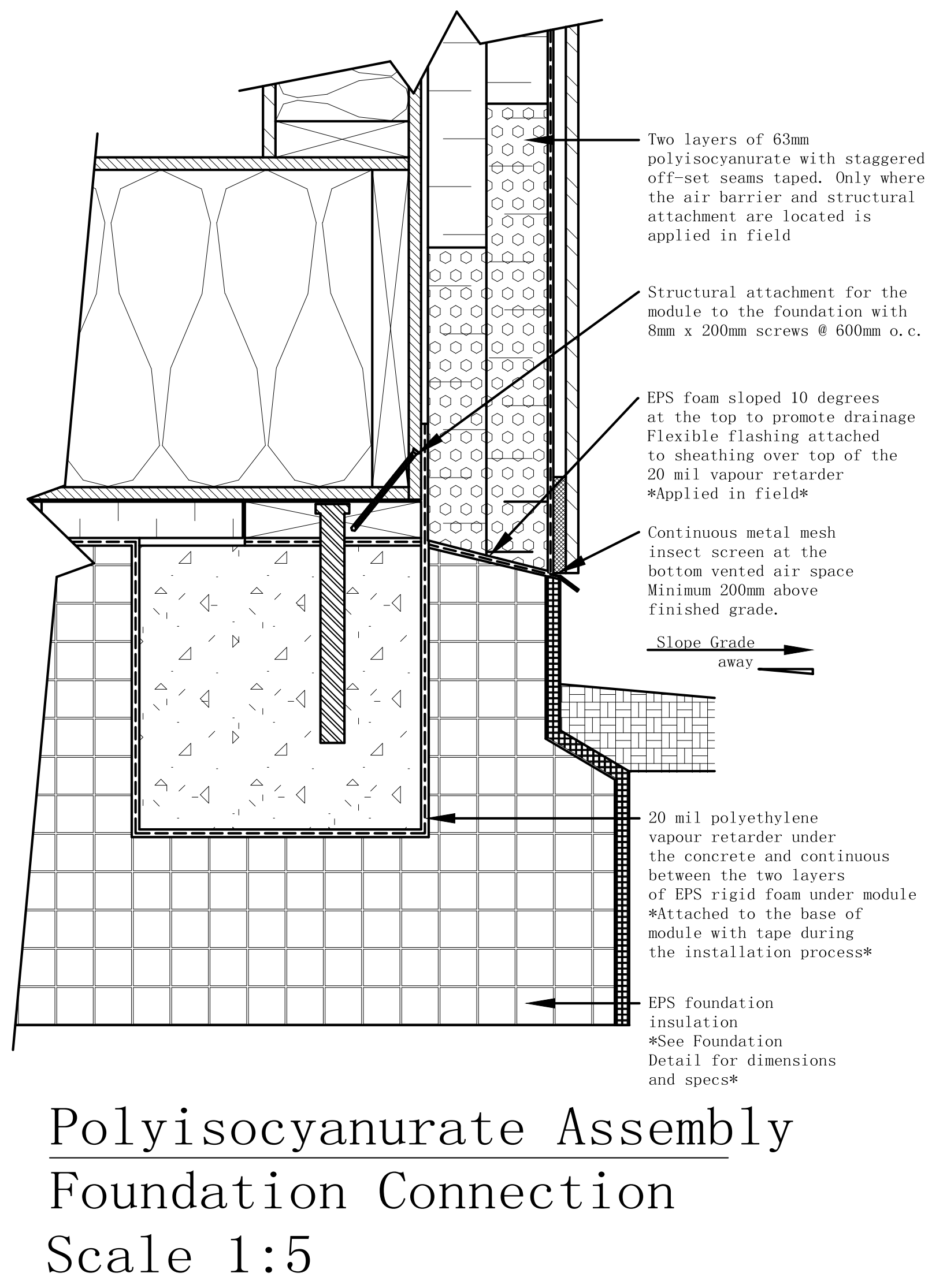




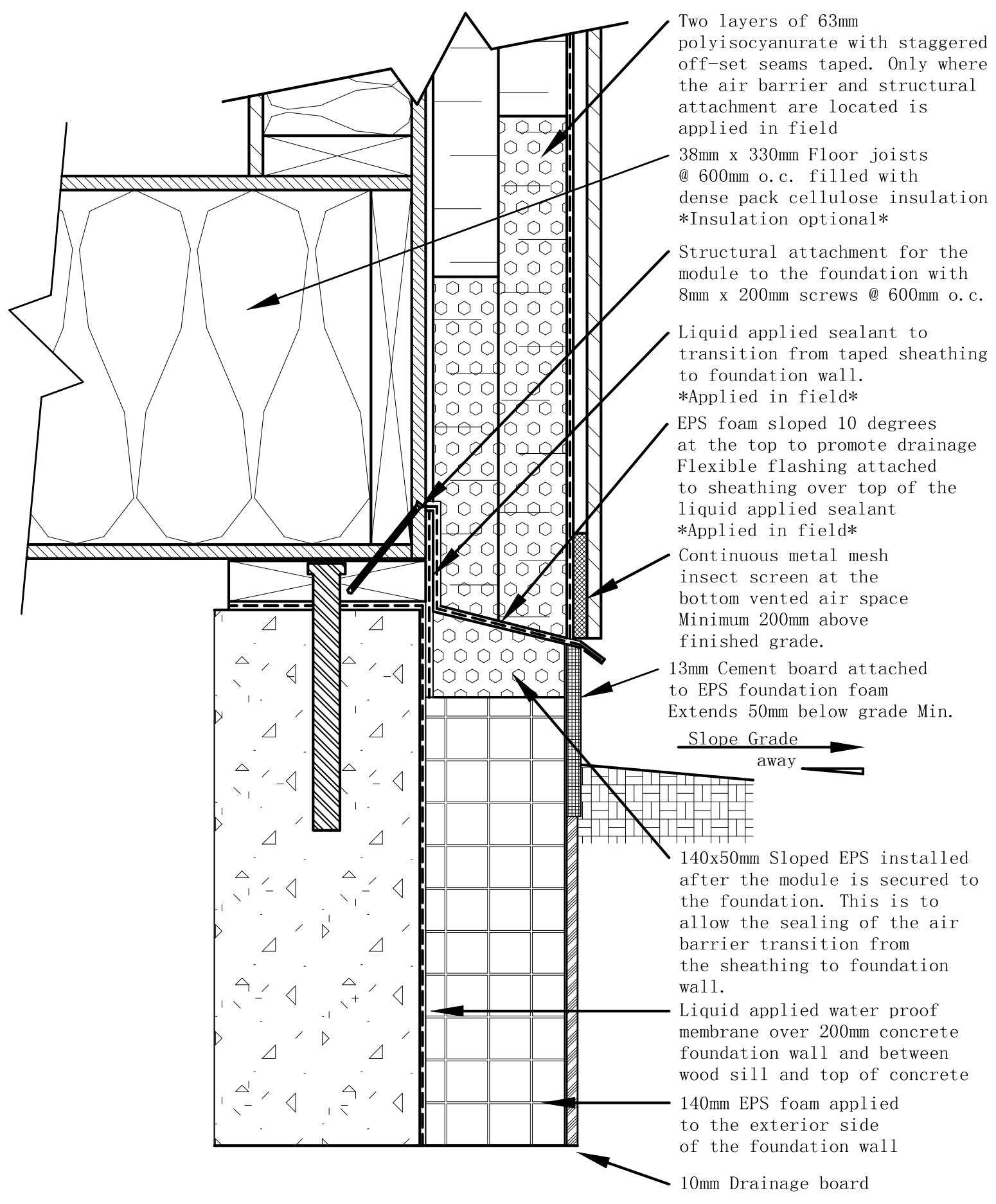

\section{Polyisocyanurate Assembly} Foundation Connection Scale 1:5 


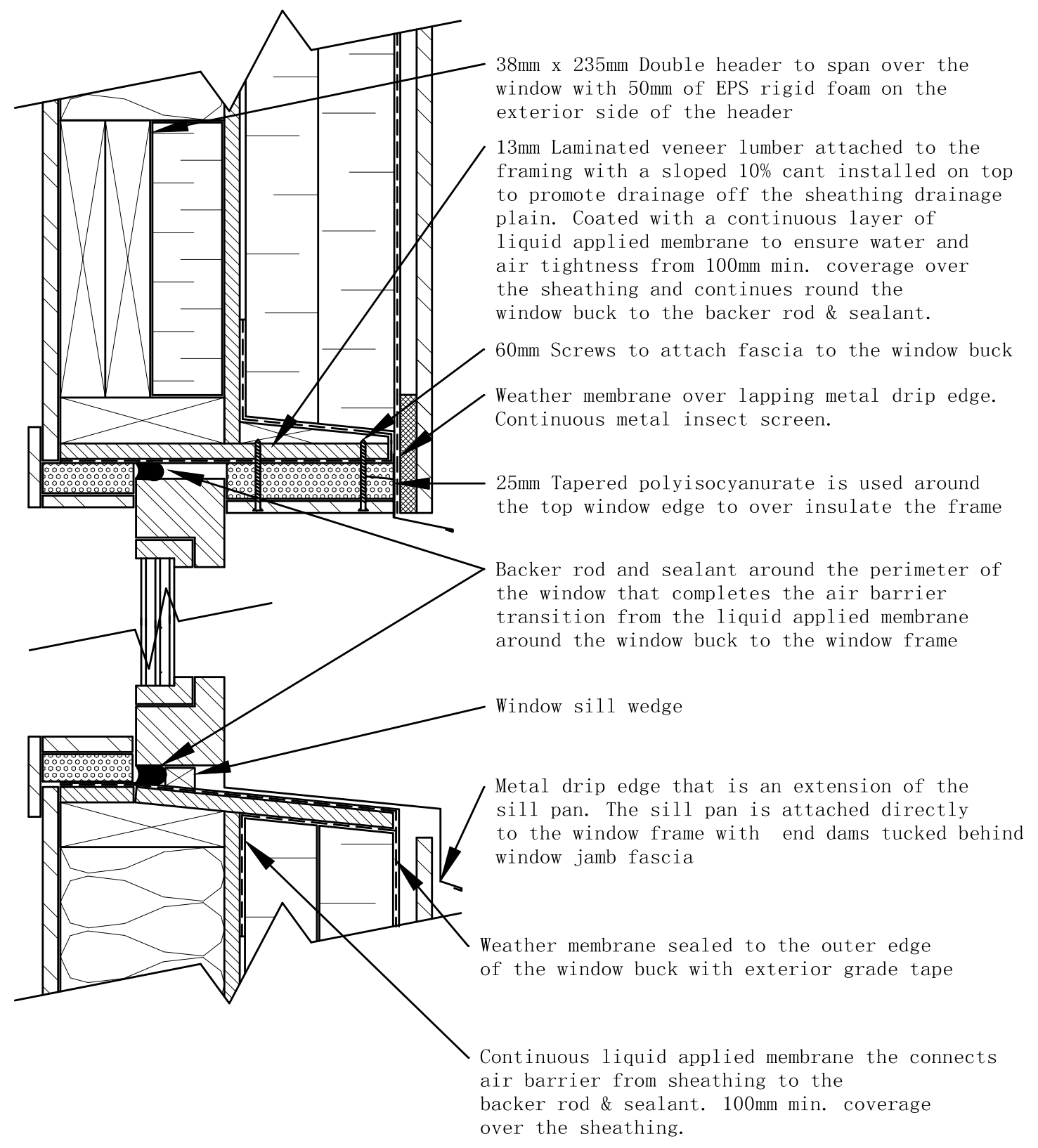

\section{Polyisocyanurate Assembly Window Header and Sill Scale 1:5}




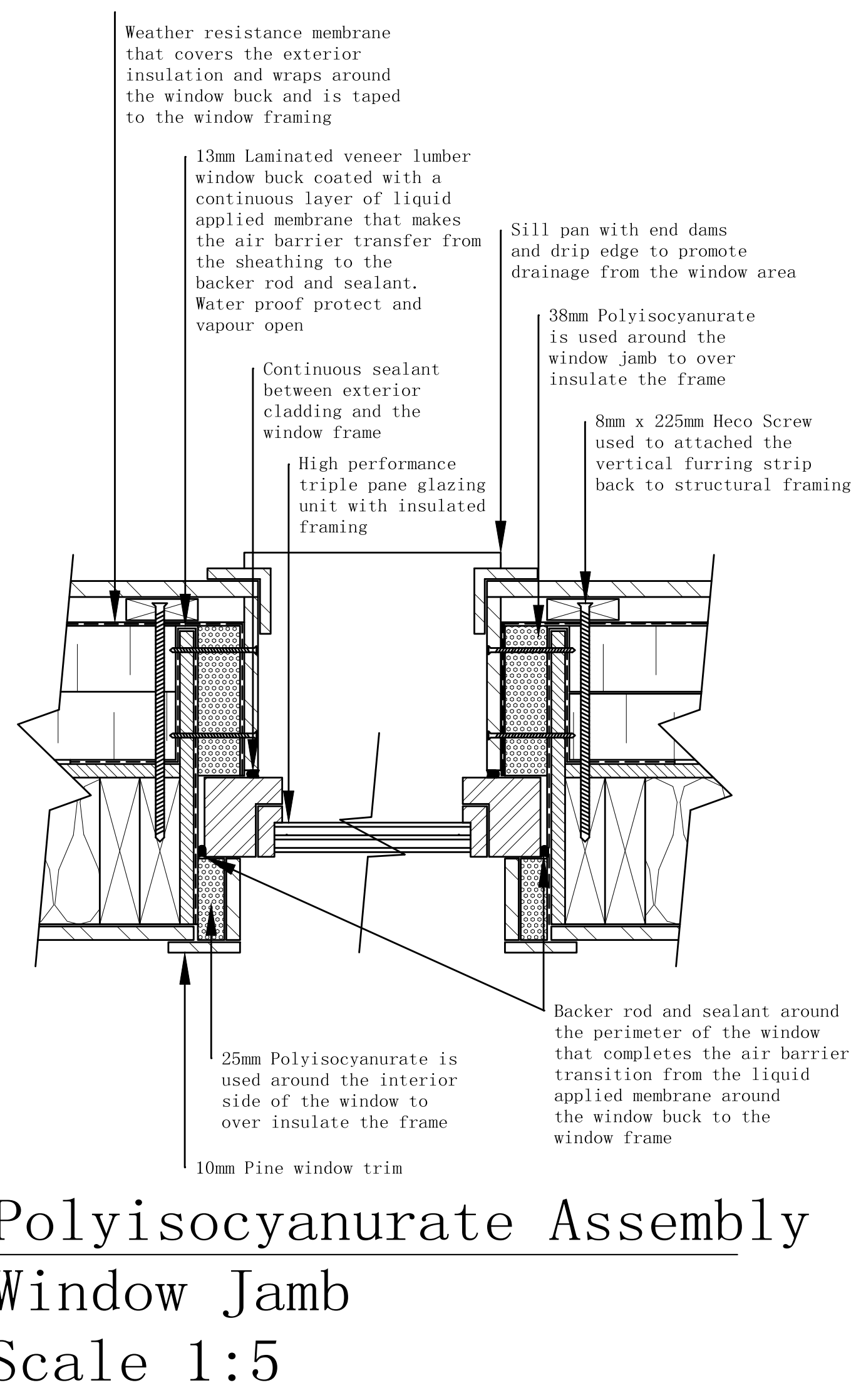




\section{Appendix B - Mineral Wool Assembly Details}

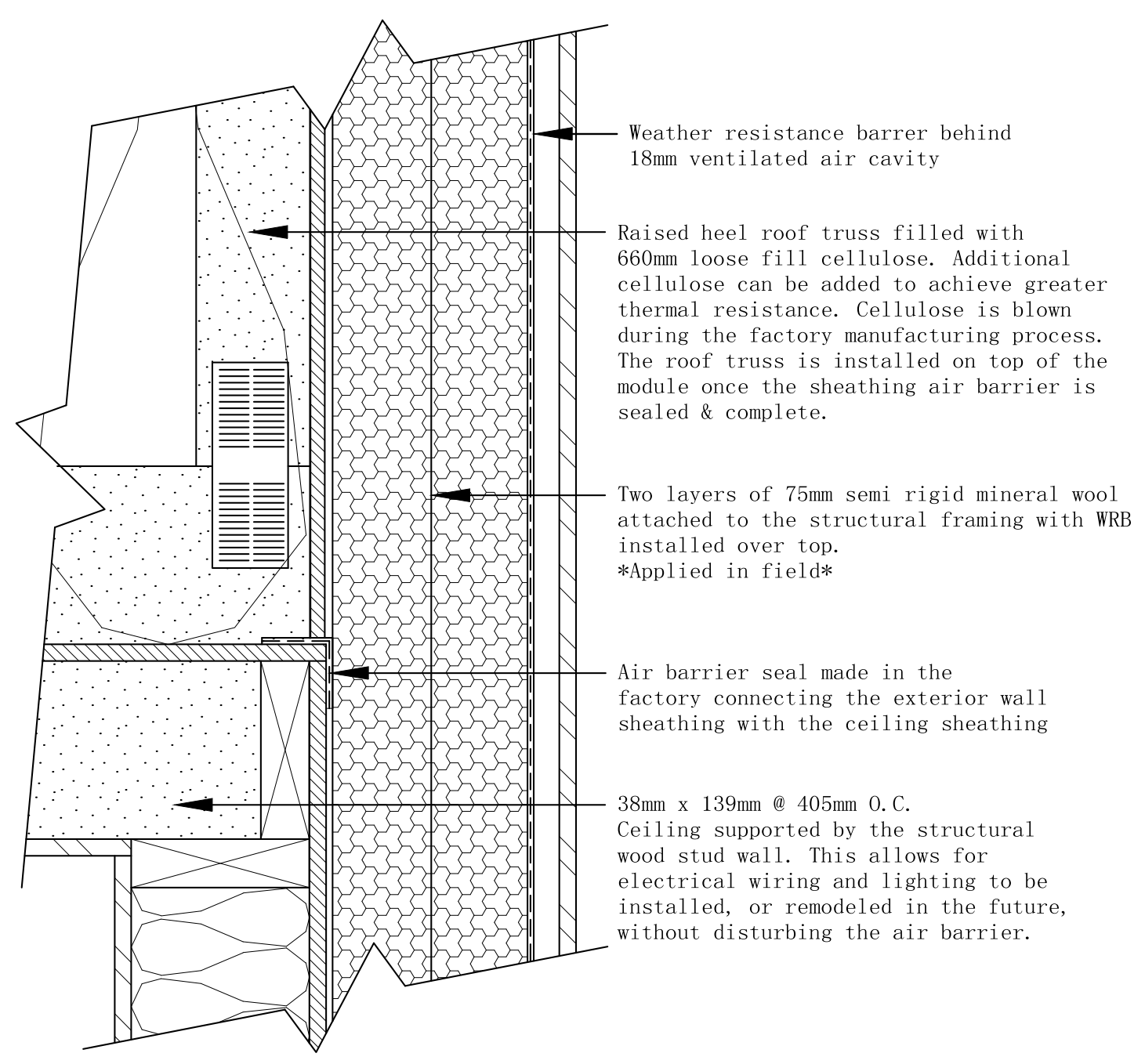

\section{Mineral Wool Assembly Wall to Ceiling Connection Scale 1:5}




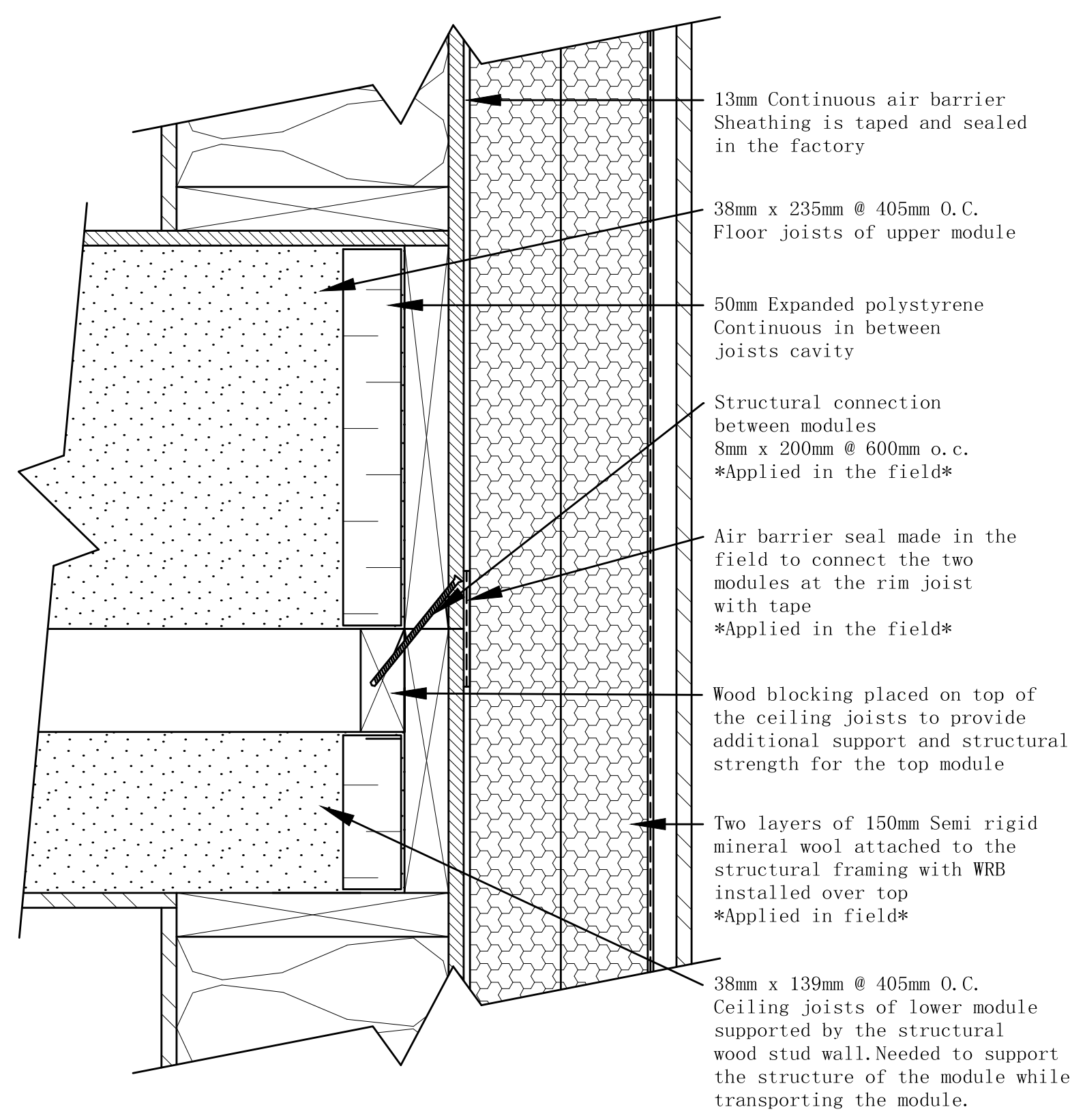

\section{Mineral Wool Assembly \\ Rim Joist Connection \\ Scale 1:5}




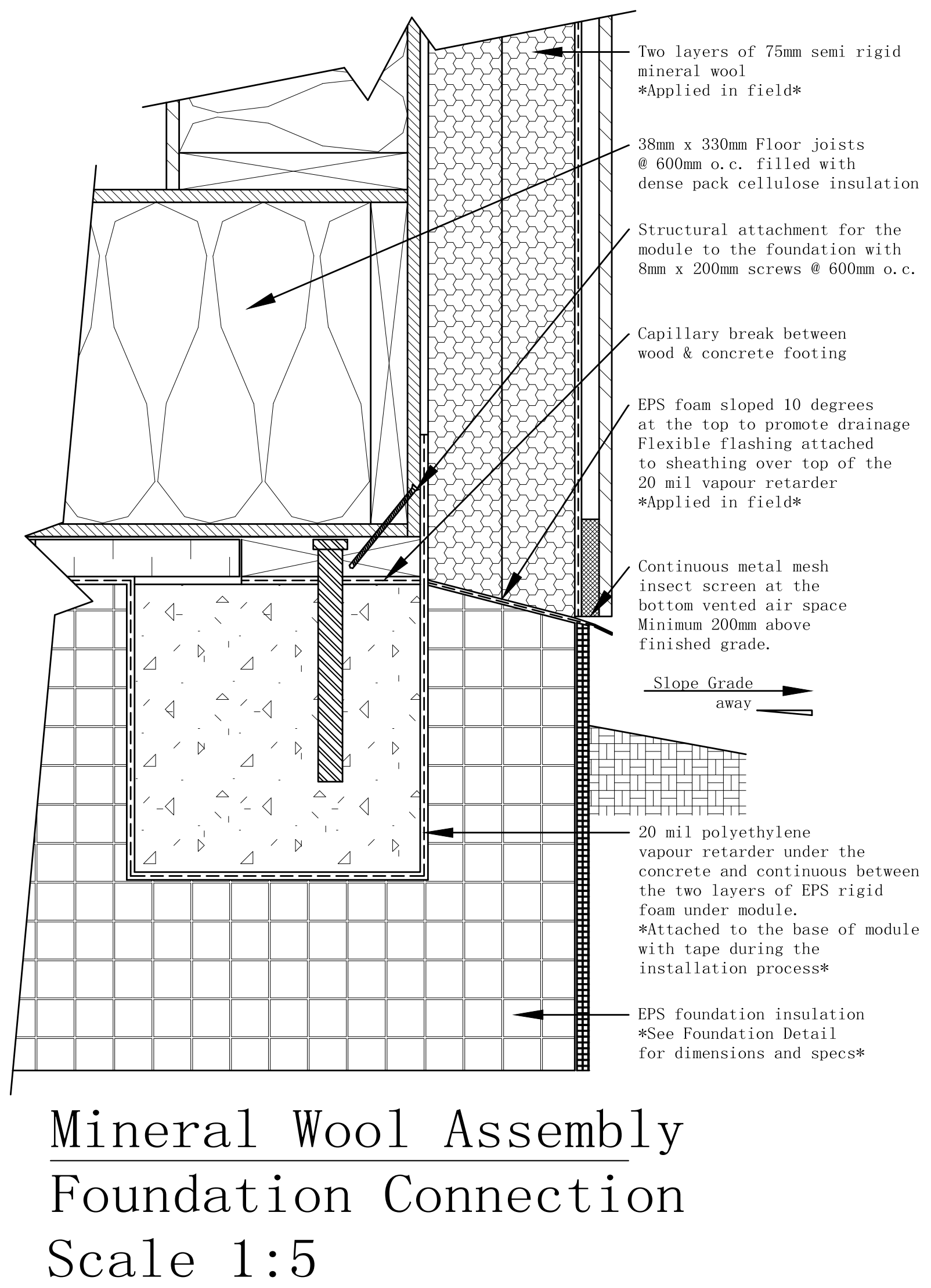




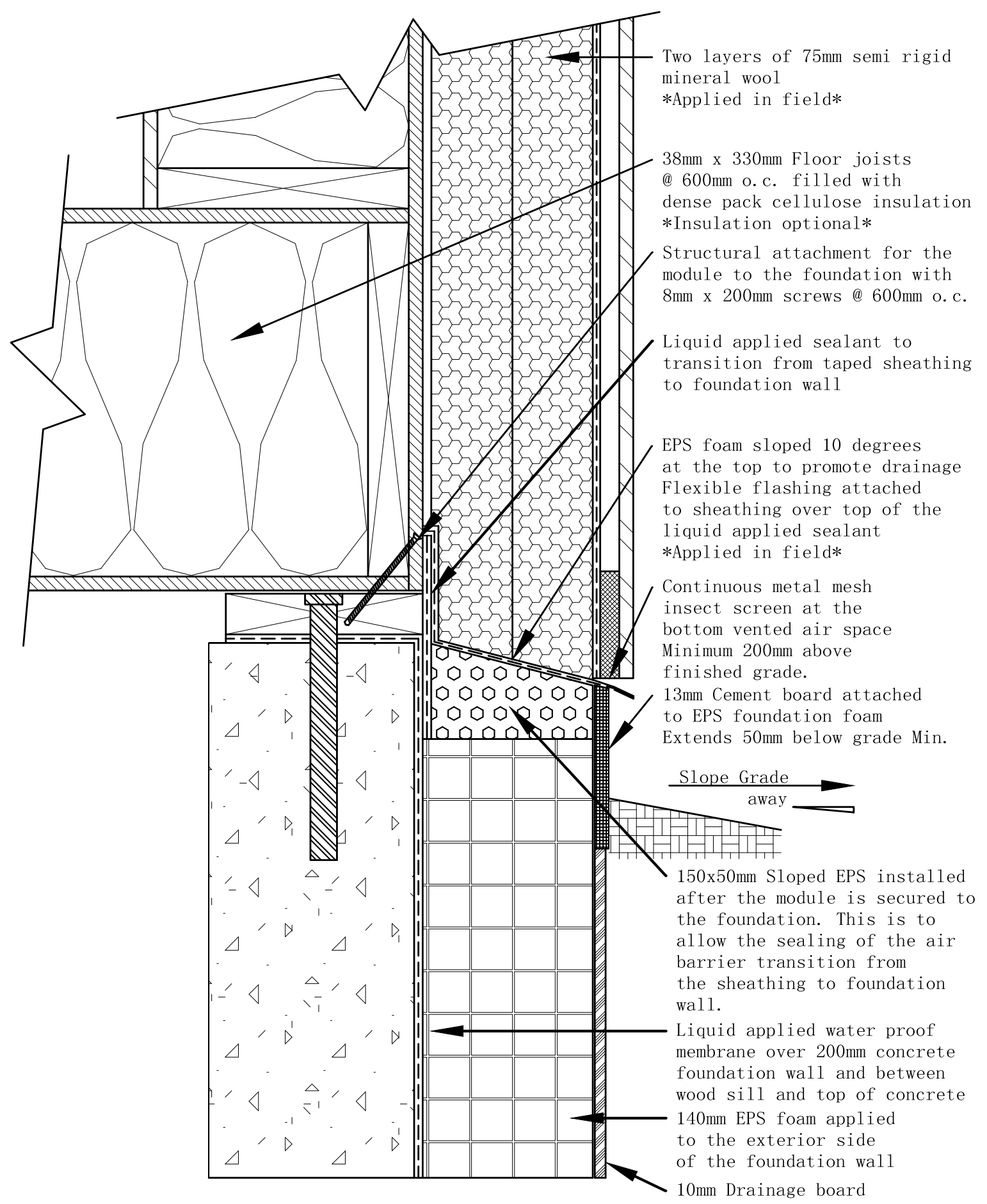

Mineral Wool Assembly

Foundation Connection

\section{Scale 1:5}




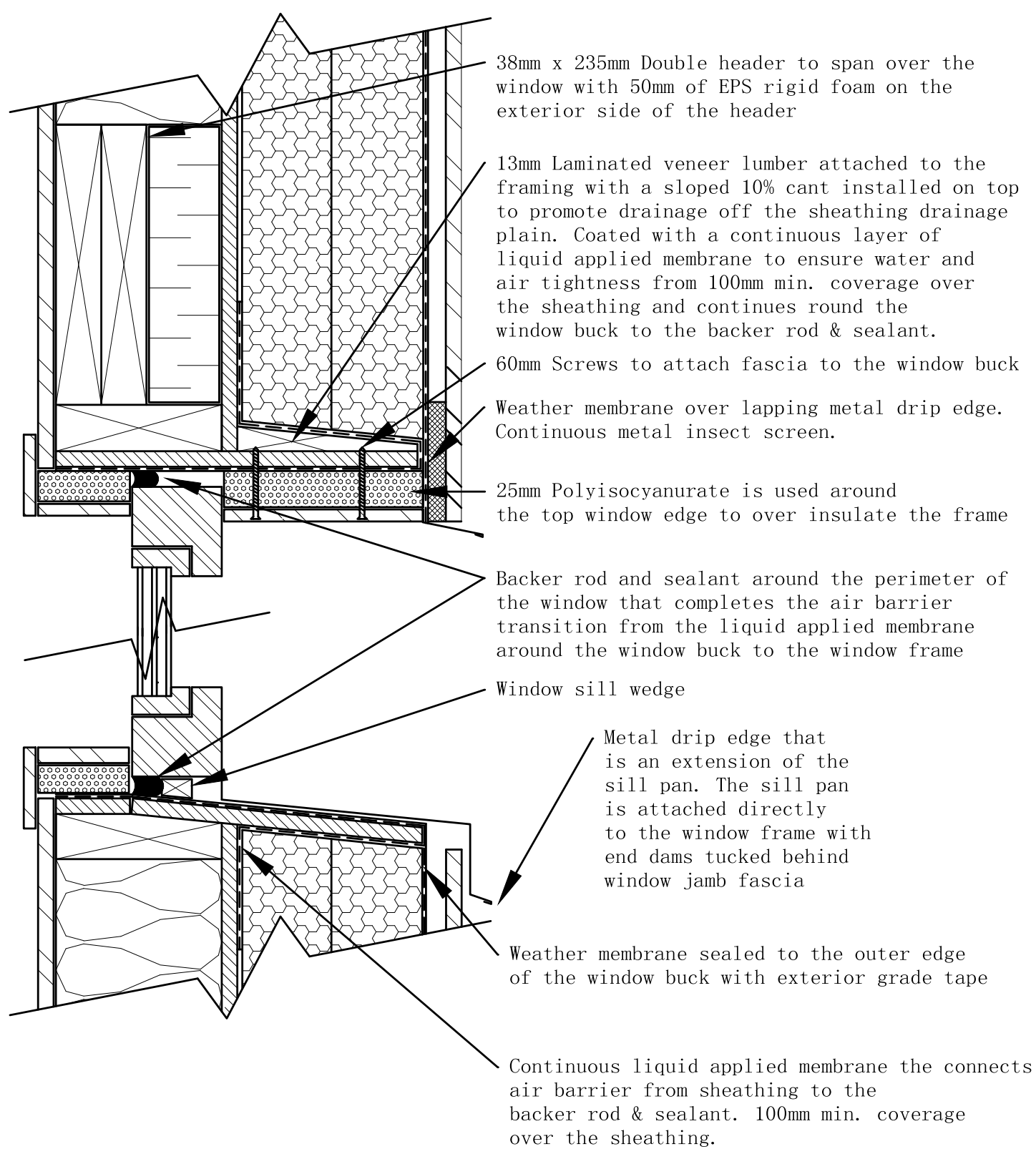

Mineral Wool Assembly

Window Header and Sill

Scale 1:5 


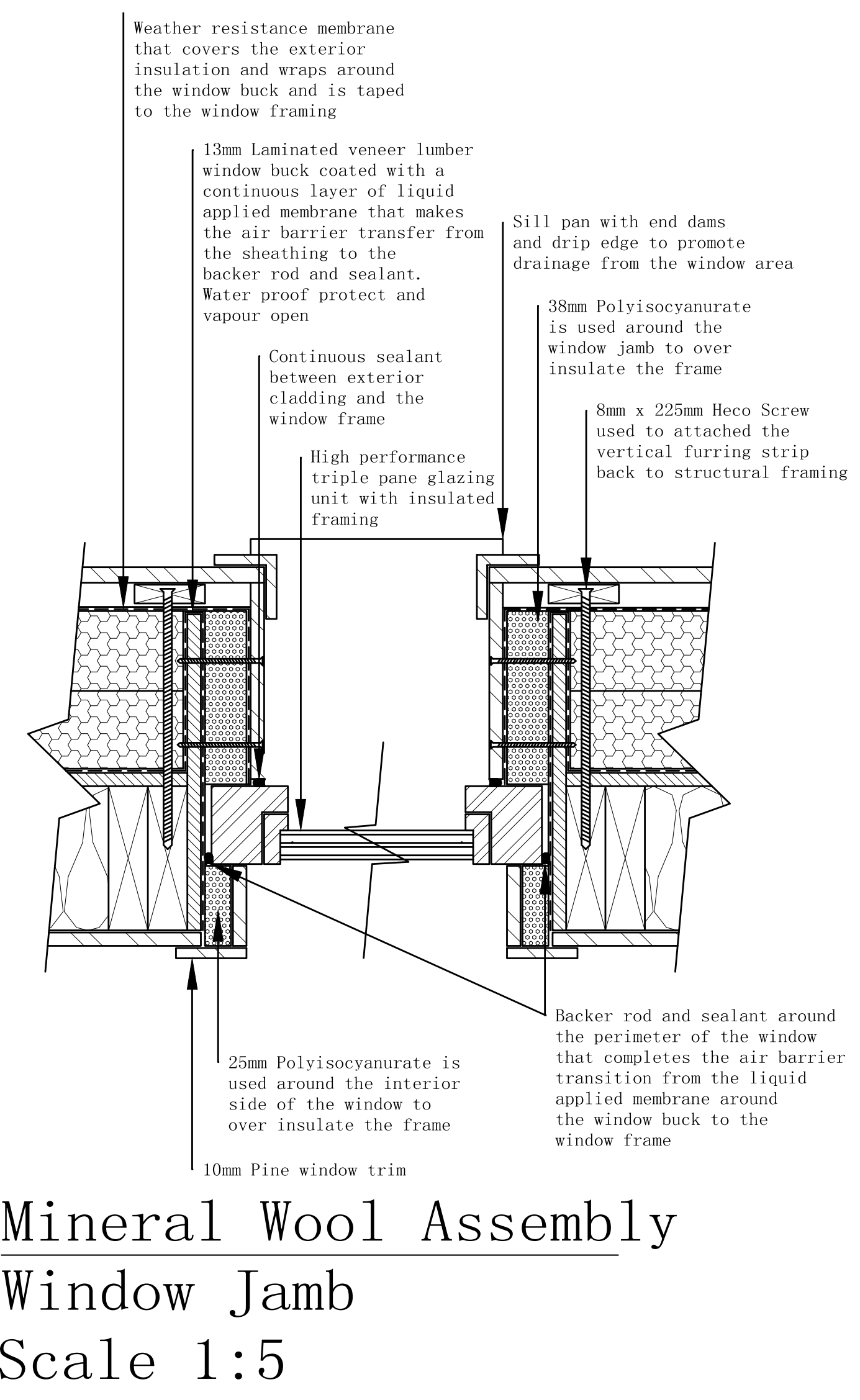




\section{Appendix C - Vertical I-Beam Assembly Details}

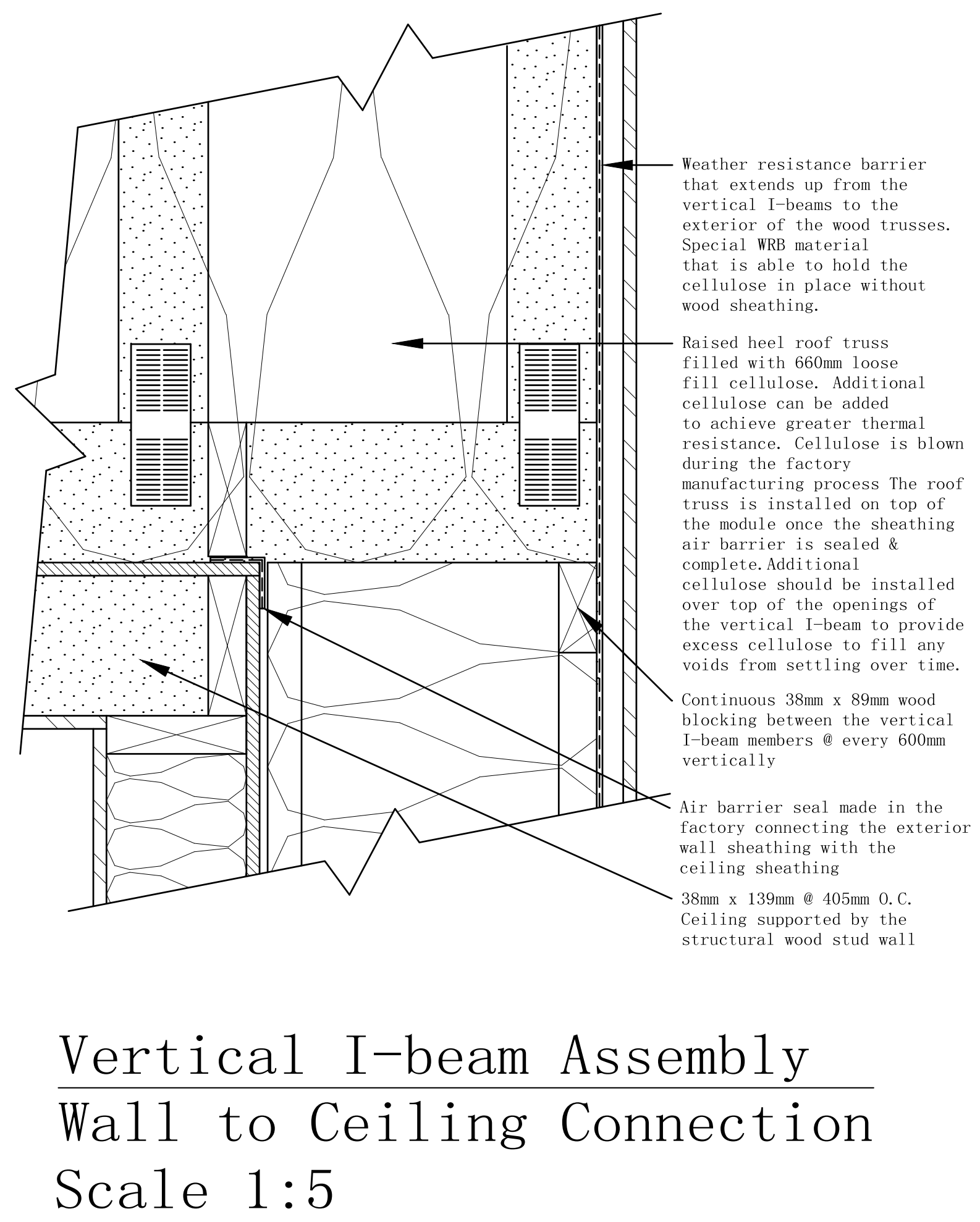




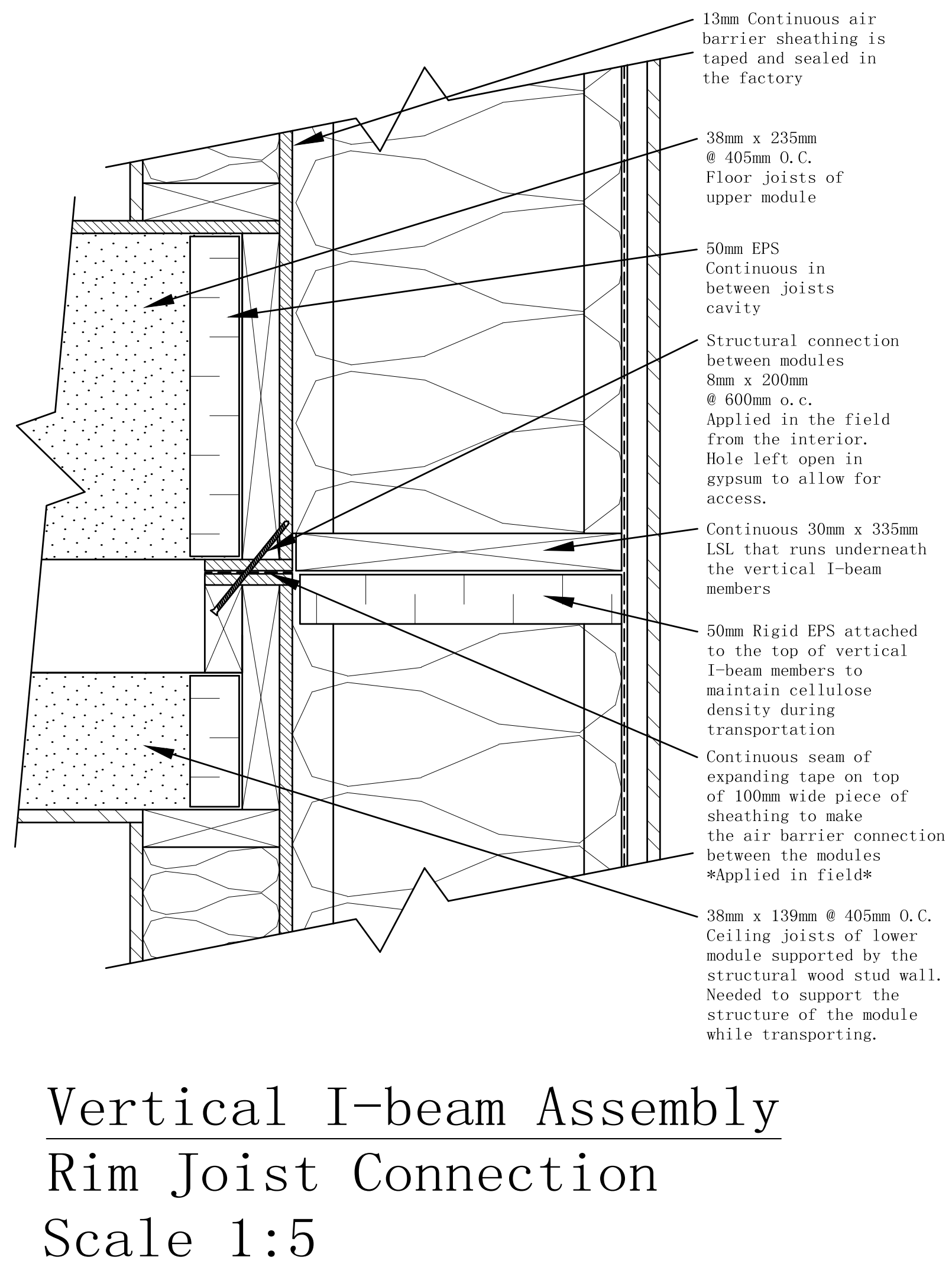




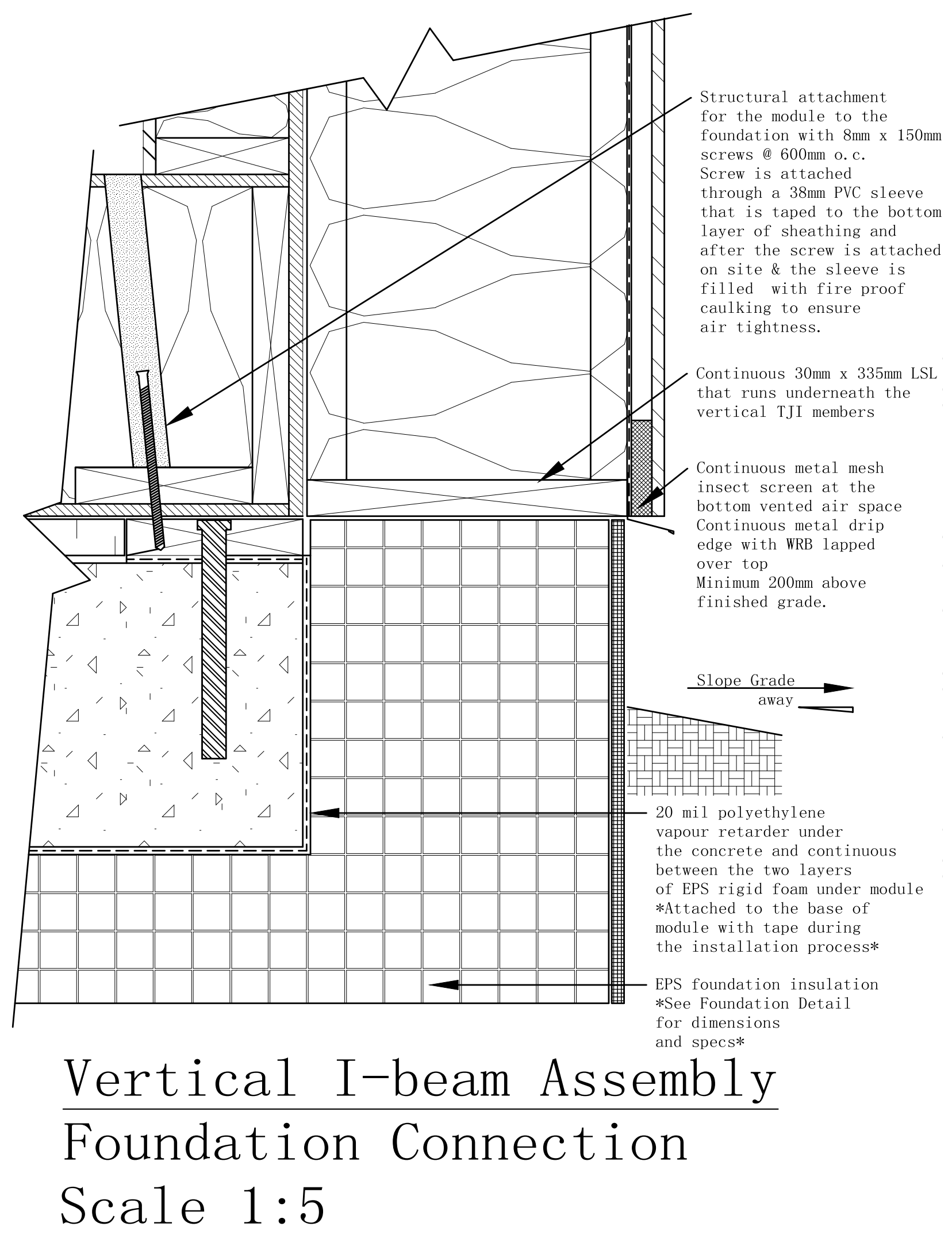




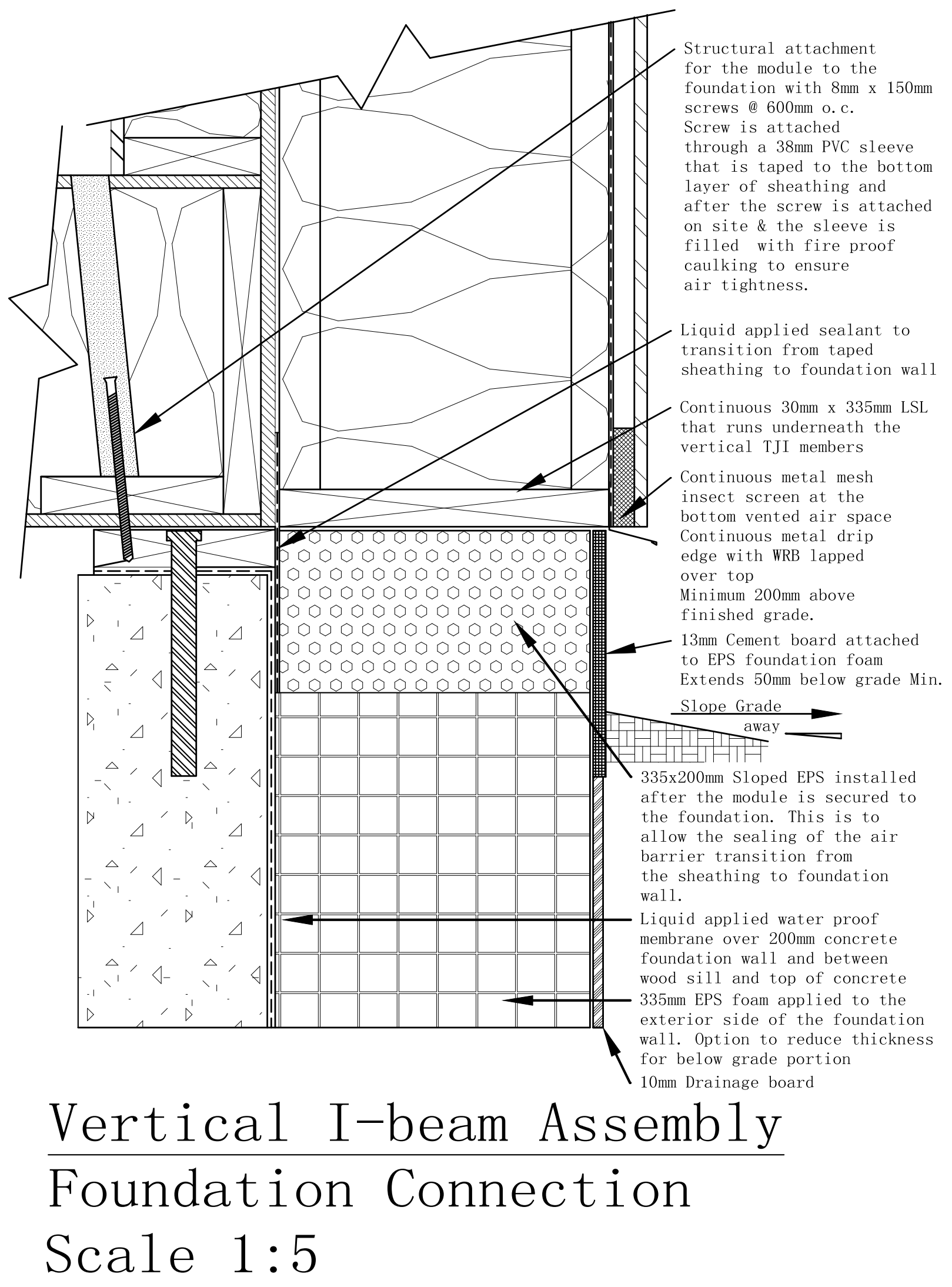




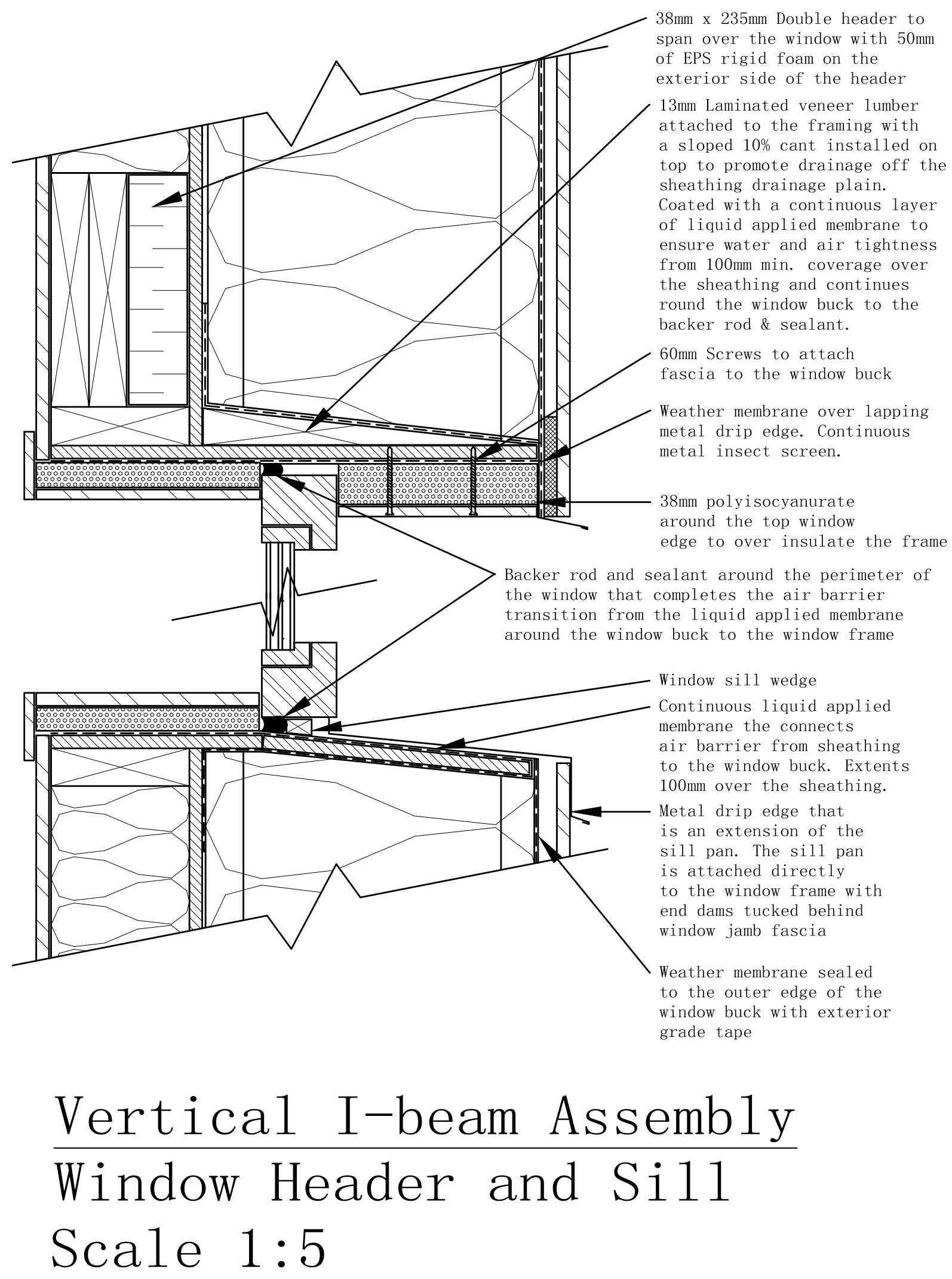




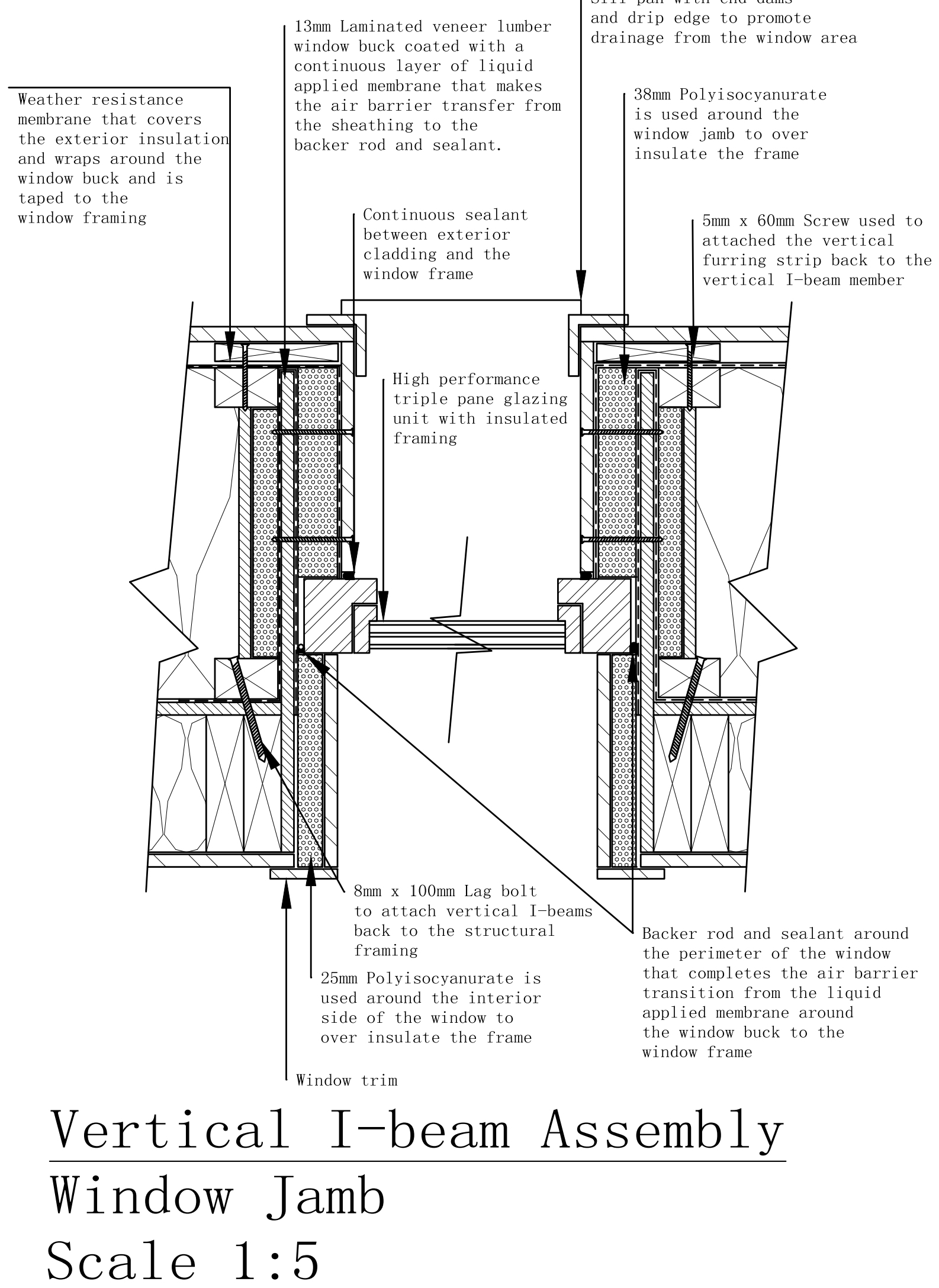




\section{Appendix D - Vacuum Insulated Panel Assembly Details}

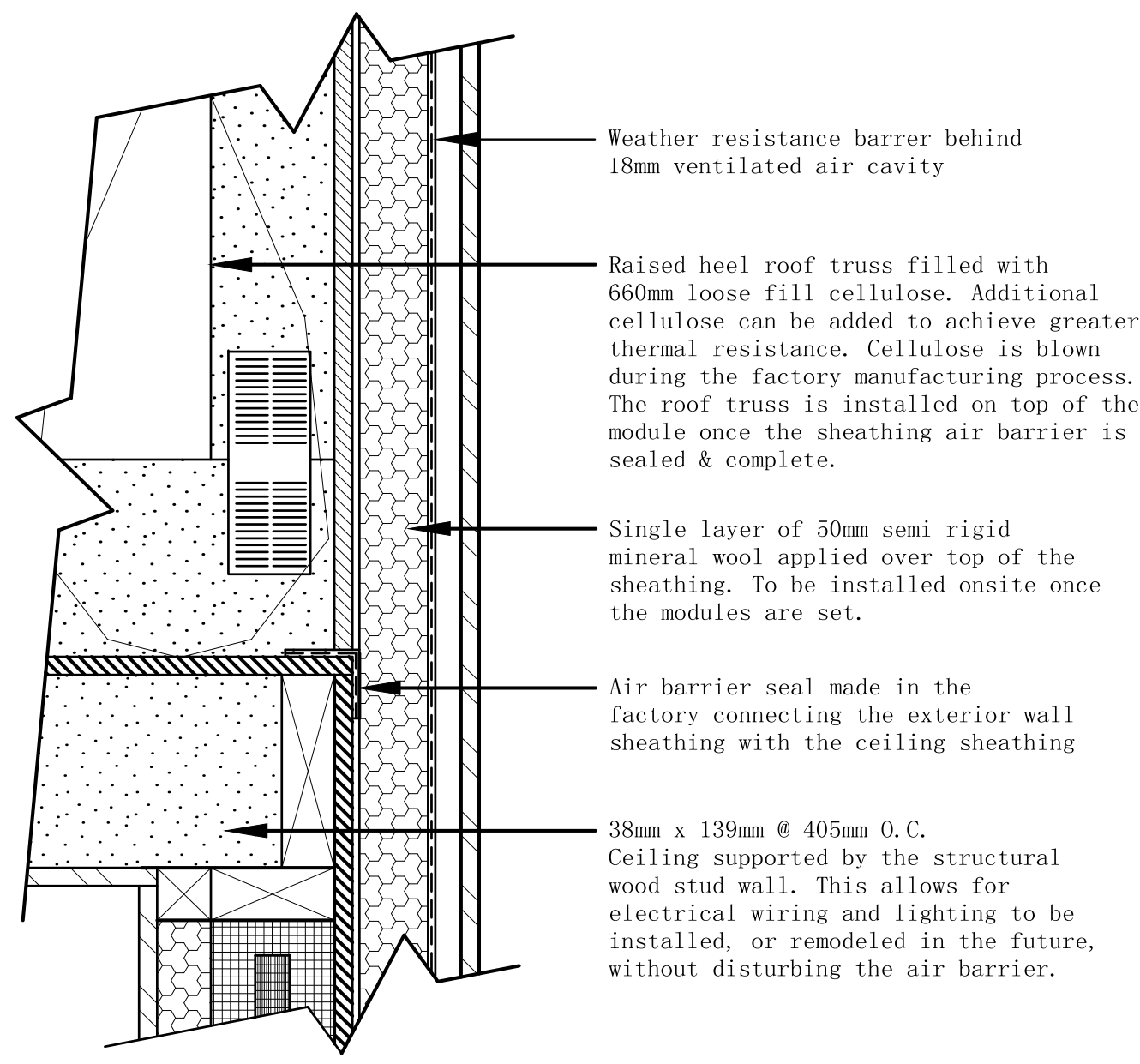

VIP Assembly

Wall to Ceiling Connection Scale 1:5 


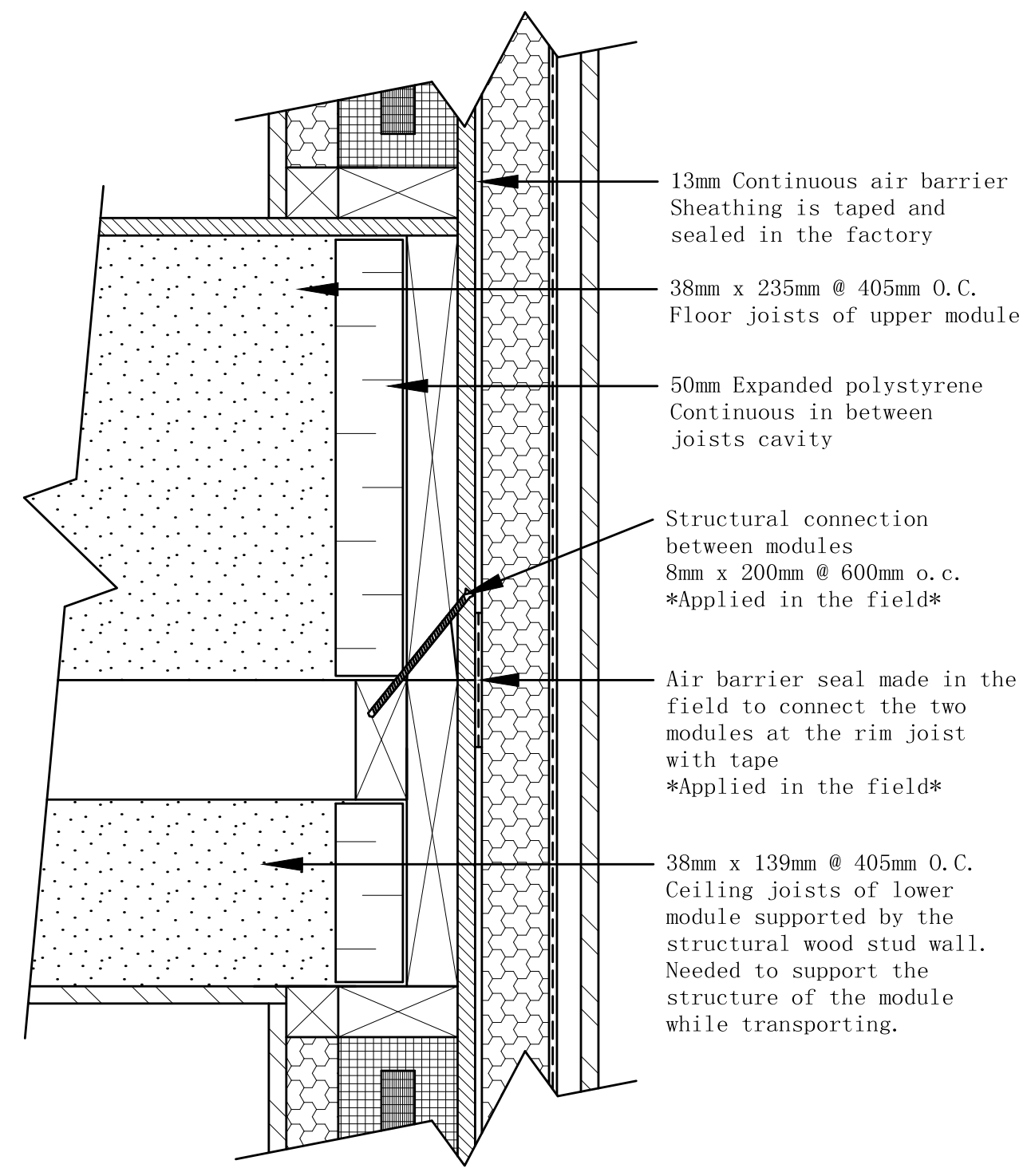

VIP Assembly

Rim Joist Connection

Scale 1:5 


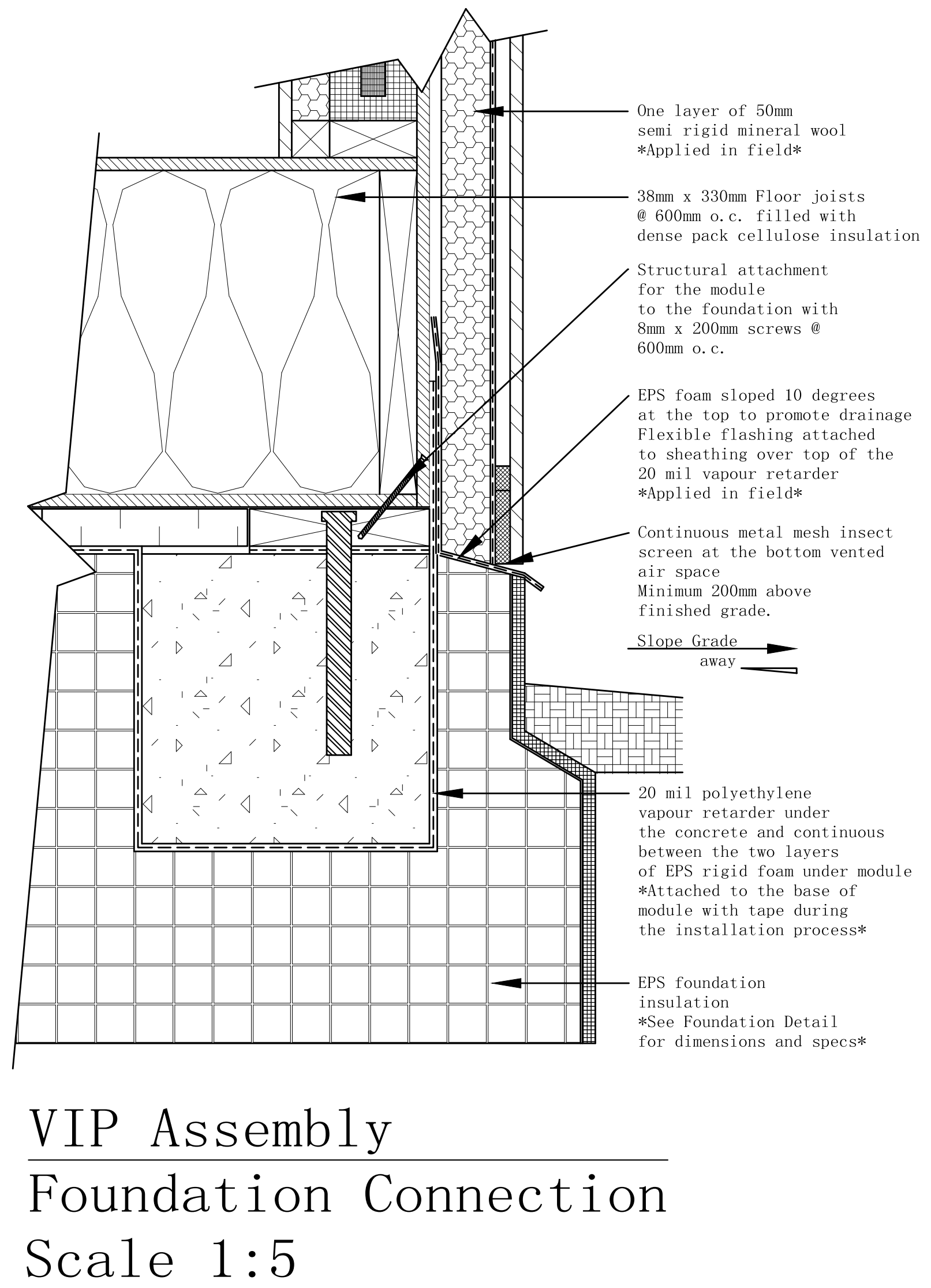




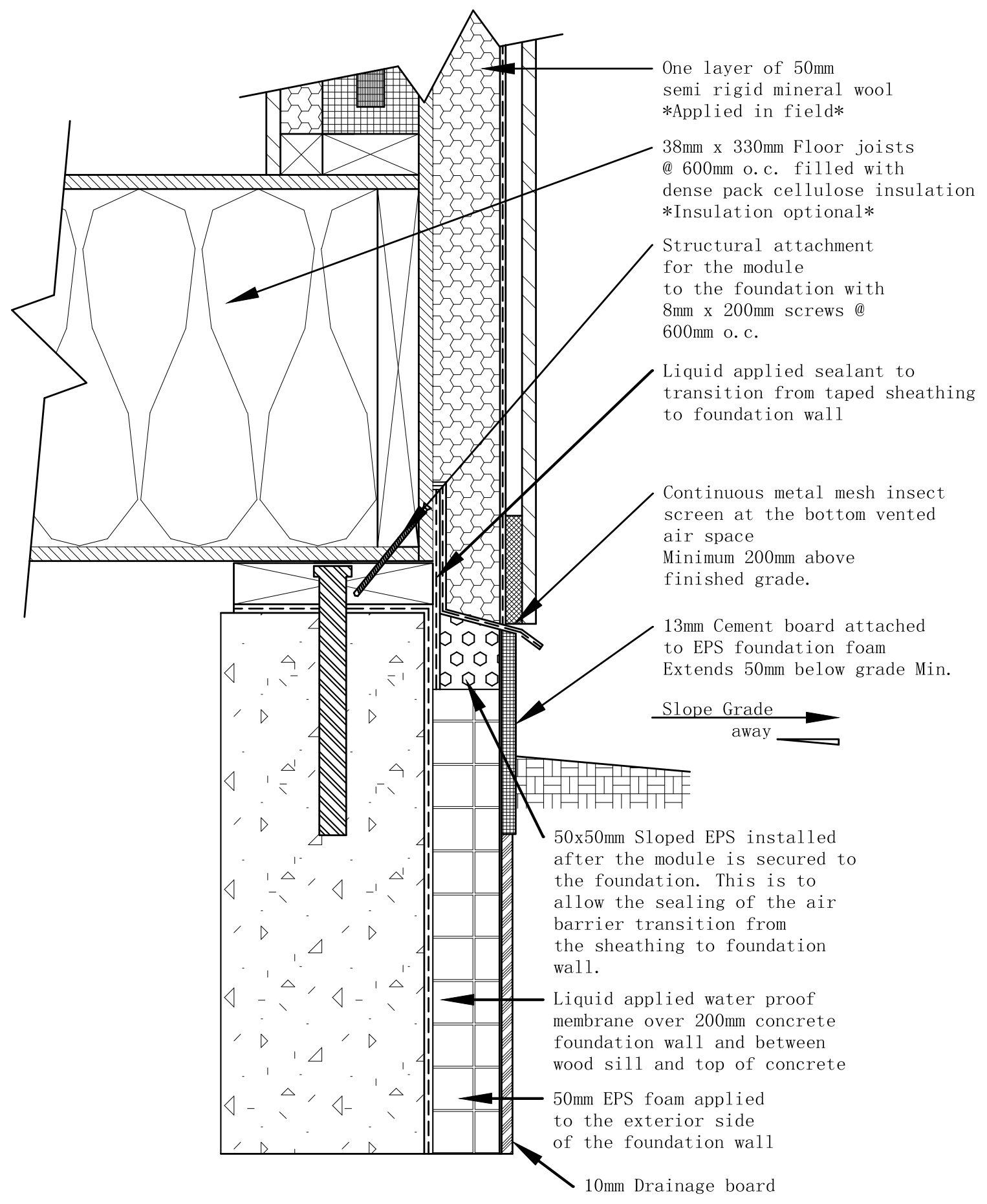

\section{VIP Assembly}

Foundation Connection

\section{Scale 1:5}




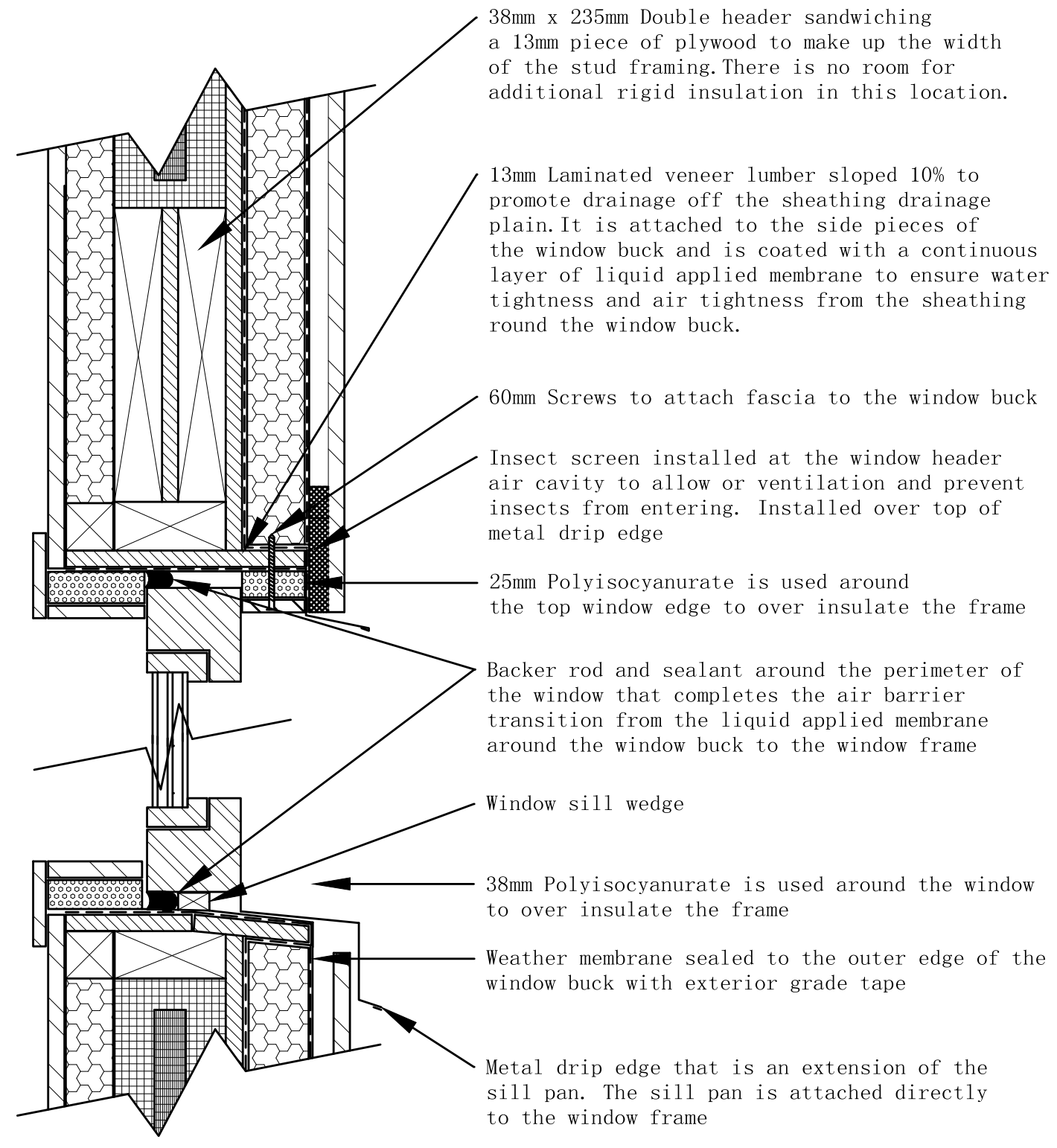

\section{VIP Assembly}

Window Header and Sill

\section{Scale 1:5}




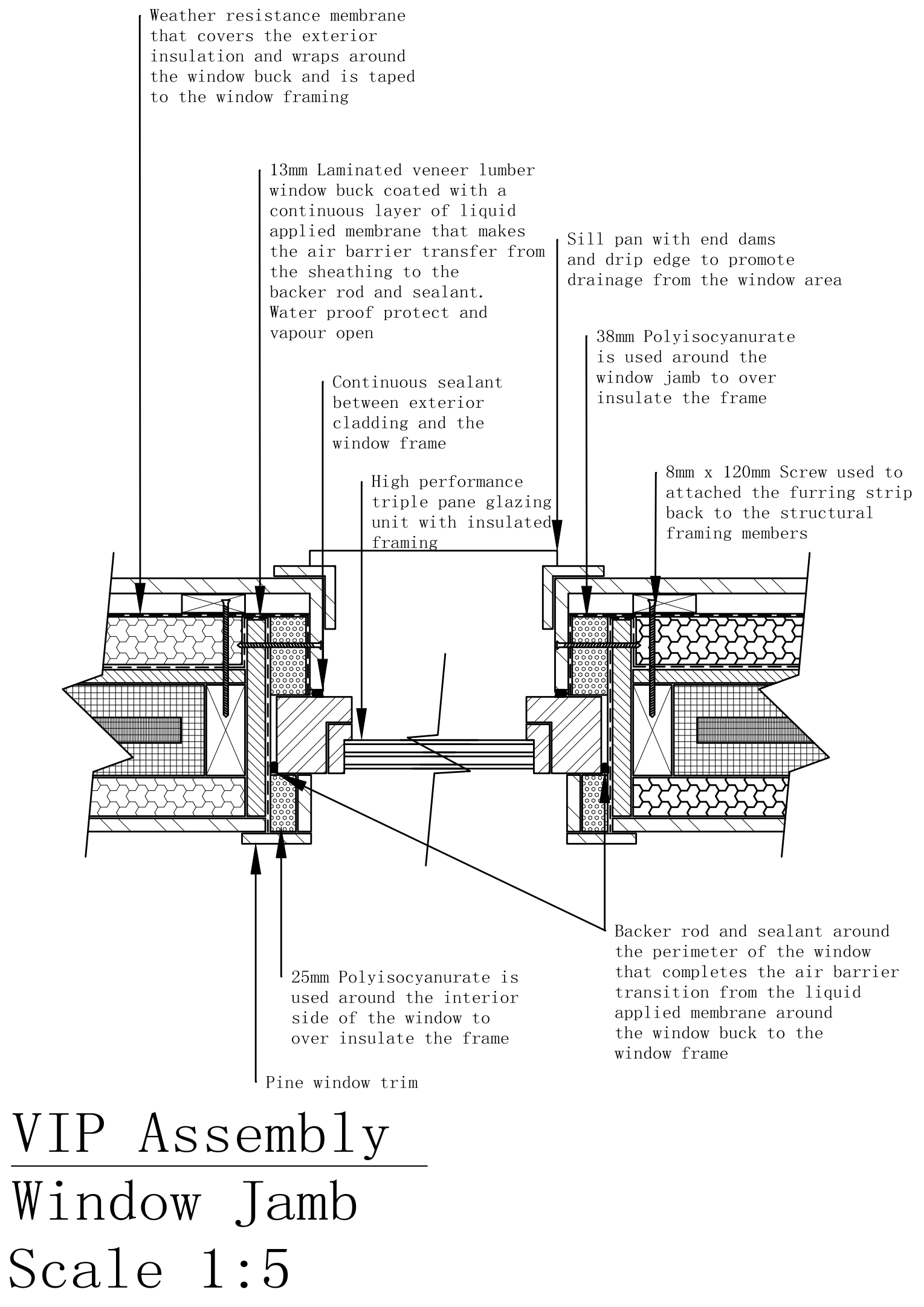




\section{Appendix E - Marriage Connection Details}

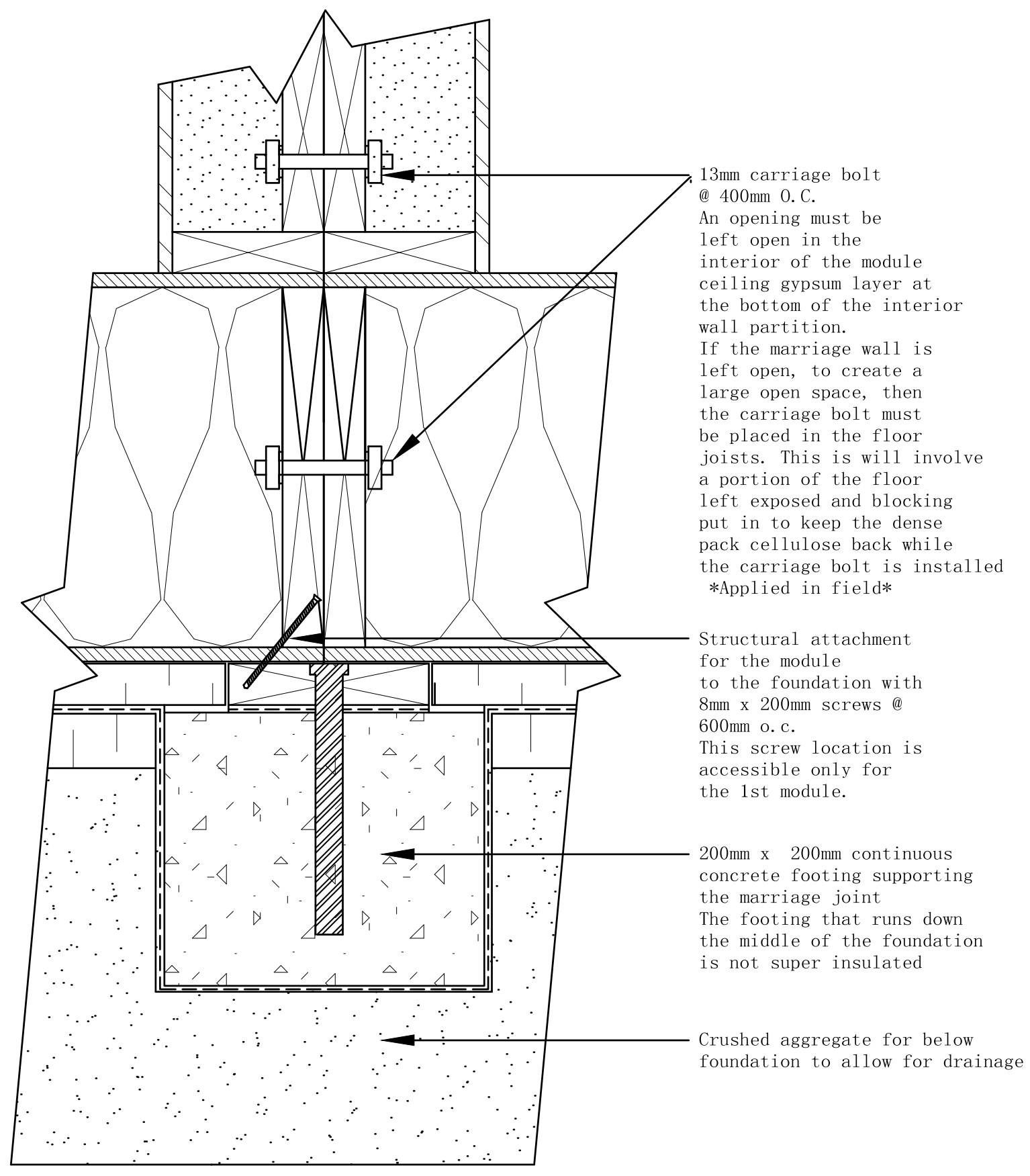

\section{Marriage Connection \\ Foundation \\ Scale $1: 5$}




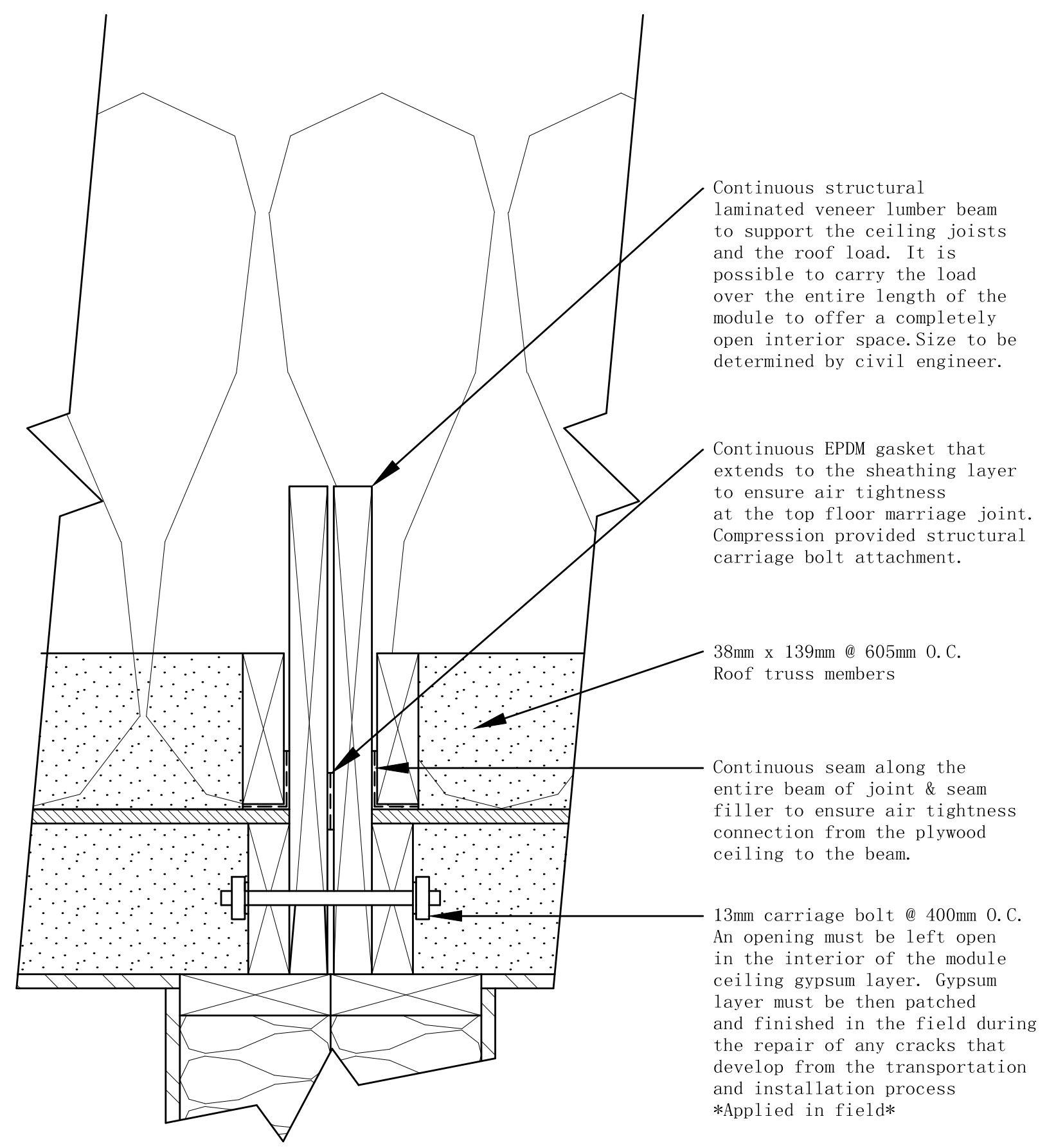

\section{Marriage Connection \\ Top Floor Ceiling \\ Scale 1:5}




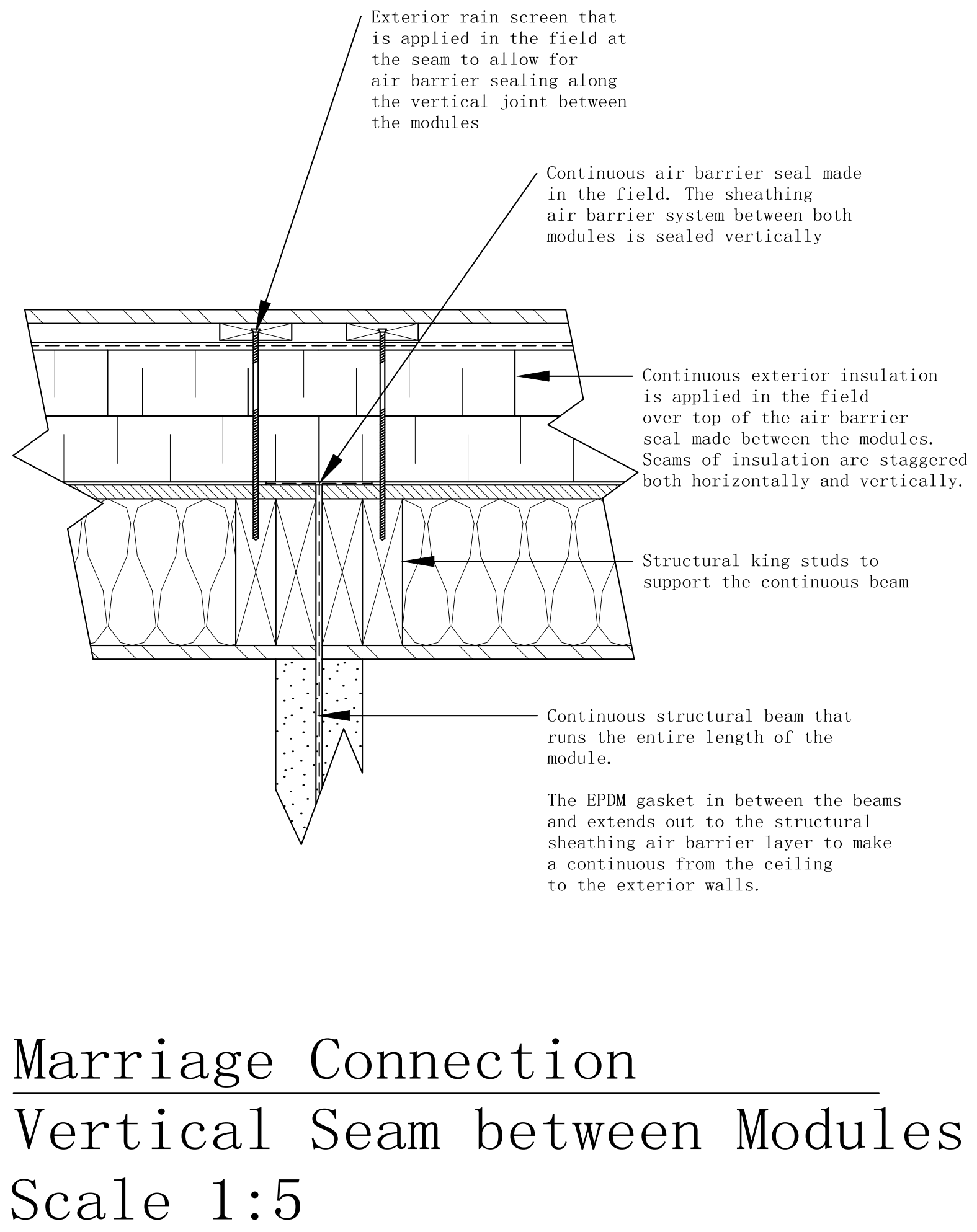




\section{Appendix F}

Polyisocyanurate Assembly WUFI® Results Graphs

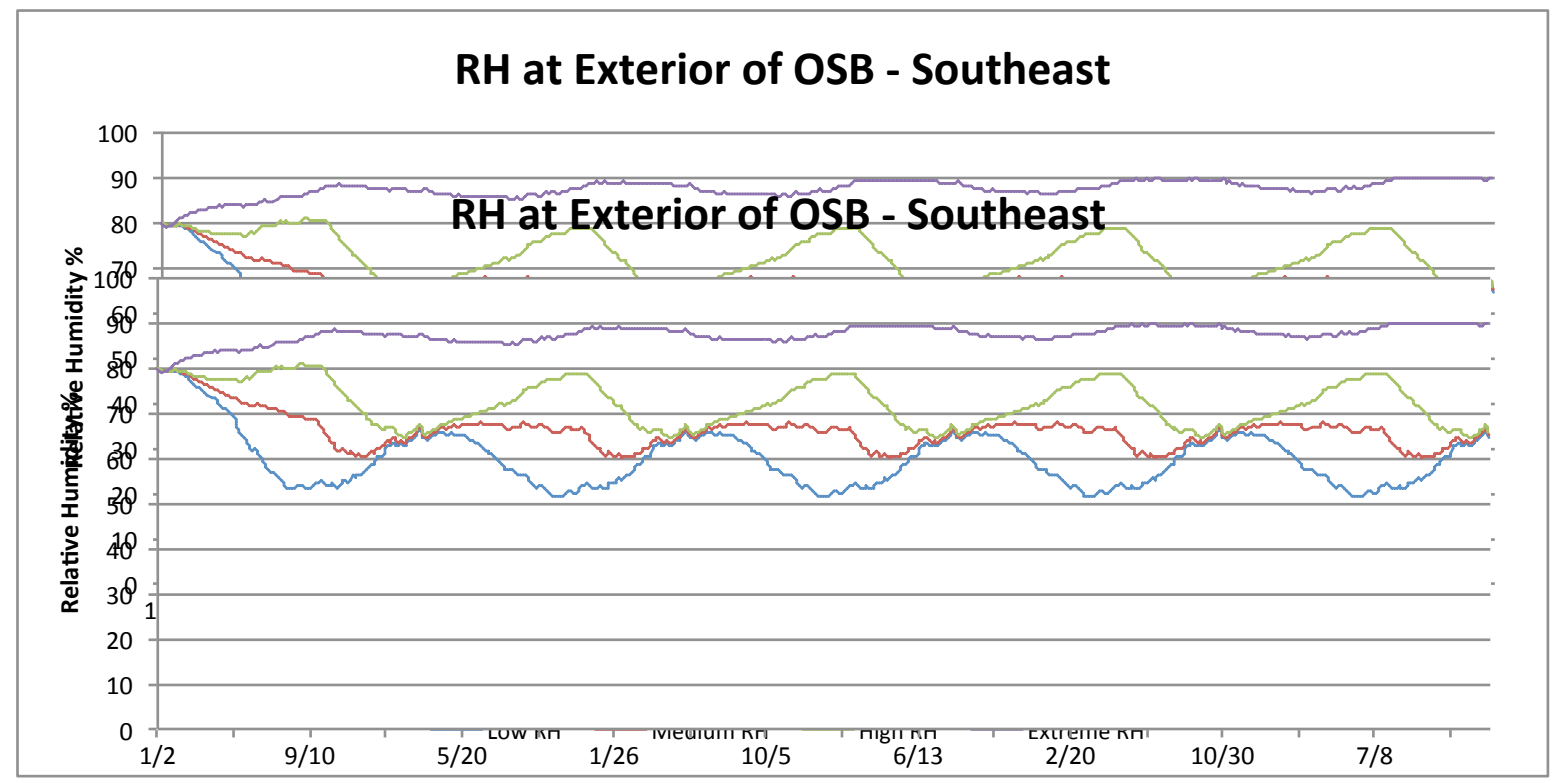

RH of exterior OSB edge of polyisocyanurate assembly - Standard Case

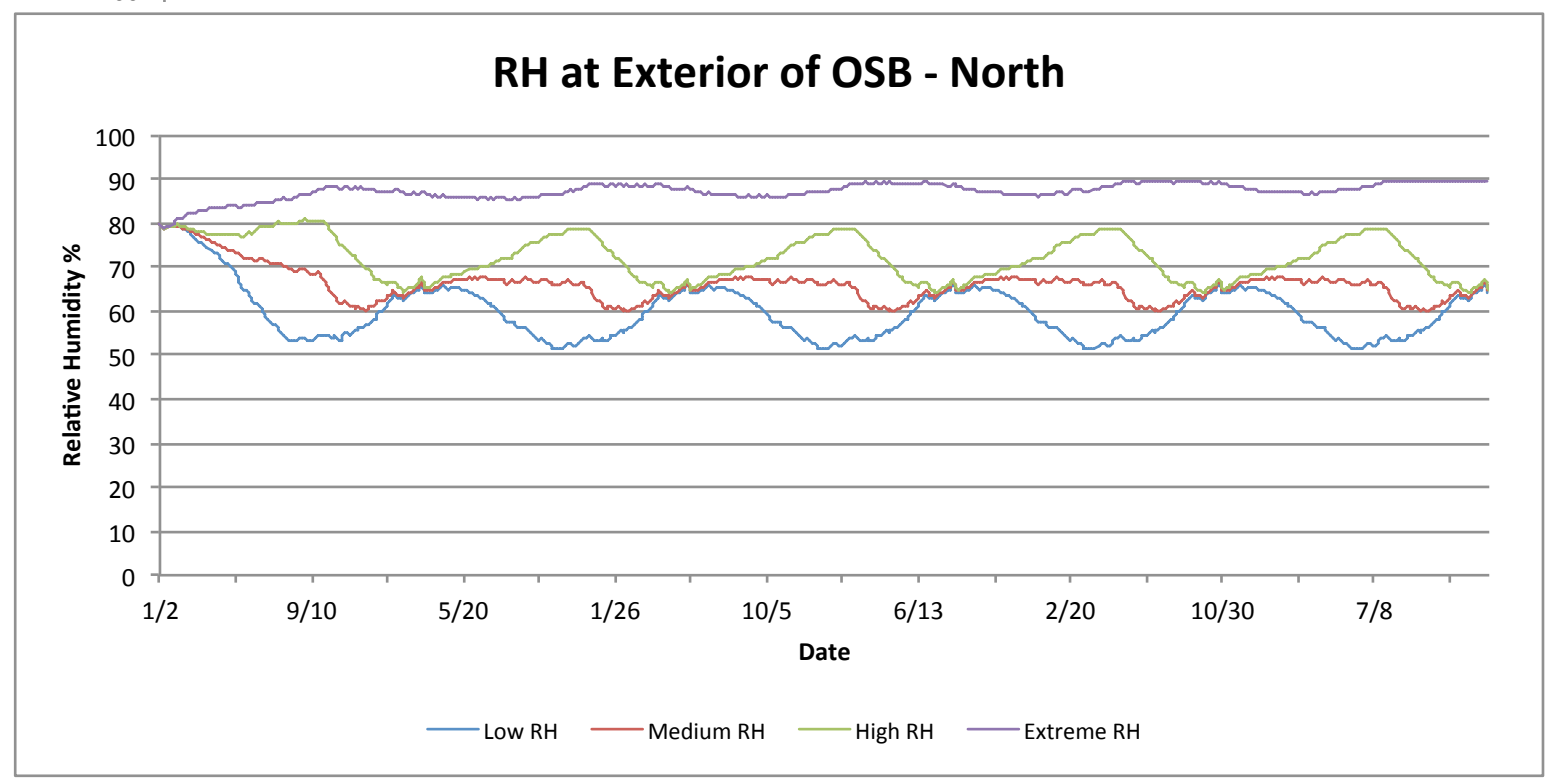

RH of exterior OSB edge of polyisocyanurate assembly - Standard Case 


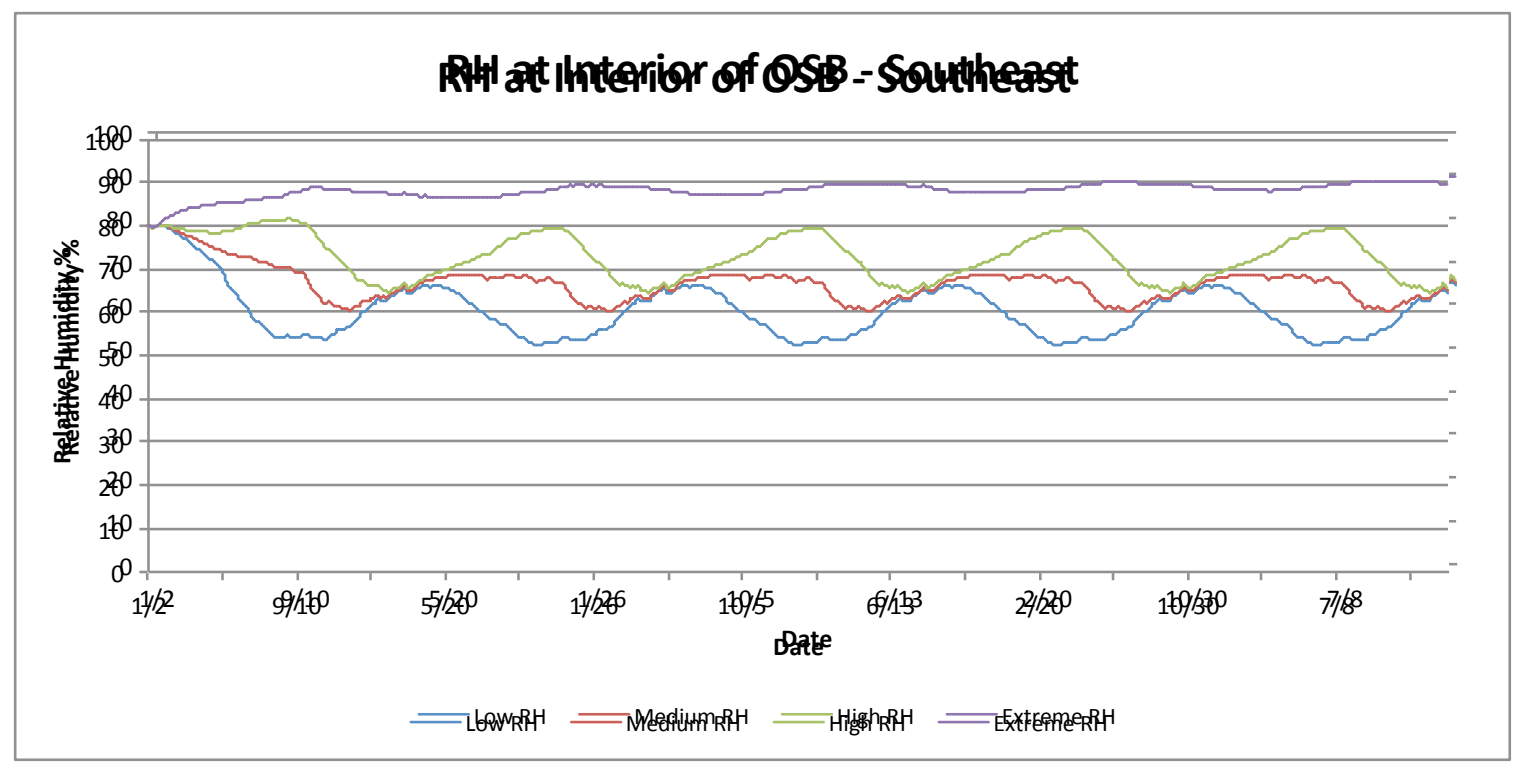

RH of interior OSB edge of polyisocyanurate assembly - Standard Case

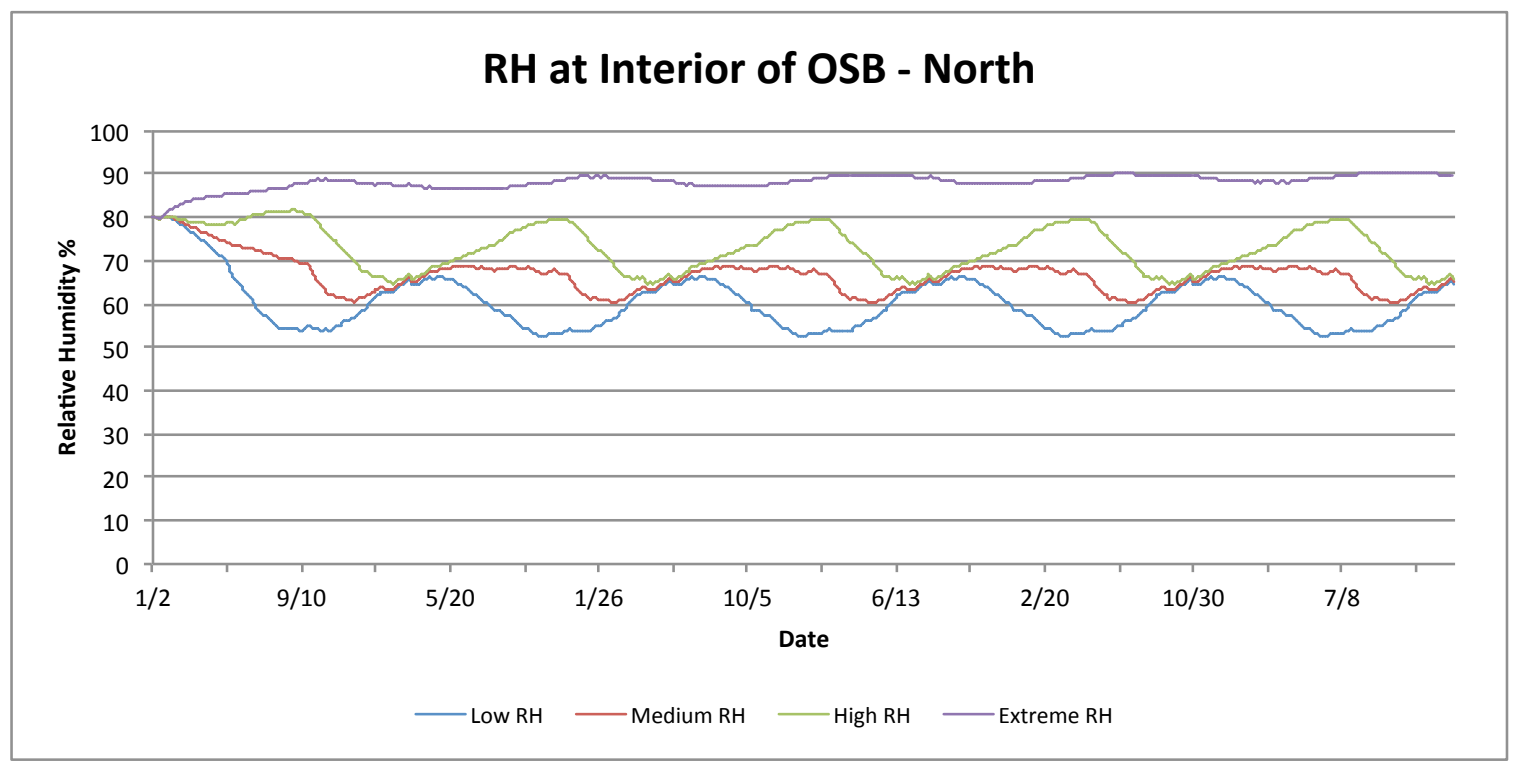

RH of interior OSB edge of polyisocyanurate assembly - Standard Case 


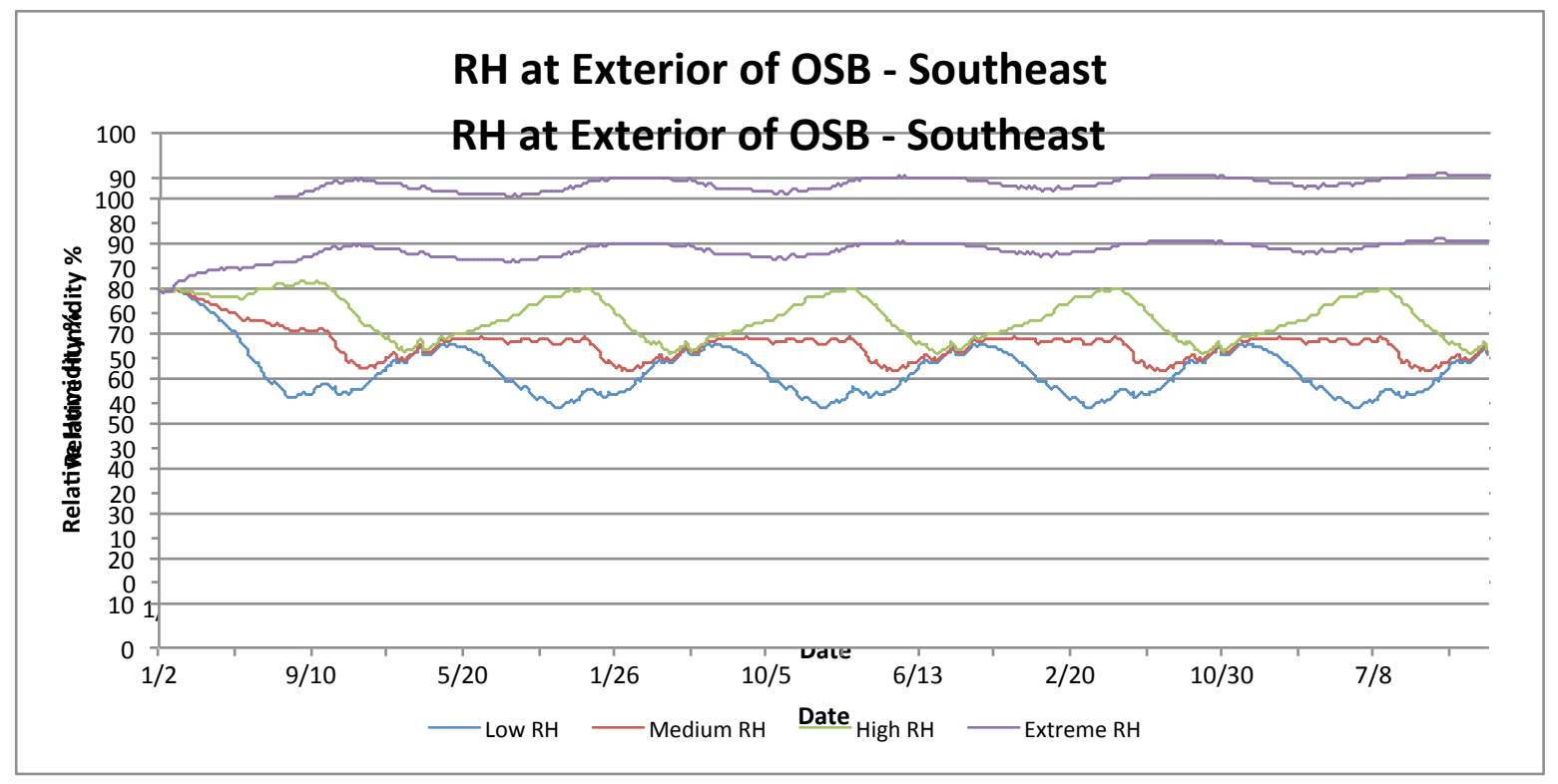

RH of exterior OSB edge of polyisocyanurate assembly - Intensified Case

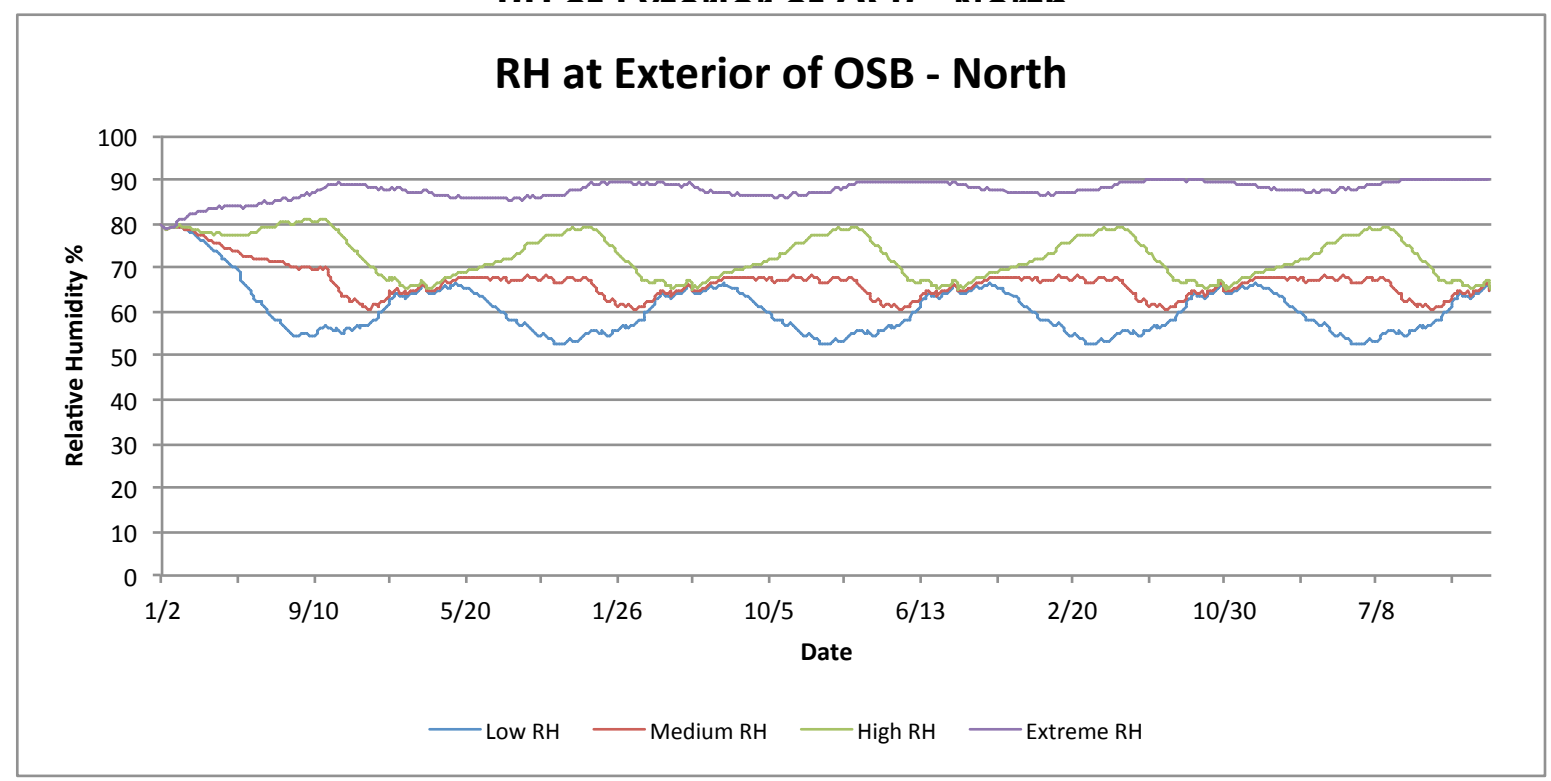

RH of exterior OSB edge of polyisocyanurate assembly - Intensified Case 


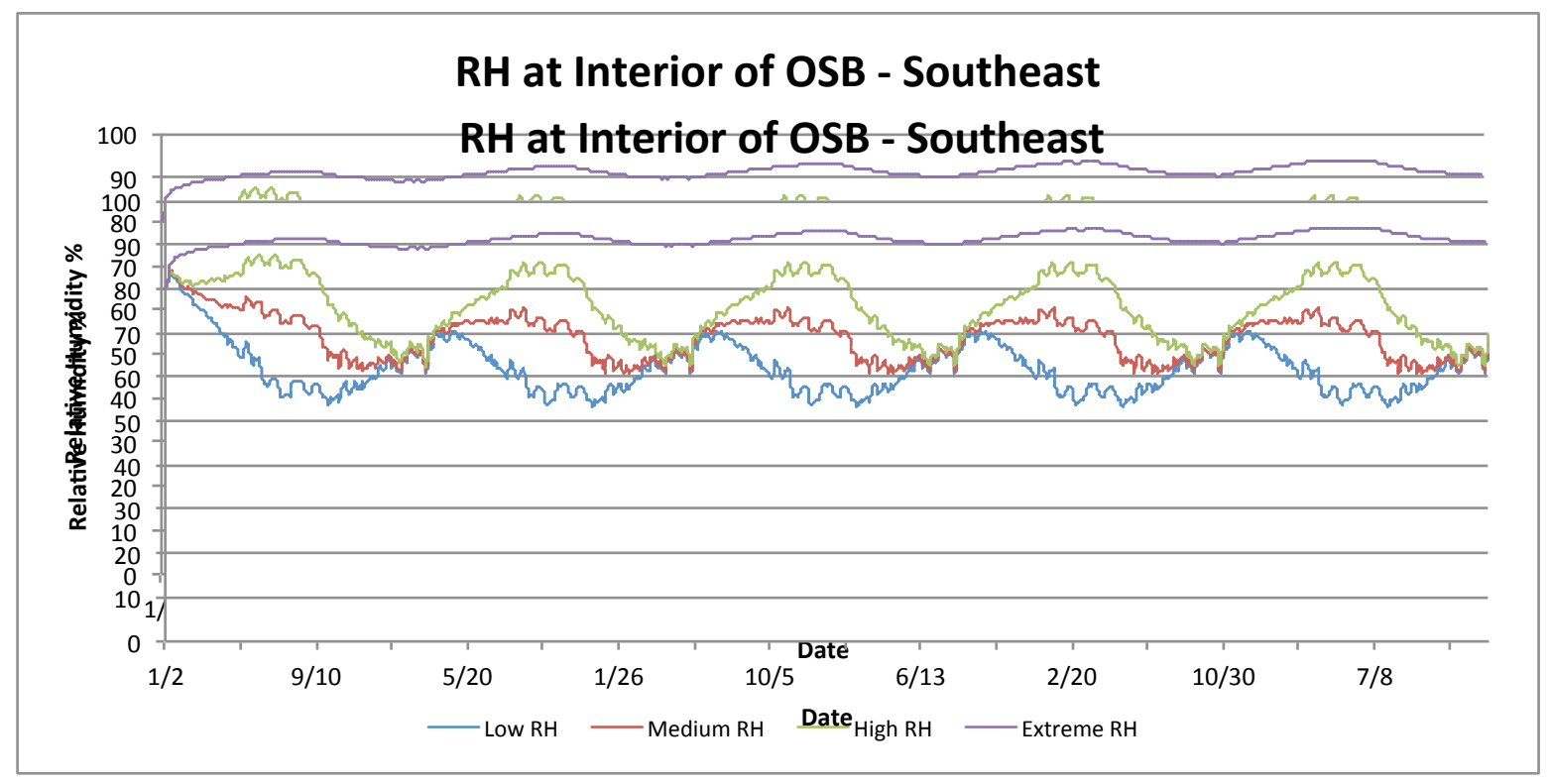

RH of interior OSB edge of polyisocyanurate assembly - Intensified Case

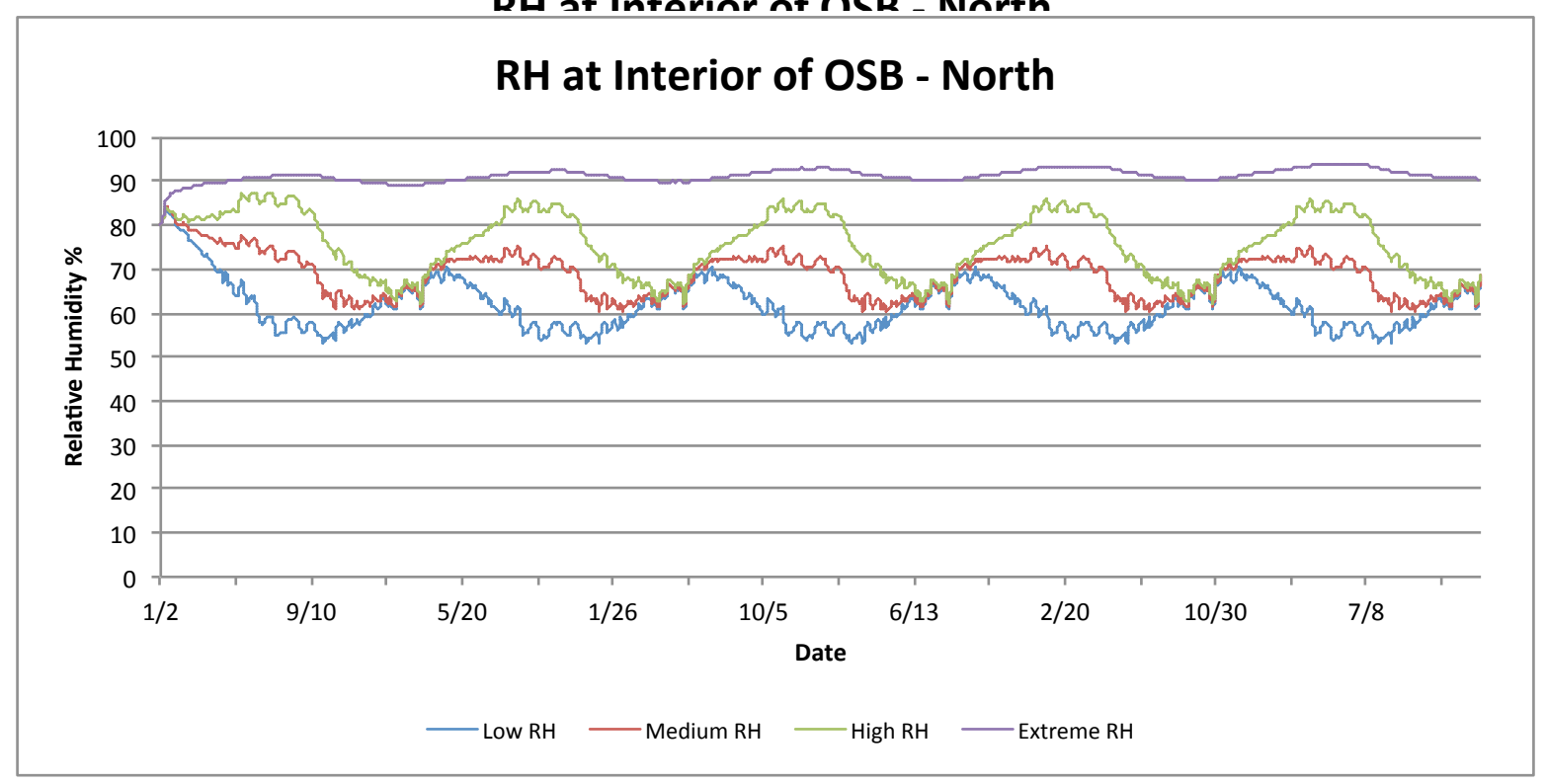

RH of interior OSB edge of polyisocyanurate assembly - Intensified Case 


\section{Appendix G}

Mineral Wool Assembly WUFI® Results Graphs

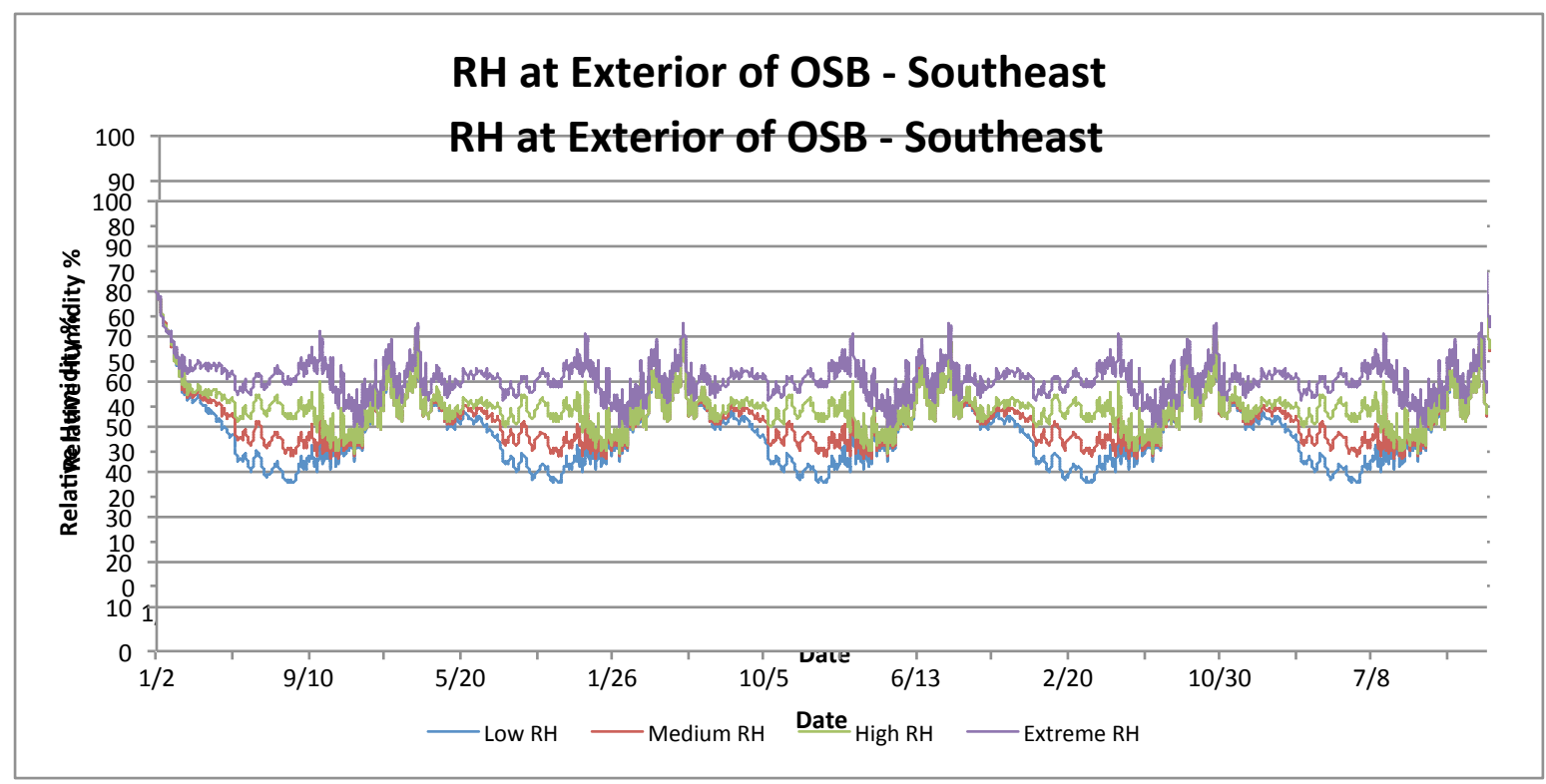

RH of exterior OSB edge of mineral wool assembly - Standard Case

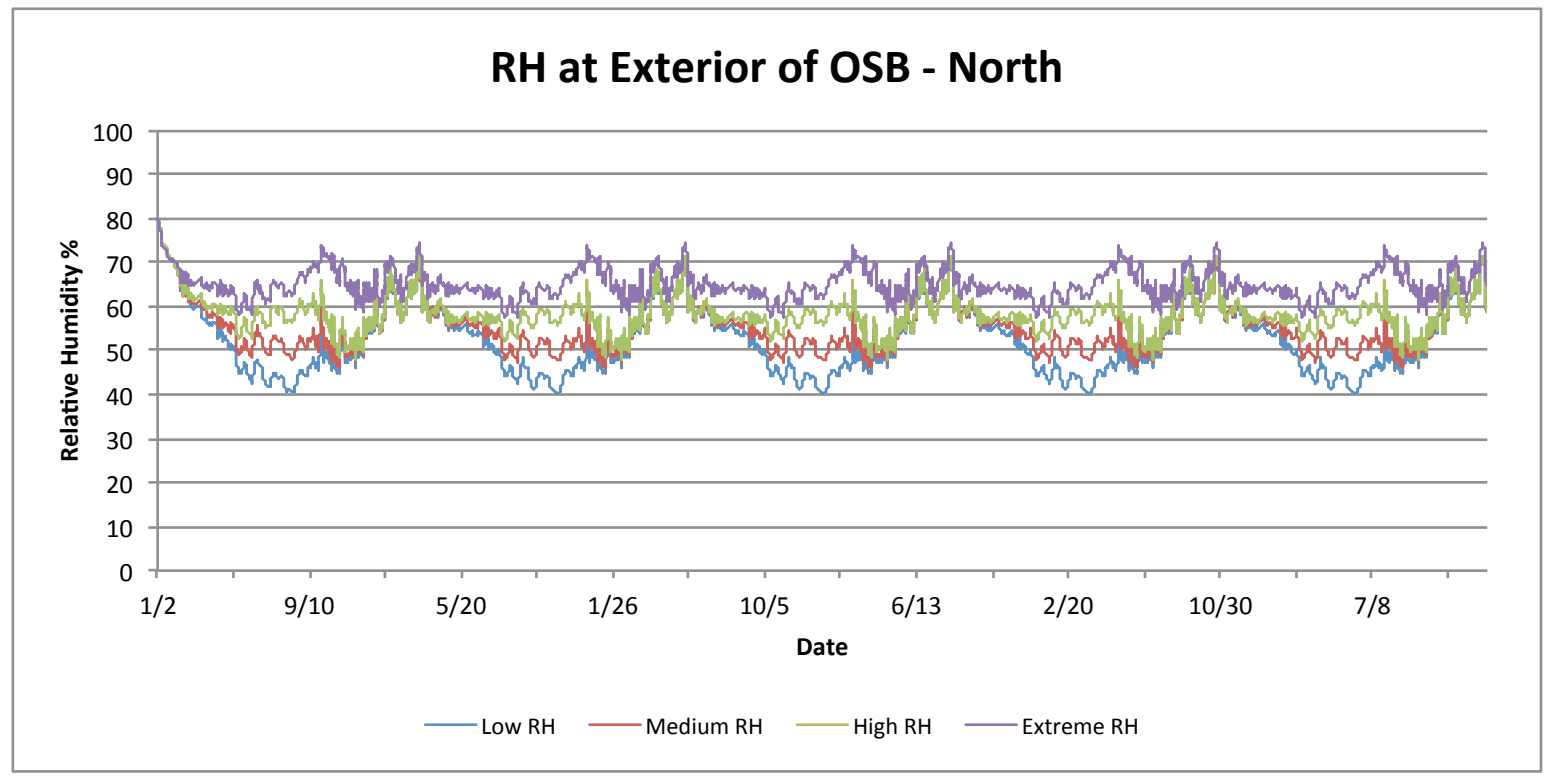

RH of exterior OSB edge of mineral wool assembly - Standard Case 


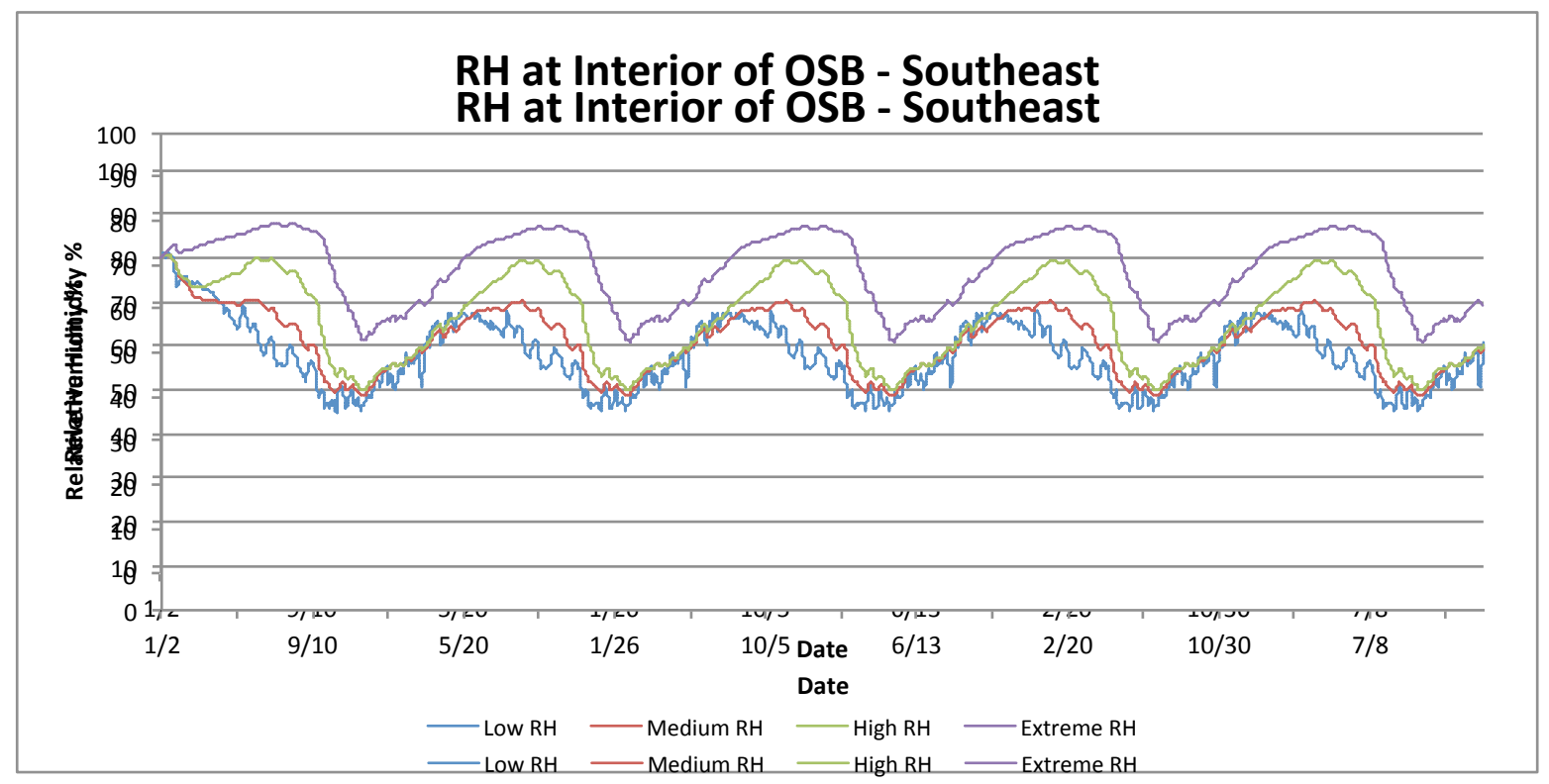

RH of interior OSB edge of mineral wool assembly - Standard Case

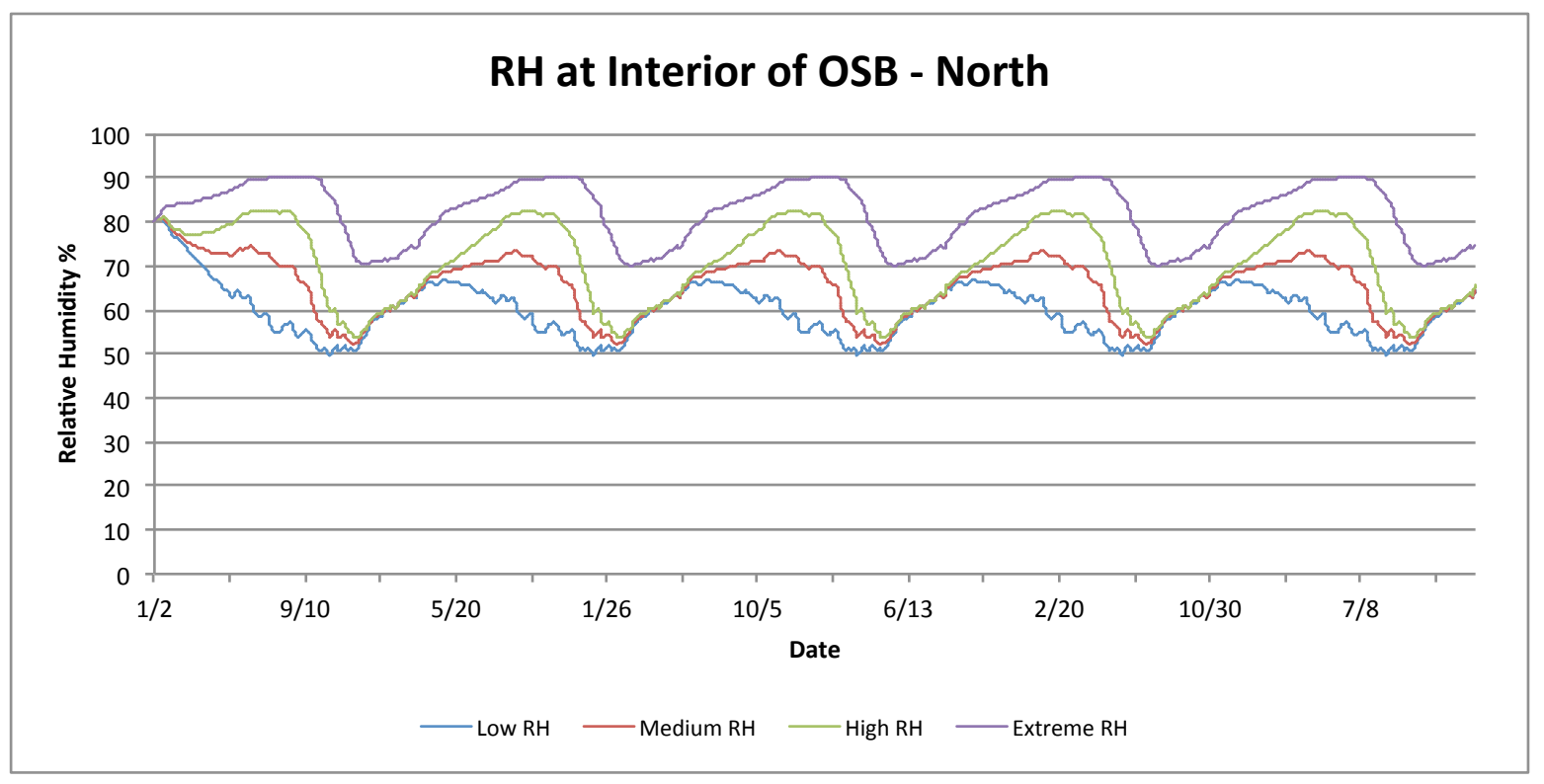

RH of interior OSB edge of mineral wool assembly - Standard Case 


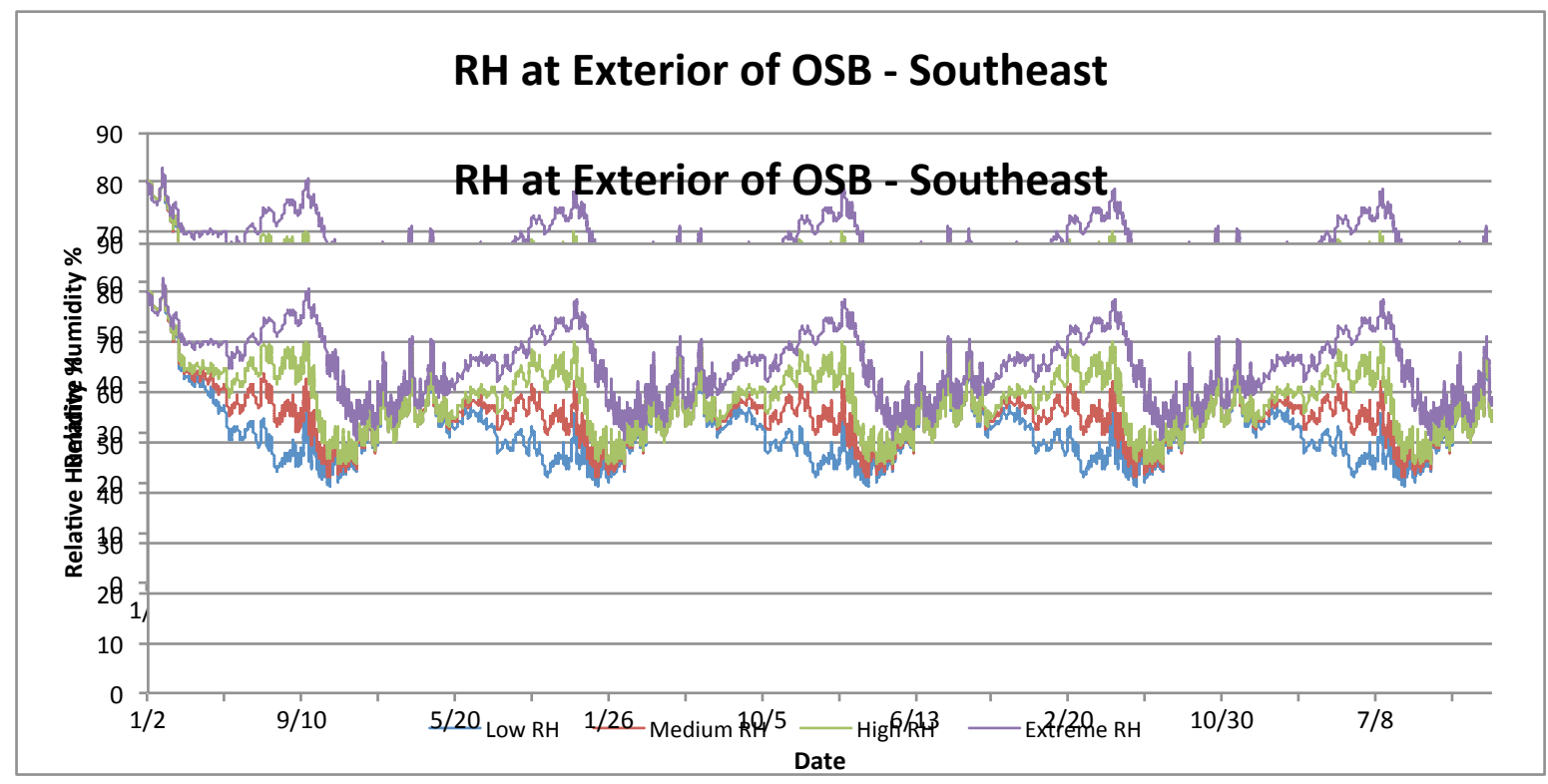

RH of exterior OSB edge of mineral wool assembly - Intensified Case

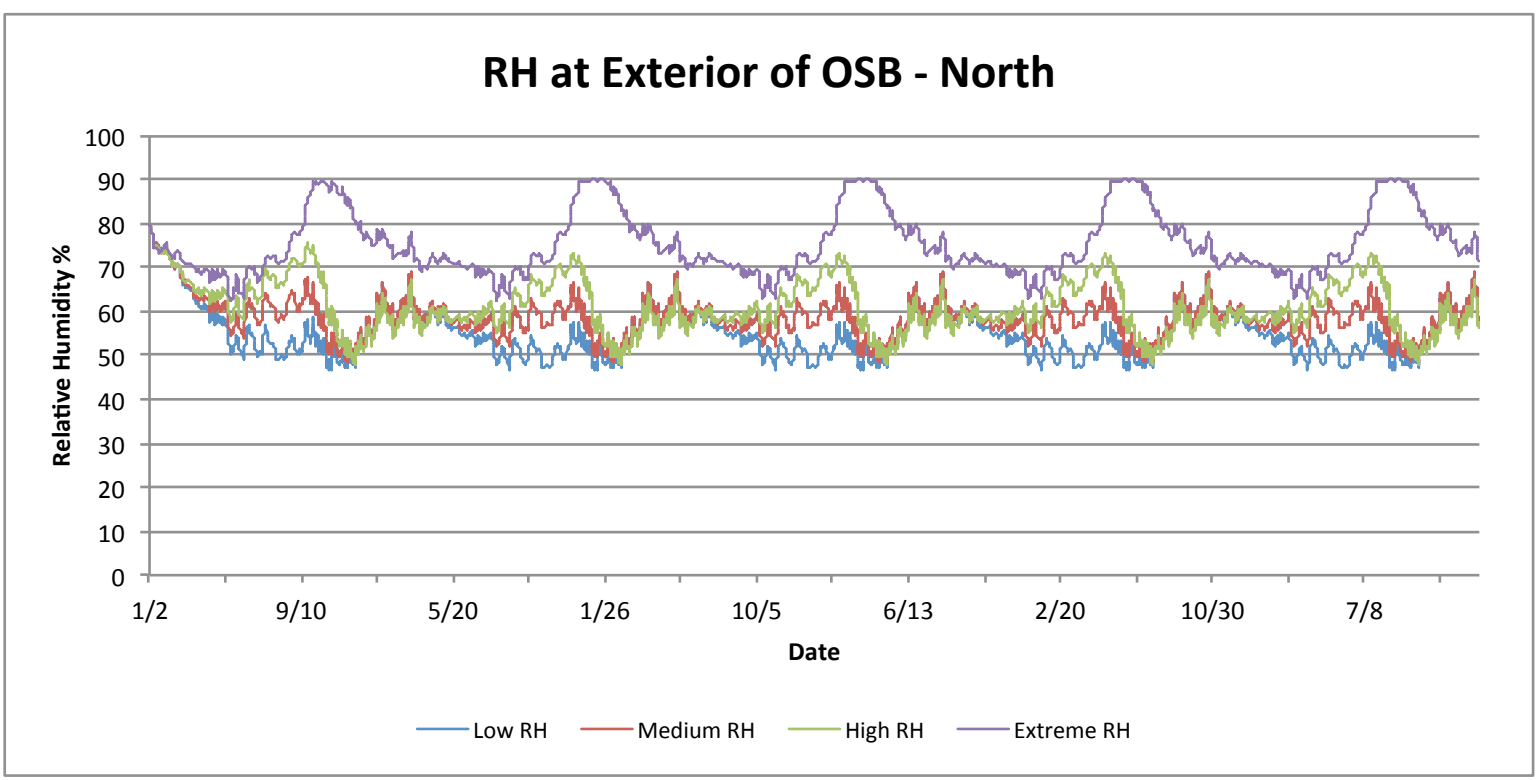

RH of exterior OSB edge of mineral wool assembly - Intensified Case 


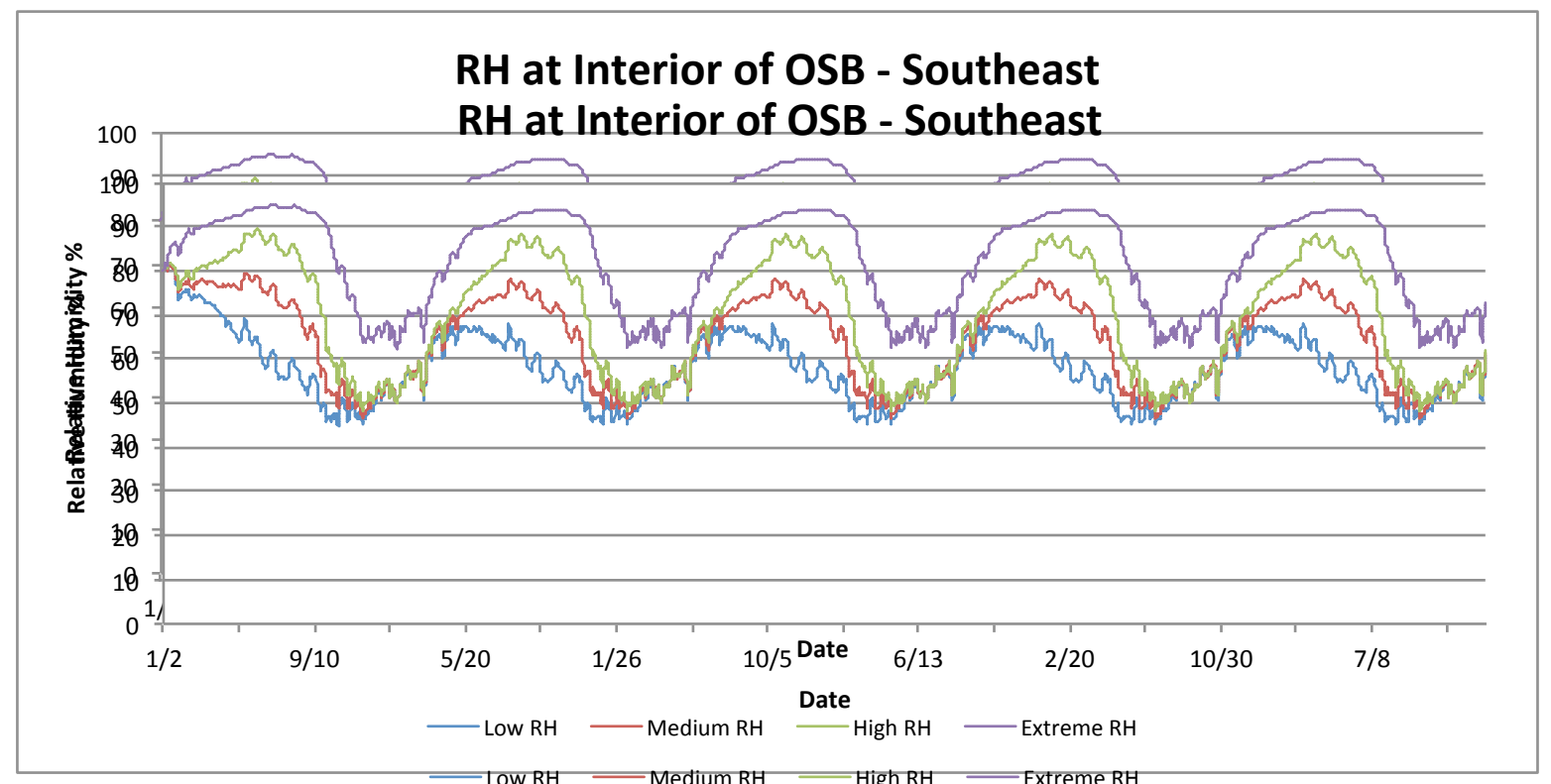

RH of interior OSB edge of mineral wool assembly - Intensified Case

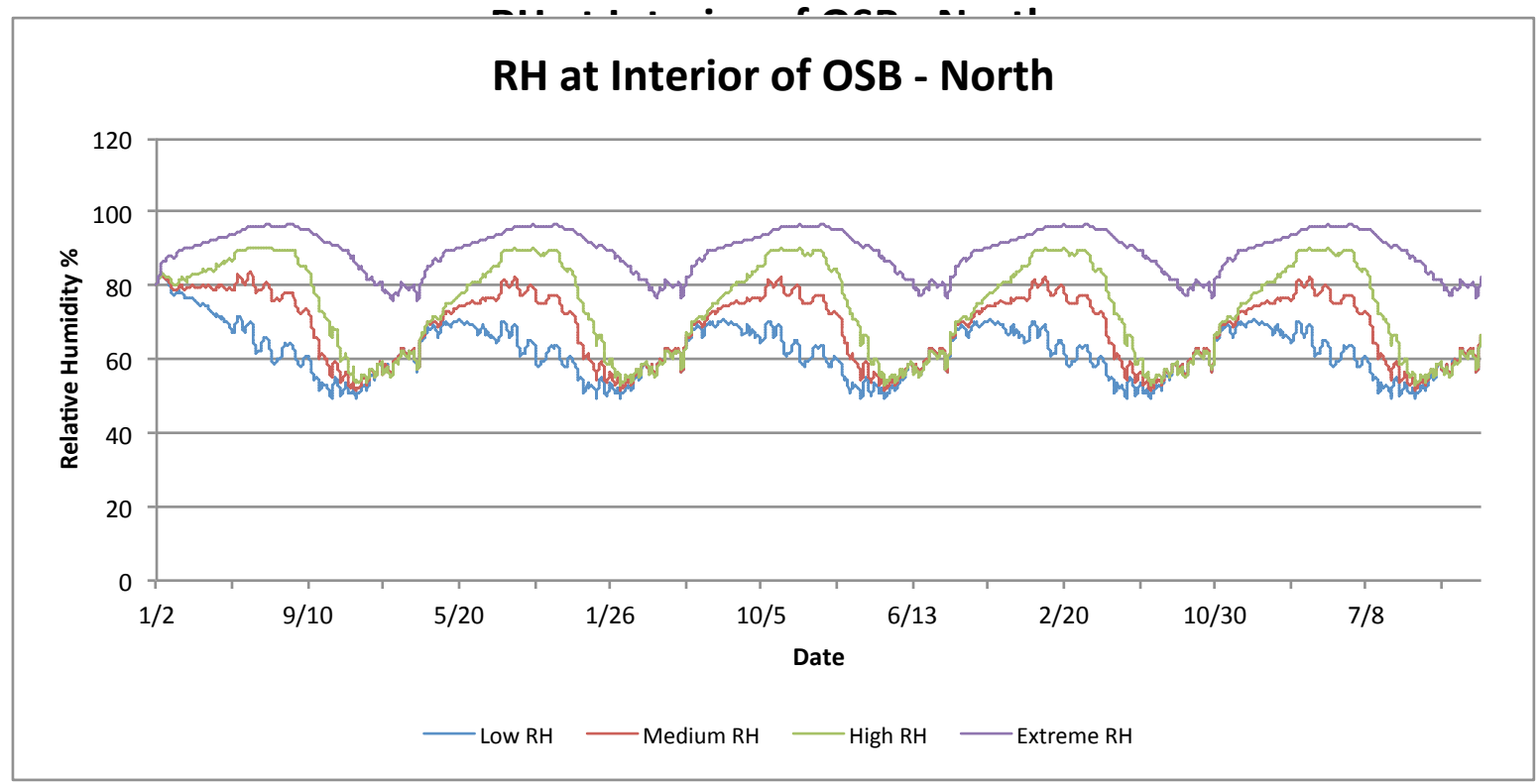

RH of interior OSB edge of mineral wool assembly - Intensified Case 


\section{Appendix H}

Vertical I-beam Assembly WUFI® Results Graphs

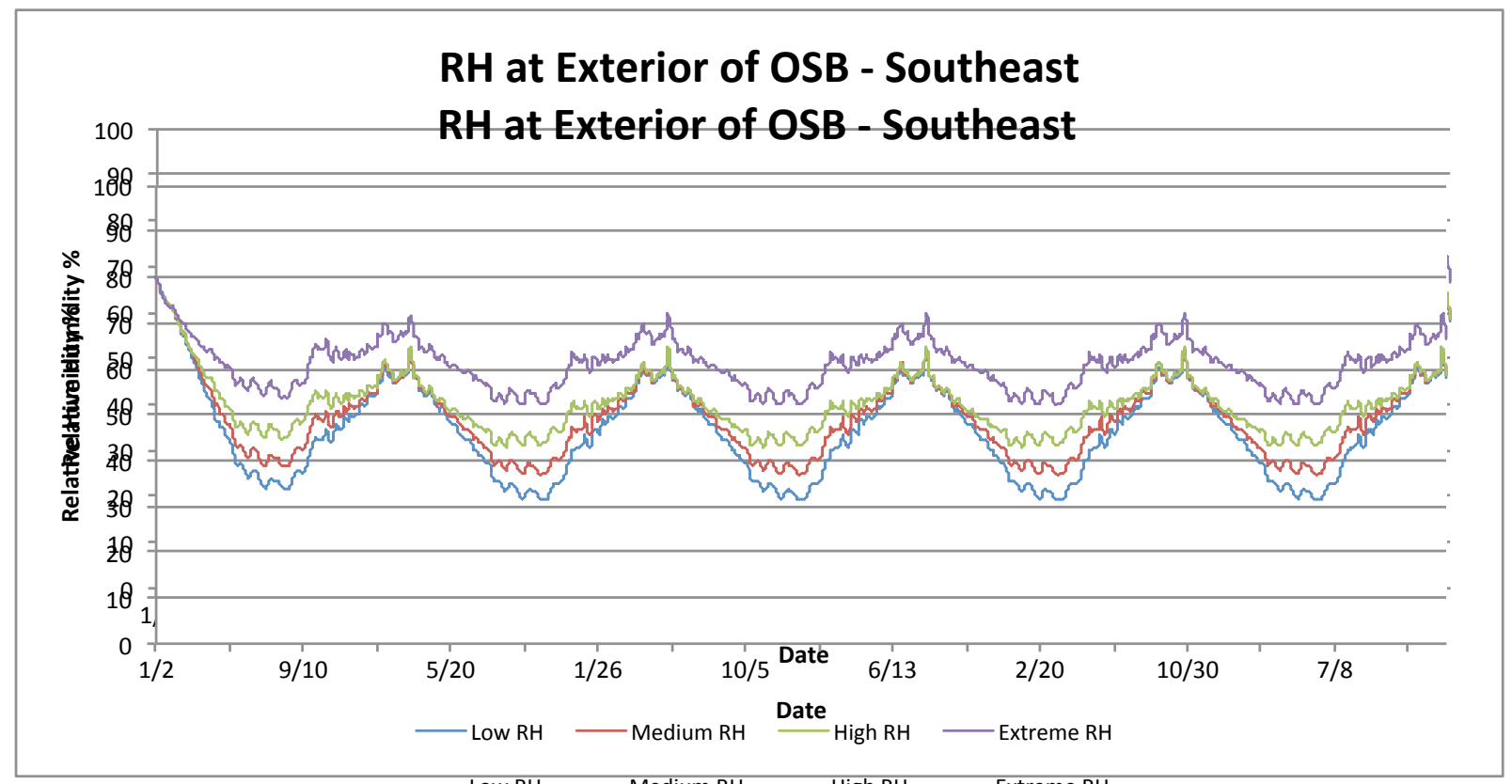

RH of exterior OSB edge of vertical I-beam assembly - Standard Case

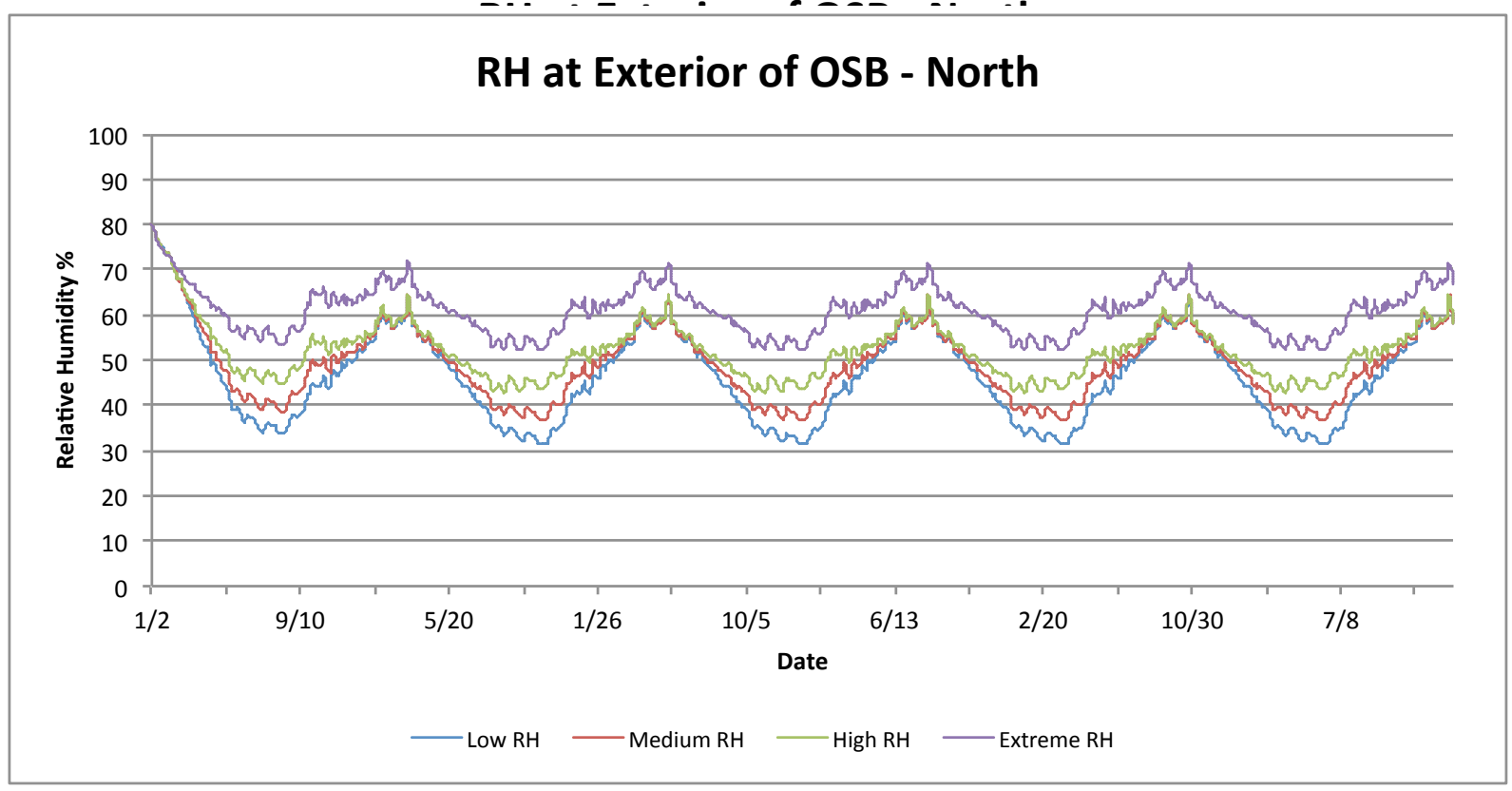

RH of exterior OSB edge of vertical I-beam assembly - Standard Case 


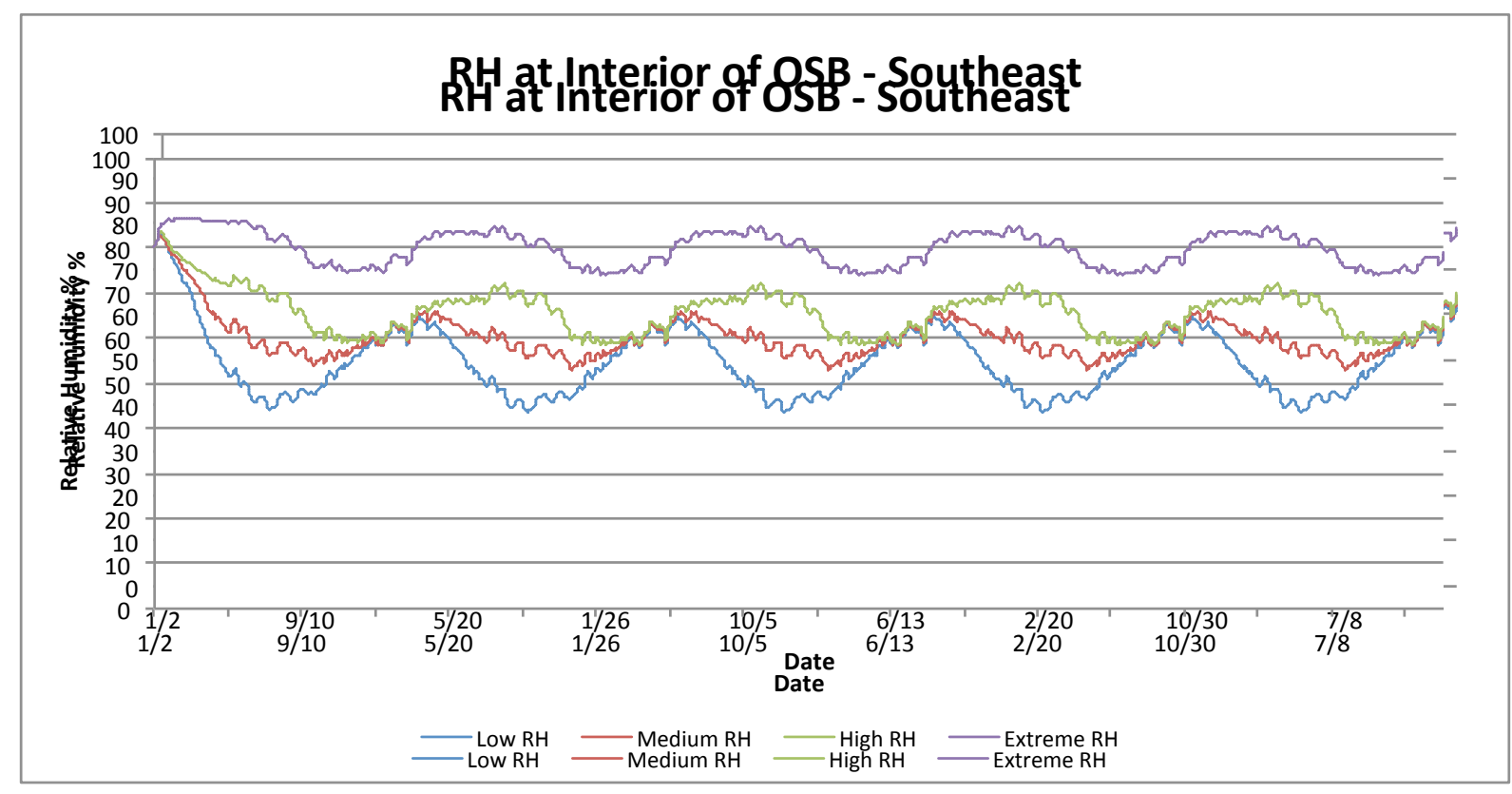

RH of interior OSB edge of vertical I-beam assembly - Standard Case

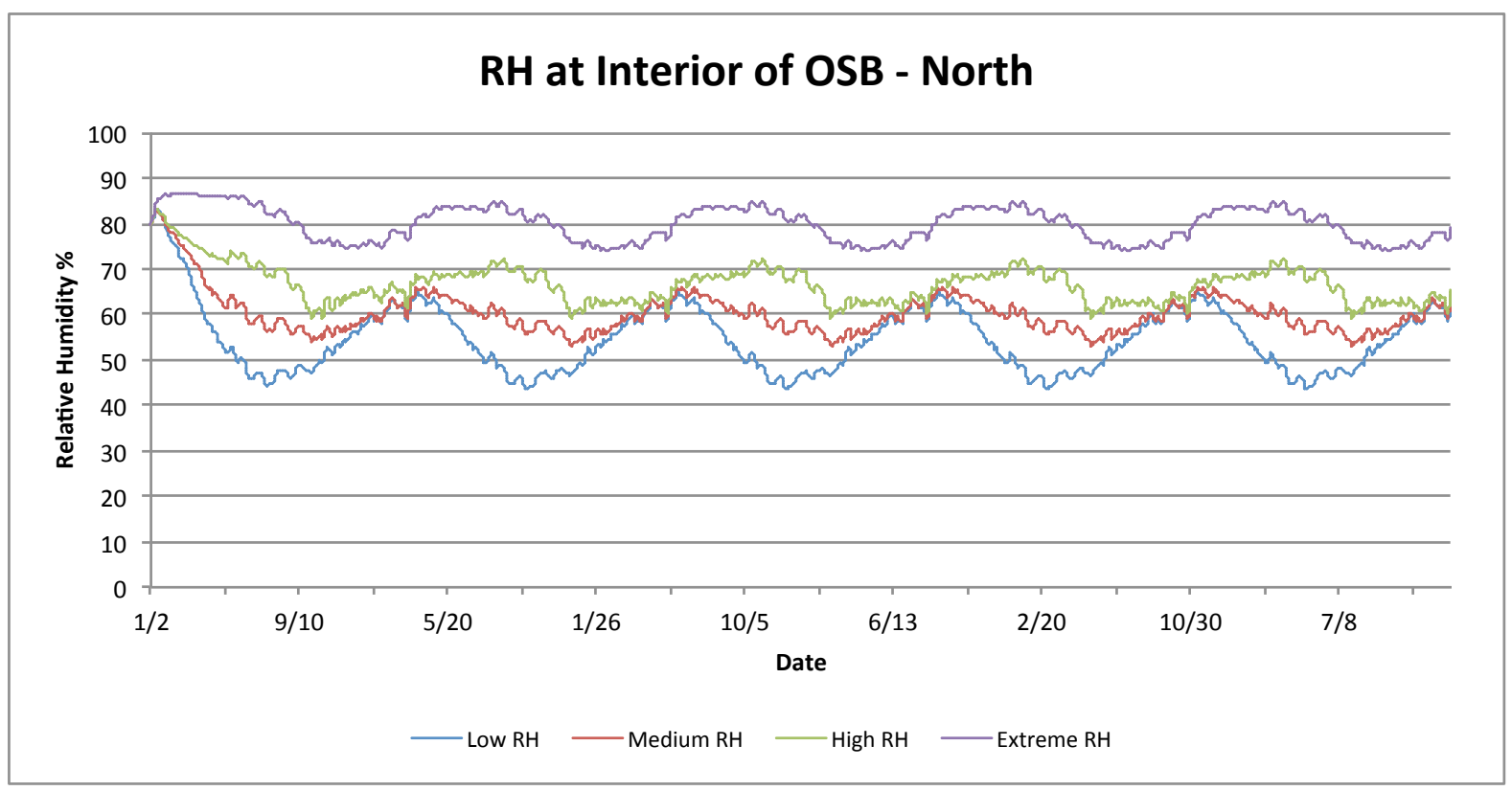

RH of interior OSB edge of vertical I-beam assembly - Standard Case 


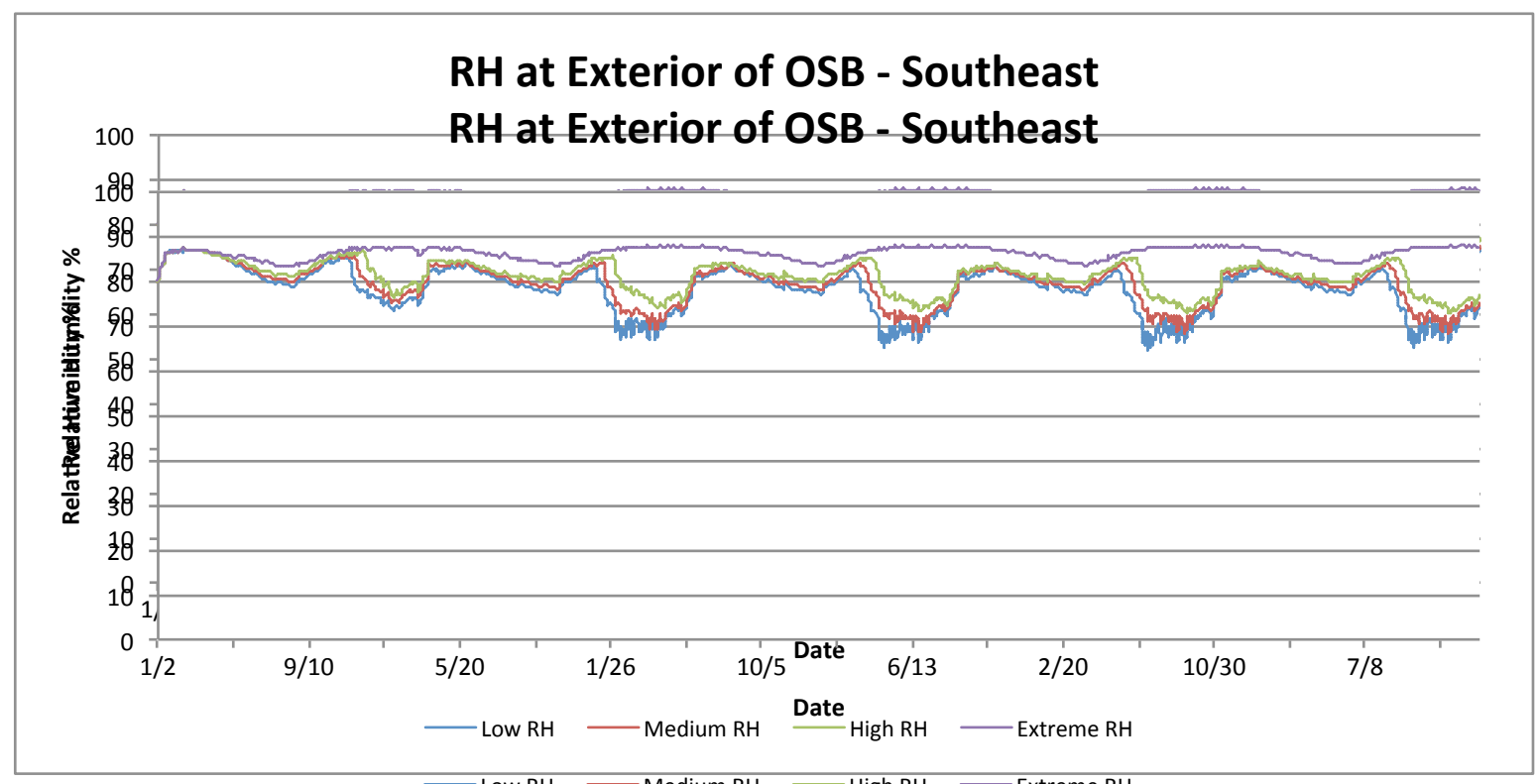

RH of exterior OSB edge of vertical I-beam assembly - Intensified Case

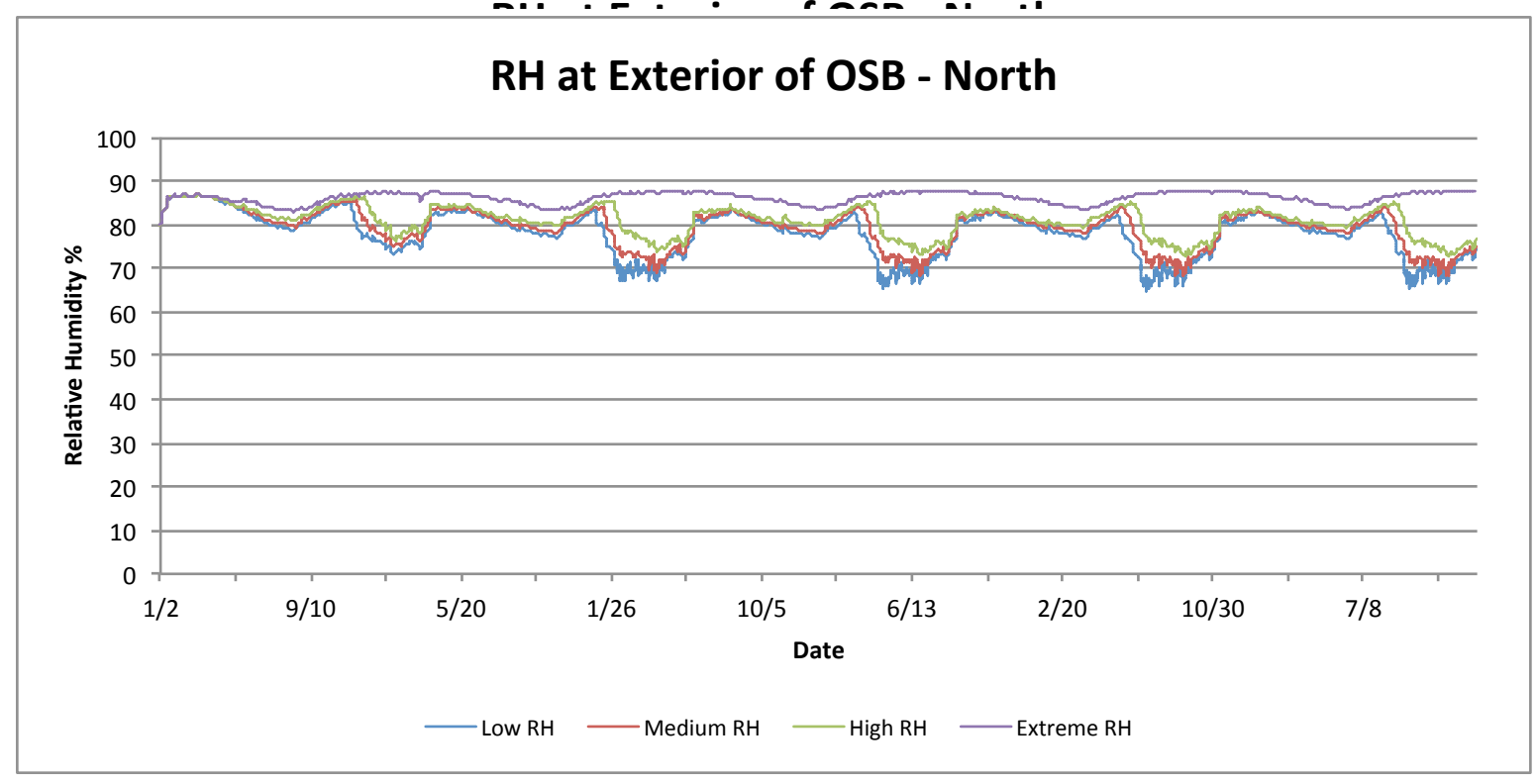

RH of exterior OSB edge of vertical I-beam assembly - Intensified Case 


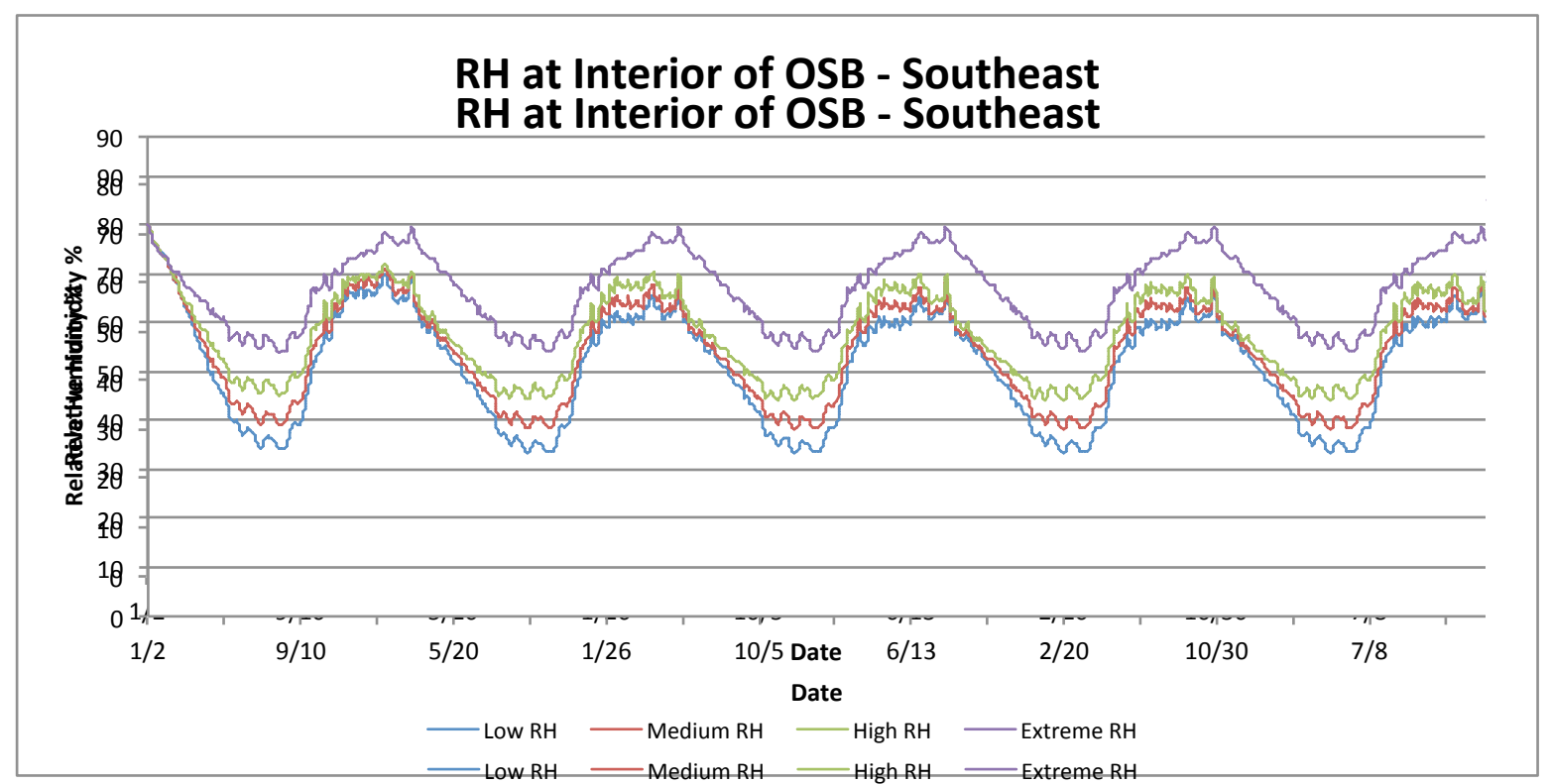

RH of interior OSB edge of vertical I-beam assembly - Intensified Case

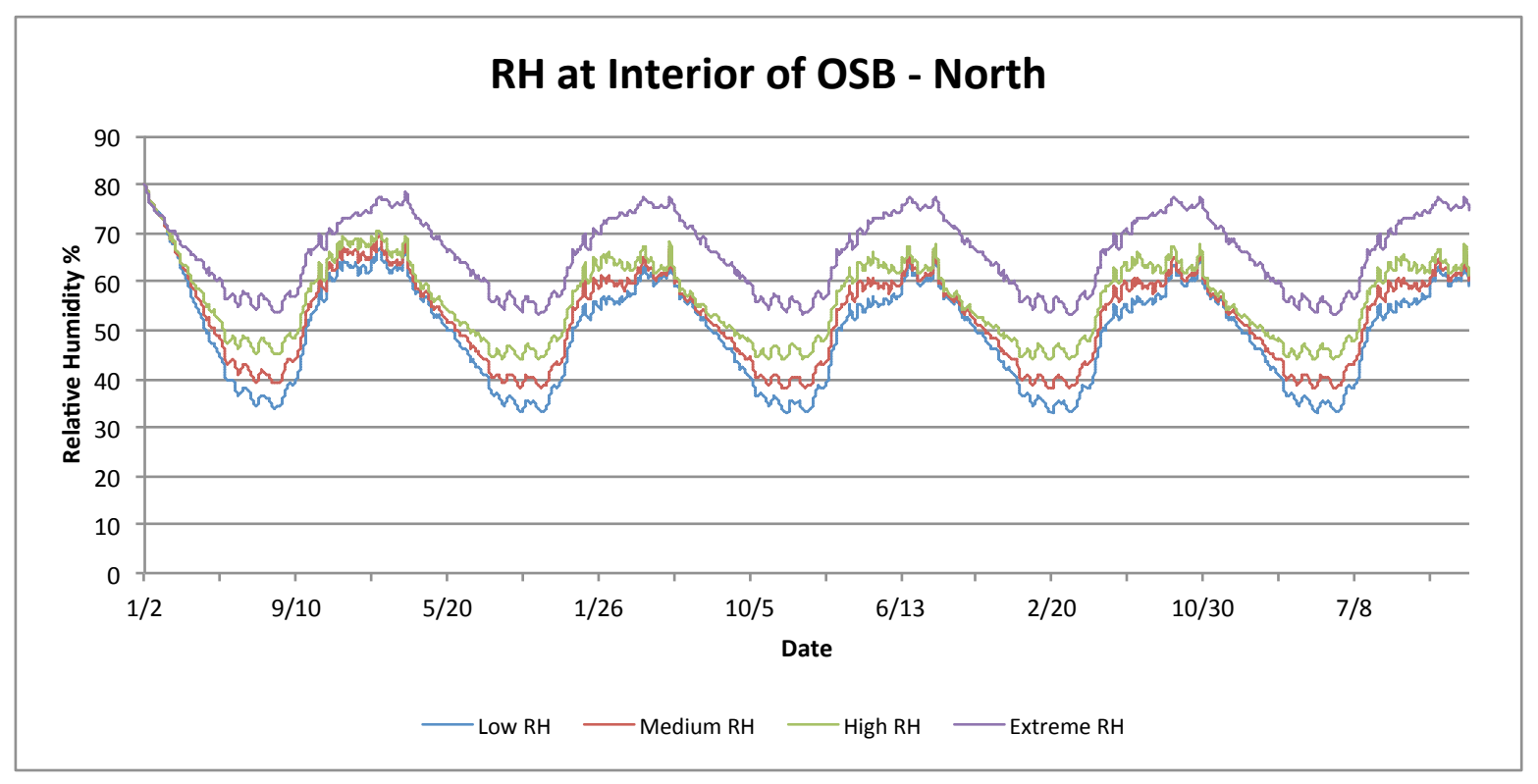

RH of interior OSB edge of vertical I-beam assembly - Intensified Case 


\section{Appendix I}

Vacuum Insulated Panel Assembly WUFI® Results Graphs

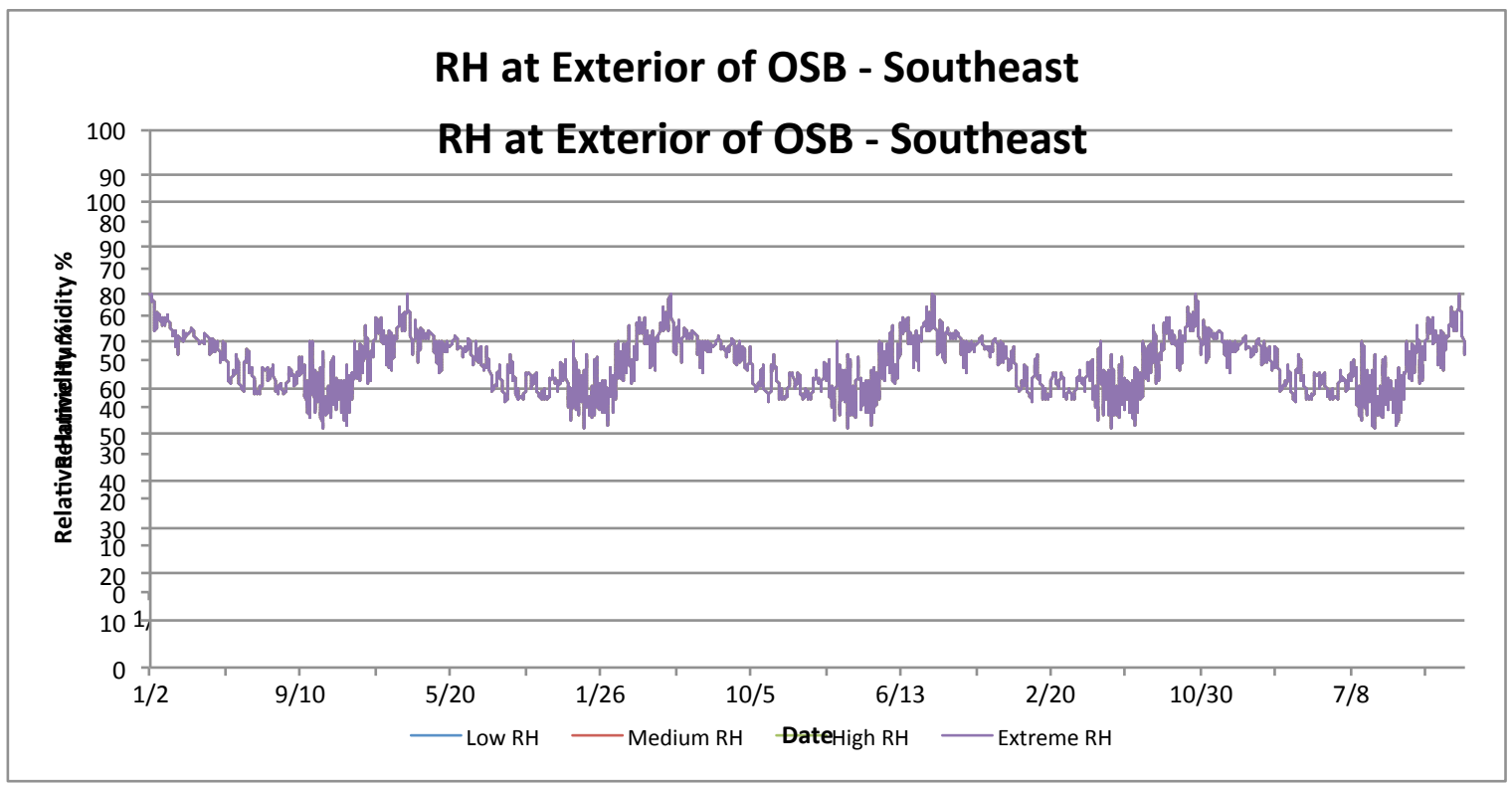

RH of exterior OSB edge of VIP assembly - Standard Case

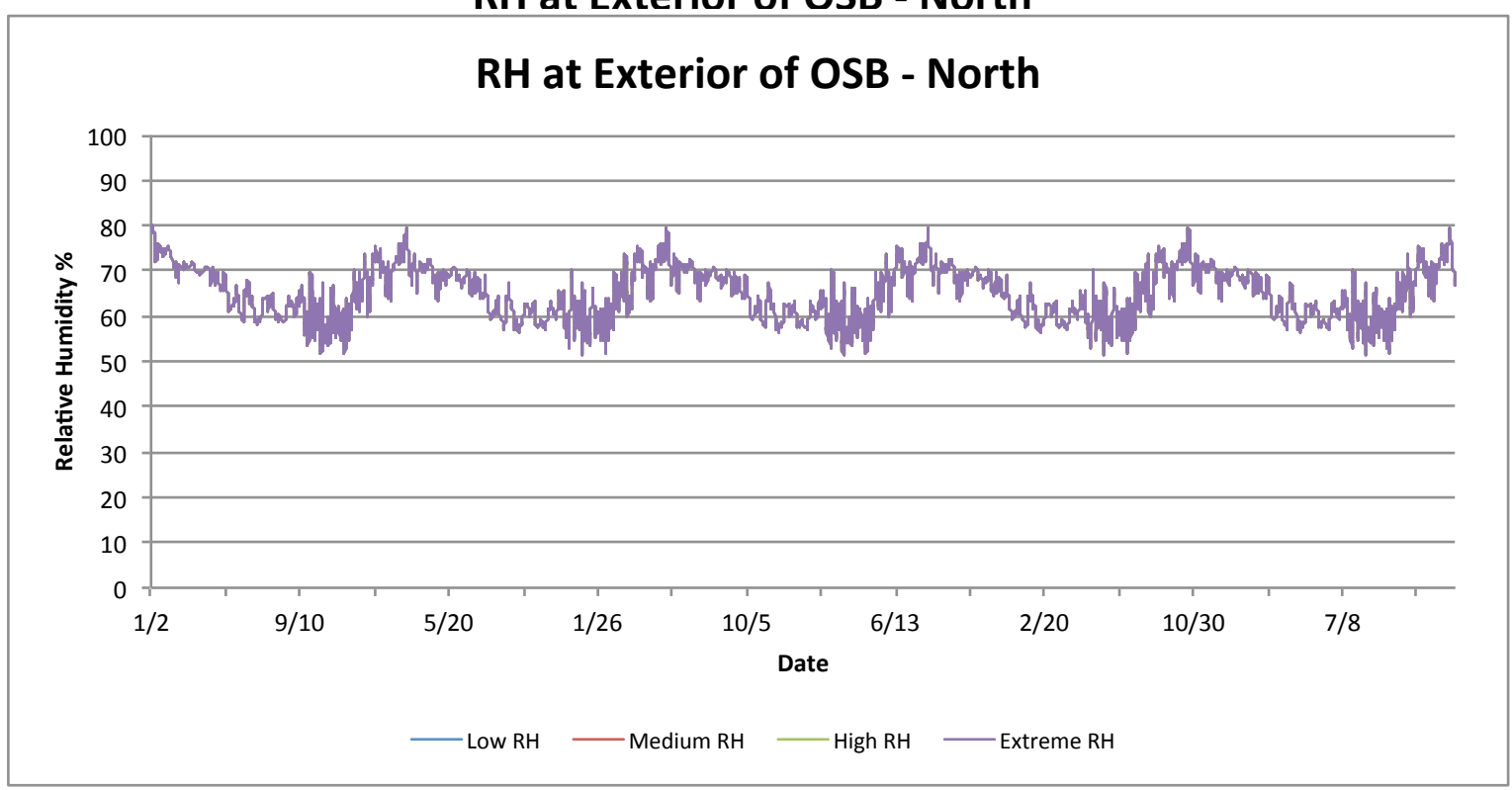

RH of exterior OSB edge of VIP assembly - Standard Case 


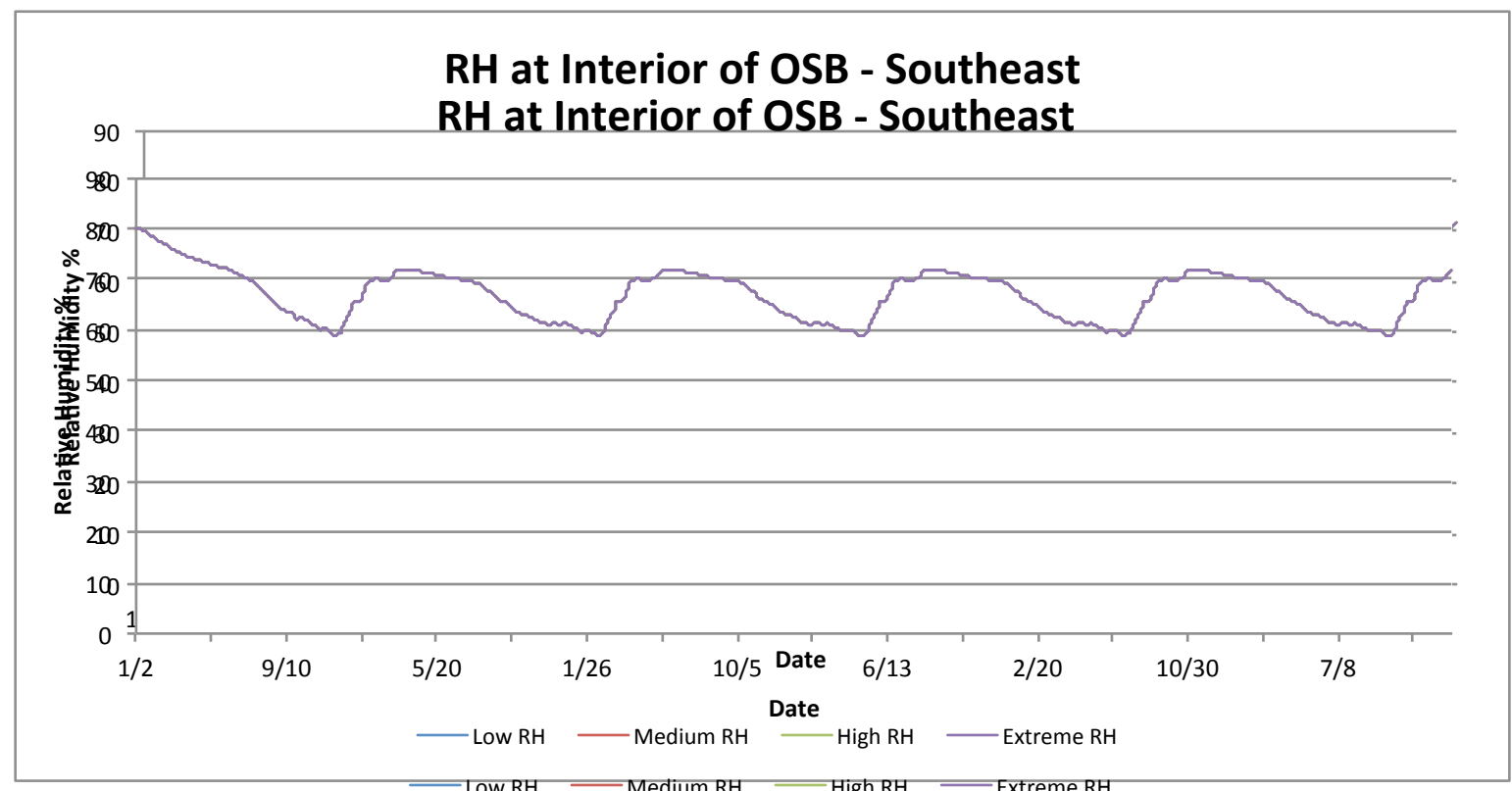

RH of Interior OSB edge of VIP assembly - Standard Case

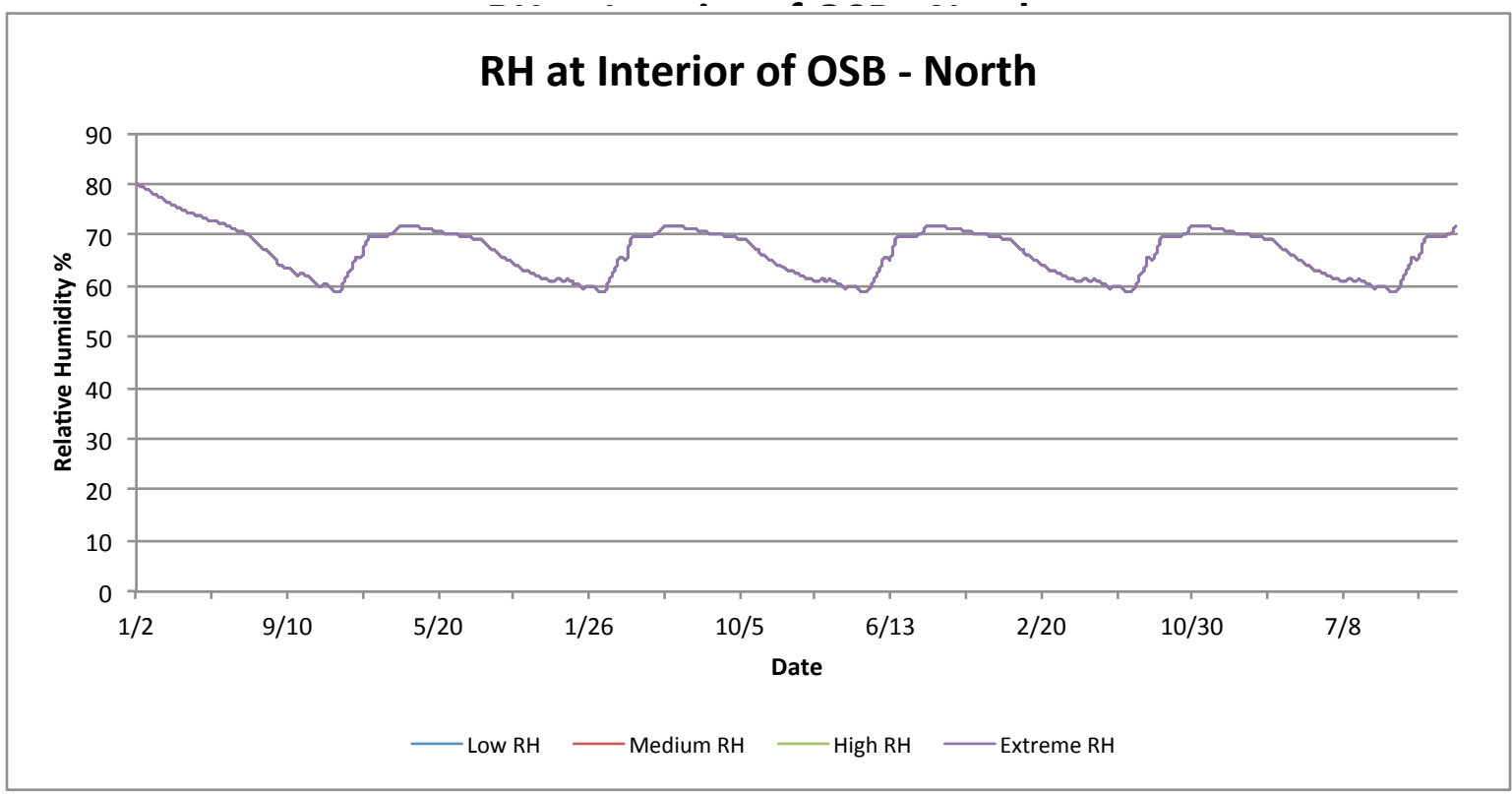

RH of Interior OSB edge of VIP assembly - Standard Case 


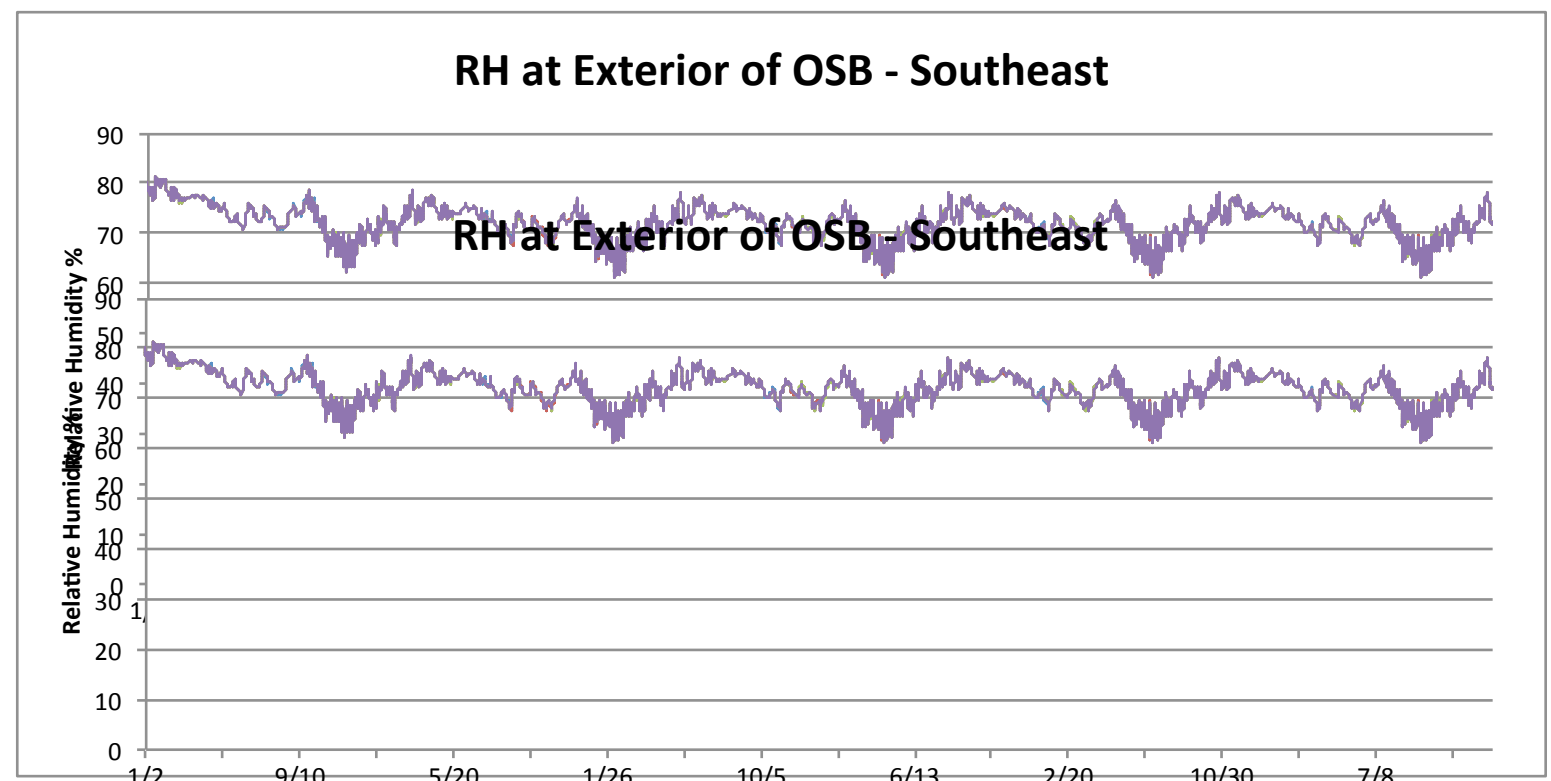

RH of exterior OSB edge of VIP assembly - Intensified Case

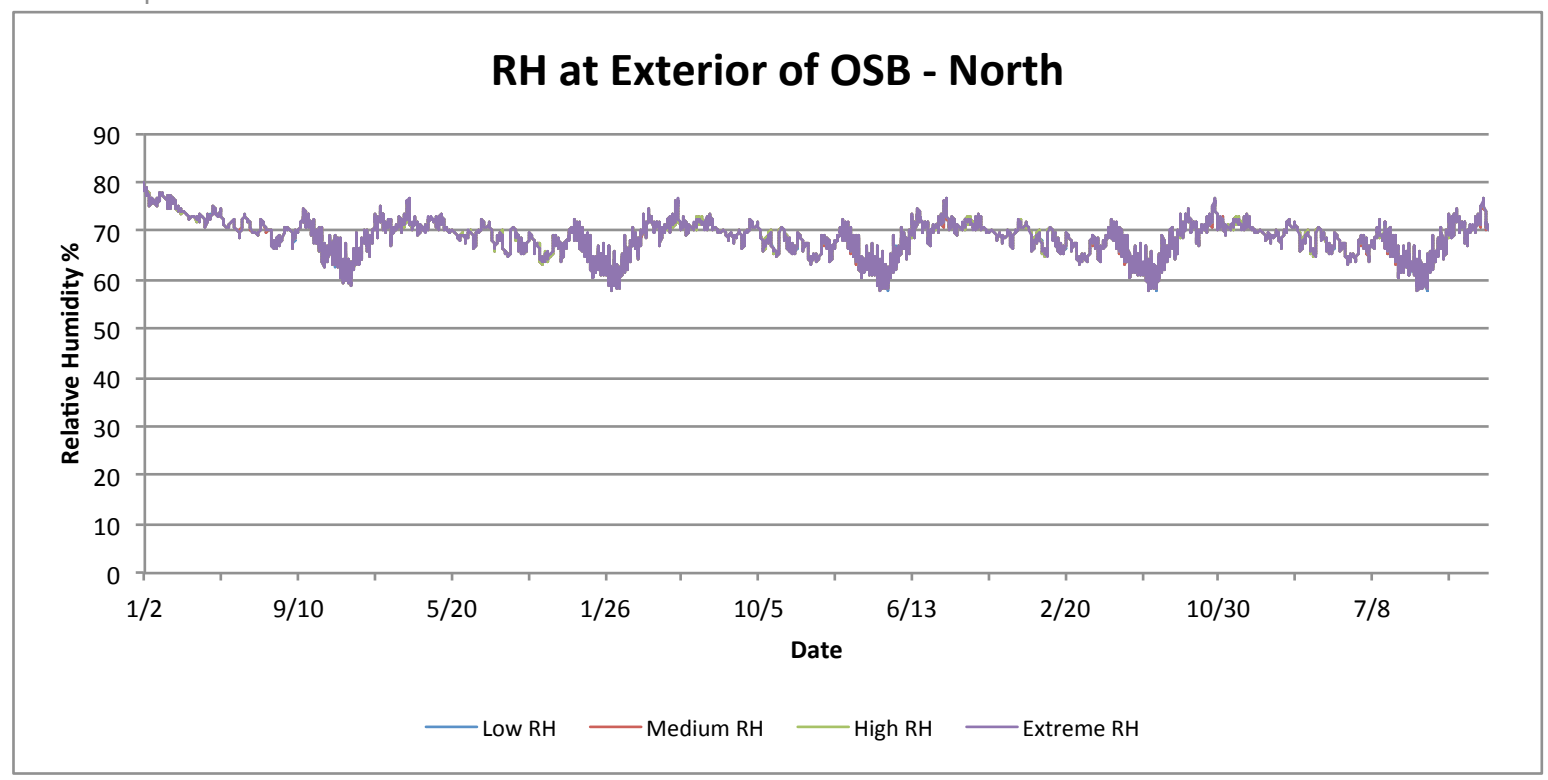

RH of exterior OSB edge of VIP assembly - Intensified Case 


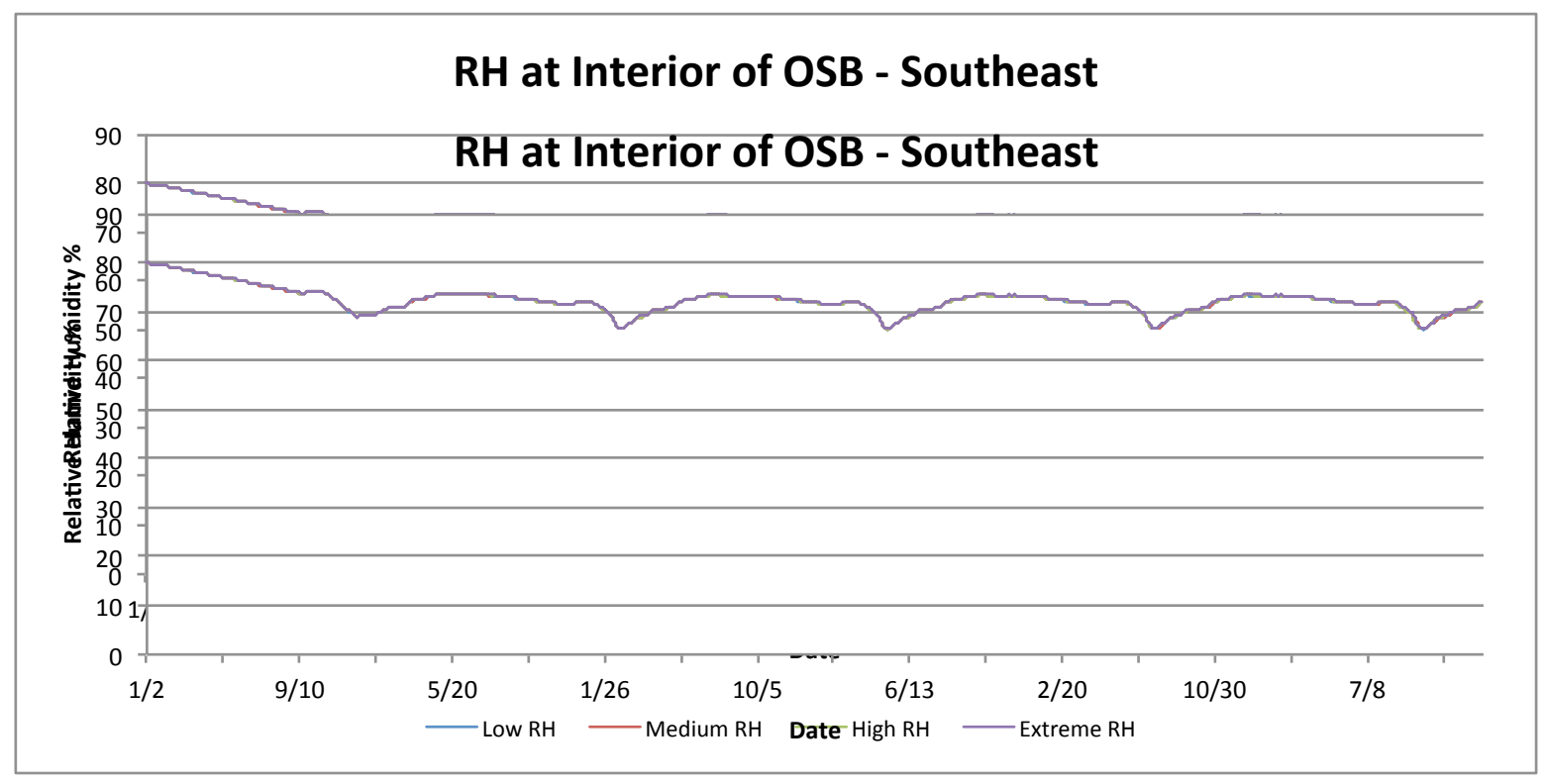

RH of interior OSB edge of VIP assembly - Intensified Case

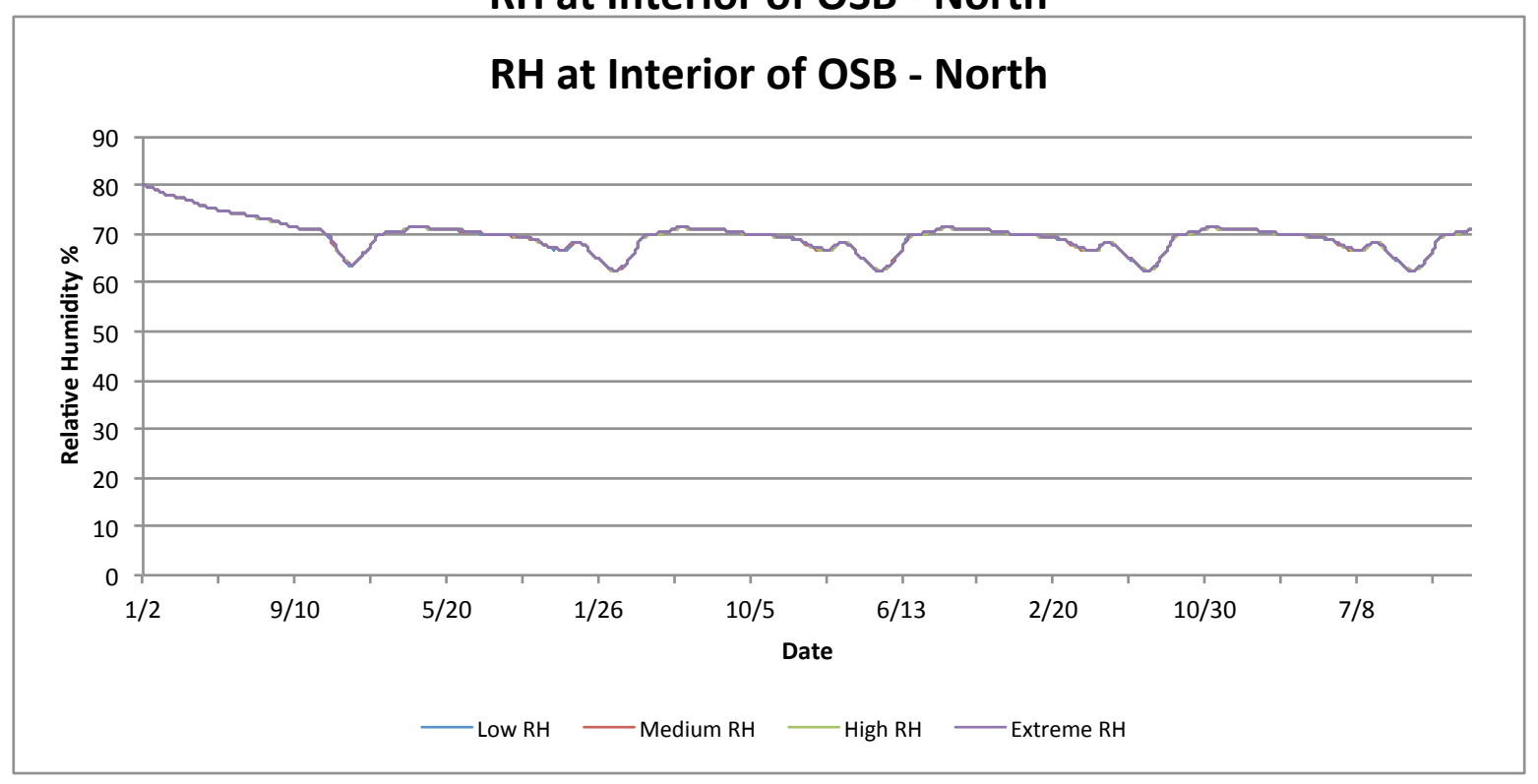

RH of interior OSB edge of VIP assembly - Intensified Case 


\section{References}

Aldrich. R, Mantha. P, Puttagunta. S. (2012). Measure Guideline: Basement Insulation Basics. U.S. Department of Energy. Building Technologies Program.

ASHRAE Standard 160P. (2009ª). Criteria for Moisture-Control Design Analysis in Buildings. ASHRAE: Atlanta, GA.

ASHRAE Handbook - Fundamentals. $\left(2009^{\mathrm{b}}\right)$. Typical Thermal and Water Vapour Permeability Properties of Common Building and Insulating Materials. ASHRAE: Atlanta, GA.

Ballard, G. (2000). The Last Planner System of Production Control. PhD thesis, Dept. of Civil Engineering, University of Birmingham, Birmingham, U.K.

Barden Home. (2013). Retrieved from: http://www.bardenhomes.com on October $8^{\text {th }}, 2013$

BC Passive House. (2012). Retrieved from: http://www.bcpassivehouse.com on December $5^{\text {th }}$, 2012

Bernstein, Harvey. Gudgel, John. Laquidara-Carr, Donna. (2011). Prefabrication and Modularization: Increasing Productivity in the Construction Industry. Bedford, MA: McGraw Hill Construction

Biebel, Tim. (2012). Energy-Efficient Modular. JLC, March Edition. Retrieved from: http://www.jlconline.com/modular-building/energy-efficient-modular.aspx? dfpzone $=$ general on January 18th, 2013.

Bomberg, M.T. Kumaran, M.K. (1999). Use of Field-Applied Polyurethane Foams in Buildings. Institute for Research in Construction. Ottawa, Canada.

Boqvist, Albert. (2010). Symbiosis between Construction Efficiency \& Energy Efficiency. Licentiate Thesis. Lund University, Division of Structural Engineering. Lund, Sweden.

Brock, L. (2005). Designing the Exterior Wall: an Architectural Guide to the Vertical Envelope. John Wiley \& Sons, Inc. New York, NY.

Brute Force. (2013). Retrieved from: http://bruteforcecollaborative.com/wordpress/category/ passivhaus-2/page/23/ on September $22^{\text {nd }}, 2013$

Building Industry Association of Philadelphia. (2010). Going Mod. Fit It Philly. Philadelphia, Pennsylvania. Retrieved from: http://may8consulting.com/publications/Going_Mod.pdf on September 12 $2^{\text {th }}, 2013$. 
Canadian Mortgage \& Housing Corporation. (2011). EcoTerra Modular Construction. Equilibrium Housing InSight. Retrieved from: http://www.cmhc-schl.gc.ca/en/inpr/su/ eqho/upload/EcoTerra-Modular-Construction_E-Jun22.pdf on October 24 2013.

Cameron J. Peter \& Di Carlo G. Nadia. (2007). Piecing Together Modular: Understanding the Benefits and Limitations of Modular Construction Methods for Multifamily Development. Department of Architecture and Urban Studies \& Planning. Massachusetts Institute of Technology. Boston, MA.

Chan, Wanyu. Price, Phillip. Sohn, Michael. Gadgil, Ashok. (2003). Analysis of U.S. Residential Air Leakage Database. Indoor Environment Department. Lawrence Berkeley National Laboratory.

Chen, Yuxiang. Athienitis, A.K. Galal, Khaled. (2010). Modeling, design and thermal performance of a BIPV/T system thermally coupled with a ventilated concrete slab in a low energy solar house: Part 1, BIPV/T system and house energy concept. Science Direct. Solar Energy 84, 1892-1907. Concordia University, Montreal, Canada.

Chin, Chang-Sun. (2008). An Investigation to Improve Construction Information Flows. $\mathrm{PhD}$ Thesis, Department of Civil and Environmental Engineering, University of Wisconsin. Madison, Wisconsin.

Clapp, Jeanie. (2013). Off-Site Modular Construction Improves Quality and Safety of Projects. Constructor Magazine, February $28^{\text {th }}$ Edition. Gainesville, FL.

Clupp, Thorsten. (2012). Cold Climate Building Design Proceedings from: 2012 North American Passive House Conference (NAPHC). Denver, CO.

Cohen, Adam. Whitmore, Dan. Kernagis, Mike. (2013). Proceedings from: Passive House Builders Training Session - Philadelphia, PA. February 13-16 ${ }^{\text {th }}$, 2013. Passive House Institute of the United States. Chicago, IL.

Conservation Technology. (2008). Energy efficient design: Air Leakage Pathways: Figures. Retrieved from http://www.conservationtechnology.com/building_design.html on January $14^{\text {th }}, 2014$.

Doiron, Matthew. (2011). Whole-Building Energy Analysis and Lessons Learned for a Near Net-Zero Energy Solar House. M.A.Sc. Thesis for the Department of Building, Civil and Environmental Engineering. Concordia University, Montreal, Canada.

Eco Classic Homes. (2013). Retrieved from http://ecoclassichomes.blogspot.com/2012/01/ montgomery-near-square-inaugural-home.html on October $18^{\text {th }}, 2013$. 
Eriksson, Per Erik. (2010). Improving Construction Supply Chain Collaboration and Performance: A Lean Construction Pilot Project. Supply Chain Management: An International Journal, Vol. 15 Issue 5. Luleå University of Technology, Luleå, Sweden.

Fazio, Paul. Miljana, Horvat. Poliquin, Louis. Robichaud, Francois. (2000). Assessment of the Prefabricated Building Industry. Concordia University \& Forintek Canada Crop. Canada Mortgage \& Housing Corporation, Eastern Division, Ste-Foy, Canada.

Fazio, Paul. (2000) Visits to prefabricated homes manufacturers in Canada. Concordia University \& Forintek Canada Corp. Montreal, QE

Fazio, Paul. $\left(2000^{\mathrm{b}}\right)$ Visits to prefabricated homes manufacturers in United States. Concordia University \& Forintek Canada Corp.

Feist, Wolfgang. (2007). What is a Passive House? Passive House Institute. Darmstadt, Germany. Retrieved from: http://www.passiv.de/old/07_eng/PHI/ Flyer_quality assurance.pdf on February $28^{\text {th }} 2013$.

Garnier G., S. Marouani, B. Yrieix, C. Pompeo, M. Chauvois, L. Flandin, Y. Brechet. (2011). Interest and durability of multilayers: from model films to complex films. Polymer Advanced Technologies, 22, 847-856. John Wiley \& Sons, Ltd. New York City, USA.

Haavi, Thomas. Jelle, Bjorn Petter. Gustavsen, Arild. (2012). Vacuum Insulation Panels in Wood Frame Wall Construction with Different Stud Profiles. Journal of Building Physics, 36(2), pg 212-226.

Hamzeh, Farook Ramiz. (2009). Improving Construction Workflow-- The Role of Production Planning and Control. PhD Thesis, University of California, Berkeley. Berkeley, CA.

Han, Hyeok Sang. (2010). Automated Post-Simulation Visualization of Modular Building Production Assembly Line. Master of Science in Construction Engineering \& Management. Department of Civil \& Environmental Engineering. University of Alberta. Calgary, Alberta.

Harvey, Danny. (2009). Reducing energy use in the buildings sector: measures, costs and examples. Journal of Energy Efficiency Vol. 2 Issue 2. Springer Science. Heidelberg, Germany.

Harvey, Danny. (2007). Net climatic impact of solid foam insulation produced with halocarbon and non-halocarbon blowing agents. Building \& Environment. Science Direct. Toronto, Canada. 
Hergunsel, Mehmet F. (2011). Benefits of Building Information modeling for Construction Managers and BIM Based Scheduling. Master Thesis, Department of Science and Engineering, Worcester Polytechnic Institute, USA.

Horvat, Miljana. Fazio, Paul. Poliquin, Louis. Robichaud, Francois. (2001). Survey of Canadian Prefabricated Building Industry - Findings. Proceedings from: International Conference on Building Envelope Systems \& Technologies (ICBEST) 2001, National Research Council of Canada, Institute for Research in Construction, Ottawa, Canada.

International Organization of Standardization [ISO]. (2007). Thermal bridges in building construction - Heat flows and surface temperatures - Detailed calculations. Geneva, Switzerland.

Jacobson, Rolf. (2012). Performance of 8 Passive House Envelopes in Cold Climates. Conference. Proceedings from: North American Passive House Conference (NAPHC), Denver, CO.

Klingenberg, Katrin. (2012) Proceedings from: Chicago, IL Certified Passive House Consultant Training Session. January $4-9^{\text {th }} \&$ February $13-16^{\text {th }}, 2012$. Passive House Institute of the United States. Chicago, IL.

Knight, K. D., Boyle, B. J. Phillips, B. G. (2002) Guidelines for Delivering Effective Air Barriers. Canadian Mortgage \& Housing Corporation. Retrieved from: http:// www.docstoc.com/docs/73220791/Guidelines-for-Delivering-Effective-Air-BarrierSystems---G on October $18^{\text {th }}, 2013$.

Koskela, Lauri. (2000). An Exploration Towards a Production Theory and its Application to Construction. PhD Thesis, Helsinki University of Technology.

Kunzel, Hartwig M. (2006) WUFI® PC-Program for calculating the coupled heat and moisture transfer in buildings. Fraunhofer Institute for Building Physics. Holzkirchen, Germany.

Lefebvre, Rock. Simonova, Elena. Wang, Liang. (2012) Labour Shortages in Skilled Trades The Best Guestimate? Issue in Focus. Certified General Accountants Association of Canada. Ottawa, Canada. Retrieved from: http://ppm.cga-canada.org/en-ca/Documents/ ca_rep_2012-07 labour-shortage.pdf on March 15 th 2013.

Lstiburek, Joseph. (2012). Foam Shrinks, and Other Lessons. Fine Home Building February/March Edition. Retrieved from: http://www.buildingscience.com/ search? show all $=1 \&$ doctypes $=$ published $\&$ SearchableText $=1$ stiburek on March $25^{\text {th }}, 2013$.

McDonald, Tim. (2012). Pump Up the Volume - Modular Building System. Proceedings from: North American Passive House Conference (NAPHC). Denver, CO. 
Modular Building Institute [MBI]. (2011). Permanent Modular Construction Annual Report. Modular Construction Institute. Retrieved from: http://www.modular.org/documents/ document publication/ 2011permanent.pdf on February 25 $5^{\text {th }}, 2013$.

Mukhopadhyaya P., M.K. Kumaran, G. Sherrer and D. Van Reenen. (2011). An Investigation on Long- Term Thermal Performance of Vacuum Insulation Panels (VIPs). Proceedings from: International Vacuum Insulation Symposium (IVIS-X), pp. 10, 2011, Ottawa, ON, Canada.

National Association of Home Builders [NAHB]. (2013). Modular Homes - Custom Construction at Warp Speed. Retrieved from: https://www.nahb.org/generic.aspx? genericContentID=179100] on December 12th, 2013.

Nisson, J.D. Ned \& Dutt, Gautam. (1985). The Superinsulated Home Book, John Wiley \& Sons. New York, NY.

Ontario Building Code [OBC]. (2012). Supplementary Standard SB-12, Energy Efficiency for Housing.

Parekh, Anil. Mattock, Chris. (2012). Incorporation of Vacuum Insulation Panels in a Wood Frame Net Zero Energy Home. Institute for Research in Construction, National Research Council of Canada. Ottawa, ON.

Prosoco. (2013). Little House, Big Promise. from: http://greenpiece1.wordpress.com/2010/10/25/ little-house-big-promise/Retrieved on November 12th, 2013.

Quale, John. (2010). Comparing Environmental Impacts of On-Site verses Off-Site Construction. School of Architecture, University of Virginia. Charlottesville, VA.

RS Means. (2012). Building Construction Cost Data 2012. Deed Construction Data Inc. Washington D.C.

Salonvarra, Mikael. Karagiozis, Achilles N. Pazera, Marcin. Miller, William. (2007). Air Cavities Behind Claddings- What Have We Learned? Oak Ridge National Laboratory. Oak Ridge, Tennessee. Retreieved from: http://web.ornl.gov/sci/buildings/ 2012/2007\%20B10\%20papers/210 Salonvaara.pdf on October 13 ${ }^{\text {th }}, 2012$.

Schoenborn, M. Joseph. (2012). A Case Study Approach to Identifying the Constraints and Barriers to Design Innovation for Modular Construction. Master Thesis. Faculty of the Virginia Polytechnic Institute and State University. Charlottesville, VA. 
Shurcliff, William. (1988). Superinsulated Houses \& Air to Air Heat Exchangers. Brick House Publishing Co. New York, NY.

Siggner, Rebecca. Munro, James. (2011). Benefits, Challenges and Lessons Learned. British Columbia Housing. Retrieved from: www.bchousing.org on September 13 ${ }^{\text {th }}, 2013$.

Sloditskie, Greg. (2013). Modular building construction consultant. San Francisco, CA.

Structural Insulated Panel Association (SIPA). (2012). Structural Insulated Panels Product Guide. Retrieved from: http://www.r-control.com/downloads/brochure/H650-SIPA.pdf on May 5th 2013.

Van Mulligen, P Calvin. (2012). Improving the Efficiency, Productivity, and Cost-Effectiveness of Modular Design and Construction Processes. Master of Science in Construction Engineering \& Management. Department of Civil \& Environmental Engineering. University of Alberta. Calgary, AB.

United States Environmental Protection Agency [US EPA]. (2013). Ventilation Guidance for Spray Polyurethane Foam Application. Retrieved from: http://www.epa.gov/dfe/pubs/ projects/spf/ventilation-guidance.html on January 18th, 2013.

Wambeke, Brad William. (2011). Identifying, Prioritizing, and Reducing Variation of Construction Related Tasks. PhD Thesis, Department of Civil Engineering, North Carolina State University, USA.

Wayne Tsuang, MD, Yuh-Chin T. Huang. (2012). Asthma Induced by Exposure to Spray Polyurethane Foam Insulation in a Residential Home. Department of Medicine, Duke University Medical Center, Durham, NC.

Wilson, Alex. (1995). Insulation Materials: Environmental Comparisons. Environmental Building News Volume 4, No.1. Retrieved from: http:/www.buildinggreen.com/auth/ article.cfm/2005/1/1/Insulation-Thermal-Performance-is-Just-the-Beginning/ on January 18 th, 2013.

Womack, J.P., Jones, D.T. and Roos, D. (1990). The Machine that Changed the World. Rawson Associates. New York, NY.

Womack, J.P. and Jones, D.T. (1996). Lean Thinking. Simon and Schuster. New York, NY.

Woods, T. (2001). Reducing Air Leakage Through the Building Envelope Cuts Energy Demand and Consumption. Proceedings from: Air Barriers III: Air Barrier Solutions for Buildings in North American Climates. Washington, DC. 
Yu, Haitao. (2010). An Integrated Approach Toward Lean for Production Homebuilders. PhD Thesis, Dept. of Civil and Environmental Engineering, University of Alberta. 